\title{
ESTIMACIÓN DE LA EVAPOTRANSPIRACIÓN A ESCALA REGIONAL MEDIANTE TELEDETECCIÓN SATELITAL
}

Tesis de Maestría presentada por Gabriela Helena Calvo

Ante la Facultad de Ingeniería de la Universidad Nacional de La Plata Para optar al Grado Académico de MAGÍSTER EN GEOMÁTICA

Director de Tesis: Dr. Daniel Barrera Codirector de Tesis: Dr. Héctor Gustavo Rosatto La Plata, 16 de abril de 2019 


\section{Agradecimientos}

Agradezco la gran ayuda desinteresada del Ing. Mg. Di

Paolo Luciano y el importante aporte realizado por el Dr. Marcelo Soria y Laura Mordasini.

Fundamentalmente de Marcelo y Laura quiero destacar que sin su colaboración esta tesis no hubiese llegado a destino de la manera en que lo hizo.

No puedo dejar de nombrar a Belén, Laura, Sandra, Paula, Adriana, Florencia, Janis, Gabriela y Mabel quienes me acompañaron y apoyaron en todo este tiempo y bajo cualquier circunstancia por las que he pasado. A ustedes nueve las quiero con todo mi corazón.

Y por su puesto a todos lo que de algún modo u otro estuvieron conmigo. 


\section{Índice}

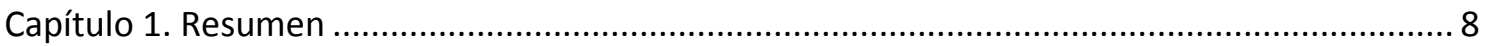

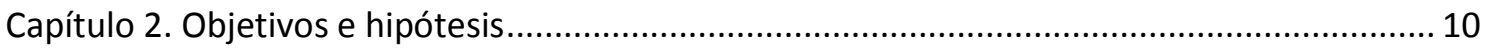

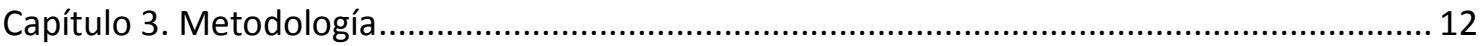

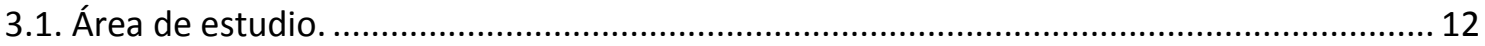

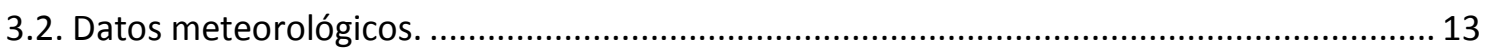

Capítulo 4. Introducción y estado de la cuestión ....................................................................... 15

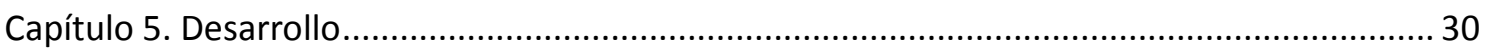

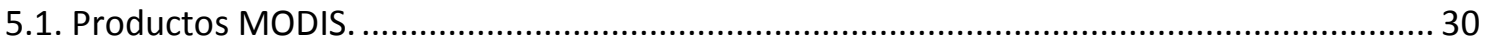

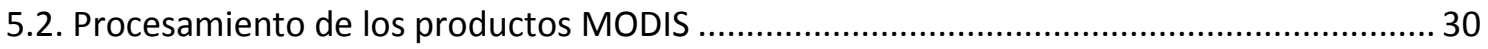

5.2.a. Adecuación de los valores físicos de los píxeles................................................................. 31

5.2.b. Posicionamiento y resolución espacial de las imágenes.................................................... 32

5.3. Estimación de la evapotranspiración instantánea y sus pasos intermedios.......................... 33

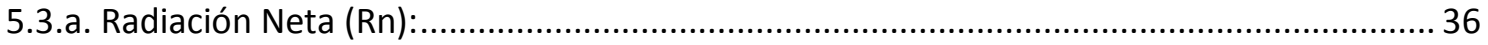

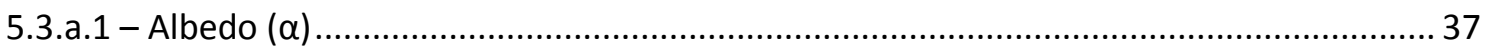

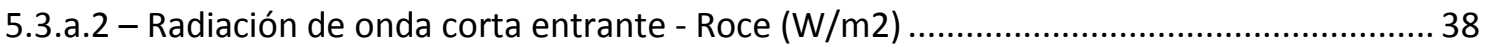

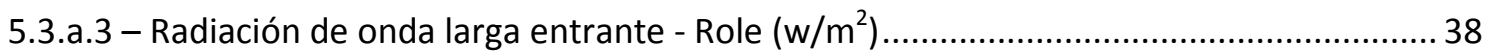

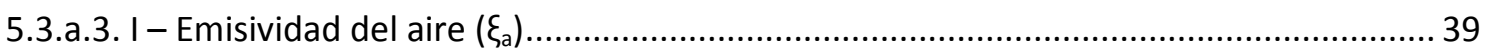

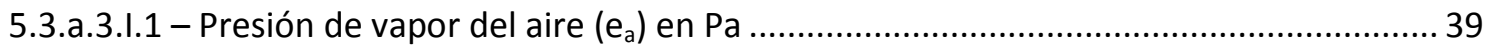

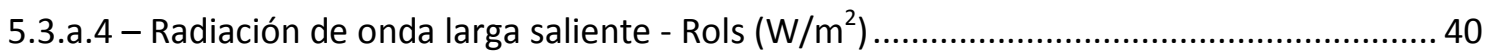

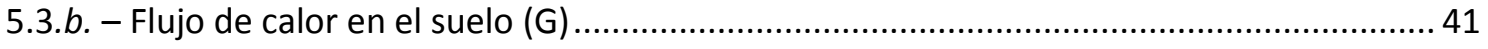

5.3.b.1- Índice de vegetación de diferencia normalizado (NDVI) ............................................. 42

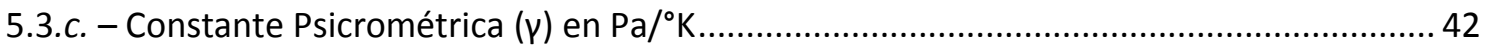

5.3.d - Pendiente de la curva de Clausius-Clapeyron $(\Delta)$........................................................... 43

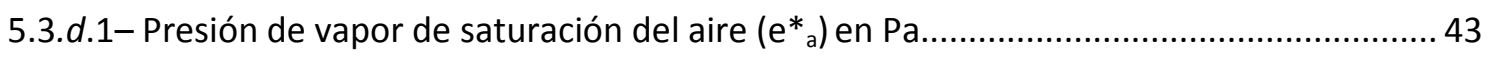

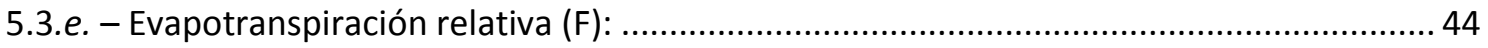

5.3.e.1- Presión de vapor de saturación de la superficie $\left(\mathrm{e}_{\mathrm{s}} \mathrm{s}\right)$ en Pa ......................................... 44

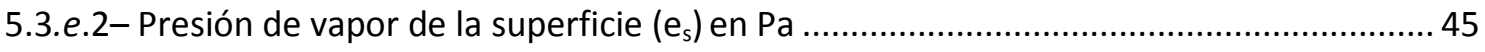

5.4. Estimación de la evapotranspiración diaria y sus pasos intermedios .................................... 45

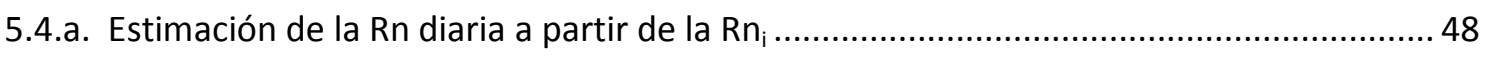


5.4.b - Cálculo de la hora del amanecer y del atardecer.

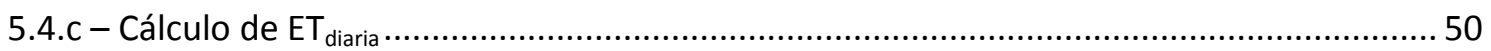

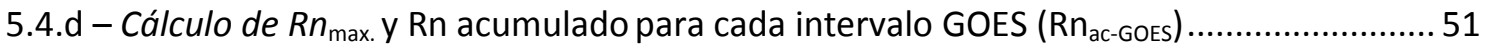

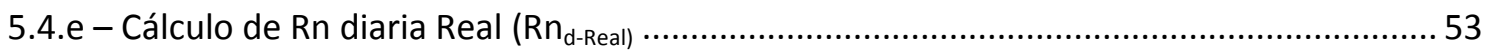

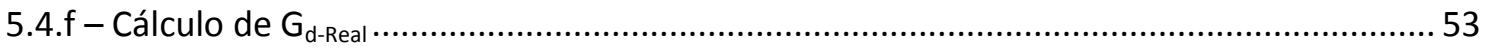

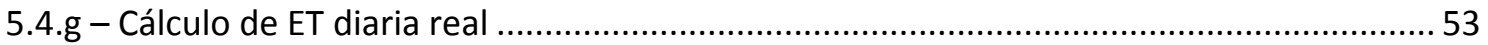

5.5 - Cálculo de la $\mathrm{ET}_{\mathrm{r}}$ según el Balance Hidrológico de Thornthwaite-Mather .......................... 54

5.5.a - Cálculo de la ET $\mathrm{E}_{\mathrm{c}}$ según Penman-FAO - Cálculo del Kc.................................................... 55

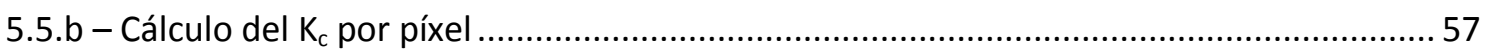

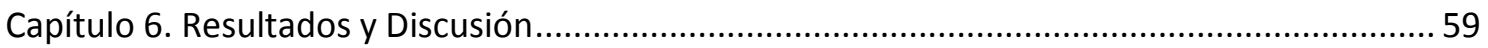

6.1.- Radiación Neta Instantánea y Evapotranspiración Instantánea ...........................................59

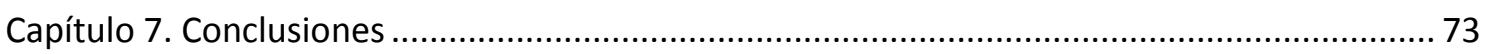

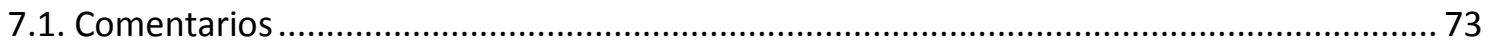

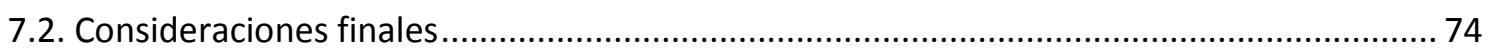

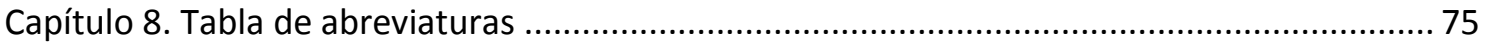

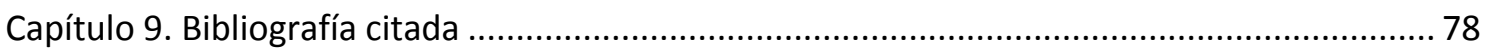

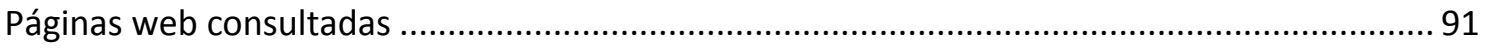

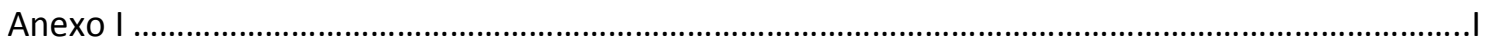

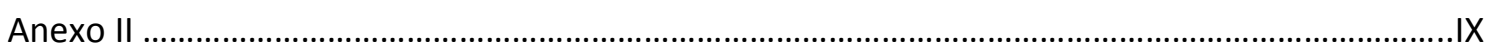

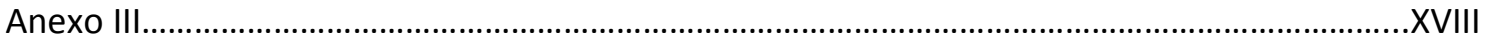

\section{Índice de Tablas}

Tabla 3. 2: RN Y LVE, LOTE DE SOJA. FUENTE: TONTI ET AL. (2013)........................................... 13

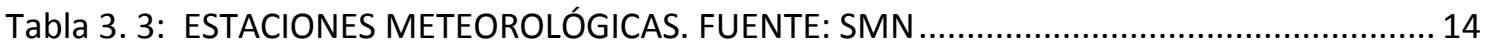

Tabla 5. 1: Hora UTC de visita del satélite GOES y el lapso entre visitas consecutivas, para el día 4 de enero de 2013

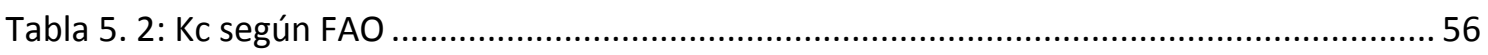

Tabla 6. 1: Rni medido in situ y Rni estimado a partir de imágenes MODIS ................................59

Tabla 6. 2: $\mathrm{ET}_{\mathrm{i}}$ medida in situ y estimada a partir de imágenes MODIS ......................................60 
Tabla 6. 3: Resultados de estimaciones MODIS-GOES comparados con el testigo para el día 4 de enero de 2013

Tabla 6. 4: Resultados de estimaciones MODIS-GOES comparados con el testigo para el día 6 de enero de 2013

Tabla 6. 5: Resultados de estimaciones MODIS-GOES comparados con el testigo para el día 7 de enero de 2013

Tabla 6. 6: Resultados de estimaciones MODIS-GOES comparados con el testigo para el día 8 de enero de 2013

Tabla 6. 7: Resultados de estimaciones MODIS-GOES comparados con el testigo para el día 9 de enero de 2013

Tabla 6. 8: Resultados de estimaciones MODIS-GOES comparados con el testigo para el día 13 de enero de 2013.

Tabla 6. 9: Resultados de estimaciones MODIS-GOES comparados con el testigo para el día 19 de enero de 2013

Tabla 6. 10: Test de significancia para R. $\mathrm{ET}_{\mathrm{r}} \mathrm{Vs} E_{\mathrm{dr}}$ y $\mathrm{ET}_{\mathrm{r}} \mathrm{Vs} E_{\mathrm{dd}}$ diario y 16 días .70

\section{Índice de Figuras}

Figura 3. 1: Área de estudio y su relación con la toma 12-13 MODIS.

Figura 4. 1: Firmas espectrales. (Chuvieco et al, 2002)

Figura 4. 2: Esquema del $\mathrm{K}_{\mathrm{c}}$ según condiciones de suelo húmedo y suelo seco para un cultivo anual y sus etapas de desarrollo. Fuente: Manual n56 de FAO-1992

Figura 4. 3: Esquema de las etapas del desarrollo de un cultivo anual. Fuente: Manual $n^{\circ} 56$ de FAO-1992.

Figura 5. 1: BEAM VISAT - metadato b31-Mod11de productos MODIS. 31

Figura 5. 2: Esquema 1A - Metodología utilizada 35

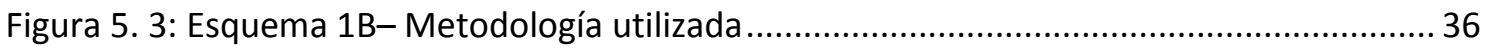

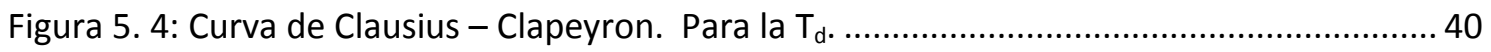

Figura 5. 5: Curva de C - C. Para la presión de vapor de saturación ............................................ 44

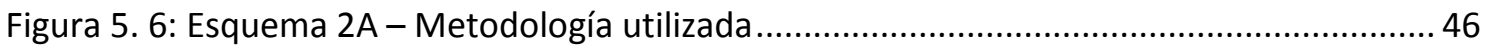

Figura 5. 7:1 Esquema 2B - Metodología utilizada ................................................................ 47

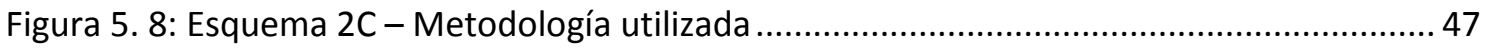


Figura 5. 9: Esquema del modelo sinusoidal propuesto por Bisht et al. (2005) para la estimación del ciclo diurno de la radiación neta. Adaptado por Mulleady (2011) ....................................... 48

Figura 5. 10: Esquema Del contenido hídrico de los suelos.................................................... 55

Figura 5. 11: Píxel correspondiente a la estación meteorológica (Villa Gesell y Cnel. Pringles

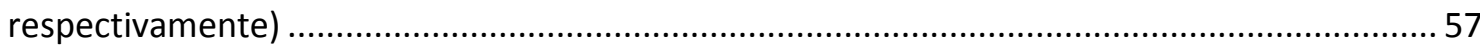

\section{Índice de Fórmulas}

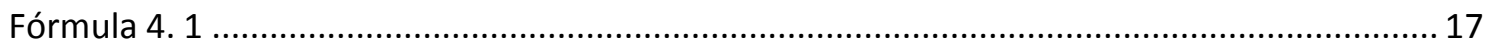

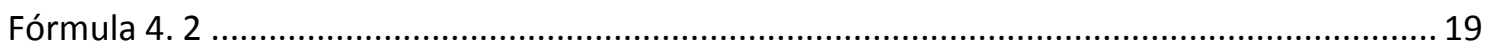

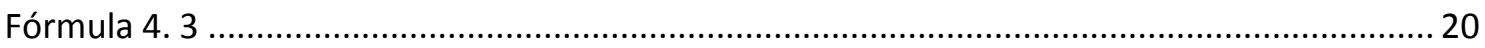

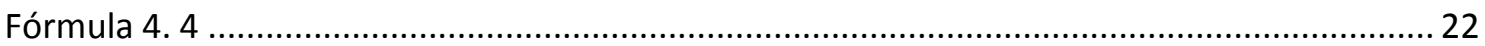

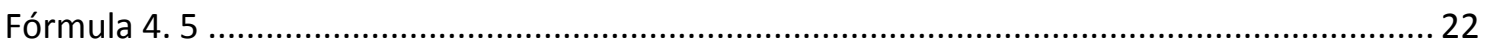

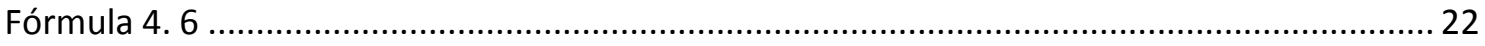

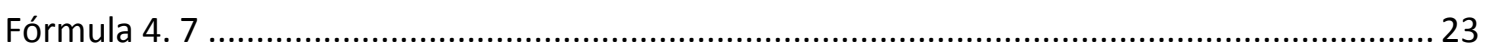

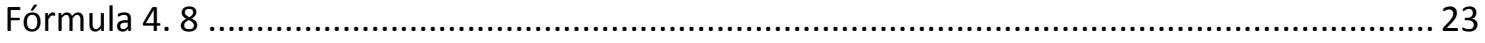

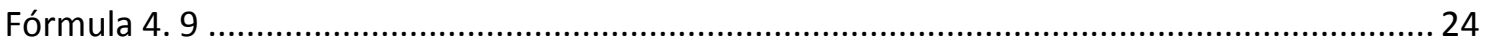

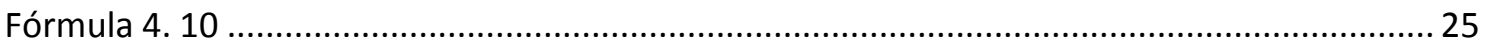

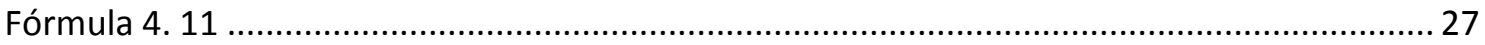

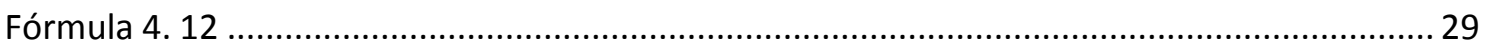

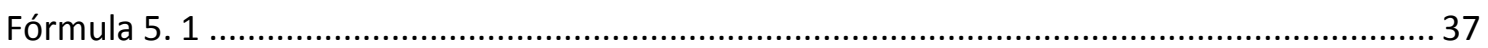

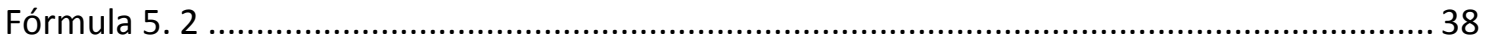

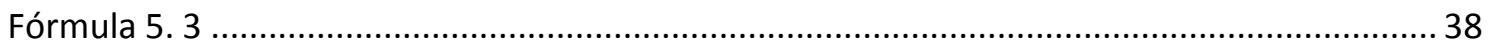

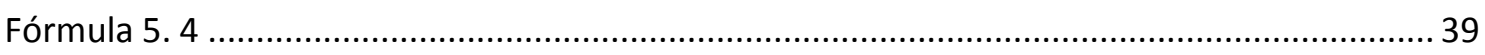

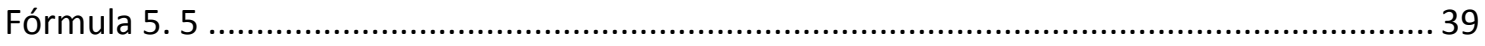

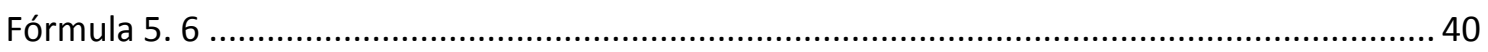

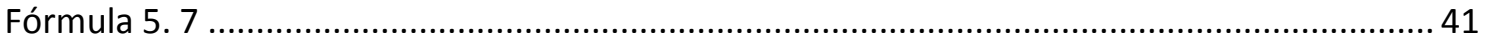

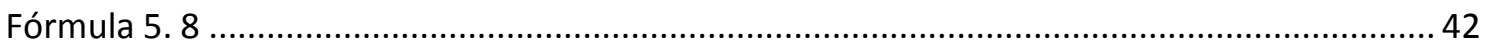

Fórmula 5.9

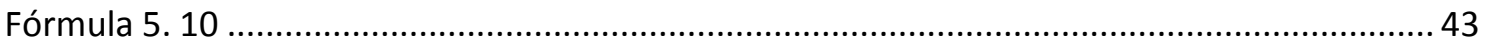

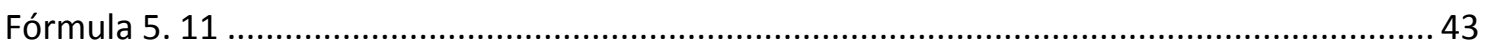


Fórmula 5. 12

Fórmula 5.13

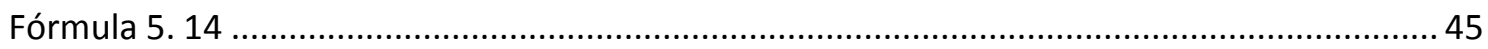

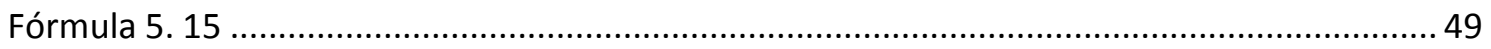

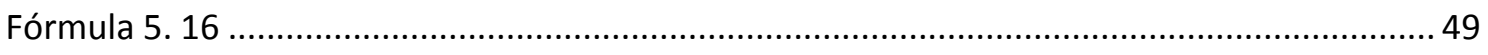

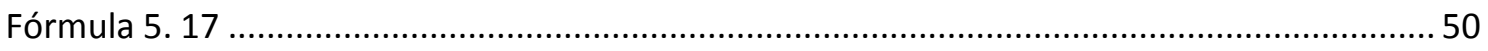

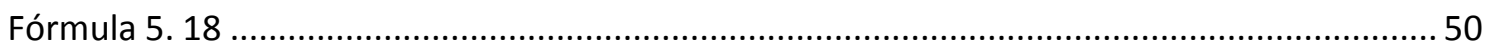

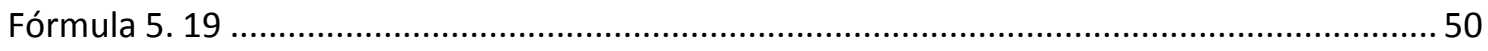

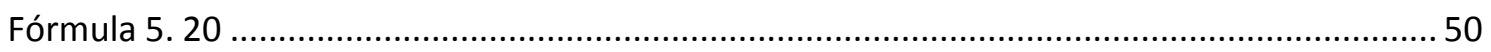

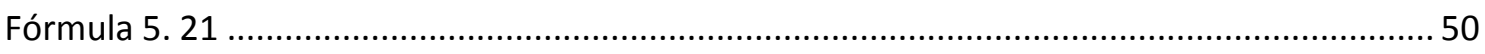

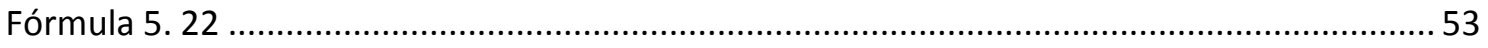

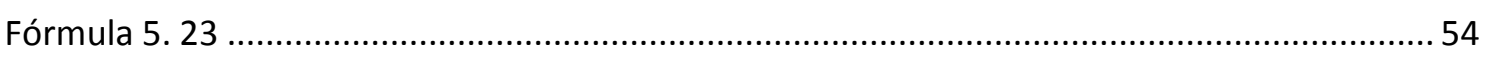

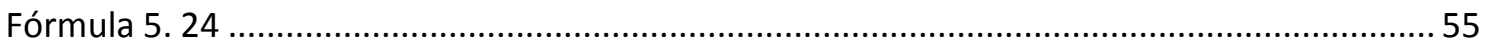

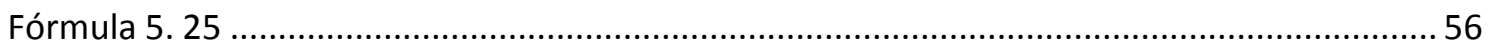

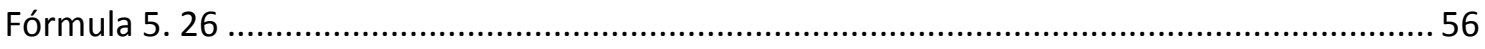

\section{Índice de Gráficos}

Gráfico 6. 1: Regresión lineal - $\mathrm{Rn}_{\mathrm{i}}$ “in situ” Vs $\mathrm{Rn}_{\mathrm{i}}$ estimada - diario y 16 días ........................60 60

Gráfico 6. 2: Regresión lineal - $\mathrm{ET}_{\mathrm{i}}$ “in situ” Vs $\mathrm{ET}_{\mathrm{i}}$ estimada - diario y 16 días........................ 61

Gráfico 6. 3: Regresión lineal -4 de enero $-E_{\mathrm{dr}} \mathrm{Vs}_{\mathrm{ET}}-$ diario y 16 días.................................65

Gráfico 6. 4: Regresión lineal -6 de enero $-E_{\text {dr }}$ vs ET $_{r}-$ DIARIO y 16 días............................ 66

Gráfico 6. 5: Regresión lineal -7 de enero $-E_{\mathrm{dr}}$ vs ETr - diario y 16 días ..............................66

Gráfico 6. 6: Regresión lineal -8 de enero $-E_{\mathrm{dr}}$ vs $\mathrm{ET}_{\mathrm{r}}-$ diario y 16 días ..............................6 67

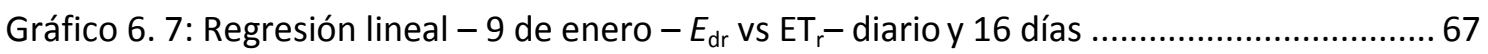

Gráfico 6. 8: Regresión lineal -13 de enero $-E_{\mathrm{dr}} \mathrm{vs} \mathrm{ET}_{\mathrm{r}}-$ diario y 16 días ..............................68

Gráfico 6. 9: Regresión lineal - 19 de enero $-E_{\mathrm{dr}} \mathrm{vs} \mathrm{ET}_{\mathrm{r}}-$ diario y 16 días ............................68

Gráfico 6. 10: Regresión lineal - Todas las estaciones meteorológicas y todos los días $-E_{\mathrm{dr}}$

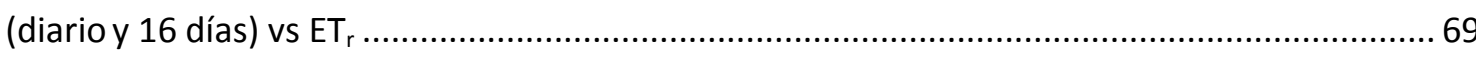

Gráfico 6. 11: Regresión lineal - Todas las estaciones meteorológicas y todos los días $-E_{\mathrm{dd}}$

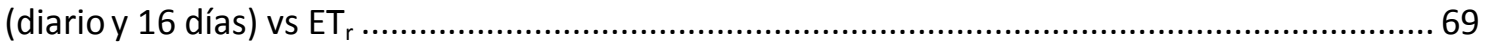

Gráfico 6. 12: PRCC para los 5 parámetros que componen la ecuación $4.8 \ldots \ldots \ldots \ldots \ldots \ldots \ldots \ldots \ldots . . . . . . . . . . . . . . . .11$ 


\section{Capítulo 1. Resumen}

La evapotranspiración es el pasaje de agua desde diferentes coberturas del suelo hacia la atmósfera, en forma de vapor. Parte de esta agua se encuentra en cuerpos libres o en el suelo y en la vegetación. En términos más estrictos, la evapotranspiración es la suma de dos procesos físicos diferentes que ocurren simultáneamente: a) la evaporación, que se produce a partir de cuerpos de agua o suelo encharcado, de la matriz porosa del suelo superficial cuando este tiene humedad suficiente, y de gotas de agua retenidas en el follaje luego de una lluvia o del rocío; y b) la transpiración de las plantas. Estos dos procesos se engloban bajo el término "evapotranspiración” y su estimación se realiza en forma integrada.

Mediante la evapotranspiración se transfiere a la atmósfera, por un lado, masa de agua, y por otro, la energía necesaria para que el agua cambie de estado líquido a gaseoso; esta energía se denomina calor latente de vaporización.

El presente trabajo tiene como objetivo estimar la evapotranspiración instantánea en gran parte de la Provincia de Buenos Aires, República Argentina, utilizando imágenes satelitales del sensor MODIS como única fuente de datos. Debido a la escasa información in situ para ser utilizada como testigo, la evapotranspiración instantánea $\left(\mathrm{W} / \mathrm{m}^{2}\right)$ se transformó en evapotranspiración diaria real $(\mathrm{mm} /$ día $)$ a partir de información provista por imágenes GOES del satélite GOES-Este para que la misma pueda ser comparada con la Evapotranspiración real obtenida a partir de Balance Hidrológico de Thornthwaite -Mather.

Se evaluó la posibilidad de obtener estimaciones aceptables de evapotranspiración a nivel regional, prescindiendo de mediciones in-situ y, por lo tanto, susceptibles de ser obtenidas en forma operativa en tiempo cuasi-real para su consulta por diferentes usuarios.

Para la estimación de la evapotranspiración instantánea se utilizó la metodología propuesta por Venturini con la modificación efectuada por Girolimetto, trabajando con datos instantáneos obtenidos diariamente por el sensor MODIS y productos MODIS desarrollados por la NASA, como el albedo y el NDVI.

Los resultados de evapotranspiración instantánea obtenidos (con una resolución espacial de $1 \mathrm{Km}^{2}$ ) se contrastaron con mediciones puntuales de flujo de calor latente 
disponibles en solo un sitio de la región de estudio (Lote de soja de 19 has, en la Estación Experimental del INTA - Balcarce), mostrando una muy buena correlación.

La evapotranspiración diaria real estimada (también con resolución espacial de $1 \mathrm{Km}^{2}$ ) se contrastó con la evapotranspiración real calculada a partir del Balance Hidrológico para varias estaciones meteorológicas de la región de estudio.

La evapotranspiración diaria real estimada a partir de sensores remotos muestra una buena correspondencia con la evapotranspiración real, teniendo en cuenta que: a) el método del balance hidrológico supone que la vegetación se encuentra libre de enfermedades y bajo cobertura completa, mientras que la estimada en este trabajo refleja las condiciones propias de la vegetación; y b) se compara una estimación areal media sobre $1 \mathrm{Km}^{2}$ con un cálculo puntual en la estación meteorológica.

Por otra parte, los valores obtenidos en mm/día son similares a los obtenidos por otros autores en otras regiones del mundo, o bien, en áreas pequeñas dentro de la misma zona de estudio, pero bajo una cobertura homogénea. 


\section{Capítulo 2. Objetivos e hipótesis}

El presente trabajo persigue los siguientes objetivos generales:

1. Estimar la evapotranspiración instantánea como flujo de calor latente de vaporización, utilizando únicamente imágenes satelitales del sensor MODIS.

2. Estimar la evapotranspiración acumulada diaria como flujo de calor latente de vaporización, utilizando adicionalmente imágenes satelitales del sensor GOES a bordo del satélite geoestacionario GOES-Este, para luego transformarla en evapotranspiración expresada como velocidad de masa.

En función de las particularidades de nuestro segundo objetivo general, se plantean objetivos específicos en este marco:

1. Estimar la evapotranspiración diaria en condiciones de cielo despejado.

2. Estimar la disminución de la evapotranspiración diaria debido a nubosidad y transformarla en evapotranspiración real diaria.

A continuación, se presentan las hipótesis más importantes que sustentan el trabajo;

1. La tasa de evapotranspiración instantánea puede estimarse bajo la forma de flujo de calor latente, a partir de información provista por los sensores MODIS a bordo de los satélites heliosincrónicos Terra y Aqua de la NASA, al momento de su visita.

2. La evapotranspiración diaria en condiciones de cielo despejado puede estimarse a partir de la radiación neta diaria sobre la misma superficie evaporante.

3. La disminución de la evapotranspiración diaria (para condiciones de cielo despejado) debido a la nubosidad puede determinarse con la ayuda 
de imágenes sucesivas del satélite geoestacionario GOES-Este a lo largo del período diurno. 


\section{Capítulo 3. Metodología}

Se utilizó la metodología propuesta por Venturini et al. (2008) y modificada por Girolimetto y Venturini (2014) para la estimación de la $\mathrm{ET}_{\mathrm{i}}$ a partir de sensores remotos. Se trabajó con productos MODIS diarios y con productos MODIS de dieciséis días para el albedo y el NDVI. Estos productos de dieciséis días son mosaicos, donde cada píxel es elegido según su calidad, optando por el mejor de los dieciséis valores medidos.

En función de la metodología utilizada se obtuvieron resultados para evapotranspiración instantánea $\left(\mathrm{ET}_{\mathrm{i}}\right)$ como flujo de energía en forma de calor latente, cuyas unidades son $\mathrm{W} / \mathrm{m}^{2}$. La técnica es aplicable en áreas con cielo despejado, donde los sensores reciben la radiación emitida o reflejada por la superficie y no por las nubes.

A su vez, se introdujo una modificación al cálculo de $\Omega$ propuesto por Girolimetto y Venturini (2014), que cuantifica el estado de humedad del suelo.

Luego se estimó la evapotranspiración acumulada diaria $\left(\mathrm{ET}_{\mathrm{dd}}\right)$, bajo el supuesto de cielo despejado durante el ciclo diurno.

Para el pasaje de la $\mathrm{ET}_{\mathrm{i}}$ a $\mathrm{ET}_{\mathrm{dd}}$ se utilizó el criterio de Bisht et al. (2005).

Por otra parte, se ajustó la $\mathrm{ET}_{\mathrm{dd}}$ según la nubosidad durante cada día a partir de imágenes GOES, obteniendo la evapotranspiración diaria real $\left(\mathrm{ET}_{\mathrm{dr}}\right)$, para luego expresarla en $\mathrm{mm} /$ día.

\section{1. Área de estudio.}

Se realizó la estimación satelital de evapotranspiración para gran parte de la Provincia de Buenos Aires, República Argentina.

El área de estudio está relacionada con la región que abarca la toma de imágenes MODIS para la provincia de Buenos Aires. En la figura 3.1 se puede observar el área de estudio, la cual coincide con la toma 12-13 de MODIS. 


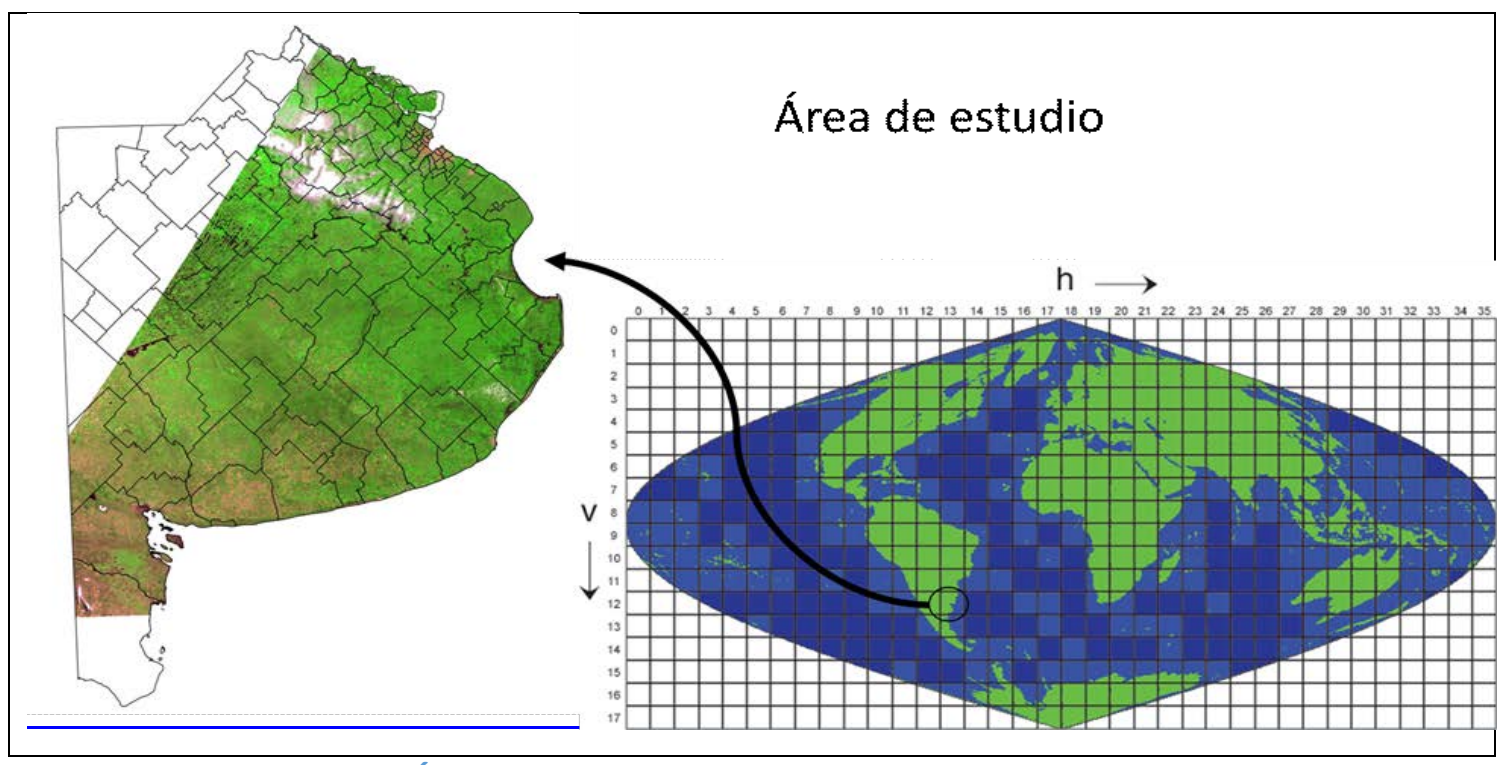

FIGURA 3. 1: ÁREA DE ESTUDIO Y SU RELACIÓN CON LA TOMA 12-13 MODIS

\subsection{Datos meteorológicos.}

Se contó con mediciones “in situ” del flujo de calor latente $\left(\mathrm{W} / \mathrm{m}^{2}\right)$ y Radiación Neta $\left(\mathrm{W} / \mathrm{m}^{2}\right)$, registrados en la Estación Experimental - INTA Balcarce, para un lote de soja de 19 Has. En la Tabla 3.1 podemos observar la información publicada por Tonti et al. (2013).

\begin{tabular}{|c|c|c|c|}
\hline DIA & HORA UTC & Rni (W/m2) & $\begin{array}{c}\text { LvE (W/m2) - } \\
\text { flujo de calor } \\
\text { latente }\end{array}$ \\
\hline $04 / 01 / 2013$ & 13,55 & Sin dato & 154,8 \\
\hline $05 / 01 / 2013$ & 14,37 & 673,4 & Sin dato \\
\hline $06 / 01 / 2013$ & 13,43 & 614,3 & 302,5 \\
\hline $07 / 01 / 2013$ & 14,25 & 404,7 & 117,7 \\
\hline $08 / 01 / 2013$ & 13,31 & 569,1 & 255,3 \\
\hline $09 / 01 / 2013$ & 14,13 & 628,7 & 220,6 \\
\hline $13 / 01 / 2013$ & 13,49 & 412,7 & 209,4 \\
\hline $14 / 01 / 2013$ & 14,31 & 237 & 51,3 \\
\hline $16 / 01 / 2013$ & 14,19 & 338,5 & 165,2 \\
\hline $19 / 01 / 2013$ & 13,13 & 313,9 & 54,9 \\
\hline TABLA 3. 1: RN Y LVE, LOTE DE SOJA. FUENTE: TONTI ET \\
\hline \multicolumn{4}{|c}{ AL. (2013) } \\
\hline
\end{tabular}

Los días de estudio se eligieron a partir de la Tabla 3.1, según aquellos días que tuvieron información del flujo de calor latente. Por eso, los días elegidos fueron: $4-6-$ $7-8-9-13-14-16$ y 19 donde la toma de las imágenes fuera lo más cercana a la 
hora de medición in situ. Por otra parte, los días 14 y 16 fueron descartados por ser días nublados prácticamente en toda la provincia, incluyendo Balcarce.

A su vez, se contó con datos puntuales de parámetros atmosféricos, medidos en estaciones meteorológicas del SMN y del INTA. Estos datos, fueron utilizados para calcular la evapotranspiración real en mm/día, obtenida mediante el balance hidrológico de Thornthwaite - Mather (1955) - BH-TM -. En la Tabla 3.2 se muestran las veintiún estaciones meteorológicas y sus coordenadas de ubicación.

Los datos brindados para estas estaciones fueron: a) temperaturas máximas y mínimas, b) humedad relativa máxima y mínima, c) presión atmosférica, d) velocidad del viento, e) heliofanía, f) precipitación, g) coordenadas y h) fecha.

\begin{tabular}{|l|r|r|}
\hline \multicolumn{1}{|c|}{ Estaciones } & \multicolumn{1}{c|}{ latitud } & \multicolumn{1}{c|}{ longitud } \\
\hline San Fernando & $-34,4500$ & $-58,5833$ \\
Las Flores Aero & $-36,0333$ & $-59,1333$ \\
San Miguel & $-34,5500$ & $-58,7333$ \\
Ezeiza Aero & $-34,8167$ & $-58,5333$ \\
La Plata Aero & $-34,9667$ & $-57,9000$ \\
Punta Indio (BA) & $-35,3667$ & $-57,2833$ \\
Coronel Suárez Aero & $-37,4333$ & $-61,8833$ \\
Bolívar Aero & $-36,2000$ & $-61,0667$ \\
Azul Aero & $-36,8333$ & $-59,8833$ \\
Olavarría Aero & $-36,8833$ & $-60,2167$ \\
Tandil Aero & $-37,2333$ & $-59,2500$ \\
Dolores Aero & $-36,3500$ & $-57,7333$ \\
Benito Juárez Aero & $-37,7167$ & $-59,7833$ \\
Villa Gesell Aero & $-37,2333$ & $-57,0167$ \\
Pigüé Aero & $-37,6000$ & $-62,3833$ \\
Coronel Pringles Aero & $-38,0167$ & $-61,0333$ \\
Barrow INTA & $-38,3167$ & $-60,2500$ \\
Balcarce INTA & $-37,7500$ & $-58,3000$ \\
Mar del Plata Aero & $-37,9333$ & $-57,5833$ \\
Hilario Ascasubi INTA & $-39,3833$ & $-62,6167$ \\
Bahía Blanca & $-38,7336$ & $-62,1669$ \\
& & \\
\hline TABLA 3. 2: ESTACIONES METEORO LÓ GICAS. \\
FUENTE: SMN & \multicolumn{2}{|}{} \\
\hline
\end{tabular}




\section{Capítulo 4. Introducción y estado de la cuestión}

La evapotranspiración es el proceso a través del cual parte del agua retenida en los suelos, vegetación y cuerpos de agua son devueltos a la atmósfera en forma de vapor. En términos más estrictos, la evapotranspiración es la suma de dos procesos físicos diferentes que ocurren simultáneamente: a) la evaporación, que se produce a partir de cuerpos de agua o suelo encharcado, de la matriz porosa del suelo superficial cuando este tiene humedad suficiente, y de gotas de agua retenidas en el follaje luego de una lluvia; y

b) la transpiración de las plantas, proceso mediante el cual se transfiere a la atmósfera a través de los estomas de las hojas, el agua del suelo que ingresa a la planta a nivel de las raíces; mediante la transpiración la planta elimina el calor generado por los procesos biológicos y es este mecanismo el que tracciona el agua del suelo.

Estos dos procesos no son enteramente independientes, pues dependen de las condiciones meteorológicas reinantes, producen cambios en la concentración de vapor de agua en la capa de aire contigua a la superficie terrestre, con lo que modifican el gradiente vertical de humedad en el aire, el cual influye sobre ambos.

Se engloban bajo el término "evapotranspiración" y su estimación se realiza en forma integrada.

Mediante la evapotranspiración se transfiere a la atmósfera, por un lado, masa de agua, y por otro, la energía necesaria para que el agua cambie de estado líquido a estado gaseoso; esta energía se denomina calor latente de vaporización.

La evapotranspiración suele estimarse de tres formas diferentes, explicadas aquí según la aproximación de Brutsaert (1984): 
1. Como tasa de transferencia vertical de masa de agua a través de la superficie. Físicamente es la velocidad de la evapotranspiración (en $\mathrm{m} / \mathrm{s}$ ) que por lo general se la expresa en (mm/día). La llamamos $E$.

2. Como flujo de masa, al multiplicar $E$ por la densidad del agua $\left(\rho_{\mathrm{w}}\right)$. Expresa la cantidad de masa de agua que atraviesa una unidad de superficie en una unidad de tiempo. Se expresa en $\left(\mathrm{Kg} / \mathrm{m}^{2} \mathrm{~s}\right)$.

3. Como flujo de calor latente de vaporización. Se obtiene al multiplicar el flujo de masa por el calor latente de vaporización $(\lambda)$, que es la cantidad de energía necesaria para evaporar $1 \mathrm{Kg}$ de agua. Se expresa en $\left(\mathrm{J} / \mathrm{m}^{2} \mathrm{~s}\right)$, o también en $\left(\mathrm{W} / \mathrm{m}^{2}\right)$. La llamamos $E T_{f}=\rho_{\mathrm{w}} \lambda E$.

Pese a la importancia de conocer bien la evapotranspiración (ET), ya sea expresada como volumen de agua transpirada o como energía involucrada en el proceso, resulta muy complejo realizar estimaciones precisas, -al tratarse de un proceso relacionado con múltiples factores- debido a que, por un lado, están aquellas variables relacionadas con las condiciones meteorológicas que determinan la demanda atmosférica de vapor; por otro, la humedad del suelo y la presencia de agua retenida en el follaje; y por último, pero también importante, las características fisiológicas de las especies vegetales, ya que la transpiración está directamente relacionada con los mecanismos de resistencia a la sequía que posee cada planta (Monteith, 1981; Brutsaert, 1984; Shuttleworth y Wallace, 1985 entre otros).

Los cuatro factores principales que controlan la evapotranspiración son: la disponibilidad de agua en los suelos, la cantidad de energía radiante disponible, el déficit de saturación del aire y los mecanismos de transporte para remover el vapor de agua desde la superficie evapotranspirante -suelo desnudo y cubierta vegetal- (Monteith, 1985).

Cuando la superficie evapotranspirante es una cubierta vegetal corta y densa de pastizales naturales, sin estrés hídrico, y libre de enfermedades, la transferencia de vapor hacia la atmósfera se denomina "Evapotranspiración de Referencia" $\left(\mathrm{ET}_{0}\right)$ según el modelo Penman-Monteith presentado en 1977 en la publicación de la Serie de Riego y Drenaje de la FAO No. 24, cuyos autores fueron J. Doorenbos y W. Pruitt. Sin embargo, si se considera a la superficie evapotranspirante, una cubierta cultivada y el cultivo se encuentra bajo condiciones óptimas, entonces se habla de Evapotranspiración 
del Cultivo $\left(\mathrm{ET}_{\mathrm{c}}\right)$. Dichas condiciones corresponden a un desarrollo del cultivo libre de enfermedades, con buena fertilización, que crece en un campo extenso en condiciones óptimas de humedad del suelo y alcanzando su producción máxima bajo ciertas condiciones climáticas.

El balance de energía, la temperatura de superficie, la vegetación y la humedad en el suelo, están intrínsecamente relacionados, siendo esto, tema de estudio para meteorólogos, hidrólogos, agrónomos y biólogos entre otros. Hacia mitad del siglo XX en adelante, se han desarrollado diferentes modelos para estimar la evapotranspiración en distintas escalas, tanto de tiempo como de espacio, en condiciones de cobertura vegetal y humedad de suelo propias del lugar, a partir de mediciones in situ de variables meteorológicas, de la vegetación y del suelo. La mayoría de estos modelos parten de la ecuación de Penman (1948), como es el caso del de Monteith (1965), Priestley y Taylor (1972) y Shuttleworth y Wallace (1985).

Con el advenimiento de la era satelital, surgieron a su vez, más modelos de estimación de la evapotranspiración. A pesar de la larga tradición con la que cuentan los estudios de evapotranspiración, y de la amplia cantidad de técnicas de teledetección satelital propuestas, no existe un acuerdo generalizado sobre los métodos más recomendables en cada zona (Chuvieco, 2002).

Asimismo, Brutsaert (1984), propuso estimar la evapotranspiración como residuo a partir de la ecuación de conservación de energía en la superficie evapotranspirante. La ecuación que rige el balance de energía está dada por: la distribución de la radiación neta (Rn) a nivel de superficie, por el flujo de calor en el suelo (G) y los flujos atmosféricos de calor sensible $(H)$ y de calor latente $\left(\rho_{\mathrm{w}} \lambda \mathrm{E}\right)$ :

$$
\begin{gathered}
R n=G+H+\rho w \lambda E \\
\text { FÓRMULA 4.1 }
\end{gathered}
$$

Todos los estudios realizados bajo este enfoque usan modelos unidimensionales (verticales) para describir la radiación, la conducción y los mecanismos de transporte que influencian la temperatura de superficie $\left(\mathrm{T}_{\mathrm{s}}\right)$ y el balance de energía (Mulleady y Barrera, 2013). 
Varios autores, Sánchez y Chuvieco (2000); Chuvieco (2002); Venturini (2006; 2007; 2008 y 2012) entre muchos otros, han propuesto metodologías para estimar la evapotranspiración, a partir de información proveniente de sensores remotos.

Entre los métodos utilizados hasta el momento para estimar la evapotranspiración con teledetección, podemos establecer dos grandes grupos, según se trate de modelos elaborados para este fin (directos) o creados para el estudio de otros fenómenos o procesos superficiales (indirectos), pero útiles en el campo que nos ocupa dada su relación con el problema (Mulleady y Barrera, 2013).

Dentro de los primeros se encuentra el modelo general basado en el balance de energía, mientras que en los segundos se insertan todas las aproximaciones relacionadas con la temperatura superficial, con ciertas características de la vegetación (como la expresada a través de ciertos índices, especialmente el NDVI) y aquellas que aprovechan simultáneamente ambos aspectos.

La relación entre evapotranspiración y la vegetación se basa en el efecto del vigor de los tejidos vegetales (variable asociada al NDVI), el mecanismo fotosintético y la relación entre la temperatura de aire y de la vegetación. Los dos primeros parámetros son afectados por elementos meteorológicos como la temperatura, radiación solar y déficit de presión de vapor entre otros.

Para la temperatura de superficie e índices de vegetación se ha verificado una alta correlación negativa, dado que existe una disminución en la $T_{\mathrm{s}}$ cuando la vegetación se encuentra sin estrés hídrico, producto del enfriamiento provocado en la vegetación por el flujo de calor latente o evapotranspiración, producido por el cambio de estado del agua líquida al estado gaseoso (Nemani \& Running, 1989; Nemani et al., 1993; Yang et al. 1997; Kalluri et al., 1998 entre otros).

Otra relación de importancia que vincula la temperatura de superficie e índices de vegetación con la evapotranspiración es la existente entre la diferencia de temperatura de superficie y del aire $\left(\mathrm{T}_{\mathrm{s}}-\mathrm{T}_{\mathrm{a}}\right)$ y la evapotranspiración. Esta relación se basa en el hecho de que normalmente en un punto cualquiera la $T_{s}$ es mayor que la $T_{a}$, (para días despejados). Esta diferencia tiende a reducirse si en la cubierta se produce flujo de calor latente o evapotranspiración, con el consecuente efecto refrigerante, dependiente a su vez del contenido de agua de la cubierta; de esta manera se asocia evapotranspiración y estrés hídrico vegetal. Por lo tanto, existe una relación entre la magnitud de la diferencia entre $\mathrm{T}_{\mathrm{s}} \mathrm{y} \mathrm{T}_{\mathrm{a}} \mathrm{y}$ el valor alcanzado por el NDVI (Moran, 1994). 
Para un mismo valor de NDVI, una mayor diferencia entre las temperaturas indicará que la cubierta está padeciendo estrés hídrico y que el efecto refrigerante que genera la evapotranspiración es limitado o no se produce por falta de agua.

El NDVI se relaciona también con el cociente entre evapotranspiración real $\left(\mathrm{ET}_{\mathrm{r}}\right)$ y evapotranspiración potencial $\left(\mathrm{ET}_{\mathrm{p}}\right)$ - siendo la $\mathrm{ET}_{\mathrm{r}}$ la evapotranspiración que se produce en condiciones reales, donde la cobertura vegetal no siempre es completa y el contenido de humedad en el suelo no siempre es abundante, mientras que la $\mathrm{ET}_{\mathrm{p}}$ es la máxima evapotranspiración posible bajo las mismas condiciones climáticas, pero con un suelo abundantemente provisto de agua y la cobertura vegetal es completa-. Esta relación es llamada evapotranspiración relativa $(\mathrm{F})$, evidenciando nuevamente la estrecha relación entre evapotranspiración y estrés hídrico vegetal.

Además, conociendo el valor del WDI (Water Deficit Index - siendo WDI el complemento de $\mathrm{F}$, WDI $=1-\mathrm{F}$ ) (Morán, 1994) y la $\mathrm{ET}_{\mathrm{P}}$, con algún método convencional, es posible luego obtener la $\mathrm{ET}_{\mathrm{r}}$, parámetro muy difícil de determinar con precisión en superficies extensas con los métodos convencionales. Esto constituye un gran aporte de la teledetección al estudio de la evapotranspiración, (Sánchez y Chuvieco, 2000) al permitir estimar la evapotranspiración sobre grandes extensiones de superficie.

Friedl (2002), sostiene que la mayor parte de los estudios que utilizan la ecuación de balance de energía con teledetección asumen que la radiación neta y el flujo de calor en el suelo son calculables a partir de información remota, mientras que; $\mathrm{H}$ y $\rho_{\mathrm{w}} \lambda E$, son flujos verticales producidos por transporte turbulento $\mathrm{y}$ son difíciles de estimar. Generalmente, estos términos son calculados a partir de expresiones que consideran que la capa turbulenta adyacente a la cobertura es muy eficiente en la transferencia de vapor de agua vertical (Jarvis y McNaughton, 1986). Ejemplo de estas expresiones son las propuestas por Monteith (1973):

$$
H=\frac{\rho \times C_{p} \times\left(T_{0}-T_{a}\right)}{r_{a}}
$$




$$
\rho_{w} \lambda E=\frac{\rho \times C_{p} \times\left(e_{s}-e_{a}\right)}{\gamma \times\left(r_{c}+r_{a}\right)}
$$

FÓRMULA 4. 3

donde:

- $\rho$ es la densidad del aire.

- $\mathrm{C}_{\mathrm{p}}$ es el calor específico del aire a presión constante.

$-\gamma$ es la constante psicrométrica.

$-\mathrm{T}_{0}$ es la temperatura aerodinámica (Temperatura en la película de aire contigua a la superficie evaporante)

- $e_{s}$ es la presión de vapor de la superficie.

- $e_{a}$ es la presión de vapor del aire por encima de la superficie.

- $r_{c}$ es la resistencia de la superficie al transporte vertical de vapor que opone el suelo debido a la tensión mátrica y vegetal, relacionada con las resistencias del xilema y los estomas.

- $r_{a}$ es la resistencia del aire al transporte vertical del vapor de agua, relacionada con la difusividad turbulenta.

Los modelos que estiman el flujo de calor latente como un término residual de la ecuación (4.1), lo hacen combinando ésta con las ecuaciones (4.2) y (4.3) para determinar los valores de las resistencias $r_{a}$ y $r_{c}$ y seguidamente el valor de la tasa de evapotranspiración.

El advenimiento de la tecnología satelital proporcionó observaciones de la temperatura superficial en forma rutinaria y distribuida en el espacio. La teledetección ha sido ampliamente utilizada con este tipo de modelos sustituyendo la $T_{0}$ por la temperatura radiométrica de superficie $\left(\mathrm{T}_{\mathrm{s}}\right)$ en la ecuación (4.2), a pesar de que pueden diferir en hasta $2^{\circ} \mathrm{C}$ para canopias densas y aún más para suelo parcialmente desnudo, (Boegh et al. 2002). Algunos investigadores desarrollaron sus modelos simplemente haciendo dicha sustitución; otros, al hacerla, agregan una resistencia adicional a $\mathrm{r}_{\mathrm{a}}$ (Boegh et al., 2002 y 2004; Friedl, 2002). Ellos obtienen la evapotranspiración para períodos cortos de tiempo a partir de una única medida de la temperatura de superficie. 
Uno de los métodos teóricos para estimar la evapotranspiración es la ecuación (4.1) del balance de energía, que describe la distribución de la radiación neta recibida por la superficie terrestre en diferentes procesos. Esta ecuación deriva en el denominado método residual que constituye una de las aproximaciones más ampliamente utilizadas en la determinación de la evapotranspiración instantánea $\left(\mathrm{ET}_{\mathrm{i}}\right)$ y diaria $\left(\mathrm{ET}_{\mathrm{d}}\right)$ al calcular cada uno de los términos que igualan al flujo de calor latente y obtener este como el residuo de dicha ecuación (Chuvieco, 2002).

Como ya se mencionó, la evapotranspiración depende fuertemente de la $T_{0}$ de la superficie evaporante, sea ésta del suelo sin vegetación o de la canopia. Lo hace a través del término $\mathrm{H}$ de flujo de calor sensible hacia la atmósfera, y del término Rn. El gran problema asociado a este hecho es que la estimación de $\mathrm{T}_{0}$ a partir de la temperatura radiativa de la superficie, dada por el sensor infrarrojo montado en un satélite, trae aparejado un error de estimación que en muchos casos es significativo. Dicho error se propaga y amplifica ya que la energía calórica emitida por los cuerpos terrestres, según la ley de Stefan-Boltzmann, depende de la cuarta potencia de su temperatura.

Por ello, se intenta evitar que $\left(\mathrm{T}_{0}\right)^{4}$ aparezca en forma explícita en el cálculo de Rn y del mismo modo con $\mathrm{T}_{0}$ en el cálculo de $\mathrm{H}$.

Con esta consideración, Ibáñez y Caselles (1999) proponen usar la denominada razón de Bowen $\beta$ (relación entre $\mathrm{H}$ y $\rho_{\mathrm{w}} \lambda \mathrm{E}$ ) y de esta forma prescindir del cálculo de $\mathrm{H}$.

El método denominado "razón de Bowen", es conocido también como método de energía radiativa y balance de energía. Es aplicado para estimar la evapotranspiración a escala regional incorporando la información aportada por las imágenes de satélite. Los datos radiométricos satelitales, tales como los del sensor NOAA/AVHRR y el TERRA/MODIS, permiten determinar el albedo y la temperatura radiativa de superficie. Boegh et al. (2002), recomiendan utilizar la diferencia $\left(\mathrm{T}_{0}-\mathrm{T}_{\mathrm{a}}\right)$ que se puede estimar con un error absoluto más pequeño que el asociado a $\mathrm{T}_{0}$.

Rivas y Caselles (2004) desarrollaron en la región centro de la provincia de Buenos Aires, República Argentina, una relación lineal en $\mathrm{T}_{0}$ para expresar $\left(\mathrm{T}_{0}\right)^{4}$, que es válida en el rango de temperaturas de $7^{\circ} \mathrm{C}$ a $65^{\circ} \mathrm{C}$; de este modo consiguieron que el error asociado a $\mathrm{T}_{0}$ no se amplifique con la cuarta potencia.

Por otra parte, varios autores han obtenido expresiones para estimar $\mathrm{T}_{0}$ utilizando la técnica denominada "split-window" que relaciona mediciones en dos canales del 
infrarrojo térmico tomadas con sensores satelitales; Rivas y Caselles (2004) usan la fórmula desarrollada por Coll y Caselles (1997).

Rivas (2005), menciona que, si un modelo de este tipo se aplica a escala regional, la superficie de seguro presentará una heterogeneidad fácilmente apreciable cuando uno mira un mapa de usos de los suelos. Para obtener la evapotranspiración en diferentes suelos, con coberturas vegetales iguales o distintas, se requiere del conocimiento de características tales como: resistencia de la superficie, rugosidad superficial, humedad en el suelo, cubierta vegetal y condiciones de la capa atmosférica más próxima a la superficie.

Por otra parte, Bouchet (1963) postula que, a medida que el suelo se seca, la evapotranspiración real disminuye y, en respuesta a ello, la evapotranspiración potencial aumenta a causa de las nuevas condiciones ambientales, y la comienza a nombrar como "relación complementaria". De este modo:

$$
\mathrm{ET}_{r}+E T_{P}=2 E T_{w}
$$

FóRMULA 4. 4

donde "ET ${ }_{\mathrm{w}}$ " es la tasa de evapotranspiración que ocurre cuando "ET $\mathrm{r}_{\mathrm{r}}=\mathrm{ET}_{\mathrm{P}}$ " en un complejo suelo-planta sin restricciones de agua.

Más tarde, Granger (1989a) derivó una relación similar, pero con base físico-teórica:

$$
E T+E T_{P} \times \frac{\gamma}{\Delta}=E T_{w} \times\left[\left(\frac{\gamma+\Delta}{\Delta}\right)\right]
$$

FÓRMULA 4.5

Donde:

$-\Delta$ es la pendiente de la ecuación de presión de vapor saturante de Clausius-Clapeyron (C-C).

A su vez, Granger (1989b) postuló que la $\mathrm{ET}_{\mathrm{P}}$ puede definirse según la ecuación de Dalton, como.

$$
\begin{gathered}
\mathrm{ET}_{p}=f u \times\left(e s^{*}-e a\right) \\
\text { FÓRMULA } 4.6
\end{gathered}
$$

$f_{\mathrm{u}}$ : es una función del viento

$\mathrm{e}_{\mathrm{s}}^{*}$ : Presión de saturación de la superficie 
Poco después, Granger y Gray (1989) trabajaron con la relación $F\left(F=E T_{r} / E_{P}\right)$, y propusieron una concordancia empírica de este cociente con $\left[E_{a} /\left(E_{a}+R n-G\right)\right]$, donde $\mathrm{E}_{\mathrm{a}}$ es el poder evaporante de la atmósfera definido por Penman (1948) como: $\left[\mathrm{E}_{\mathrm{a}}=f_{\mathrm{u}}\right.$ $\left.\left(e^{*}{ }_{a}-e_{a}\right)\right], y$ donde:

- $\mathrm{e}_{\mathrm{a}}{ }^{*}$ es la presión de saturación del aire $(\mathrm{hPa})$

Por otro lado, $\mathrm{Rn}-\mathrm{G}$ es la energía disponible para el intercambio de calor sensible y latente entre la atmósfera y la superficie.

Como se mencionó anteriormente, Granger y Gray (1989), basándose en la relación complementaria, desarrollaron el concepto de evapotranspiración relativa $(\mathrm{F})$, donde, en condiciones de estrés hídrico, $\mathrm{ET}_{\mathrm{r}}<\mathrm{ET}_{\mathrm{p}}$. Además, consideraron que la ley de Dalton también vale para la evapotranspiración real, de esta manera: $\mathrm{ET}_{\mathrm{r}}=\mathrm{fu}\left(\mathrm{e}_{\mathrm{s}}-\mathrm{e}_{\mathrm{a}}\right)$, siendo $\mathrm{e}_{\mathrm{s}}$ $<\mathrm{e}_{\mathrm{s}}{ }^{*}$. También se cumple que $\mathrm{e}_{\mathrm{s}}>\mathrm{e}_{\mathrm{a}}$ porque de otra manera, se produciría condensación en vez de evaporación.

A partir de lo expuesto anteriormente, Granger y Gray (1989) propusieron calcular F de la siguiente manera.

$$
F=\frac{\mathrm{ET}_{r}}{E T_{P}}=\frac{f u \times(e s-e a)}{f u \times(e s *-e a)}
$$

FÓRMULA 4. 7

La validez de la esta relación ha sido estudiada por varios autores, como ser: Crago y Crowley (2005); Crago et al. (2005); Xu y Singh (2005); Han et al. (2011); Huntington et al. (2011).

Sin estrés hídrico, la $\mathrm{ET}_{\mathrm{r}}=\mathrm{ET}_{\mathrm{p}}$ por lo que $\mathrm{e}_{\mathrm{s}}=\mathrm{e}_{\mathrm{s}}{ }^{*}$. En caso contrario, $\mathrm{e}_{\mathrm{s}}<\mathrm{e}_{\mathrm{s}}{ }^{*}$ debido al cierre estomático y por lo tanto $\mathrm{ET}_{\mathrm{r}}<\mathrm{ET}_{\mathrm{p}}$, (Boegh et al., 2002).

Venturini (2006, 2007, 2008, 2011, 2012), retomó el trabajo de Granger y Gray, pero usando la ecuación de Priestley y Taylor para estimar la evapotranspiración potencial en lugar de usar la ecuación de Penman. Llegaron a la expresión:

$$
E T=\alpha P T \times\left[\frac{F \times \Delta}{(F \times \Delta)+\gamma}\right] \times(R n-G)
$$

FÓRMULA 4.8

donde $\alpha_{\mathrm{PT}}=1.26$ (parámetro de Priestley-Taylor) 
También usaron estimaciones de la temperatura radiativa de superficie $T_{s}$ y de la temperatura de rocío $\left(\mathrm{T}_{\mathrm{d}}\right)$ disponibles como productos del sensor MODIS obtenidos a partir de imágenes hiperespectrales, bajo la condición de cielo despejado.

Para resolver la ecuación (4.8) es necesario conocer $e_{s}$. La ecuación (4.7), está gobernada por el déficit de presión de vapor de la superficie evaporante $\left(e_{s}{ }^{*}-e_{s}\right)$ o por la disponibilidad de agua en la superficie. En otras palabras, en una superficie saturada $\left(\mathrm{s}_{\mathrm{s}}\right)$ $e_{s}$ es igual a $e_{s}{ }^{*}$, mientras que, en una superficie muy seca, $e_{s}$ tiende a $e_{a_{-}}$(Granger y Gray, 1989).

La relación entre $e_{s}$ y $e_{s}{ }^{*}$ fue analizada por Barton (1979), quien, en virtud de describir la evaporación desde una superficie no saturada, introdujo el parámetro $\Omega$ definido como el cociente entre una condición real y potencial de presiones:

$$
\Omega=\frac{e_{s}}{e_{s}^{*}}
$$

\section{FÓRMULA 4. 9}

Barton (1979), definió a ' $\Omega$ como una medida de la relación entre la humedad del suelo disponible por las plantas y la condición de máxima disponibilidad (sin estrés hídrico). Girolimetto (2014), utilizó para estimar ' $\Omega$, la energía radiativa en la región de onda corta del infrarrojo del espectro solar (Short Wave Infrared - SWIR) que es absorbida por el agua, por lo que estas bandas son sensibles a las variaciones del contenido de agua de una superficie, según comenta Chen (2005) y son ampliamente utilizadas para derivar incluso el agua en la vegetación y en el suelo, (Knaeps, 2012).

La gran absorción producida por el agua en longitudes de onda mayores a 1,0 $\mu \mathrm{m}$, tiene un efecto significativo sobre la reflectancia, la cual está negativamente relacionada con el contenido de agua de la superficie (Yilmaz et al., 2008). Así, los suelos secos presentan una alta reflectividad en contraste con la baja reflectancia de los suelos húmedos (Lobell y Asner, 2002).

Esta región del espectro electromagnético sería sensible al vapor de agua atmosférico. Sin embargo, en áreas relativamente pequeñas y en ausencia de nubes, la variabilidad espacial atmosférica sería insignificante y las variaciones de las bandas SWIR se relacionan con la presencia de agua en la superficie (Tucker, 1980; Hunt et al., 1987; Ceccato et al., 2001).

Claramente, como puede apreciarse en la figura 4.1, a medida que aumenta el contenido de agua en la cubierta, la reflectancia en el SWIR disminuye, alcanzando valores 
cercanos a cero para $S_{\mathrm{s}}$. Esta propiedad fue utilizada en el trabajo de Girolimetto (2014) y también en este trabajo, pero con una variante al trabajar con el NDVI.

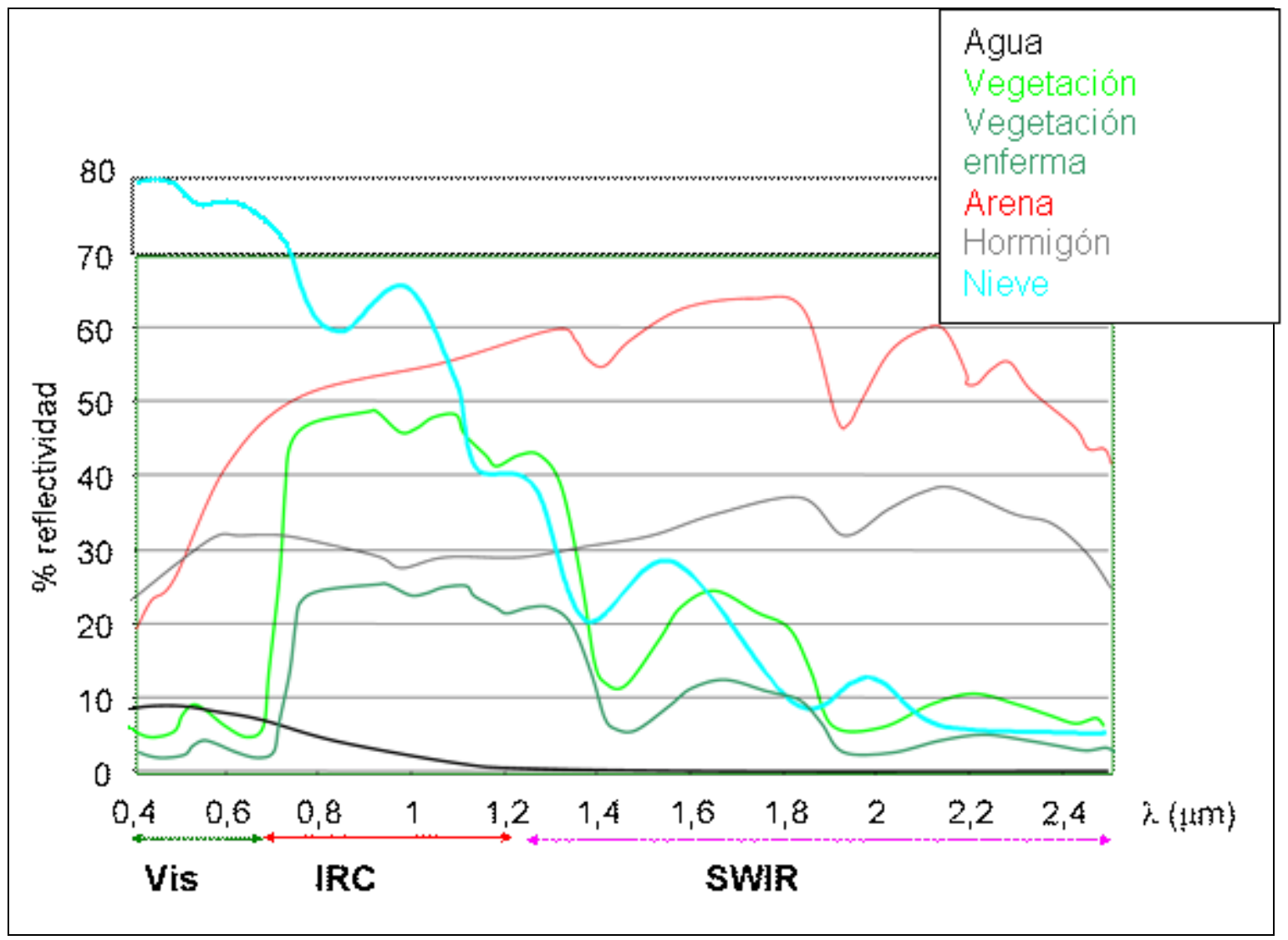

FIgURA 4. 1: FIRMAS ESPECTRALES. (ChuvieCO ET AL, 2002)

Si consideramos al complejo suelo-vegetación como una superficie, a medida que aumenta el contenido de agua en ella, la reflectancia en el SWIR disminuye. Considerando dicha relación inversa y asumiendo que la disminución de la reflectancia en el SWIR se debe esencialmente al contenido de agua de la superficie, $\Omega$ puede aproximarse como:

$$
\Omega=\frac{R_{\text {sat }}}{R_{i}}
$$

\section{FÓRMULA 4. 10}

Donde $\mathrm{R}_{\text {sat }}$, es el promedio de la reflectancia de una $\mathrm{s}_{\mathrm{s}}$ en SWIR, y Ri es la reflectancia en SWIR de cada píxel (Girolimetto, 2014).

Como puede apreciarse por lo expuesto hasta aquí, existen amplias y variadas propuestas de abordaje en la determinación de la evapotranspiración. Sin embargo, es difícil la estimación de la evapotranspiración teniendo en cuenta el tipo de cobertura vegetal existente. 
Según FAO (1977) la evapotranspiración de un cultivo $\left(\mathrm{ET}_{\mathrm{c}}\right)$ o de una superficie vegetada cualquiera, será diferente a la del cultivo de referencia debido a las características del cultivo en cuestión. Los efectos de las características que distinguen al cultivo de una superficie vegetada cualquiera, están incorporados en el coeficiente del cultivo $\left(\mathrm{K}_{\mathrm{c}}\right)$, mientras que los factores meteorológicos aparecen incorporados en la metodología usada para estimar $\mathrm{ET}_{0}, \mathrm{FAO}$ (1997). Como se describe en el manual n²4 de FAO (1977) la $\mathrm{ET}_{\mathrm{c}}$ es igual al producto entre $\mathrm{K}_{\mathrm{c}} \mathrm{y} \mathrm{ET}_{0}\left(\mathrm{ET}_{\mathrm{c}}=\mathrm{K}_{\mathrm{c}} \mathrm{x} \mathrm{ET}_{0}\right)$.

A partir de esta relación, podemos afirmar que el $\mathrm{K}_{\mathrm{c}}$ es el cociente entre la $\mathrm{ET}_{\mathrm{c}}$ y la $\mathrm{ET}_{0}$. Diferentes cultivos tendrán coeficientes de cultivo distintos ya que sus carácterísticas varían, como así también ocurre para diferentes estadíos de un mismo cultivo (figura 4.2 y 4.3). Por último, debido a que la evaporación es un componente de la evapotranspiración del cultivo, los factores que afectan la evaporación en el suelo también afectaran al valor de $\mathrm{K}_{\mathrm{c}}$.

Según FAO (1977) el $\mathrm{K}_{\mathrm{c}}$ puede tener valores mayores a 1 , frecuentemente 5 a $10 \%$ mayor que el valor de referencia $\left(\mathrm{K}_{\mathrm{c}}=1\right)$, lo cual suele ocurrir para cultivos con espacios estrechos entre surcos, mayor altura y rugosidad de las plantas. En algunos casos, la evapotranspiración del cultivo puede llegar hasta un $20 \%$ más que la $\mathrm{ET}_{0}$, siendo típico para cultivos que toman gran altura como el maíz, el sorgo y la caña de azúcar. 


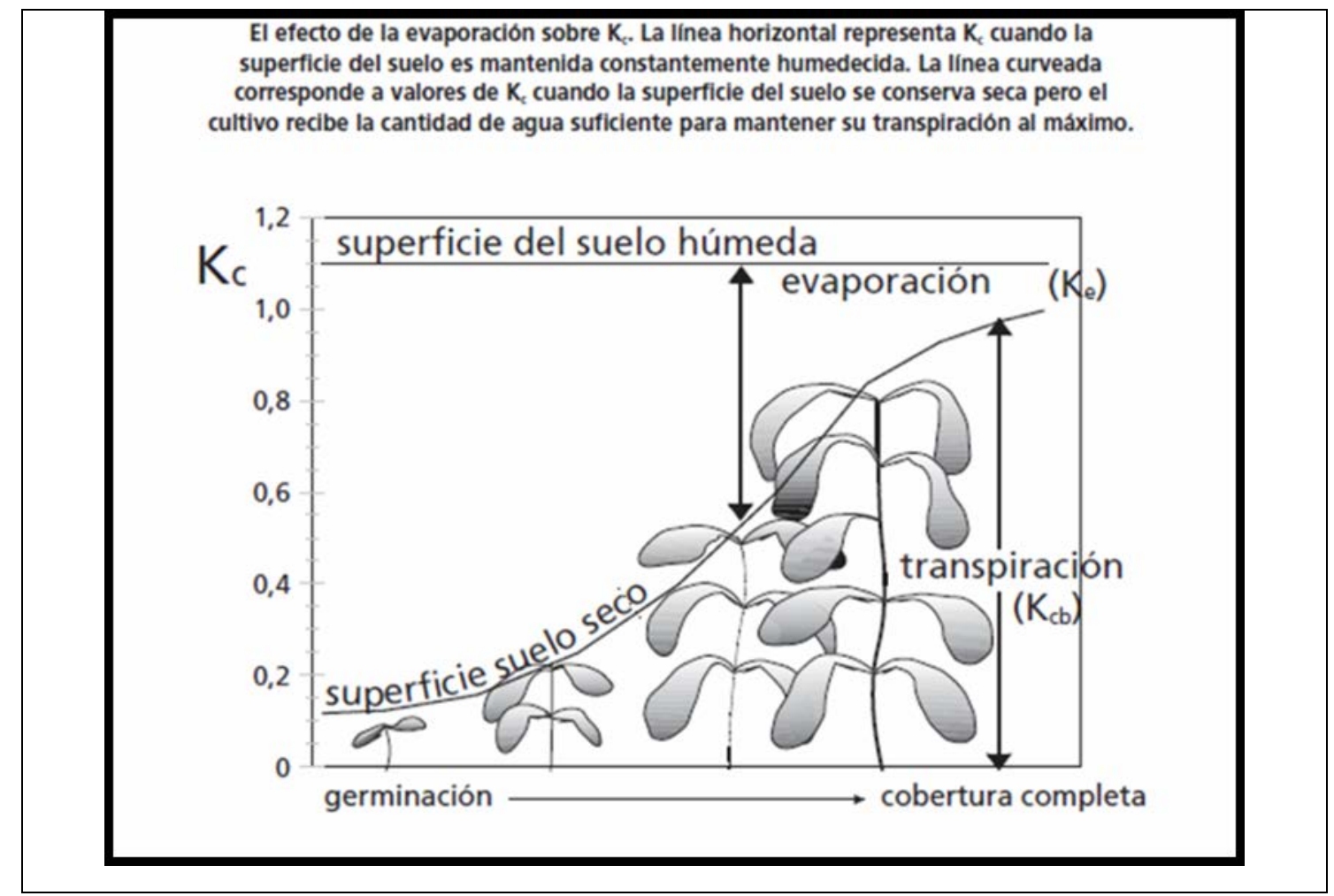

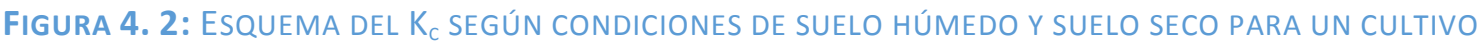
ANUAL Y SUS ETAPAS DE DESARROLlo. Fuente: MANUAL N56 DE FAO-1992

En la figura 4.3 se muestran las etapas de desarrollo para cultivos anuales. El máximo valor posible para el $\mathrm{K}_{\mathrm{c}}$ ocurre en las etapas medias del desarrollo de cultivos anuales.

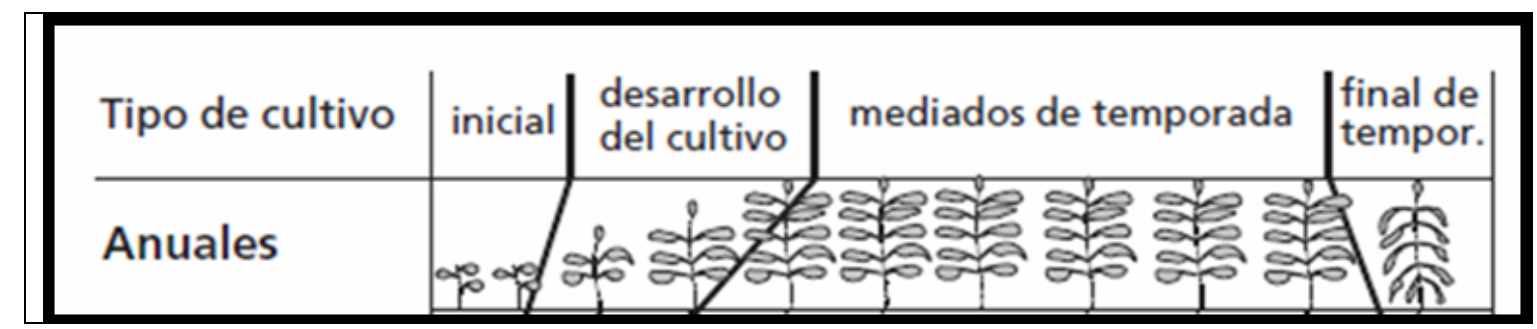

FigurA 4. 3: ESQUEMA DE LAS ETAPAS DEL DESARROLLO de UN CULTIVO ANUAL. Fuente: MANUAL $N^{\circ} 56$ DE FAO-1992

Por otra parte, Murillas Rayo y Londoño Cruz (2015), muestran la relación establecida entre la Evapotranspiración instantánea $\left(\mathrm{ET}_{\mathrm{i}}\right)$ obtenida a partir de sensores remotos y la $\mathrm{ET}_{0 \mathrm{i}}\left(\mathrm{ET}_{0}\right.$ para el mismo momento dado). Esta relación es llamada Fracción de la evapotranspiración de referencia $\left(\mathrm{ET}_{\mathrm{r}} \mathrm{F}\right)$. Según Bastiaanssen et al. (2002):

$$
E T r F=\frac{E T i}{E T 0 i}
$$

FÓRMULA 4. 11 
Para Murrillas Rayo y Londoño Cruz (2015), la $\mathrm{ET}_{\mathrm{r}} \mathrm{F}$ es un término equivalente al coeficiente del cultivo $\mathrm{K}_{\mathrm{c}}$, siempre que no exista restricción hídrica y las condiciones del cultivo sean óptimas.

El proceso evaporativo, es continúo mientras los estomas de las hojas permanecen abiertos, condición que ocurre durante el día (mientras exista radiación fotosintéticamente activa). Como se comentó anteriormente, los estomas permanecen abiertos en condiciones de humedad óptimas, cerrándose a medida que el suelo se seca. Mientras tanto, por la noche los estomas permanecen parcialmente cerrados (a excepción de las plantas con metabolismo ácido de las crasuláceas, también llamadas CAM), evitando así una excesiva pérdida de agua de éstas durante el día (Winter \& Smith, 1996).

Siguiendo este proceso fisiológico de las plantas a lo largo de un día, aparece el concepto de Evapotranspiración diaria $\left(\mathrm{ET}_{\mathrm{d}}\right)$, siendo éste la pérdida de agua por la vegetación y el suelo a lo largo del día.

Las estimaciones a partir de sensores remotos de evapotranspiración implican indefectiblemente una estimación instantánea, correspondiente al momento de paso del satélite por el lugar de estudio. Sin embargo, las mediciones y estimaciones de evapotranspiración diaria poseen una utilidad más apropiada para estudios agronómicos e hídricos.

Existen muchos estudios que intentan estimar la $\mathrm{ET}_{\mathrm{d}} \mathrm{y}$ muchos de ellos a partir de sensores remotos. En este sentido, aparecen trabajos como el de Bastiaanssen et al. (2002), que se basa en la suposición de Jackson et al. (1983) quienes proponen que la evolución diurna de la evapotranspiración sigue el curso de la radiación neta.

Por otro lado, Bisht et al. (2005) propusieron un modelo sinusoidal de variación de la radiación neta a lo largo del ciclo diurno, bajo condiciones de cielo claro. Estos autores observaron que, para días totalmente despejados, la radiación neta adopta un comportamiento sinusoidal desde aproximadamente una hora después del amanecer hasta una hora antes de la puesta del sol.

Jiang et al. (2009) mostraron que para días despejados la extrapolación de valores instantáneos de evapotranspiración a valores diarios siguiendo el modelo sinusoidal de Bisht et al. (2005) tiene asociado un error relativamente pequeño.

Brutsaert y Sugita (1992) propusieron desarrollar técnicas para estimar la evapotranspiración diaria en condiciones de cielo despejado $\left(\mathrm{ET}_{\mathrm{dd}}\right)$ basadas en la 
similitud de la evolución diurna de la evapotranspiración y el comportamiento diurno del balance de energía superficial.

En la literatura aparecen varios trabajos que combinan la $\mathrm{ET}_{\mathrm{i}}$ con el balance de energía diurno para obtener estimaciones de $\mathrm{ET}_{\mathrm{dd}}$, ejemplo de ellos son: Islam et al. (2003); Nishida et al. (2003); Norman et al. (2003); Jiang et al. (2009).

En este trabajo se combinan distintas variables $\left(E T_{i}, R_{d_{d d}}\right.$ y $\left.G_{d d}\right)$ para obtener una estimación de la $\mathrm{ET}_{\mathrm{dd}}$. El esquema utilizado fue:

$$
E T d d=E T i \times\left(R n_{d d}-G_{d d}\right)
$$

FÓRMULA 4. 12

Donde, el subíndice "dd" significa diurno en condiciones de cielo despejado, siendo una simplificación de la ecuación (4.8) para valores acumulados diurnos.

Por otra parte, en el presente trabajo se habla de ET para condiciones de cielo despejado. Durante un día despejado, la radiación de onda corta entrante (Roce) equivale según FAO (1977) al $75 \%$ de la radiación solar al tope de la atmósfera, mientras que, para días totalmente nublados, la Roce baja hasta el 25\%. La relación entre la máxima radiación solar que puede llegar a una superficie y la que realmente llega se conoce como Radiación Relativa (Rr).

La $\mathrm{Rr}$ expresa el grado de nubosidad del día. De esta manera, la $\mathrm{Rr}$ varía entre 1 para cielo despejado y 0,33 para cielo totalmente nublado según FAO (1992).

Según la ecuación (4.1) la evapotranspiración es función de la Radiación neta y esta última varía según la nubosidad del día. Por lo tanto, la evapotranspiración también se verá afectada por la nubosidad del día. Por ello, en el presente trabajo se determinó la ET diaria para condición de cielo despejado y luego se ajustó y transformó en ET diaria real $\left(\mathrm{ET}_{\mathrm{dr}}\right)$, la cual tiene en cuenta la nubosidad durante el día.

Para lograr este ajuste a las condiciones de nubosidad diurnas, se trabajó además con imágenes GOES, las que permitieron observar la nubosidad del día debido a la alta resolución temporal que poseen, obteniendo así datos cada 30 minutos o menos, aproximadamente. 


\section{Capítulo 5. Desarrollo}

Este capítulo detalla el procedimiento utilizado para arribar a los objetivos propuesto en el presente trabajo.

Inicialmente, se puntualiza en las imágenes satelitales utilizadas y luego sobre la metodología propuesta.

\subsection{Productos MODIS.}

Se trabajó con productos del sensor MODIS de la plataforma TERRA.

Se utilizaron los productos MOD07 (en superficie - 1000 y $950 \mathrm{hPa}$ ) - MOD09 MOD11 - MOD13 - MOD43. Utilizando información que dichos productos traen y generando información nueva.

Los perfiles en altura del producto MOD07 se categorizan según la presión atmosférica, las distintas alturas de sondeo son comentadas en el Anexo III. Aquí se resalta que los valores de temperatura de rocío requeridos para este trabajo fueron obtenidos de los perfiles de altura del MOD07 a la presión atmosférica de $1000 \mathrm{hPa}$ (considerado como valor de superficie), también fueron utilizados los datos a $950 \mathrm{hPa}$ en aquellas áreas y días donde la presión atmosférica fue inferior a los $1000 \mathrm{hPa}$.

Los valores de temperatura obtenidos de las imágenes de $950 \mathrm{hPa}$, fueron corregidos según un gradiente térmico igual a $6,5^{\circ} \mathrm{C}$ por $\mathrm{Km}$ y se consideró que una presión de 950 hPa se corresponde con $550 \mathrm{msnm}$.

Se optó por aplicar la misma metodología, para productos MODIS diarios donde, el cálculo del NDVI y del albedo son obtenidos a partir del MOD09 y se corresponden con el día de paso del satélite por el lugar; y de productos de dieciséis días como lo son el MOD13 para NDVI y el MOD43 para el albedo donde, la información surge del paso del satélite por el lugar durante dieciséis días continuos.

\subsection{Procesamiento de los productos MODIS}

Los productos MODIS deben, en algunos casos, ser ajustados espacialmente; lo que permite darle posicionamiento a la imagen satelital; y físicamente, lo que permite trabajar con valores físicos y no con valores digitales o nivel digital (ND). 


\section{2.a. Adecuación de los valores físicos de los píxeles}

Varios de los productos MODIS requieren de una adecuación del valor digital o nivel digital del píxel (ND) a valores con sentido físico. Dicha adecuación se basa generalmente en la aplicación de un factor de escala y uno de adición. Estos factores pueden encontrarse en la web o bien en los metadatos del producto. En este trabajo se utilizó el software BEAM VISAT para visualizar los mismos y poder aplicarle el factor de escala correspondiente a cada una de las imágenes MODIS. En la figura 5.1 se observa una captura de pantalla de dicho software a fin de apreciar los metadatos de los productos MODIS. Este ejemplo, corresponde a la banda 31 del MOD11, información que se puede conseguir en el siguiente sitio web. https://lpdaac.usgs.gov/dataset_discovery/modis/modis_products_table

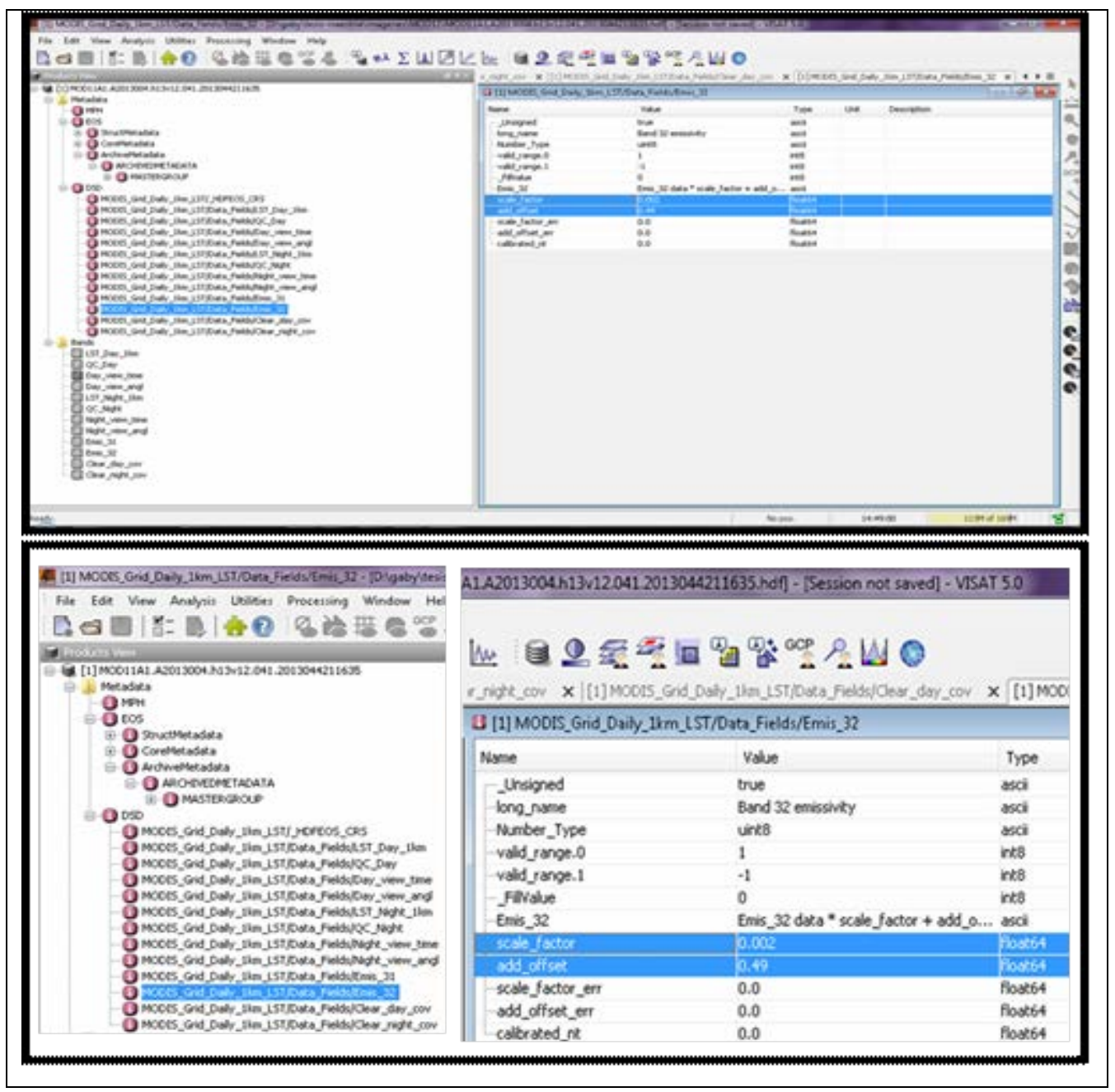

FIGURA 5. 1: BEAM VISAT - METADATO B31-MOD11DE PRODUCTOS MODIS 
A partir de los metadatos de cada producto MODIS se obtuvieron los factores de escala y adición; a continuación, se muestra cómo se pasó de ND a valor físico para cada producto utilizado.

MOD11: Los datos de temperatura son expresados en grados Kelvin y a los niveles digitales se les debió aplicar un factor de escala igual a 0.02 .

$$
N D \times 0,02=\text { Temperatura } \cdot \text { radiométrica } \cdot \text { del } \cdot \text { píxel } \cdot \text { en } \cdot{ }^{\circ} \mathrm{K}
$$

Para obtener los valores de emisividad (sin unidades) de las bandas 31 y 32 además de un factor de escala se requiere uno de adición.

$$
N D \times 0,002+0,49=\text { pixel } \cdot \text { de } \cdot \text { emisividad }
$$

MOD09: Se utilizan de este producto las 6 bandas de reflectividad (sin unidades) para el cálculo del albedo, del NDVI para cada día de estudio y los valores de SWIR para la estimación $\Omega$. Para llegar a valores de reflectividad al ND se le debió aplicar un factor de escala.

$$
N D \times 0,0001=\text { píxel } \cdot \text { de } \cdot \text { reflectividad }
$$

MOD07: No requiere aplicar ningún factor para los datos de temperatura y de presión atmosférica. Los datos de temperatura vienen expresados en grados Kelvin y los de presión en $\mathrm{hPa}$. Mientras que, para el ángulo cenital solar, sí es necesario aplicar un factor de escala.

$$
N D \times 0,01=\text { ángulo } \cdot \text { cenital } \cdot \operatorname{solar}\left(\text { en } \cdot{ }^{\circ} \text { sexagesimal }\right)
$$

MOD43 y MOD13: Ninguno de los productos requiere corrección. Estos productos se utilizaron para estimar la $\mathrm{ET}_{\mathrm{i}}$ pero con albedo y NDVI de 16 días.

\section{2.b. Posicionamiento y resolución espacial de las imágenes.}


MOD07: Resolución espacial de 5000m de lado, siendo la menor resolución de los productos utilizados. Para lograr posicionarla se utilizó la aplicación "Map / Georeference MODIS del software ENVI.

MOD09: Resolución espacial de 500m de lado (banda 1 y la banda 2 poseen $250 \mathrm{~m}$ de resolución espacial) siendo la mayor resolución de los productos utilizados. Este producto no se consiguió con información espacial. Para poder posicionarla correctamente en el espacio se utilizó un producto que tuviese igual resolución espacial y posicionamiento. Dicho producto fue el MOD13. Simplemente copiando la información espacial del producto MOD13 al MOD09, este último queda bien posicionado espacialmente debido a que se utiliza la misma "plancha" de corte para diversos productos.

MOD11: Resolución de 1000m, con información espacial en el dato.

MOD13: Resolución de 500m, con información espacial en el dato.

MOD43: Resolución de 500m. Este producto no se consiguió con información espacial. Para poder posicionarla correctamente en el espacio se utilizó un producto que tuviese igual resolución espacial y posicionamiento, dicho producto fue el MOD13.

Una vez posicionados correctamente todos los productos MODIS, fueron proyectados a POSGAR 2007 - faja 5 y se modificó el tamaño de píxel (resampling) para los productos MOD09, MOD43 y MOD13 a 1000m de resolución espacial a fin de poder llevar adelante los cálculos necesarios y que todas las imágenes tengan el mismo tamaño de píxel. Lo mismo ocurrió con el producto MOD07, aquí con el supuesto que la temperatura del aire, la temperatura de rocío y la presión atmosférica son homogéneas dentro del píxel de $25 \mathrm{~km}^{2}$.

\subsection{Estimación de la evapotranspiración instantánea y sus pasos intermedios}

A partir de la ecuación de conservación de la energía en la superficie que evapotranspira, bajo el supuesto de ausencia de advección horizontal, la radiación neta puede escribirse como la expresión 4.1 .

Muchos autores han estimado el flujo de calor latente a partir de esta ecuación, pero se han apoyado en mediciones in situ, en especial para determinar H. Este término es hoy en día imposible de estimar a partir de sensores remotos, pues involucra el 
conocimiento de las resistencias aerodinámica y de superficie. Por ello, utilizamos la aproximación 4.8 .

Para estimar la $\mathrm{ET}_{\mathrm{i}}$ mediante la ecuación 4.8 es necesario calcular otros parámetros que están incluidos en los considerandos de la misma. Los parámetros se describen en sus correspondientes ítems. Previamente a ello, se muestra un esquema de los pasos realizados para el cálculo de dichos parámetros.

A continuación, en las figuras 5.2 y 5.3, se muestra el esquema 1 (1A y 1B), correspondiente a los pasos desarrollados para la obtención de la $\mathrm{ET}_{\mathrm{i}}$ con productos MODIS diarios.

Un esquema similar les correspondería a los pasos desarrollados para la obtención de la $\mathrm{ET}_{\mathrm{i}}$ con productos MODIS de dieciséis días. Simplemente, saldrían del esquema la obtención del NDVI y del albedo, pues son obtenidos directamente de los productos MOD13 y MOD43 respectivamente. 


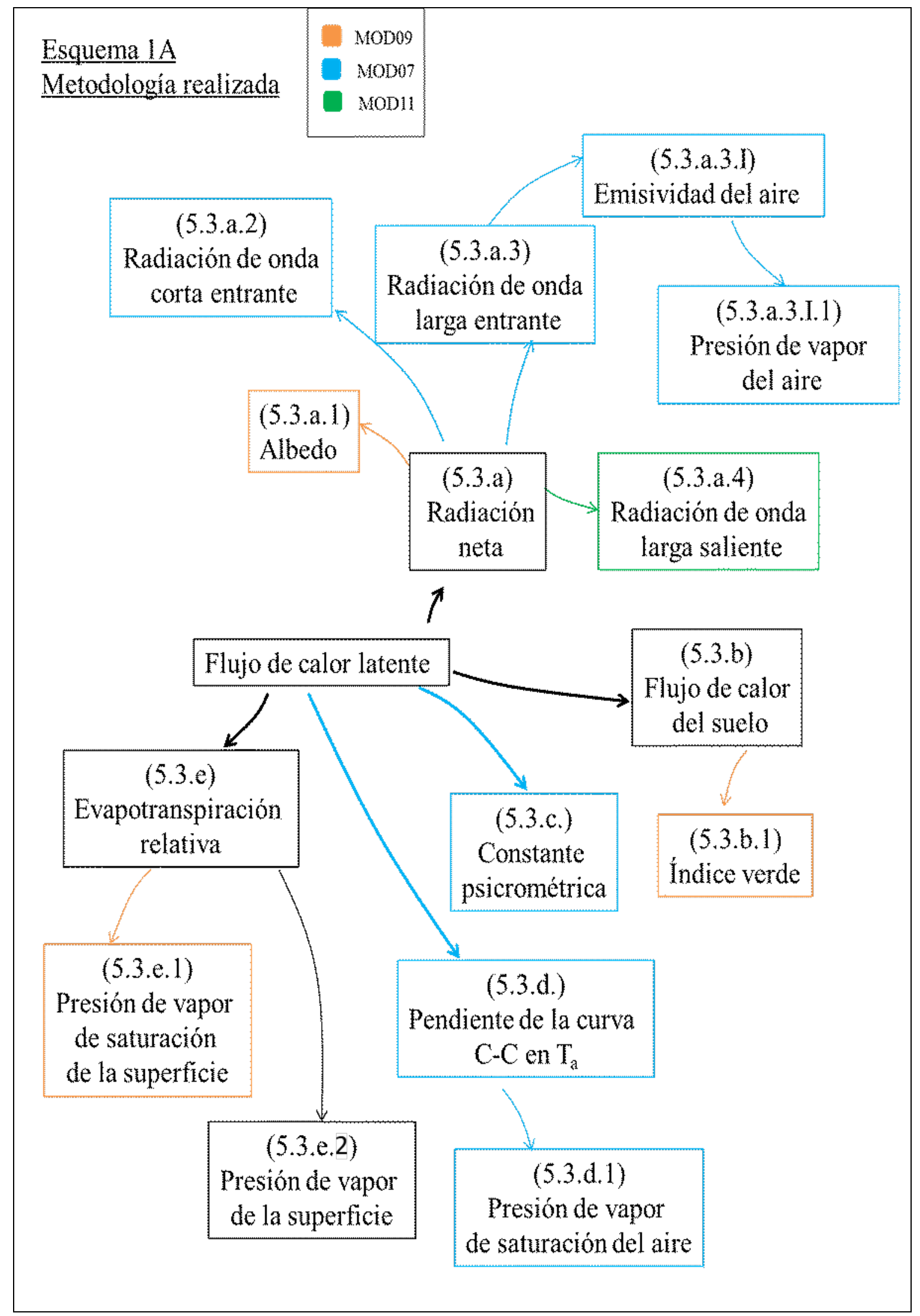

Figura 5. 2: Esquema 1A - Metodología utilizAdA 


\section{Esquema $1 \mathrm{~B}$ \\ Metodologia realizada}

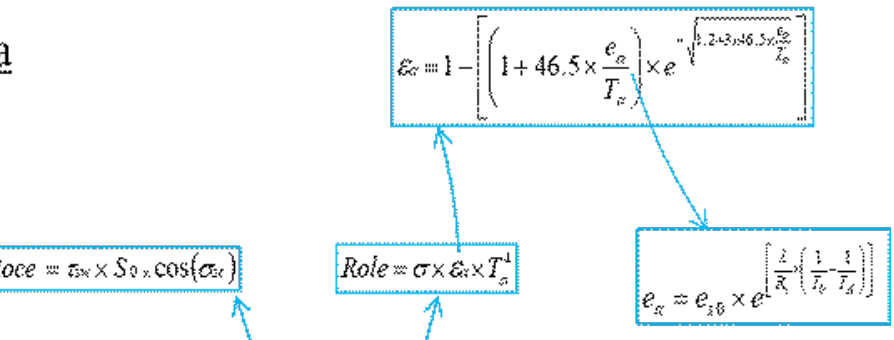

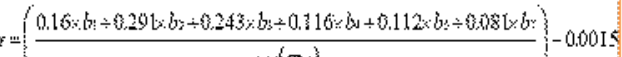

$\cos (\pi)$

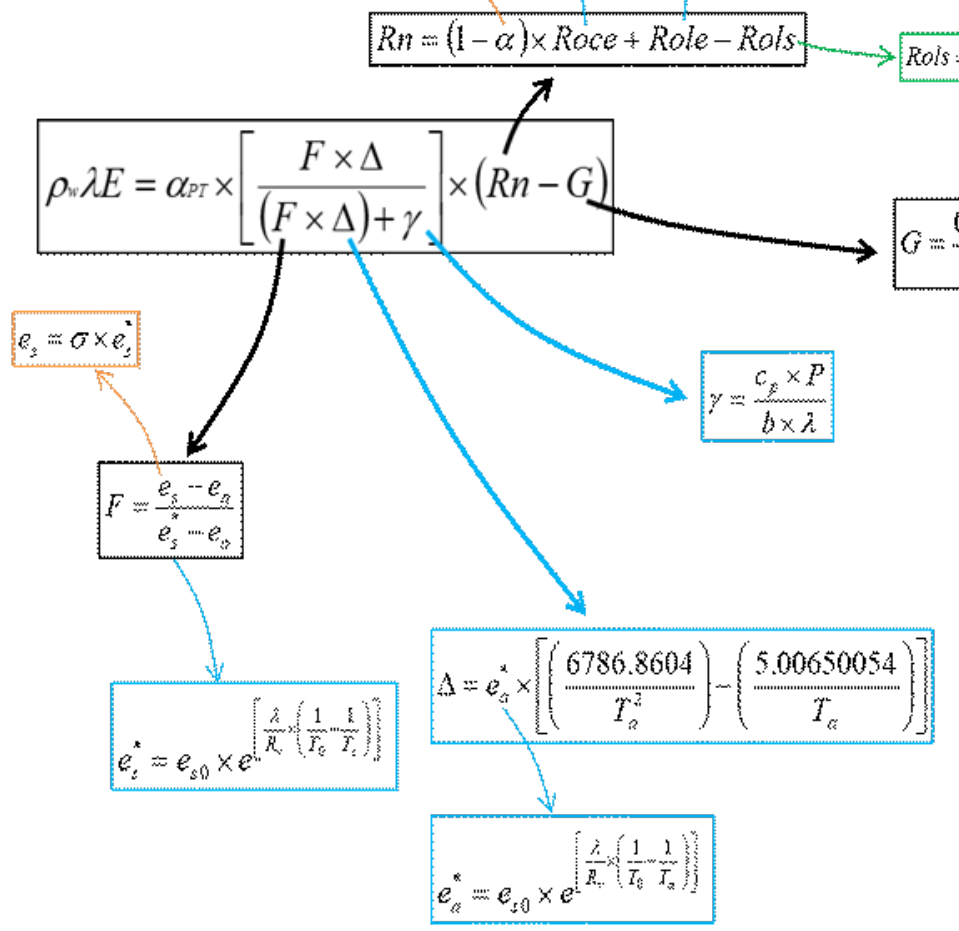

$h=2,4.5 \times 10^{6} \mathrm{MKg}$. Es el calor latente de vaporización (energía necesaria para el cambio de estado del agua liquida al vapor)

$\rho_{w}:=1000 \mathrm{~kg}_{\mathrm{g}} \mathrm{m}^{3}$ o $1 \mathrm{~g}^{\mathrm{m}} \mathrm{cm}^{3}$. Densidad del agua

$\boldsymbol{f}_{\mathrm{rr}}$ … 1.26 sin tuidades, siendo la constante

de Priestley-Taylor

Figura 5. 3: Esquema 1B- Metodología utilizAdA

\section{3.a. Radiación Neta (Rn):}

Existen dos tipos de radiación, la radiación de onda corta; aquella proveniente del sol y

la de onda larga; aquella que surge de la emisión de la tierra y la atmósfera. Para ambos tipos de radiación, existe una fracción entrante y otra saliente. 
Asimismo, existen numerosos trabajos que estiman la $\mathrm{Rn}$, pero la mayoría utilizan teledetección y mediciones de superficie, como por ejemplo el trabajo de Jacobs et al. (2000). En el presente trabajo, se tomó la metodología propuesta por Bisht et al. (2005), donde la estimación de la Rn no utiliza datos medidos en superficie. Todos los parámetros se estiman a partir de productos MODIS lo que permite obtener estimaciones de $\mathrm{Rn}\left(\mathrm{W} / \mathrm{m}^{2}\right)$ para amplias regiones y días despejados. De este modo se estimaron los componentes del balance de energía según la ecuación (5.1).

$$
R n=(1-\alpha) \times \text { Roce }+ \text { Role }- \text { Rols }
$$

FóRMULA 5. 1

Donde:

$\alpha$ : es el albedo de la superficie

Roce $\left(\mathrm{Wm}^{2}\right)$ : es la radiación de onda corta entrante

Role $\left(\mathrm{W} / \mathrm{m}^{2}\right)$ : es la radiación de onda larga entrante

Rols $\left(\mathrm{W} / \mathrm{m}^{2}\right)$ : es la radiación de onda larga saliente

\section{3.a.1-Albedo $(\alpha)$}

Se trata de aquella porción de la radiación entrante de onda corta que es reflejada por la superficie terrestre en todas las direcciones.

En este trabajo, se utilizaron dos caminos para la obtención del albedo.

El primero consiste en utilizar el producto MODIS como sugiere Bisht et al. (2005) proponiendo el uso de la Función de Distribución de Reflectividad Bidireccional (BRDF - siglas en inglés), función utilizada por MODIS para el cálculo del albedo MOD43 - (combina los datos de los sensores de ambas plataformas, TERRA y AQUA). Este producto brinda información de los albedos de cielo negro (radiación directa) y cielo blanco (radiación difusa). Utilizar un producto MODIS de dieciséis días, como lo es el MOD43, permitió obtener un dato de albedo que considera la reflexión de la radiación en varias direcciones (según la posición del satélite en cada visita), mientras que el albedo obtenido con un producto diario, solo permite obtenerlo a partir de una única dirección de reflexión.

A su vez, se asumió que la superficie terrestre se comporta como una superficie lambertiana, por lo que la reflectancia es isotrópica. Con esta suposición y siguiendo a Tsouni et al. (2008) quienes asumen que los errores producidos al considerar la 
superficie como lambertiana son pequeños para observaciones satelitales desde ángulos cercanos al nadir, es que se optó también por utilizar la parametrización propuesta por Liang (2002), donde el albedo es posible de ser calculado a partir de una combinación lineal de la reflectancia medida por el sensor MODIS en 6 bandas del MOD09.

$$
\alpha=\left(\frac{0.16 \times b 1+0.291 \times b 2+0.243 \times b 3+0.116 \times b 4+0.112 \times b 5+0.081 \times b 7}{\cos (\sigma c s)}\right)-0.0015
$$

FóRMULA 5. 2

Siendo " $\mathrm{b}_{\mathrm{n}}$ " las bandas de reflectividad del MOD09 y " $\sigma_{\mathrm{cs}}$ " el ángulo cenital solar en radianes obtenido del MOD07, a fin de que el albedo sea vertical en cada píxel.

\section{3.a.2 - Radiación de onda corta entrante - Roce (W/m2)}

Desde luego que también existen numerosas aproximaciones para este parámetro. Ejemplo de ellas es el esquema propuesto por Zillman (1972) donde la Roce depende de la presión de vapor del aire a nivel de superficie, la constante solar, y el ángulo cenital solar.

En este trabajo, se optó por la ecuación de Niemelä et al. (2001) quienes propusieron que la radiación de onda corta entrante puede estimarse del siguiente modo:

$$
\text { Roce }=\tau s w \times S 0 \times \cos (\sigma c s)
$$

FÓRMULA 5. 3

Donde:

$\tau_{\mathrm{sw}}=0.72$ es el factor de transmisividad de la atmósfera

$\mathrm{S}_{0}=1.367 \mathrm{w} / \mathrm{m}^{2}$ es la constante solar en el tope de la atmósfera

Ahora bien, podemos decir que el balance de onda corta es la diferencia entre la Roce y aquella porción de la radiación de onda corta que es reflejada nuevamente hacia la atmósfera, llamada albedo. Así, dicho balance corresponde al primer término de la ecuación (5.1).

\section{3.a.3 - Radiación de onda larga entrante - Role $\left(\mathrm{w} / \mathrm{m}^{2}\right)$}


La radiación emitida por cualquier cuerpo se fundamenta en la Ley de Stefan-Boltzman (S-B), quien anunció que la radiación emitida por un cuerpo negro es proporcional a la cuarta potencia de su temperatura absoluta. Debido a que no nos encontramos en presencia de un cuerpo negro, la radiación emitida por cualquier cuerpo será la misma de un cuerpo negro a igual temperatura, pero aplicándole un coeficiente de emisividad particular para cada cuerpo.

Para el caso de la Role, se trata de la energía emitida por el aire. Según la ley de S-B la Role se expresa de la siguiente manera:

$$
\text { Role }=\sigma \times \varepsilon a \times T_{a}^{4}
$$

FÓRMULA 5.4

Donde:

$\sigma$ es la constante de Steffan-Boltzmann $0.5668 * 10^{-8} \mathrm{~J} / \mathrm{m}^{2} \mathrm{sK}^{4}$

$\xi_{\mathrm{a}}$ es la emisividad del aire, sin unidades

$\mathrm{T}_{\mathrm{a}}$ es la temperatura del aire en ${ }^{\circ} \mathrm{K}$ a nivel de la superficie. Este valor se obtuvo según el producto MOD07.

\section{3.a.3. I-Emisividad del aire $\left(\xi_{\mathrm{a}}\right)$}

Para obtener el valor de la emisividad del aire, se trabajó según propuso Prata (1996), donde $\xi_{\mathrm{a}}$ se estima del siguiente modo:

$$
\varepsilon a=1-\left[\left(1+46.5 \times \frac{e_{a}}{T_{a}}\right) \times e^{-\sqrt{1.2+3 \times 46.5 \times \frac{e_{a}}{T_{a}}}}\right]
$$

FóRMULA 5. 5

donde:

la tensión de vapor del aire $\left(\mathrm{e}_{\mathrm{a}}\right)$ se expresa en $\mathrm{hPa}$.

\section{3.a.3.I.1 - Presión de vapor del aire $\left(\mathrm{e}_{\underline{a}}\right)$ en $\mathrm{Pa}$}

La tensión de vapor del aire, según la ecuación de Clausius - Clapeyron (C-C), es función de la de la temperatura de rocío, valor que se obtendría llevando el aire subsaturado en un enfriamiento isobárico hasta alcanzar el punto de saturación (figura 5.4). Aquí la $T_{d}$ es obtenida desde el MOD07, a nivel de superficie (1000hPa o 950hPa), según corresponda y haciendo la corrección por el gradiente térmico. Si se conoce la $T_{d}$ 
se puede determinar la presión parcial del vapor actual $e_{a}$, y viceversa, por medio de la ecuación de C-C.

$$
e_{a}=e_{s f} \times e^{\left[\frac{\lambda}{R_{v}} \times\left(\frac{1}{T_{f}}-\frac{1}{T_{d}}\right)\right]}
$$

FÓRMULA 5. 6

Donde:

$T_{f}$ : temperatura de fusión en CNPT $\left(273.16^{\circ} \mathrm{K}\right)$.

$e_{s f}$ presión de saturación del vapor de agua a la temperatura $T_{f}(611 \mathrm{~Pa})$. (figura 5.4).

$R_{v}$ : Constante de los gases para el vapor de agua $\left(461 \mathrm{~J} / \mathrm{Kg}^{\circ} \mathrm{K}\right)$

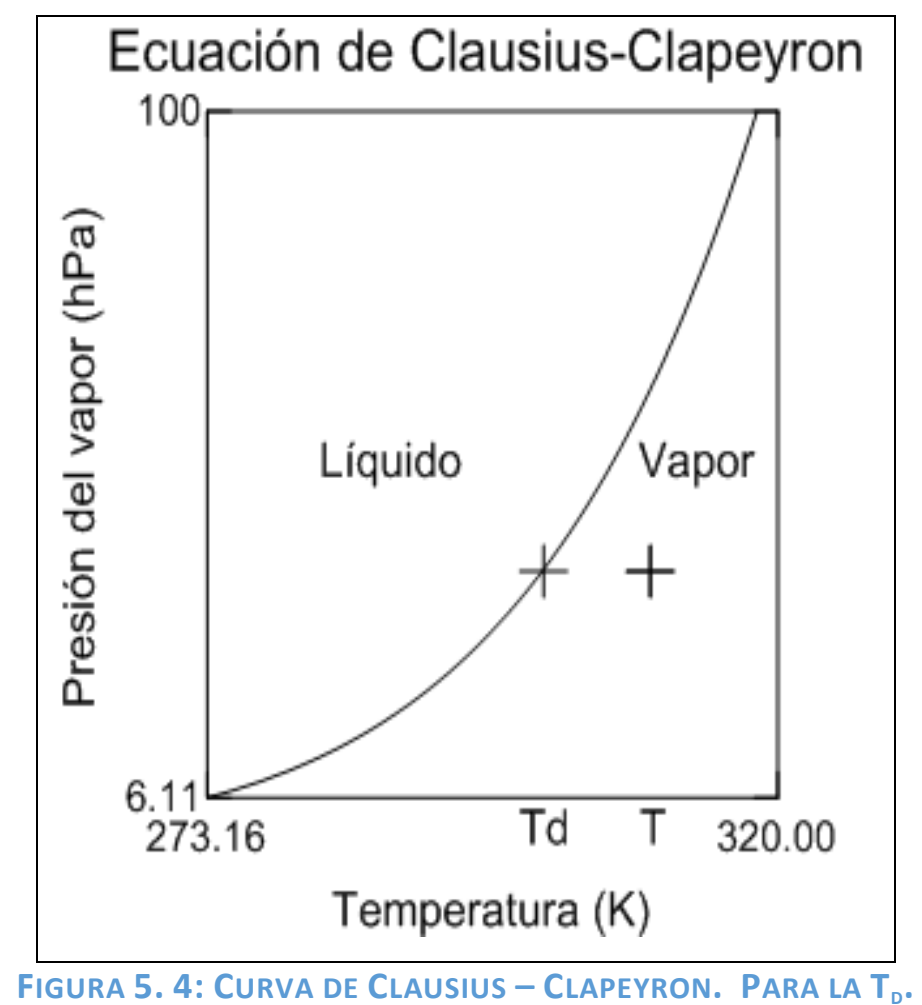

\section{3.a.4 - Radiación de onda larga saliente - Rols $\left(\mathrm{W} / \mathrm{m}^{2}\right)$}

La radiación de onda larga saliente se basa en la misma ley que la Role - Ley S-B pero el cuerpo en cuestión es la superficie terrestre. En este punto es importante la emisividad de la superficie $\xi_{\mathrm{s}}$, parámetro de interés para la caracterización superficial. Uno de los mayores inconvenientes de los modelos desarrollados para su estimación es su gran complejidad, debido a su dificultad para ser aplicados de forma operacional según comentan Valor y Caselles (1996). La mayoría de los sensores térmicos a bordo de satélites son sensibles en el rango de 10.5-12.5 $\mu \mathrm{m}$. Las bandas utilizadas para 
medir la emisividad de la superficie por el sensor MODIS son la $31(10.780-11.280$ $\mu \mathrm{m})$ y $32(11.770-12.270 \mu \mathrm{m})$ (Bisht et al., 2005) y, donde los valores de emisividad se encuentran entre 0.94 (para suelo descubierto) y 0.99 (para vegetación abundante), según; Valor y Caselles (1996); Rubio et al. (1997); Hurtado y Sobrino (2001). A su vez, Sobrino et al. (1992) propusieron un esquema para la obtención de la emisividad, diferenciando la emisividad de la vegetación y la del suelo descubierto, como también una fracción que relaciona un suelo con una cobertura vegetal menor al 100\%. En este trabajo la emisividad de la superficie surge de los canales 31 y 32 del MOD11. De este modo, la Rols se expresa de la siguiente manera:

$$
\text { Rols }=\sigma \times \varepsilon_{s} \times T_{s}^{4}
$$

FóRMULA 5.7

Donde:

$\xi_{\mathrm{s}}$ es la emisividad de la superficie, sin unidades. Obtenida como promedio de las bandas 31 y 32 del MOD11.

$\mathrm{T}_{\mathrm{s}}$ es la temperatura de la superficie en ${ }^{\circ} \mathrm{K}$ obtenida a partir de producto MOD11.

\section{3.b. - Flujo de calor en el suelo (G)}

El suelo es calentado durante el día por la radiación de onda corta proveniente del sol, a su vez, durante la noche se enfría a causa de la pérdida de radiación de onda larga que es emitida hacia la atmósfera. Foken (2008), sugiere que, para la generación del flujo turbulento de calor latente, el agua es transportada a través de los poros del suelo hacia la superficie para luego ser evaporada, parte de la energía requerida la contribuye el flujo de calor del suelo en sus capas superiores.

Generalmente, $\mathrm{G}$ es difícil de estimar o calcular, por otro lado, mediciones directas de $\mathrm{G}$ a partir de percepción remota son poco confiables (Mulleady y Barrera, 2013). Mientras que, para valores promedios de $\mathrm{G}$ en ciclos diarios de 24 horas, en condiciones de cielo despejado, el flujo neto de calor del suelo por lo general es despreciable, según; Allen et al. (1998) y Jia et al. (2009).

Para valores instantáneos de $\mathrm{G}$, se puede recurrir a una relación proporcional entre G y Rn (Mulleady y Barrera, 2013). Varios autores sugieren constante dicha relación. Idso et al. (1975) propusieron que $\mathrm{G}$ es la tercera parte de $\mathrm{Rn}$ para suelo húmedo y la mitad de la Rn para suelo seco. Stull (1988) toma valores que van de 0.1 durante el día y 0.5 
durante la noche para relacionar G con Rn. Otros autores, como Nishida et al. (2003) sugieren que $\mathrm{G}$ puede ser despreciado para superficies totalmente vegetadas.

En el presente trabajo, y siguiendo la misma lógica que Mulleady y Barrera (2013), se utilizó la ecuación propuesta por Moran et al. (1989) para estimar G y no independizarla de la cobertura vegetal del lugar.

$$
G=\frac{0.583 \times R n}{e^{-2.13 \times N D V I}}
$$

FóRMULA 5. 8

Esta fórmula es válida para píxeles con NDVI mayores a cero, en caso contrario se trataría de píxeles con agua.

\section{3.b.1- Índice de vegetación de diferencia normalizado (NDVI)}

El NDVI, es un índice de vegetación muy utilizado en teledetección, el mismo se describe en el Anexo III. En este trabajo se utilizó el producto MOD13 que se corresponde con el "mejor" valor de los dieciséis días previos a la fecha del producto. En este contexto, podemos decir que es apropiado utilizar un producto de este tipo, debido a que, en días con altas concentraciones de aerosol o vapor de agua en la atmósfera, el NDVI obtenido para dicho día sería menor dada la intervención de dichos elementos entre la superficie y el sensor.

Por otro lado, también, se calculó el NDVI a partir de las bandas 1 y 2 del MOD09 obteniendo un valor diario de NDVI, lo que permite revelar una disminución del contenido de humedad de los suelos.

\section{3.c. - Constante Psicrométrica $(\gamma)$ en $\mathrm{Pa} /{ }^{\circ} \mathrm{K}$}

La constante psicrométrica fue definida por Brunt en 1932 como la relación entre el calor específico del aire a presión constante y el calor latente de vaporización. El calor específico es la cantidad de energía requerida para aumentar la temperatura de una unidad de masa de aire en $1^{\circ} \mathrm{C}$ a presión constante. Su valor depende de la composición del aire, fundamentalmente del vapor de agua contenido en él (FAO, 1977).

En este trabajo se utilizó el esquema propuesto por Brunt (1932) y utilizada también por FAO para la estimación de la evapotranspiración diaria (mm/día). 


$$
\gamma=\frac{c_{p} \times P}{b \times \lambda}
$$

FÓRMULA 5. 9

Donde:

$\mathrm{C}_{\mathrm{p}}=1005 \mathrm{~J} / \mathrm{Kg}{ }^{\circ} \mathrm{K}$ es el calor específico del aire a presión constante

$\mathrm{b}=0.622$, es la relación de peso molecular entre el agua y el aire seco (adimensional)

$\lambda$ es expresado en MJ.

$\mathrm{P}=$ Presión atmosférica de superficie obtenida del producto MOD07

\section{3.d - Pendiente de la curva de Clausius-Clapeyron $(\Delta)$}

Uno de los parámetros necesarios para calcular la evapotranspiración es la pendiente de la curva de presión de saturación de vapor-temperatura (PSV-T) a la temperatura del aire. Existe varias formas de calcular $\Delta$ citadas en la bibliografía, entre las cuales se encuentran las de Flatau et al. (1992); Allen et al. (1998) entre otras.

En el presente trabajo, $\Delta$; es calculado a partir de la derivada de la función de ClausiusClapeyron en $\mathrm{T}_{\mathrm{a}}$.

$$
\Delta=e_{a}^{*} \times\left[\left(\frac{6786.8604}{T_{a}^{2}}\right)-\left(\frac{5.00650054}{T_{a}}\right)\right]
$$

FóRMULA 5. 10

Donde:

$\mathrm{e}_{\mathrm{a}}{ }_{\mathrm{a}}$ : es la tensión de vapor de saturación a la temperatura del aire sobre la superficie en $\mathrm{Pa}$.

$\mathrm{T}_{\mathrm{a}}$ : es la temperatura del aire en ${ }^{\circ} \mathrm{K}$ obtenida del producto MOD07 a nivel de superficie.

\section{3.d.1-Presión de vapor de saturación del aire ( $\mathrm{e}^{*}$ a 2 en Pa}

La tensión de vapor de saturación del aire en $\mathrm{Pa}$, y según la aproximación de C-C (figura 5.5), es función de la de la temperatura del aire, aquí obtenida desde el MOD07 también a nivel de superficie.

$$
e_{a}^{*}=e_{s 0} \times e^{\left[\frac{\lambda}{R_{v}} \times\left(\frac{1}{T_{f}}-\frac{1}{T_{a}}\right)\right]}
$$

FÓRMULA 5. 11 


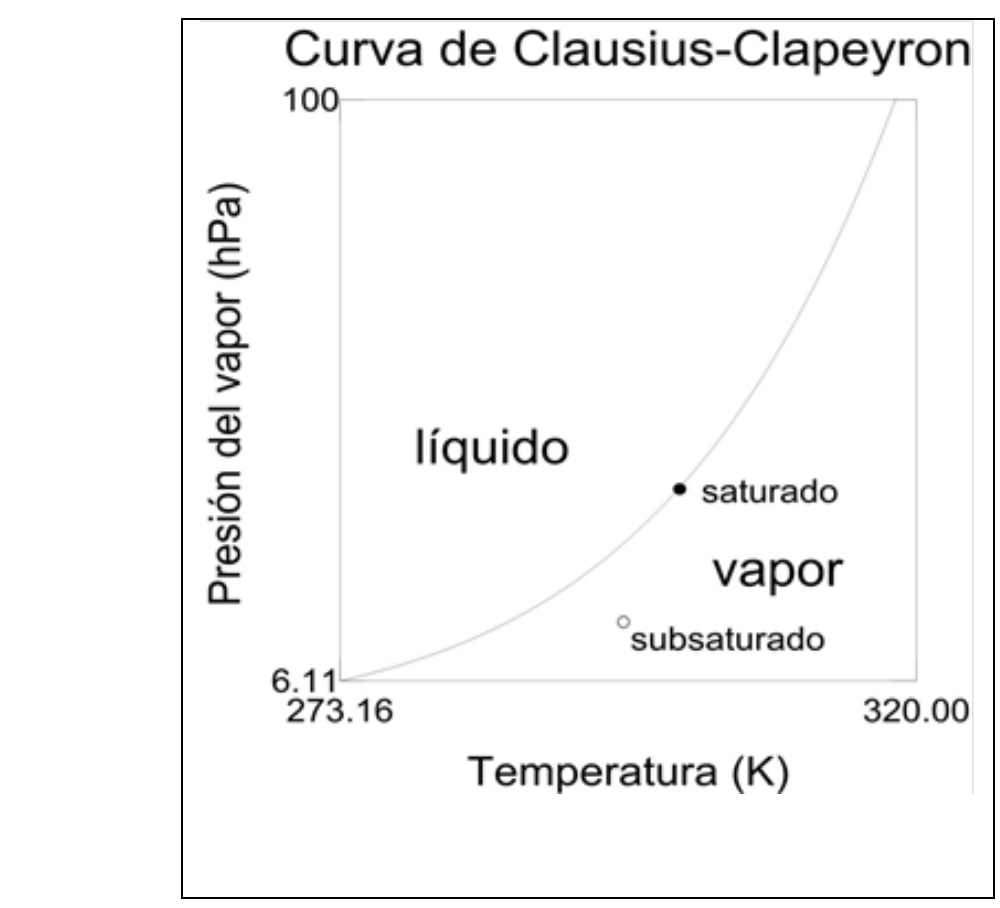

FIgURA 5. 5: CURVA DE C - C.PARA LA PRESIÓN DE VAPOR DE SATURACIÓN

\section{3.e. - Evapotranspiración relativa (F):}

Como se comentó en el capítulo anterior, $\mathrm{F}$ es difícil de estimar, dado que $\mathrm{e}_{\mathrm{s}}$ no es sencilla de valorar. Al no contar con una temperatura $\left(t_{u}\right)$ que se relacione con $e_{s}$, no es posible aplicar la fórmula de C-C para obtener $\mathrm{e}_{\mathrm{s}}$. Por otro lado, esto sí fue posible para calcular $\mathrm{e}_{\mathrm{s}}^{*}, \mathrm{e}_{\mathrm{a}} \mathrm{ye}_{\mathrm{a}}{ }_{\mathrm{a}}$

La ecuación propuesta por Granger y Gray (1989) es la que se utilizó en este trabajo para obtener F.

$$
F=\frac{e_{s}-e_{a}}{e_{s}^{*}-e_{a}}
$$

FÓRMULA 5. 12

\section{$\underline{5.3 . e .1-P r e s i o ́ n ~ d e ~ v a p o r ~ d e ~ s a t u r a c i o ́ n ~ d e ~ l a ~ s u p e r f i c i e ~(~} \mathrm{e}^{*}$ s ${ }^{\text {en }}$ Pa}

La tensión de vapor de saturación de la superficie en Pa, se obtuvo del mismo modo que $\mathrm{e}^{*}{ }_{\mathrm{a}} \mathrm{y} \mathrm{e}_{\mathrm{a}}$, a partir de la aproximación de $\mathrm{C}-\mathrm{C}$, mientras que $\mathrm{e}_{\mathrm{s}}{ }^{\mathrm{a}}$ es función de la temperatura de superficie, aquí obtenida desde el MOD11.

$$
e_{s}^{*}=e_{s 0} \times e^{\left[\frac{\lambda}{R_{v}} \times\left(\frac{1}{T_{f}}-\frac{1}{T_{s}}\right)\right]}
$$

FÓRMULA 5. 13 


\section{3.e.2- Presión de vapor de la superficie $\left(\mathrm{e}_{s}\right)$ en $\mathrm{Pa}$}

A fin de estimar el valor de $\mathrm{e}_{\mathrm{s}}$, se decidió trabajar con la técnica propuesta por Girolimetto (2014) que calcula " $\mathrm{e}_{\mathrm{s}}$ " a partir de la relación " $\Omega=\mathrm{e}_{\mathrm{s}} / \mathrm{e}_{\mathrm{s}}^{*}$ " y estimando $\Omega$ a partir de la ecuación (4.10).

$$
e_{s}=\Omega \times e_{s}^{*}
$$

\section{FÓRMULA 5. 14}

Sin embargo, en el presente trabajo se consideró una nueva alternativa para el cálculo de $\Omega$. Esta alternativa se basa en que $e_{s}$ es la presión de vapor en la película de aire contigua a la superficie evaporante y gran parte de la superficie evaporante es la vegetación.

Se propuso calcular $\Omega$ según la expresión (4.10), pero donde $\mathrm{R}_{\text {sat }}$ es el promedio de la reflectancia de una $\mathrm{S}_{\mathrm{s}} \mathrm{y}$ vegetada. De esta manera y a diferencia de lo propuesto por Girolimetto (2014) que calcula $\mathrm{R}_{\text {sat }}$ sobre cuerpos de agua, aquí se tomó el promedio de los píxeles SWIR (banda 7 del MOD09) donde la vegetación se encuentre en condiciones de buena vigorosidad, considerando píxeles con vegetación vigorosa a aquellos donde el NDVI es igual o mayor a 0,8 . De este modo, $\mathrm{R}_{\text {sat }}$ equivale al promedio de SWIR solo para aquellos píxeles cuyo NDVI fue mayor o igual a 0,8 .

Calculadas todas las variables necesarias para obtener los parámetros de la ecuación (4.8), se calculó la $\mathrm{ET}_{\mathrm{i}}$ como flujo de calor latente en $\mathrm{W} / \mathrm{m}^{2}$ para cada una de las fechas comentadas con anterioridad al momento de la visita del satélite, a excepción de aquellas áreas o días donde no se contó con información satelital, por estar nublado al momento de visita del satélite o por algún tipo de error que trajera cualquiera de las imágenes utilizadas.

\subsection{Estimación de la evapotranspiración diaria y sus pasos intermedios}

Una vez estimada la $\mathrm{ET}_{\mathrm{i}}$, se continuó con una serie de pasos para poder transformarla en la evapotranspiración diaria y expresarla como tasa $(E)$ en $\mathrm{mm} /$ día. Expresar la evapotranspiración en mm/día es de gran utilidad ya que determina una de las salidas de agua del sistema suelo-planta.

Las figuras 5.6, 5.7 y 5.8 incorporan (Esquemas 2A, 2B y 2C) la segunda parte del trabajo, de la misma manera que se representaron los pasos a seguir para la estimación de la $\mathrm{ET}_{\mathrm{i}}$. 
Esquema 2A

\section{Metodología realizada}

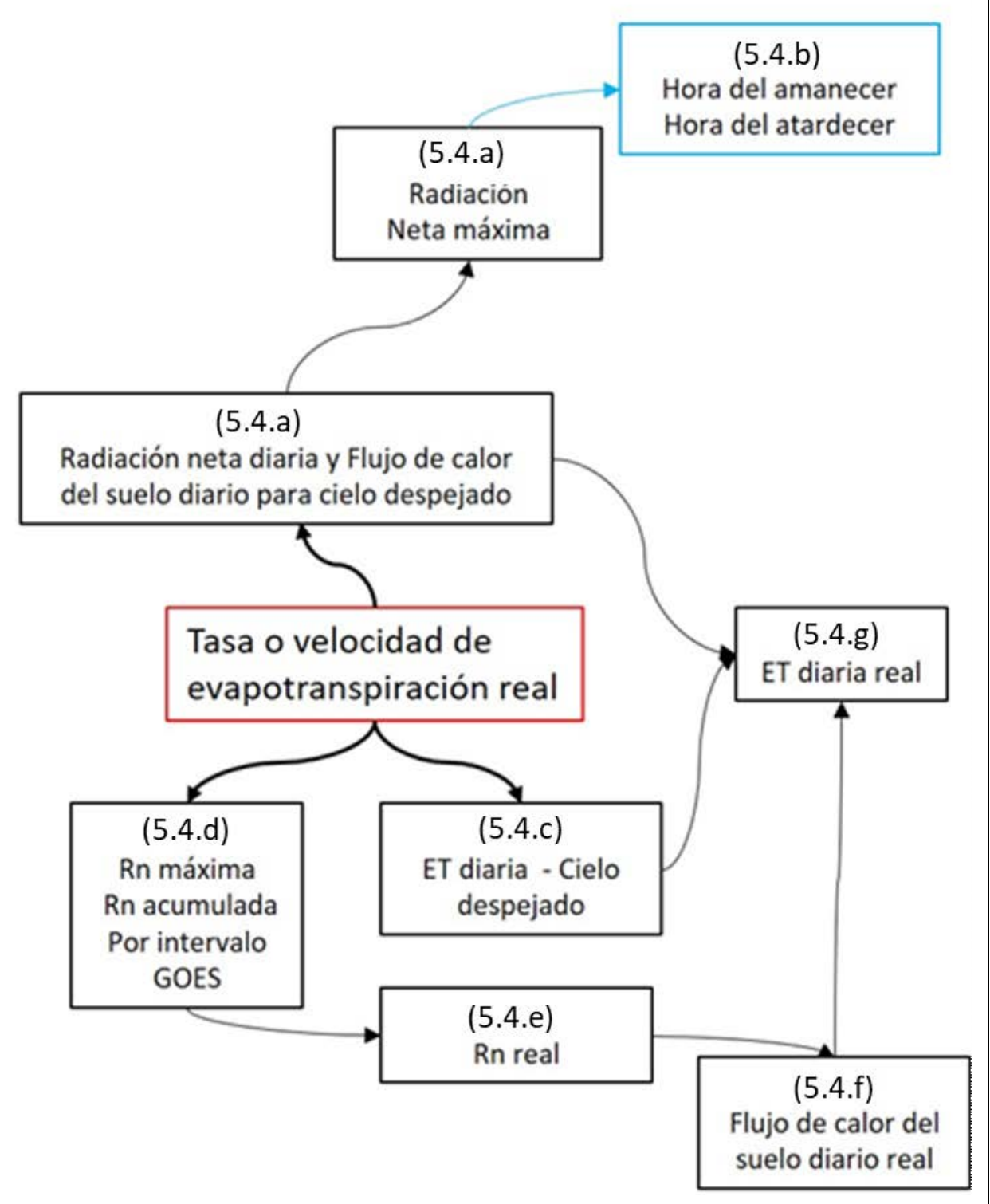

Figura 5. 6: Esquema 2A - Metodología utilizAdA 


\section{Esquema $n^{\circ} 2 B$}

Metodología realizada

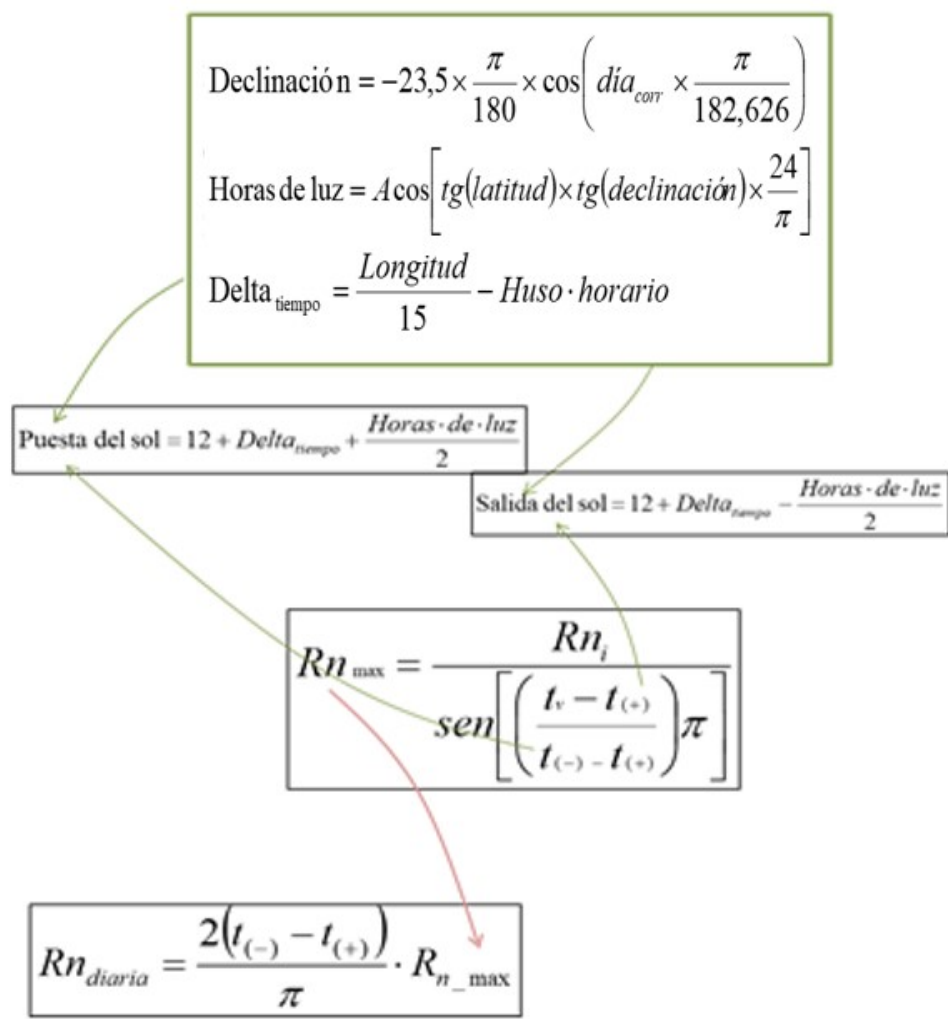

FIguRA 5. 7:1 Esquema 2B - Metodología utilizAdA

\section{Esqueman $n^{\circ} 2 \mathrm{C}$}

Metodologia realizada

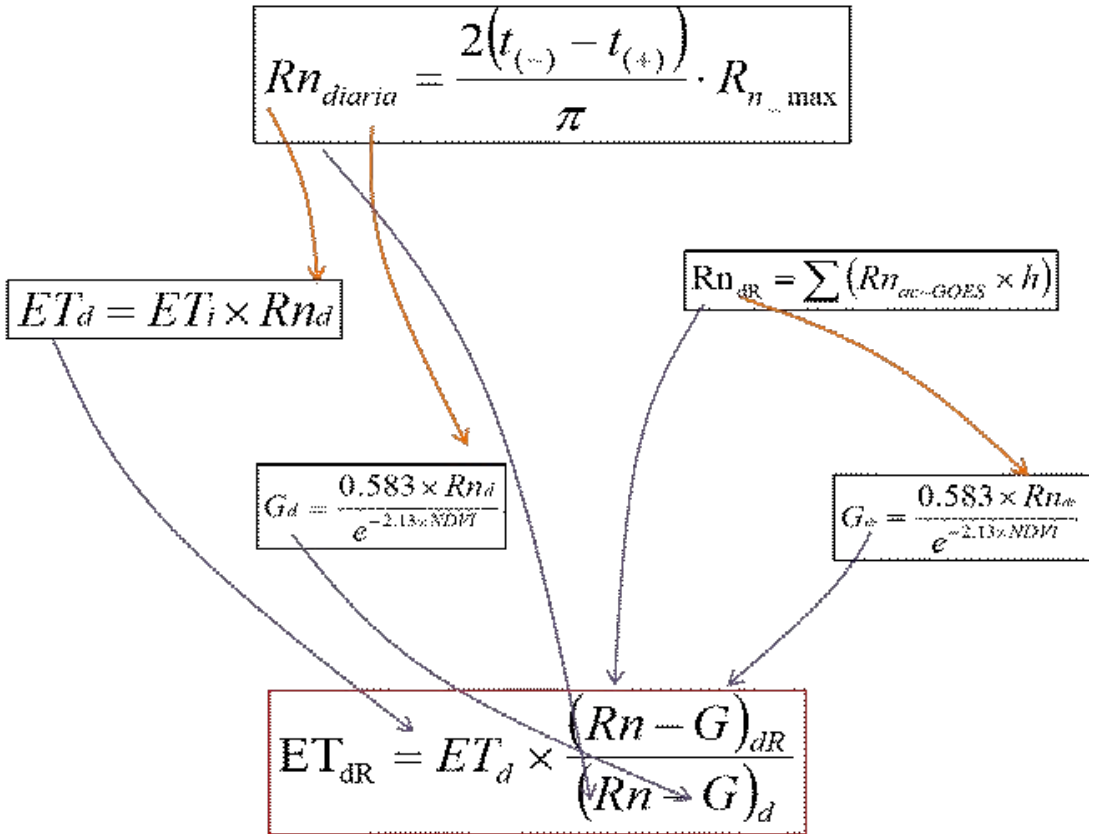

Figura 5. 8: ESQUema 2C - Metodología utilizAdA 


\section{4.a. Estimación de la $\mathrm{Rn}$ diaria a partir de la $\mathrm{Rn}_{\mathrm{i}}$}

Brutsaert y Sugita (1992) definieron la fracción evaporable $E F$ instantánea, que se calcula como el cociente entre el flujo de calor latente instantáneo $E T_{i}$ y la energía disponible $(R n-G)$ en el mismo momento. En este trabajo se utilizó dicho concepto para el pasaje de $\mathrm{ET}_{\mathrm{i}}$ a $\mathrm{ET}_{\mathrm{d}}$.

Para obtener el valor diario de la $\mathrm{Rn}\left(R_{n_{-} \text {diaria }}\right)$ se utilizó el modelo propuesto por Bisht et al. (2005). Estos autores se basaron en el modelo para la estimación del ciclo diurno de la temperatura de superficie propuesto por Lagouarde $y$ Brunet (1993) y desarrollaron un esquema para estimar el ciclo diurno de la radiación neta. En la figura 5.9 se observa dicho modelo.

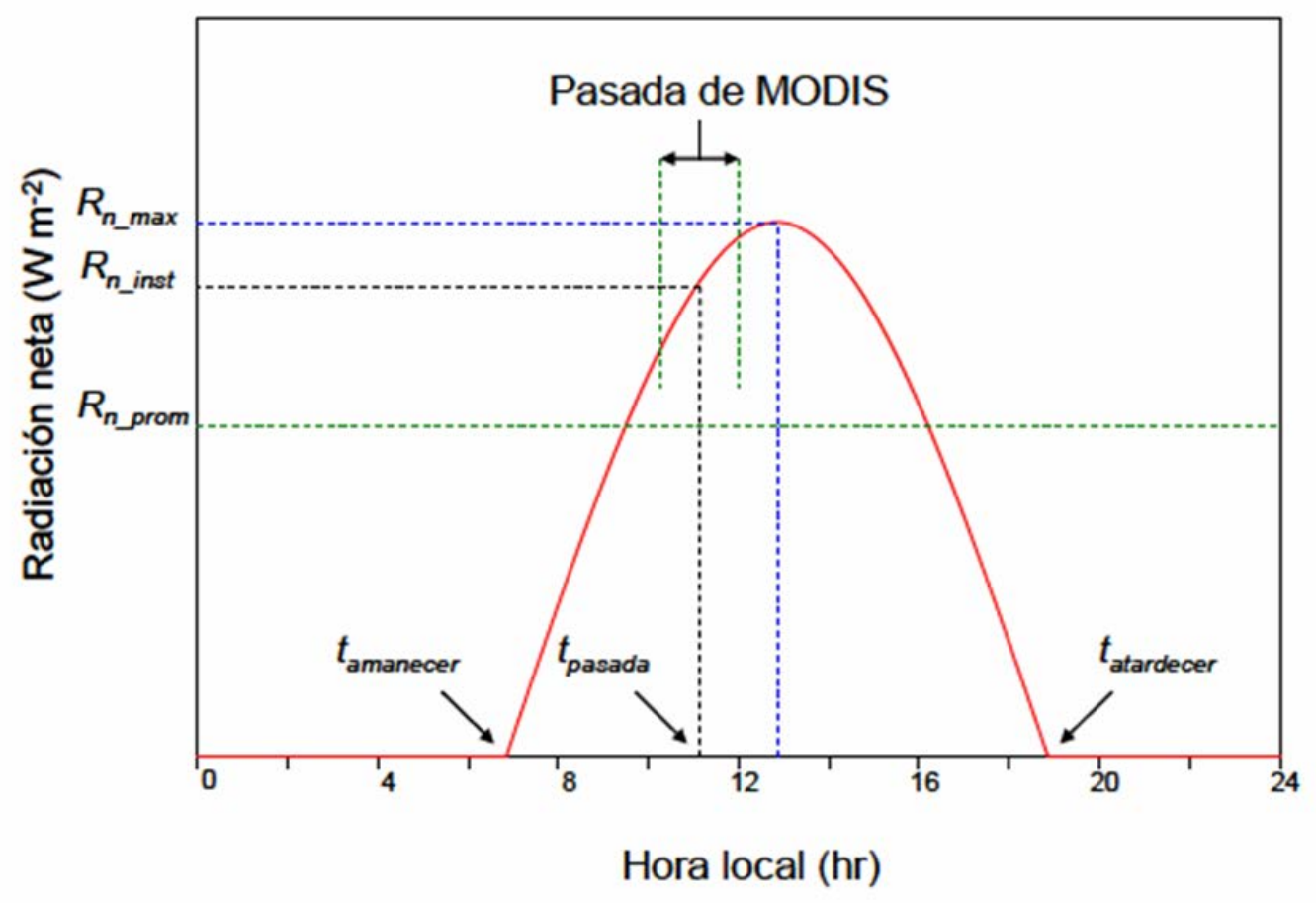

FIGURA 5. 9: ESQUEMA DEL MODELO SINUSOIDAL PROPUESTO POR BISHT ET AL. (2005) PARA LA ESTIMACIÓN DEL CICLO DIURNO DE LA RADIACIÓN NETA. AdAPTADO POR MULLEADY (2011) 
Del esquema desarrollado por Bisht et al. (2005) surge:

$$
R n_{\text {max }}=\frac{R n_{i}}{\operatorname{sen}\left[\left(\frac{t_{v}-t_{(+)}}{t_{(-)}-t_{(+)}}\right) \pi\right]}
$$

\section{FÓRMULA 5. 15}

donde, la $\mathrm{Rn}_{\max }$ es el valor máximo de radiación neta observado durante el día, $\mathrm{t}_{(+)} \mathrm{y}_{(-)}$ son las horas locales en que el valor de la radiación neta se vuelve positivo y negativo respectivamente, $\mathrm{t}_{\mathrm{v}}$ es la hora de visita del satélite $\mathrm{y} \mathrm{Rn}_{\mathrm{i}}$ es la radiación neta instantánea. Según las observaciones de estos autores, el flujo de radiación neta superficial se vuelve positivo aproximadamente 45 minutos luego del amanecer - instante $\mathrm{t}_{(+)}$- y se vuelve negativo aproximadamente 45 minutos antes del anochecer - instante $\mathrm{t}_{(-)}$-.

De la relación entre radiación neta máxima y su valor en otro momento del ciclo diurno Bisht et al.(2005), es que se estimaron la $\mathrm{Rn}_{\max }$ a partir de valores de $\mathrm{Rn}_{\mathrm{i}}$.

Para un dado día de estudio, los valores de $\mathrm{Rn}_{\mathrm{i}}$ y la hora de visita del satélite son datos conocidos, entonces el valor de radiación neta diaria $\left(\mathrm{Rn}_{\text {_diaria}}\right)$ se puede obtener como:

$$
R n_{\text {diaria }}=\frac{2\left(t_{(-)}-t_{(+)}\right)}{\pi} \cdot R_{n_{-} \max }
$$

FÓRMULA 5. 16

El modelo para la estimación de la radiación neta diaria requiere información concerniente al momento en que la radiación neta se vuelve positiva $\mathrm{t}_{(+)}$y al momento en que se vuelve negativa $t_{(-)}$.

\section{4.b - Cálculo de la hora del amanecer y del atardecer.}

Conociendo las horas de luz de un día y el horario en el cual el sol se encuentra en el cenit del lugar, es posible conocer los momentos de amanecer y de atardecer de cada día, debido a que el intervalo de tiempo entre el amanecer y el mediodía solar es igual al intervalo de tiempo entre el mediodía solar y el atardecer.

Para calcular la hora del amanecer y del atardecer para cada píxel, se utilizaron los siguientes pasos. 


$$
\text { Declinación }=-23,5 \times \frac{\pi}{180} \times \cos \left(\text { dia }_{\text {corr }} \times \frac{\pi}{182,626}\right)
$$

FÓRMULA 5. 17

$$
\text { Horas de luz }=A \cos \left[\operatorname{tg}(\text { latitud }) \times \operatorname{tg}(\text { declinación }) \times \frac{24}{\pi}\right]
$$

FÓRMULA 5. 18

$$
\text { Delta }_{\text {tiempo }}=\frac{\text { Longitud }}{15}-\mid \text { Huso } \cdot \text { horario } \mid
$$

Para el desarrollo de estos cálculos se contó con información de latitud y longitud provista por el MOD07. El día $a_{\text {corr }}$ es la cantidad de días corridos desde el 21 de diciembre anterior (Solsticio de verano para el hemisferio sur y comienzo de la onda anual de la declinación solar) hasta la fecha de adquisición de la imagen y 182,626 es la duración en días de la semionda anual. El huso horario de la Hora Oficial Argentina (HOA) es igual a (-3). Deltatiempo es la corrección necesaria para obtener la hora del mediodía astronómico, distinto del mediodía según la HOA.

A partir de los valores obtenidos de las ecuaciones (5.18) y (5.19) fue posible obtener los momentos de salida y puesta del sol para cada píxel trabajado. Ello se logró de la siguiente manera:

$$
\text { Salida del sol }=12+\text { Delta }_{\text {tiempo }}-\frac{\text { Horas } \cdot \text { de } \cdot \text { luz }}{2}
$$

FÓRMULA 5. 20

$$
\text { Puesta del sol }=12+\text { Delta }_{\text {tiempo }}+\frac{\text { Horas } \cdot \text { de } \cdot \text { luz }}{2}
$$

FÓRMULA 5. 21

\section{4.c-Cálculo de ET diaria}

Como se ve en la ecuación (4.8), la $E T_{i}$ es proporcional a la energía disponible en ese instante $(R n-G)$.

Según Islam et al. (2003) y Nishida et al. (2003) se pueden realizar estimaciones de la tasa de evapotranspiración a partir de una única aproximación de la fracción evaporable instantánea utilizando mediciones de sensores remotos, ya que $E F$ se mantiene 
aproximadamente constante durante todo el ciclo diurno. Cabe aclarar que se hizo la suposición de que la diferencia entre la Evapotranspiración diaria (24hs) y la Evapotranspiración diurna $\left(\mathrm{ET}_{24 \mathrm{hs}}-\mathrm{ET}_{\text {diurna }}\right)$ es irrelevante, ya que por la noche los estomas se encuentran prácticamente cerrados, siendo a su vez la evaporación despreciable frente a la transpiración diurna.

Luego, mediante una ecuación análoga a la (4.8) se obtuvo el valor de $\mathrm{ET}_{\mathrm{d}}$.

$$
E T d=\alpha P T \times\left[\frac{F \times \Delta}{(F \times \Delta)+\gamma}\right] \times(R n-G)_{\text {diaria }}
$$

Hasta aquí se ha estimado la $\mathrm{ET}_{\mathrm{d}}$ para días despejados $\left(\mathrm{ET}_{\mathrm{dd}}\right)$. Pero no es correcto considerar dichos valores como reales ya que no siempre en un mismo lugar es posible especular que el día se mantuvo despejado durante el total del lapso del ciclo diurno.

Para resolver esta cuestión, se utilizaron imágenes GOES. A partir de las mismas, fue posible establecer durante que lapsos de tiempo de revisita del satélite y en qué lugar dentro del área de estudio, el cielo se encontró despejado o no. Con esta información se corrigió la $E T_{\mathrm{dd}}$ a ET diaria real $\left(E T_{\mathrm{dr}}\right)$.

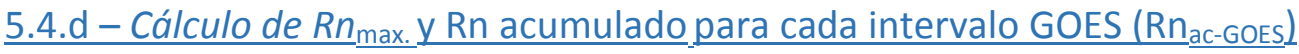

En la Tabla 5.1 se observa la hora de visita del satélite GOES para el día 4 de enero de 2013 y el lapso entre visita y revisita. La hora en la Tabla 5.1 se encuentra en valores decimales y está expresada en hora UTC. 


\begin{tabular}{|c|c|c|}
\hline \multicolumn{3}{|c|}{ GOES } \\
\hline \multicolumn{3}{|c|}{4 de Enero de 2013} \\
\hline $\begin{array}{l}\text { Hora de } \\
\text { visita }\end{array}$ & $\begin{array}{l}\text { lapso en } \\
\text { minutos de } \\
\text { revisita }\end{array}$ & $\begin{array}{c}\text { lapso en hora } \\
\text { de revis ita }\end{array}$ \\
\hline 9.667 & 55 & 0.917 \\
\hline 10.167 & 30 & 0.500 \\
\hline 10.567 & 30 & 0.500 \\
\hline 11.167 & 30 & 0.500 \\
\hline 11.667 & 17 & 0.283 \\
\hline 11.75 & 29 & 0.483 \\
\hline 12,667 & 42 & 0.700 \\
\hline 13.167 & 30 & 0.500 \\
\hline 13.667 & 30 & 0.500 \\
\hline 14.167 & 30 & 0.500 \\
\hline 14.667 & 60 & 1.000 \\
\hline 16.167 & 60 & 1.000 \\
\hline 16,667 & 30 & 0.500 \\
\hline 17.167 & 30 & 0.500 \\
\hline 17.667 & 45 & 0.750 \\
\hline 18.667 & 45 & 0.750 \\
\hline 19.167 & 30 & 0.500 \\
\hline 19.667 & 30 & 0.500 \\
\hline 20.167 & 30 & 0.500 \\
\hline 20.667 & 45 & 0.750 \\
\hline 21.667 & 45 & 0.750 \\
\hline 22,167 & 30 & 0.500 \\
\hline 22.667 & 30 & 0.500 \\
\hline
\end{tabular}

TABLA 5. 1: HORA UTC DE VISITA DEL SATÉLITE GOES Y EL LAPSO ENTRE VISITAS CONSECUTIVAS, PARA EL DÍA 4 DE ENERO DE 2013

Con estas imágenes fue posible conocer si un área se encontraba despejada o no. Para ello se utilizó la banda 4 (canal térmico) estableciendo que el píxel está nublado si la temperatura de dicho píxel es menor o igual a $7^{\circ} \mathrm{C}$, mientras que, la temperatura del canal térmico fue mayor a $7^{\circ} \mathrm{C}$ el píxel se consideró despejado. Se tomó este valor umbral ya que en enero en el área de estudio las temperaturas mínimas obtenidas de la información brindada por el SMN no fueron inferiores a $7^{\circ} \mathrm{C}$. La temperatura de superficie durante el período diurno está siempre por encima de ese valor, sobre todo para ángulos de elevación solar no extremadamente pequeños sino algo alejados de la horizontal, que es cuando el aporte a la radiación solar total diurna es significativo. Por lo tanto, si la temperatura radiativa del píxel es inferior a $7^{\circ} \mathrm{C}$ asumimos que la radiación que llega al sensor del satélite proviene del tope de una nube, ya que la temperatura del aire disminuye con la altura.

Siguiendo la misma metodología anterior, se calculó la $\mathrm{Rn}_{\max }$ a partir de la ecuación (5.15) para cada momento de visita GOES y con ella la $\mathrm{Rn}$ acumulada para cada intervalo entre imágenes GOES a partir de la ecuación (5.16) pero donde el intervalo es el que existe entre visitas consecutivas del satélite GOES y no las horas del día como en el caso anterior. 
En dicho cálculo, aún se trabaja para días despejados. La corrección surge de multiplicar a la $\mathrm{Rn}_{\mathrm{ac}-\mathrm{GOES}}$ por un factor $(\mathrm{h})$.

Este factor, representa zonas con cielo nublado o con cielo despejado. Los factores utilizados para corregir la Rn de cada intervalo GOES, fueron los propuestos por FAO y comentados en el capítulo anterior (0,33 y 1 respetivamente). De esta manera $\mathrm{h}=0,33 \mathrm{si}$ la temperatura del canal térmico de GOES es menor a $7^{\circ} \mathrm{C}$ y $\mathrm{h}=1$ si la temperatura del canal térmico de GOES es mayor a $7^{\circ} \mathrm{C}$.

\section{4.e - Cálculo de Rn diaria Real ( $R n_{\text {d-Real) }}$}

Cuando se habla de $R n_{\text {d-Real }}$ se hace referencia a que ya se realizó la corrección por cielo nublado.

$$
\mathrm{Rn}_{\mathrm{d}-\mathrm{Real}}=\sum\left(R n_{a c-G O E S} \times h\right)
$$

FÓRMULA 5. 22

\section{4.f - Cálculo de $\mathrm{G}_{\mathrm{d}-\text { Real }}$}

A partir de $R n_{\text {d-Real }}$ y siguiendo la ecuación (5.8) se obtuvo el flujo de calor del suelo para días con nubosidad.

\section{4.g-Cálculo de ET diaria real}

Como se ha mencionado anteriormente, varios autores tales como: Shuttleworth et al. (1989); Brutsaert and Chen (1996); Crago and Brutsaert (1996), observaron que EF prácticamente no varía con el tiempo durante el transcurso del día, tanto para días con cielo despejado como con nubosidad.

En esta tesis se usó el criterio de los autores mencionados. Además, se propone un procedimiento para estimar la $\mathrm{ET}_{\mathrm{d}}$ corregida por nubosidad durante el período diurno. Se trata de corregir la $\mathrm{ET}_{\mathrm{dd}}$ estimada anteriormente, aplicándole un factor que determina el porcentaje que estuvo nublado el día para cada píxel, es decir multiplicando por el balance de energía relativo. 


$$
E T_{\mathrm{dr}}=E T_{d d} \times \frac{(R n-G)_{d r}}{(R n-G)_{d d}}
$$

FÓRMULA 5. 23

donde:

$\mathrm{ET}_{\mathrm{dd}}$ : Flujo de calor latente diario en condición de cielo despejado

$(\mathrm{Rn}-\mathrm{G})_{\mathrm{dr}}$ : Balance de energía diario corregido por nubosidad

$(\mathrm{Rn}-\mathrm{G})_{\mathrm{dd}}$ : Balance de energía diario para días despejados

Luego, al dividir $\mathrm{ET}_{\mathrm{dr}}$ por la densidad del agua $\left(1000 \mathrm{~kg} / \mathrm{m}^{3}\right)$ y por el calor latente de vaporización $\left(\lambda=2.45 \times 10^{6} \mathrm{~J} / \mathrm{kg}\right)$ se obtiene la tasa de evapotranspiración expresada en $\mathrm{m} /$ día y al multiplicar por 1000 se obtiene la $E$ diaria real en $\mathrm{mm} /$ día $\left(E_{d r}\right)$, de modo de poder compararla con el valor de la $\mathrm{ET}_{\mathrm{r}}$ que se calculó en la sección siguiente con un BH-TM.

\section{5 - Cálculo de la ET según el Balance Hidrológico de Thornthwaite-Mather}

Como se comentó previamente, se trabajó sobre una muestra de mediciones meteorológicas in situ en 21 estaciones situadas en la Provincia de Buenos Aires, para los días en que se dispuso de imágenes y sondeos MODIS en enero de 2013.

El cálculo del $\mathrm{BH}$ requiere de información de precipitación, de evapotranspiración potencial $\left(\mathrm{ET}_{\mathrm{p}}\right)$, de la capacidad de campo de los suelos $(\mathrm{CC})$, del punto de marchitez permanente (PMP) y del almacenaje inicial de los mismos.

Para este trabajo se consideró la $\mathrm{ET}_{\mathrm{p}}$ como equivalente a la $\mathrm{ET}_{\mathrm{c}} \mathrm{y}$ se introdujo dicho valor como $\mathrm{ET}_{\mathrm{p}}$ en el cálculo del $\mathrm{BH}$.

Con respecto a las variables del suelo CC y PMP, se trabajó con los valores publicados por Fernandez et al. (2002). Se denomina CC a la máxima retención de agua de los suelos una vez que drenó del mismo toda el agua gravitacional, mientras que el PMP, es la máxima cantidad de agua que contiene un suelo, pero las plantas que están en él no pueden disponer de ella debido a la fuerza con la cual está retenida en el suelo. En la figura 5.10 se pueden apreciar estos dos conceptos, sumando el concepto de saturación, siendo la situación donde todos los poros del suelo se encuentran con agua.

Por otro lado, al no contar con el valor del almacenaje de agua inicial de los suelos, se trabajó con un almacenaje inicial igual a la mitad de la CC. 


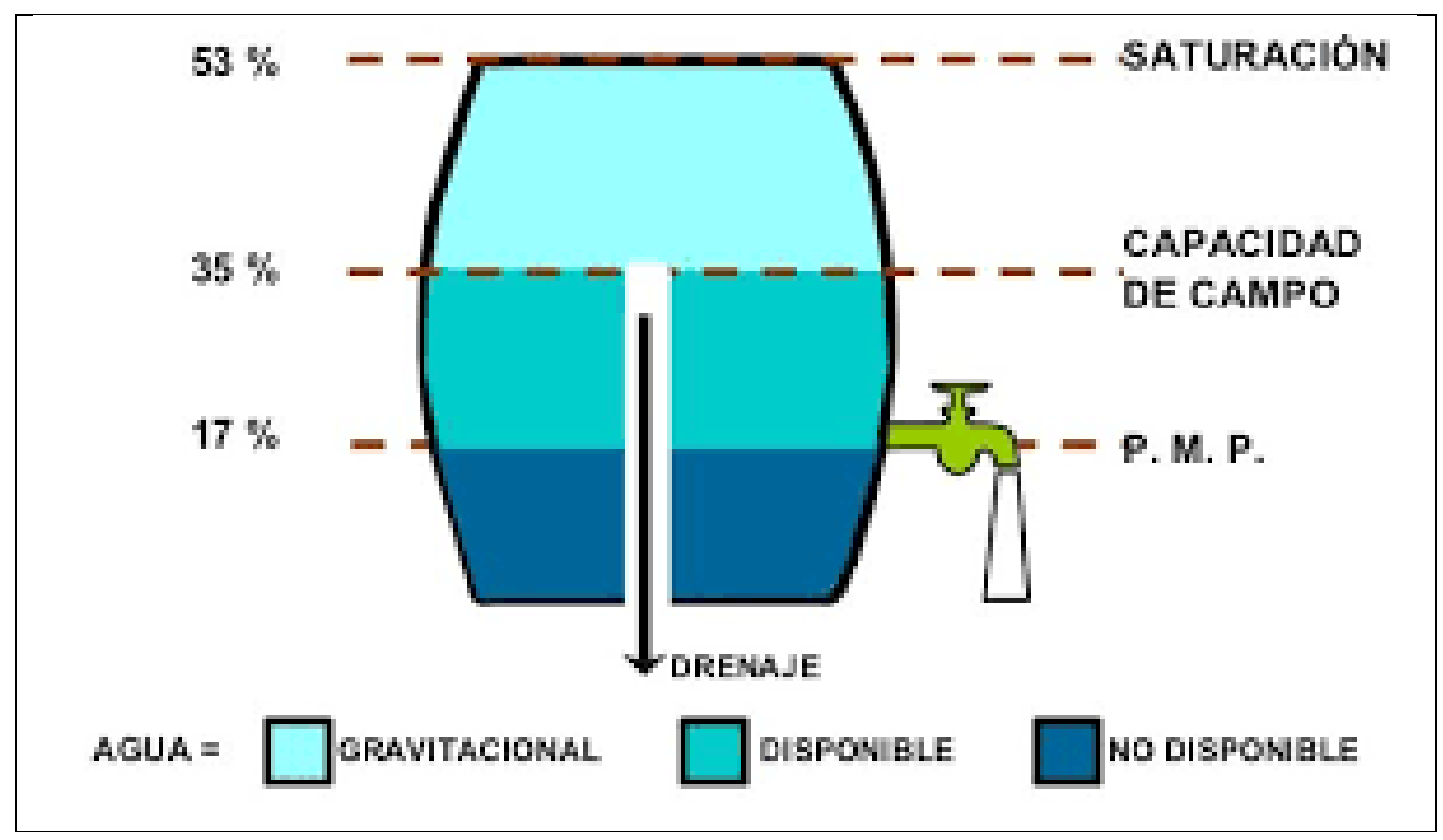

FIGURA 5. 10: ESQUEMA DEL CONTENIDO HÍDRICO DE LOS SUELOS

El $\mathrm{BH}$ brinda información de $\mathrm{ET}_{\mathrm{r}} \mathrm{y}$ del Almacenaje de agua en los suelos, como resultado de éste. Para que éstos valores sean confiables, se realizó un BH diario, con

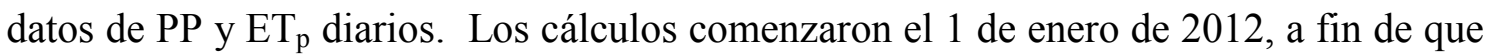
los suelos lleguen al valor de CC correspondiente antes del 4 de enero de 2013 ya que es la primera fecha de estudio. Una vez que el suelo llega a $\mathrm{CC}$, los datos que surgen de un $\mathrm{BH}$ posterior a dicho momento son considerados válidos; de lo contrario no es posible tomar a la $\mathrm{ET}_{\mathrm{r}}$ como testigo.

\section{5.a - Cálculo de la ET $\underline{\text { según Penman-FAO - Cálculo del Kc }}$}

$\mathrm{La} \mathrm{ET}_{0}$ representa la evapotranspiración de un pastizal hipotético de referencia, con una altura de 0,12 m, una resistencia de superficie de $70 \mathrm{~s} / \mathrm{m}$ y un albedo de 0,23_según FAO (1977).

La ecuación (5.24), muestra la ecuación original de Penman-Monteith. Mientras que la (5.25) pertenece al método de FAO (1977) que deriva de la ecuación (5.24).

$$
\lambda \mathrm{ET}=\frac{\Delta \times(R n-G)+\rho_{a} c_{p} \times \frac{\left(e_{s}^{*}-e_{a}\right)}{r_{a}}}{\Delta+\gamma \times\left(1+\frac{r_{s}}{r_{a}}\right)}
$$

FÓRMULA 5. 24

Donde:

$\mathrm{r}_{\mathrm{a}}: 208 / \mathrm{u}_{2}$ 
$\mathrm{r}_{\mathrm{s}}: 70 \mathrm{~m} / \mathrm{s}$

$$
\mathrm{ET}_{0}=\frac{\frac{\Delta}{\lambda} \times(R n-G)+\frac{900 \times \gamma \times u_{2}}{T} \times\left(e_{s}^{*}-e_{a}\right)}{\rho_{w} \times\left[\Delta+\gamma \times\left(1+0,34 \times u_{2}\right)\right]}
$$

FÓRMULA 5. 25

Y a su vez,

$$
\mathrm{ET}_{c}=K_{c} \times E T_{0}
$$

FÓRMULA 5. 26

Los valores de $\mathrm{K}_{\mathrm{c}}$ son particulares de cada píxel, según la cobertura vegetal involucrada; pudiendo tratarse de pastizales o de cultivos o la combinación de ambos.

Los valores de $\mathrm{K}_{\mathrm{c}}$ fueron obtenidos de FAO (1992) para diferentes cultivos y sus diferentes etapas de crecimiento. Para este trabajo se utilizaron los valores para cultivos de soja de $1^{\circ}$, soja de $2^{\circ}$, maíz, girasol, pasturas, rastrojo y forestación. Debido a que son estos los tipos mayoritarios de cobertura presente en la provincia de Buenos Aires durante el mes de enero. Para el caso de las pasturas, se utilizó el valor promedio de las especies sembradas en la provincia, para etapas medias del cultivo y efectos medios de cortes; para los montes forestales se utilizó el valor de $\mathrm{K}_{\mathrm{c}}$ del Eucaliptus sp. (Díaz y Rébori, 2003) puesto que es muy común esta especie en la provincia. En la tabla 5.2 se muestran los valores de $\mathrm{K}_{\mathrm{c}}$.

\begin{tabular}{||l|c|c|}
\hline \multicolumn{1}{|c|}{ Cultivo } & Condición & Kc \\
\hline Soja $1^{\circ}$ & medio & 1,15 \\
Soja $2^{\circ}$ & inicial & 0,50 \\
Maíz & medio & 1,2 \\
Girasol & medio & 1,075 \\
Rastrojo & & 0,3 \\
Pastos & medio & 0,96 \\
Eucaliptus & & 0,93 \\
\hline \multicolumn{2}{|l|}{ TABLA 5. 2: KC SEGÚN FAO } \\
\hline
\end{tabular}




\section{5.b - Cálculo del K ${ }_{c}$ por píxel}

En este trabajo, se obtuvo el $\mathrm{K}_{\mathrm{c}}$ solo para aquellos píxeles coincidentes con las estaciones meteorológicas. Ya que son dichos sitios donde es posible comparar ambos datos.

El $\mathrm{K}_{\mathrm{c}}$ de cada píxel surge de una ponderación de la superficie correspondiente a cada cobertura encontrada en dicho píxel (Figura 5.11).

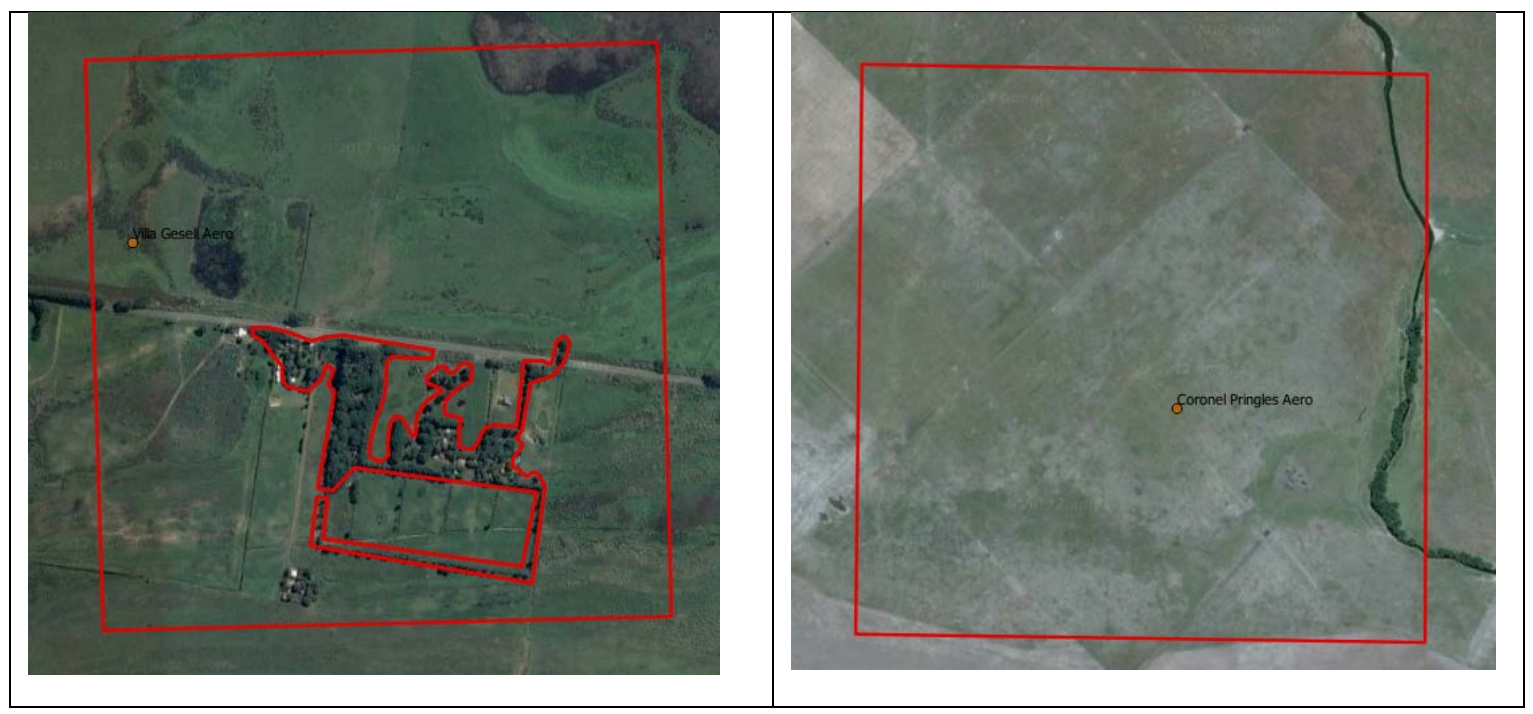

Figura 5. 11: PíXel CORRESPONDIENTE A LA ESTACIÓn METEOROLÓ GICA (VILLA GeSELL y CNEL. PRINGLES RESPECTIVAMENTE)

Se observa en la figura 5.11 el píxel que contiene al punto de la estación meteorológica, píxel donde se extrae el valor de la $E_{\mathrm{dr}}$ estimada en el presente trabajo y el valor testigo de $\mathrm{ET}_{\mathrm{r}}$ para dicha estación meteorológica. Además, en esta misma figura se puede apreciar la digitalización hecha a partir de las imágenes del programa Google earth para la fecha más cercana a enero de 2013, marcando los diferentes tipos de cobertura existente en dicho píxel. Para los píxeles que contienen cultivos, se utilizó además el dato estimado y publicado por ARBA para la campaña 2012-2013 que muestra los cultivos realizados en la provincia de Bs As a partir de imágenes Landsat, NDVI y chequeo a campo.

Cabe aclarar que como los puntos son estaciones meteorológicas y muchas de ellas situadas en aeropuertos, el área predominante en el píxel corresponde a pasturas o pastos.

Se remarca que, para este trabajo, la resolución espacial del método propuesto es de $1 \mathrm{Km}$ de lado (tamaño del píxel trabajado) ya que los datos de las imágenes MODIS fueron ajustados a dicho valor. Se extiende el valor puntual de $\mathrm{ET}_{\mathrm{r}}$ estimado con el $\mathrm{BH}$ 
en la estación meteorológica, a un área de $1 \mathrm{Km}^{2}$ (área del píxel que contiene a la estación meteorológica). 


\section{Capítulo 6. Resultados y Discusión}

En el Anexo I se muestran resultados parciales obtenidos a partir de la estimación con las imágenes MODIS.

A su vez, en el Anexo II. Aparecen las imágenes de los resultados del trabajo.

\section{1.- Radiación Neta Instantánea y Evapotranspiración Instantánea}

En la Tabla 6.1 aparecen los datos de $\mathrm{Rn}_{\mathrm{i}}$ medidos in situ en un lote de soja, INTA Balcarce, junto con las estimaciones hechas con los productos MODIS.

En la Tabla 6.2 se muestran los datos de ET $_{\mathrm{i}}$ para el mismo lote en INTA-Balcarce junto con las estimaciones hechas con los productos MODIS.

\begin{tabular}{|c|c|c|c|c|c|}
\hline DIA & HORA UTC & Rn (W/m2) & $\begin{array}{c}\left.\text { Rni (W/m }{ }^{2}\right) \\
\text { MODIS- Diario }\end{array}$ & $\begin{array}{c}\text { Rni }\left(\mathbf{W} / \mathbf{m}^{\mathbf{2}}\right) \\
\text { MODIS-16 días }\end{array}$ & $\begin{array}{c}\text { HORA UTC } \\
\text { visita } \\
\text { MODIS }\end{array}$ \\
\hline $\mathbf{4}$ & 13,55 & $\mathrm{~s} / \mathrm{d}$ & 647,14 & 654,67 & 14,21 \\
\hline $\mathbf{6}$ & 13,43 & 614,3 & 613,35 & 617,95 & 14,00 \\
\hline $\mathbf{7}$ & 14,25 & 404,7 & $\mathrm{~s} / \mathrm{d}$ & $\mathrm{s} / \mathrm{d}$ & 14,45 \\
\hline $\mathbf{8}$ & 13,31 & 569,1 & 550,40 & 588,48 & 14,63 \\
\hline $\mathbf{9}$ & 14,13 & 628,7 & 669,59 & 646,09 & 14,71 \\
\hline $\mathbf{1 3}$ & 13,49 & 412,7 & 495,23 & 567,56 & 14,08 \\
\hline $\mathbf{1 9}$ & 13,13 & 313,9 & $\mathrm{~s} / \mathrm{d}$ & $\mathrm{s} / \mathrm{d}$ & 13,50 \\
\hline
\end{tabular}

TABLA 6. 1: RNI MEDIDO IN SITU Y RNI ESTIMADO A PARTIR DE IMÁGENES MODIS

Aquellos días sin dato (s/d) para las estimaciones satelitales, se condicen con cielo nublado al momento de visita del satélite, impidiendo la estimación de la $\mathrm{Rn}_{\mathrm{i}}$. Ello, se evidencia, además, con los valores de $\mathrm{Rn}_{\mathrm{i}}$ medidos “in situ” que rondan los valores más bajos registrados en INTA-Balcarce.

Tanto en la Tabla 6.1 como en la 6.2 aparecen los momentos de medición in situ como la hora de visita del satélite. 


\begin{tabular}{|c|c|c|c|c|c|}
\hline DIA & HORA UTC & $\begin{array}{c}\text { ETi (W/m2): } \\
\text { flujo de calor } \\
\text { latente }\end{array}$ & $\begin{array}{c}\text { ETi (W/m } \mathbf{m}^{\mathbf{2}} \\
\text { MODIS- Diario }\end{array}$ & $\begin{array}{c}\text { ETi (W/m } \mathbf{m}^{\mathbf{2}} \\
\text { MODIS- 16 días }\end{array}$ & $\begin{array}{c}\text { HORA UTC } \\
\text { visita } \\
\text { MODIS }\end{array}$ \\
\hline $\mathbf{4}$ & 13,55 & 154,8 & 133,83 & 102,63 & 14,21 \\
\hline $\mathbf{6}$ & 13,43 & 302,5 & 291,88 & 319,98 & 14,00 \\
\hline $\mathbf{7}$ & 14,25 & 117,7 & $\mathrm{~s} / \mathrm{d}$ & $\mathrm{s} / \mathrm{d}$ & 14,45 \\
\hline $\mathbf{8}$ & 13,31 & 255,3 & 280,45 & 334,91 & 14,63 \\
\hline $\mathbf{9}$ & 14,13 & 220,6 & 328,07 & 328,61 & 14,71 \\
\hline $\mathbf{1 3}$ & 13,49 & 209,4 & 210,53 & 213,90 & 14,08 \\
\hline $\mathbf{1 9}$ & 13,13 & 54,9 & $\mathrm{~s} / \mathrm{d}$ & $\mathrm{s} / \mathrm{d}$ & 13,50 \\
\hline
\end{tabular}

TABLA 6. 2: ET, MEDIDA IN SITU Y ESTIMADA A PARTIR DE IMÁGENES MODIS

En los gráficos 6.1 y 6.2 se muestra la ecuación de ajuste y el coeficiente de determinación $\left(\mathrm{R}^{2}\right)$ para los datos medidos in situ en un lote de soja en INTA-Balcarce y los valores estimados con productos MODIS, siendo que el eje de las abscisas corresponde a las mediciones in situ, mientras que el eje de las ordenadas corresponde a la estimación MODIS.

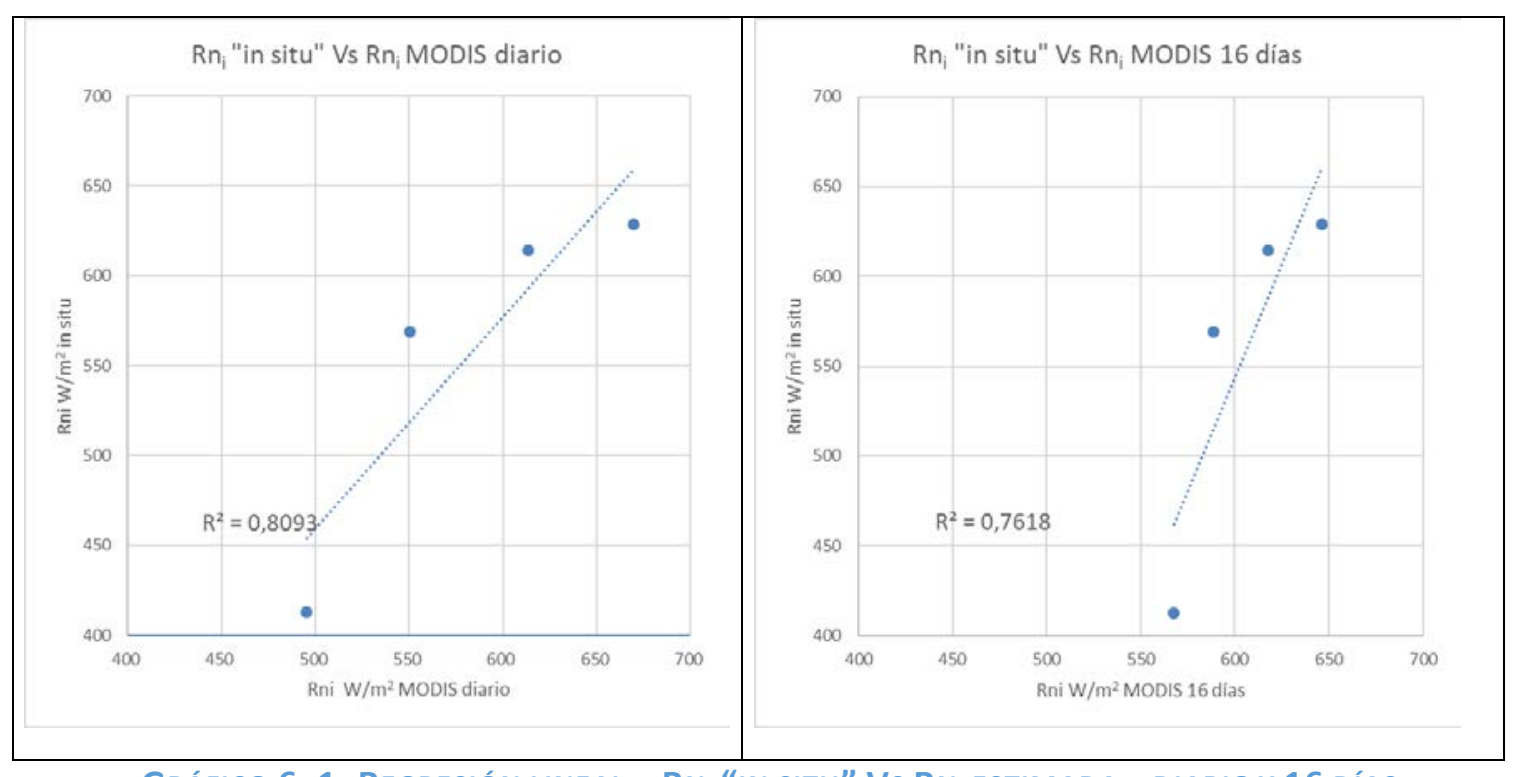

GRÁFICO 6. 1: REGRESIÓN LINEAL - RN, “IN SITU” VS RN, ESTIMADA - DIARIOY 16 DÍAS 


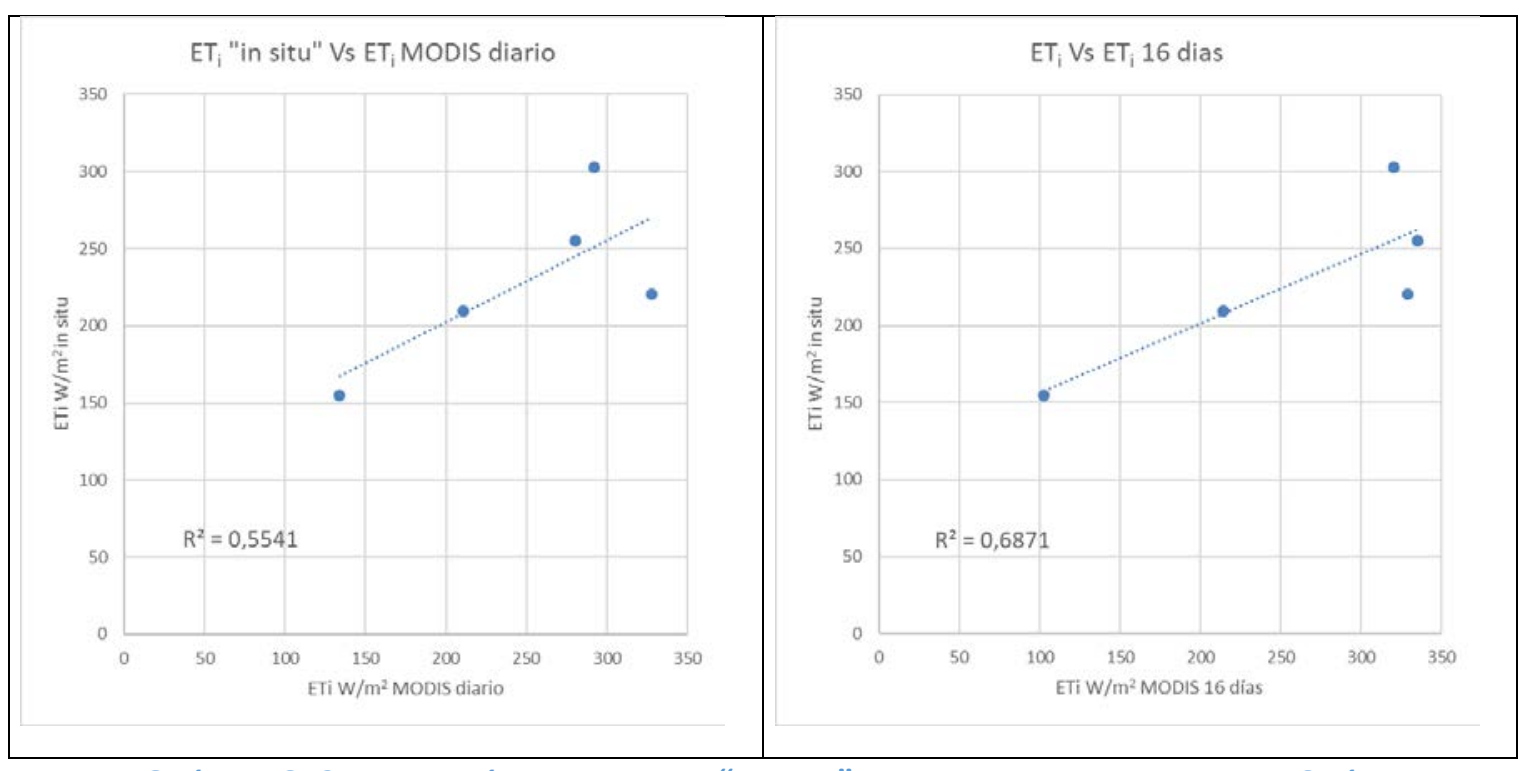

GRÁFICO 6. 2: REGRESIÓN LINEAL - ET, “IN SITU” VS ET, ESTIMADA - DIARIO Y 16 DÍAS

De los gráficos anteriores, podemos decir que los $\mathrm{R}^{2}$ son muy buenos. Sin embargo, se debe tener presente que se está comparando una medición puntual con un valor de un píxel que se corresponde con un área de $1 \mathrm{Km}^{2}$. Pero no se puede perder de vista en este caso, que son muy pocos los valores que se están contrastando y el coeficiente de determinación está sesgado.

No obstante, esta metodología ya ha sido probada en otras regiones por Venturini y sus resultados fueron buenos.

Los resultados mostrados en las tablas 6.1 y 6.2 permitirían validar la hipótesis 1: " $L a$ tasa de evapotranspiración instantánea puede estimarse bajo la forma de flujo de calor latente, a partir de información provista por los sensores MODIS a bordo de los satélites heliosincrónicos Terra y Aqua de la NASA, al momento de su visita”.

\section{2.- $\mathrm{ET}_{\mathrm{r}}-\mathrm{E}_{\mathrm{dr}}$}

Para poder corroborar la estimación satelital de evapotranspiración diaria real en $\mathrm{mm}$ /día $\left(E_{\mathrm{rd}}\right)$, se decidió estimar la $\mathrm{ET}_{\mathrm{r}}$ mediante $\mathrm{BH}-\mathrm{TM}$ para obtener valores testigos acorde a lo estimado.

En las siguientes tablas, se muestras los datos de $\mathrm{ET}_{\mathrm{r}}(\mathrm{BH}-\mathrm{TM})$, y $E_{\mathrm{rd}}$ estimada con MODIS-GOES. Cada estimación satelital $E_{\mathrm{rd}}$ fue comparada con el valor testigo $\mathrm{ET}_{\mathrm{r}}$. Dichos valores aparecen en las tablas 6.3 a 6.9 según el día, comenzando con el día 4 de enero y hasta el día 19 de enero. Los valores de $\mathrm{ET}_{\mathrm{r}}$ y $E_{\mathrm{rd}}$ están en mm/día. 


\begin{tabular}{||l|c|c|c|}
\hline \multicolumn{3}{|c|}{ 4 de enero } \\
\hline \multicolumn{1}{|c|}{ Localidad } & $\mathbf{E T}_{\mathbf{r}}$ & $\boldsymbol{E}_{d r}$ diario & $\boldsymbol{E}_{d r}$ 16 días \\
\hline Ezeiza Aero & 5,10 & 3,98 & 4,75 \\
Punta Indio (BA) & 4,90 & 3,19 & 4,86 \\
Bolívar Aero & 4,10 & 2,94 & 3,95 \\
Mar del Plata Aero & 3,80 & 3,33 & 4,07 \\
Azul Aero & 4,20 & 2,87 & 4,05 \\
Olavarría Aero & 4,30 & 2,01 & 3,36 \\
Tandil Aero & 3,60 & 2,15 & 3,45 \\
Benito Juárez Aero & 4,60 & 2,23 & 4,03 \\
Coronel Pringles Aero & 4,10 & 1,95 & 2,79 \\
Villa Gesell Aero & 5,60 & 4,96 & 5,62 \\
Barrow INTA & 4,80 & 2,57 & 3,08 \\
Balcarce INTA & 5,20 & 2,91 & 4,49 \\
\hline
\end{tabular}

TABLA 6. 3: RESULTADOS DE ESTIMACIONES MODIS-GOES COMPARADOS CON EL TESTIGO PARA EL DÍA 4 DE ENERO DE 2013

\begin{tabular}{|l|c|c|c|}
\hline \multicolumn{3}{|c|}{$\mathbf{6}$ de enero } \\
\hline \multicolumn{1}{|c|}{ Localidad } & $\mathbf{E T}_{\mathbf{r}}$ & $\boldsymbol{E}_{d r}$ diario & $\boldsymbol{E}_{d r} \mathbf{1 6}$ días \\
\hline Ezeiza & 3,60 & 1,81 & 2,49 \\
Punta Indio (BA) & 4,20 & 2,65 & 2,97 \\
Dolores Aero & 4,70 & 4,83 & 5,15 \\
Las Flores Aero & 4,40 & 3,96 & 5,44 \\
Coronel Suárez Aero & 4,60 & 3,49 & 5,65 \\
Bolívar Aero & 3,20 & 2,81 & 5,09 \\
Azul Aero & 4,40 & 3,87 & 5,74 \\
Olavarría Aero & 5,10 & 4,62 & 6,07 \\
Tandil Aero & 4,40 & 3,86 & 5,05 \\
Benito Juárez Aero & 5,60 & 3,71 & 5,32 \\
Pigüé Aero & 4,90 & 5,02 & 5,60 \\
Coronel Pringles Aero & 4,10 & 4,10 & 5,60 \\
Bahía Blanca & 3,60 & 3,05 & 4,40 \\
Barrow INTA & 4,80 & 4,50 & 4,89 \\
Balcarce INTA & 3,20 & 2,45 & 3,85 \\
Hilario Ascasubi INTA & 2,00 & 3,05 & 3,88 \\
\hline
\end{tabular}

TABLA 6. 4: RESULTADOS DE ESTIMACIONES MODIS-GOES COMPARADOS CON EL TESTIGO PARA EL DÍA 6 DE ENERO DE 2013 


\begin{tabular}{||l|c|c|c|}
\hline \multicolumn{1}{|c|}{ Localidad } & $\mathbf{E T}_{\mathbf{r}}$ & $\boldsymbol{E}_{d r}$ diario & $\boldsymbol{E}_{d r}$ 16 días \\
\hline Dolores Aero & 4,00 & 3,62 & 4,17 \\
Bolívar Aero & 4,50 & 3,60 & 4,40 \\
Azul Aero & 3,90 & 3,73 & 5,12 \\
Olavarría Aero & 4,30 & 3,61 & 4,85 \\
Benito Juárez Aero & 3,80 & 2,56 & 4,42 \\
Pigüé Aero & 3,10 & 3,03 & 4,00 \\
Coronel Pringles Aero & 3,50 & 3,82 & 4,56 \\
Bahía Blanca & 3,30 & 3,70 & 4,67 \\
Villa Gesell Aero & 3,10 & 2,25 & 3,11 \\
Barrow INTA & 4,80 & 3,11 & 4,61 \\
Hilario Ascasubi INTA & 4,70 & 4,22 & 5,79 \\
\hline
\end{tabular}

TABLA 6. 5: RESULTADOS DE ESTIMACIONES MODIS-GOES COMPARADOS CON EL TESTIGO PARA EL DÍA 7 DE ENERO DE 2013

\begin{tabular}{|l|c|c|c|}
\hline \multicolumn{3}{|c|}{ 8 de enero } \\
\hline \multicolumn{1}{|c|}{ Localidad } & ET $_{\mathrm{r}}$ & $\boldsymbol{E}_{d r}$ diario & $\boldsymbol{E}_{d r} \mathbf{1 6}$ días \\
\hline Mar del Plata Aero & 3,80 & 3,42 & 4,03 \\
Coronel Suárez Aero & 3,90 & 2,30 & 4,09 \\
Benito Juárez Aero & 4,70 & 4,22 & 4,81 \\
Pigüé Aero & 4,00 & 3,69 & 4,12 \\
Coronel Pringles Aero & 3,20 & 3,40 & 3,95 \\
Bahía Blanca & 3,00 & 2,91 & 3,22 \\
Villa Gesell Aero & 3,10 & 3,46 & 3,72 \\
Barrow INTA & 5,30 & 4,54 & 4,76 \\
Balcarce INTA & 4,40 & 4,74 & 4,82 \\
Hilario Ascasubi INTA & 3,20 & 3,00 & 4,90 \\
\hline
\end{tabular}

TABLA 6. 6: RESULTADOS DE ESTIMACIONES MODIS-GOES COMPARADOS CON EL TESTIGO PARA EL DíA 8 DE ENERO DE 2013 


\begin{tabular}{|l|c|c|c||}
\hline \multicolumn{3}{|c|}{$\mathbf{9}$ de enero } \\
\hline \multicolumn{1}{|c|}{ Localidad } & $\mathbf{E T}_{\mathbf{r}}$ & $\boldsymbol{E}_{d r}$ diario & $\boldsymbol{E}_{d r} \mathbf{1 6}$ días \\
\hline San Fernando & 3,90 & 4,53 & 5,36 \\
Las Flores Aero & 3,90 & 3,91 & 5,65 \\
Ezeiza Aero & 2,90 & 2,25 & 2,75 \\
La Plata Aero & 4,10 & 3,57 & 4,01 \\
Punta Indio (BA) & 3,90 & 4,27 & 4,69 \\
Bolívar Aero & 4,30 & 4,00 & 4,24 \\
Dolores Aero & 3,90 & 4,87 & 5,11 \\
Mar del Plata Aero & 3,40 & 3,28 & 4,89 \\
Bahía Blanca & 3,20 & 2,81 & 3,85 \\
Coronel Suárez Aero & 3,70 & 3,90 & 5,61 \\
Azul Aero & 4,00 & 4,59 & 5,45 \\
Olavarría Aero & 4,40 & 4,51 & 5,15 \\
Tandil Aero & 3,90 & 4,21 & 5,19 \\
Benito Juárez Aero & 4,80 & 4,34 \\
Pigüé Aero & 4,20 & 4,49 & 4,89 \\
Coronel Pringles Aero & 3,40 & 4,54 & 5,30 \\
Villa Gesell Aero & 3,10 & 4,66 & 5,18 \\
Barrow INTA & 2,50 & 2,60 & 3,93 \\
Balcarce INTA & 3,40 & 3,23 & 4,08 \\
Hilario Ascasubi INTA & 4,60 & 4,62 & 5,11 \\
\hline
\end{tabular}

TABLA 6. 7: RESULTADOS DE ESTIMACIONES MODIS-GOES COMPARADOS CON EL TESTIGO PARA EL DÍA 9 DE ENERO DE 2013

\begin{tabular}{||l|c|c|c|}
\hline \multicolumn{3}{|c|}{$\mathbf{1 3}$ de enero } \\
\hline \multicolumn{1}{||}{ Localidad } & $\mathbf{E T}_{\mathbf{r}}$ & $\boldsymbol{E}_{d r}$ diario & $\boldsymbol{E}_{d r} \mathbf{1 6}$ días \\
\hline Las Flores Aero & 3,50 & 3,25 & 4,20 \\
Ezeiza Aero & 3,30 & 3,38 & 4,13 \\
Bolívar Aero & 3,50 & 2,97 & 3,98 \\
Dolores Aero & 4,30 & 4,97 & 5,85 \\
Coronel Suárez Aero & 2,80 & 2,60 & 3,40 \\
Azul Aero & 3,50 & 3,31 & 4,11 \\
Olavarría Aero & 4,20 & 4,02 & 4,24 \\
Tandil Aero & 3,30 & 3,38 & 5,06 \\
Pigüé Aero & 2,90 & 2,44 & 4,23 \\
Coronel Pringles Aero & 3,40 & 3,07 & 4,23 \\
Villa Gesell Aero & 3,40 & 3,89 & 5,16 \\
Balcarce INTA & 3,00 & 3,12 & 3,65 \\
\hline
\end{tabular}

TABLA 6. 8: RESULTADOS DE ESTIMACIONES MODIS-GOES COMPARADOS CON EL TESTIGO PARA EL díA 13 DE ENERO DE 2013. 


\begin{tabular}{||l|c|c|c|}
\hline \multicolumn{1}{|c|}{ Localidad } & $\mathbf{E T}_{\mathbf{r}}$ & $\boldsymbol{E}_{\boldsymbol{d r}}$ diario & $\boldsymbol{E}_{\boldsymbol{d r}}$ 16 días \\
\hline Azul Aero & 2,10 & 2,13 & 2,96 \\
Dolores Aero & 3,50 & 2,84 & 3,45 \\
Coronel Pringles Aero & 1,80 & 2,50 & 2,72 \\
Villa Gesell Aero & 2,50 & 2,79 & 3,34 \\
Barrow INTA & 2,40 & 2,45 & 3,13 \\
Hilario Ascasubi INTA & 3,20 & 2,57 & 4,35 \\
\hline
\end{tabular}

TABLA 6. 9: RESULTADOS DE ESTIMACIONES MODIS-GOES COMPARADOS CON EL TESTIGO PARA EL

DÍA 19 DE ENERO DE 2013

En las 7 tablas anteriores se observa que, para todos los casos, la evapotranspiración estimada con productos MODIS de NDVI y albedo de 16 días (MOD 13 y MOD 43) siempre fue mayor a la estimada con los respectivos productos diarios.

Por otra parte, con los datos de las tablas precedentes se realizaron regresiones lineales; los gráficos correspondientes, gráficos 6.3 al 6.9 y el coeficiente de determinación $\mathrm{R}^{2}$ para cada uno de ellos, se muestran a continuación. En todos los gráficos, el eje de las abscisas corresponde a $\mathrm{ET}_{\mathrm{r}}(\mathrm{BH}-\mathrm{TM})$ y el eje de las ordenadas a la estimación con sensores remotos, las unidades son $\mathrm{mm} /$ día en ambos ejes.

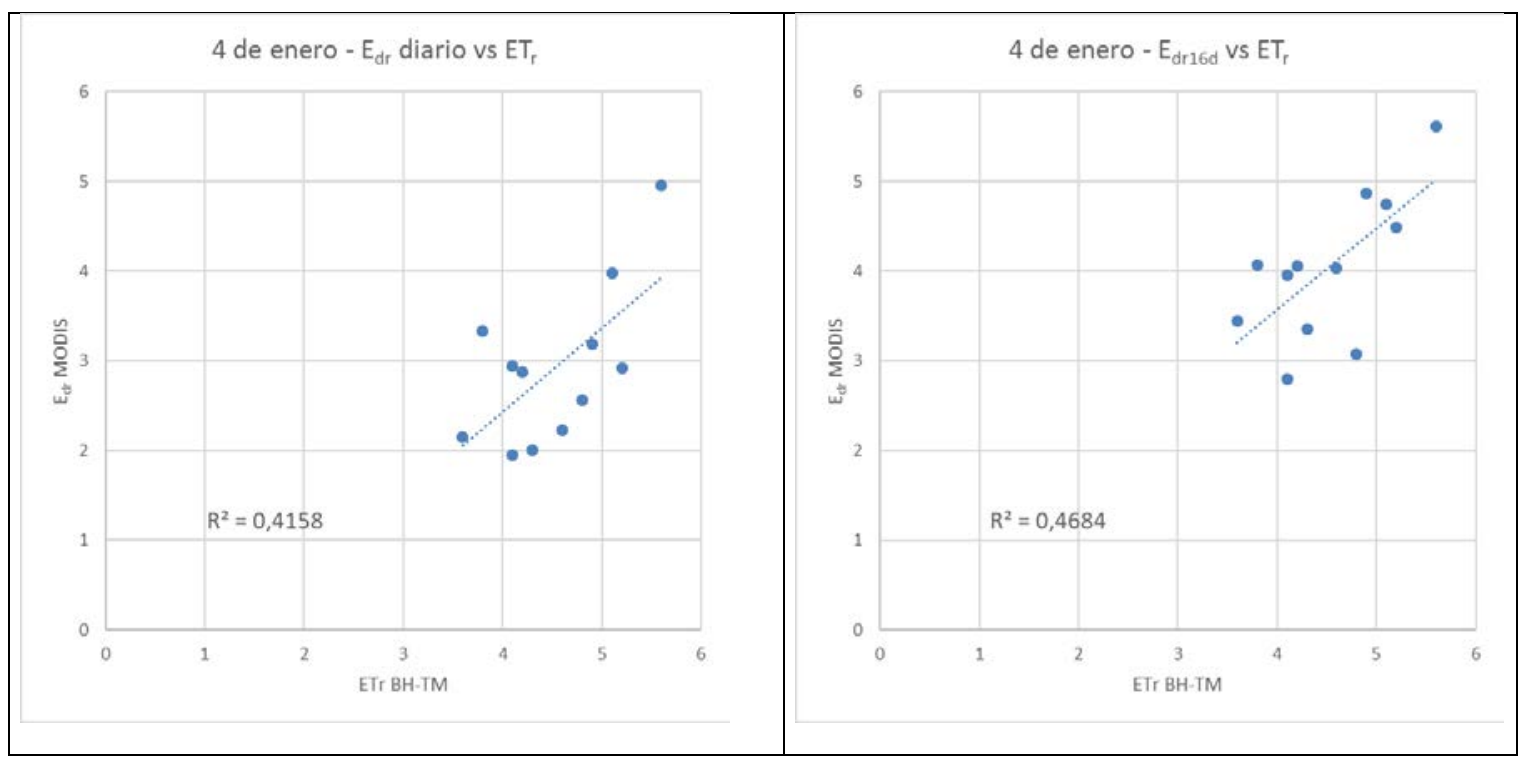

GRÁFICO 6. 3: REGRESIÓN LINEAL - 4 DE ENERO - $E_{\text {DR }}$ VS ET - DIARIO Y 16 DÍAS 


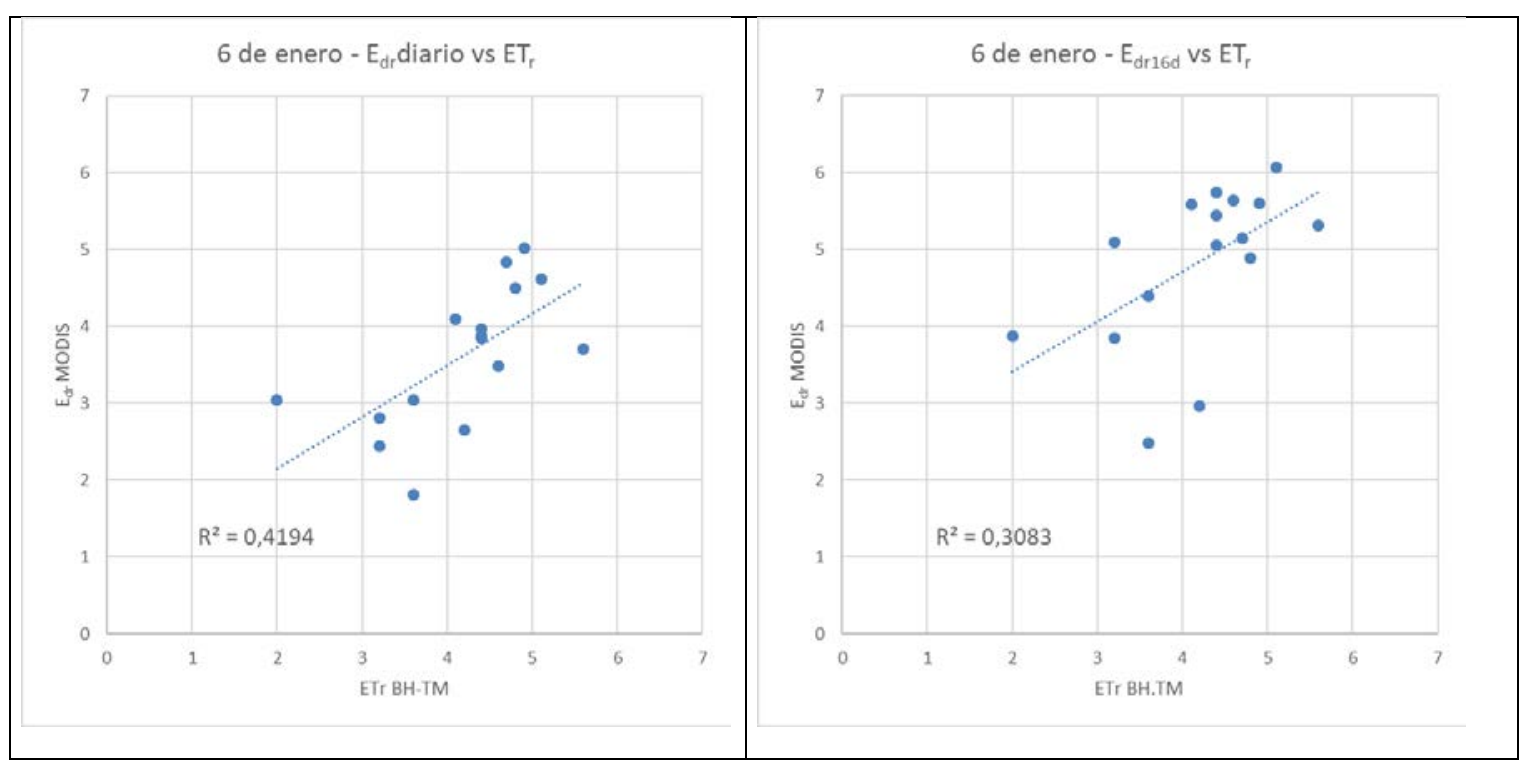

GRÁFICO 6. 4: REGRESIÓN LINEAL - 6 DE ENERO - $E_{\mathrm{DR}}$ VS ET $\mathrm{R}_{\mathrm{R}}-$ DIARIO Y 16 DÍAS

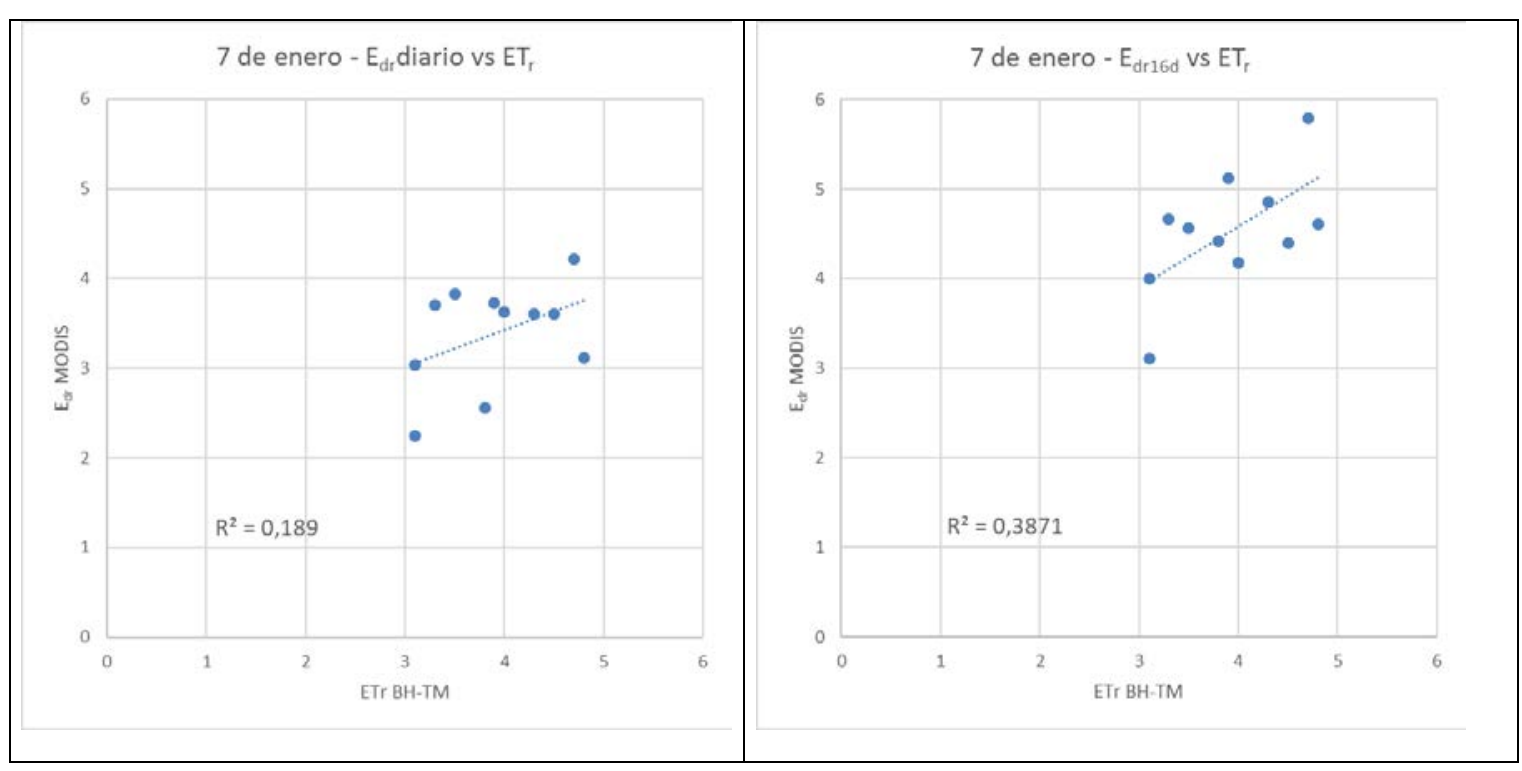

GRÁFICO 6. 5: REGRESIÓN LINEAL - 7 DE ENERO - $E_{\mathrm{DR}}$ VS ETR - DIARIO Y 16 DÍAS 


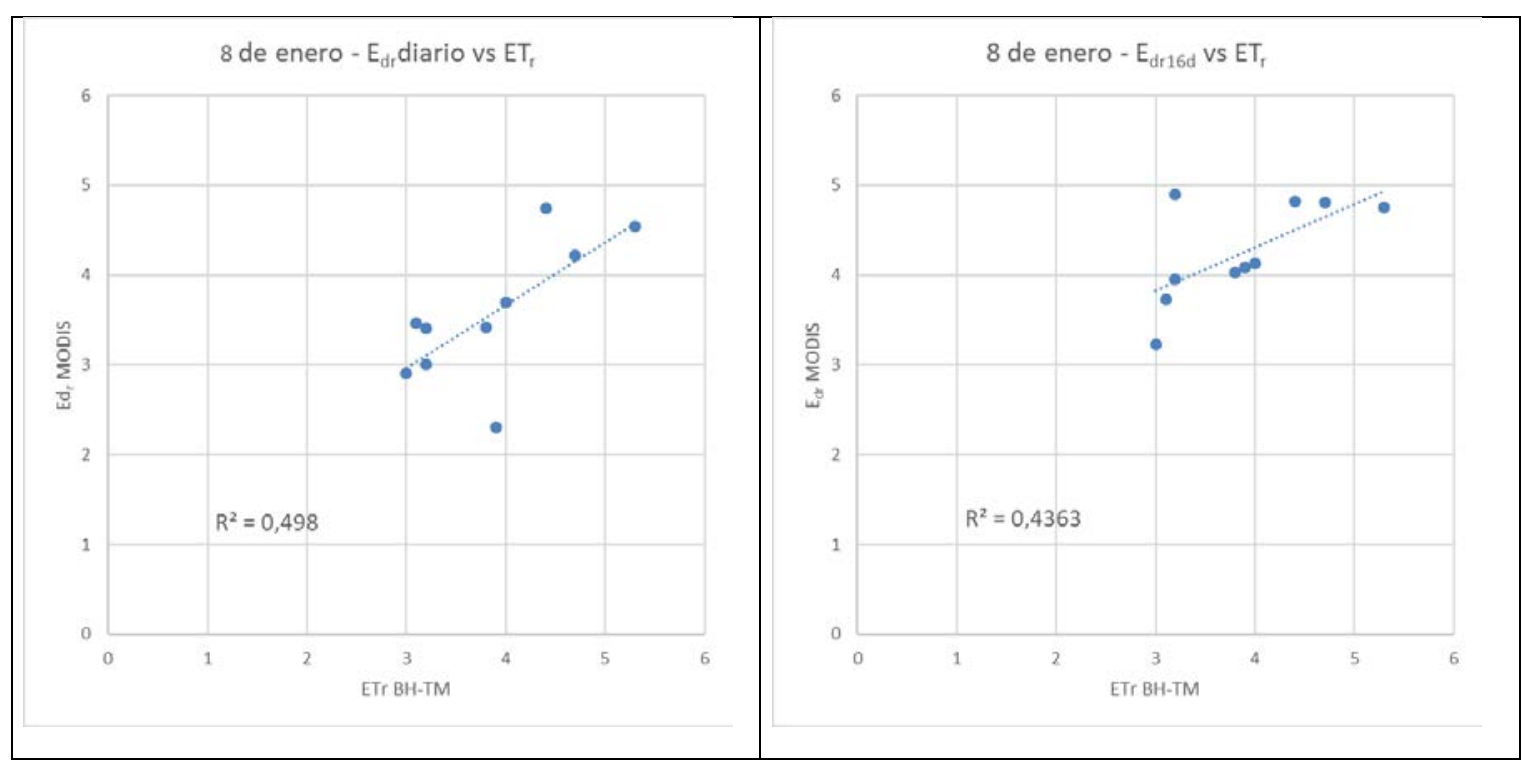

GRÁFICO 6. 6: REGRESIÓN LINEAL - 8 DE ENERO - $E_{D R}$ VS ET ET $_{R}$ DIARIO Y 16 DÍAS

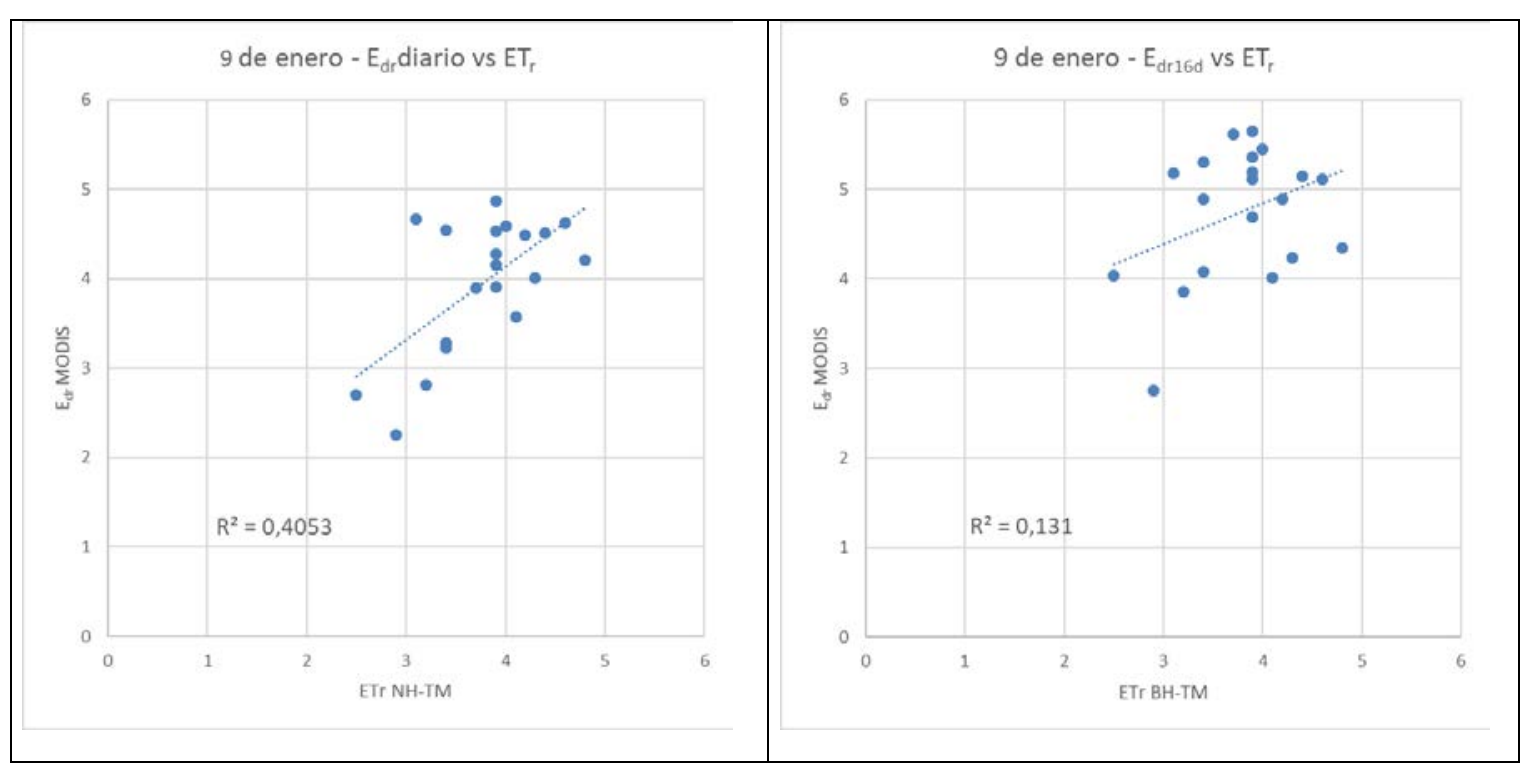

GRÁFICO 6. 7: REGRESIÓN LINEAL - 9 DE ENERO - $E_{\mathrm{DR}}$ VS ET - DIARIO Y 16 DÍAS 


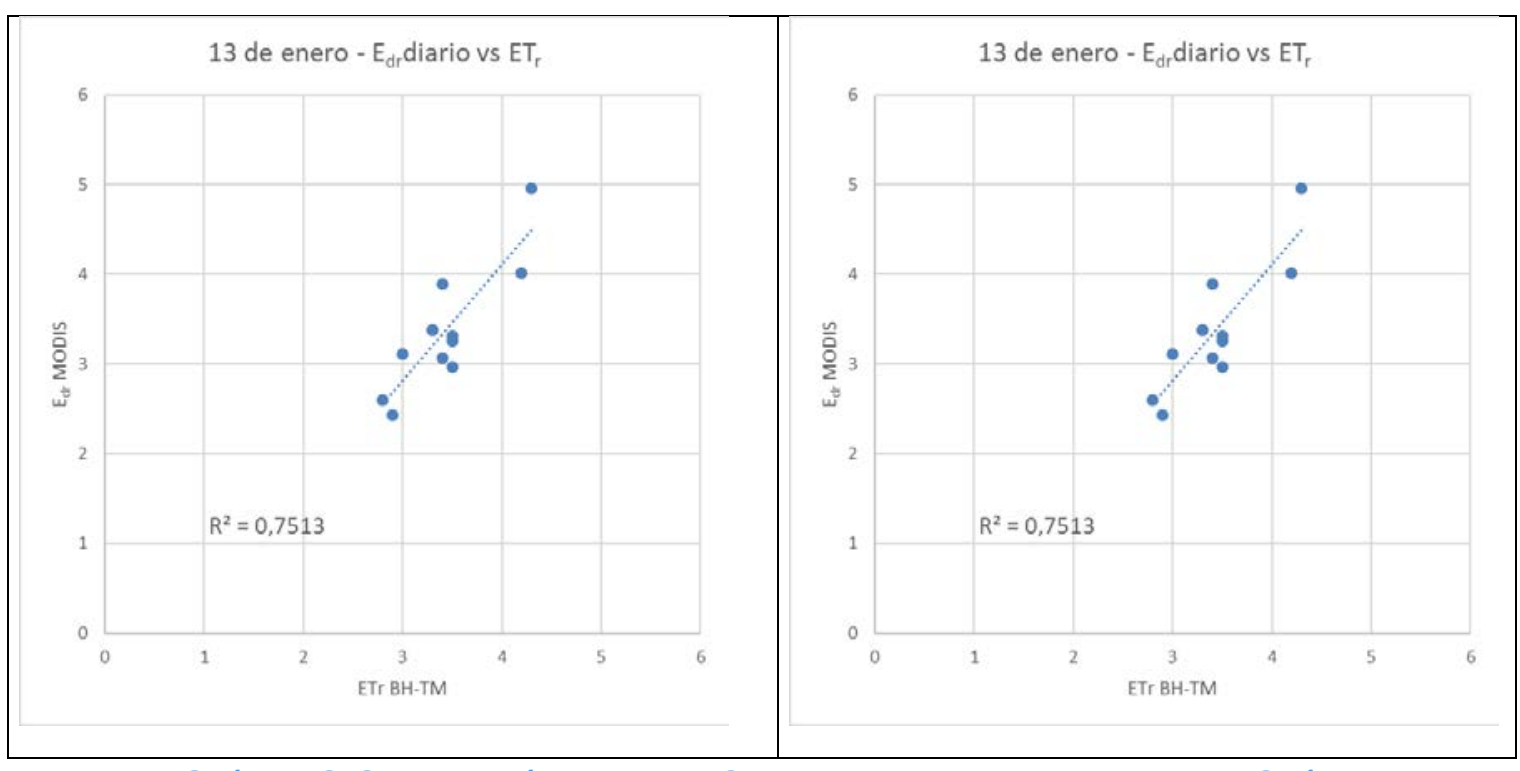

GRÁFICO 6. 8: REGRESIÓN LINEAL - 13 DE ENERO - $E_{\text {DR }}$ VS ET - DIARIO Y 16 DÍAS

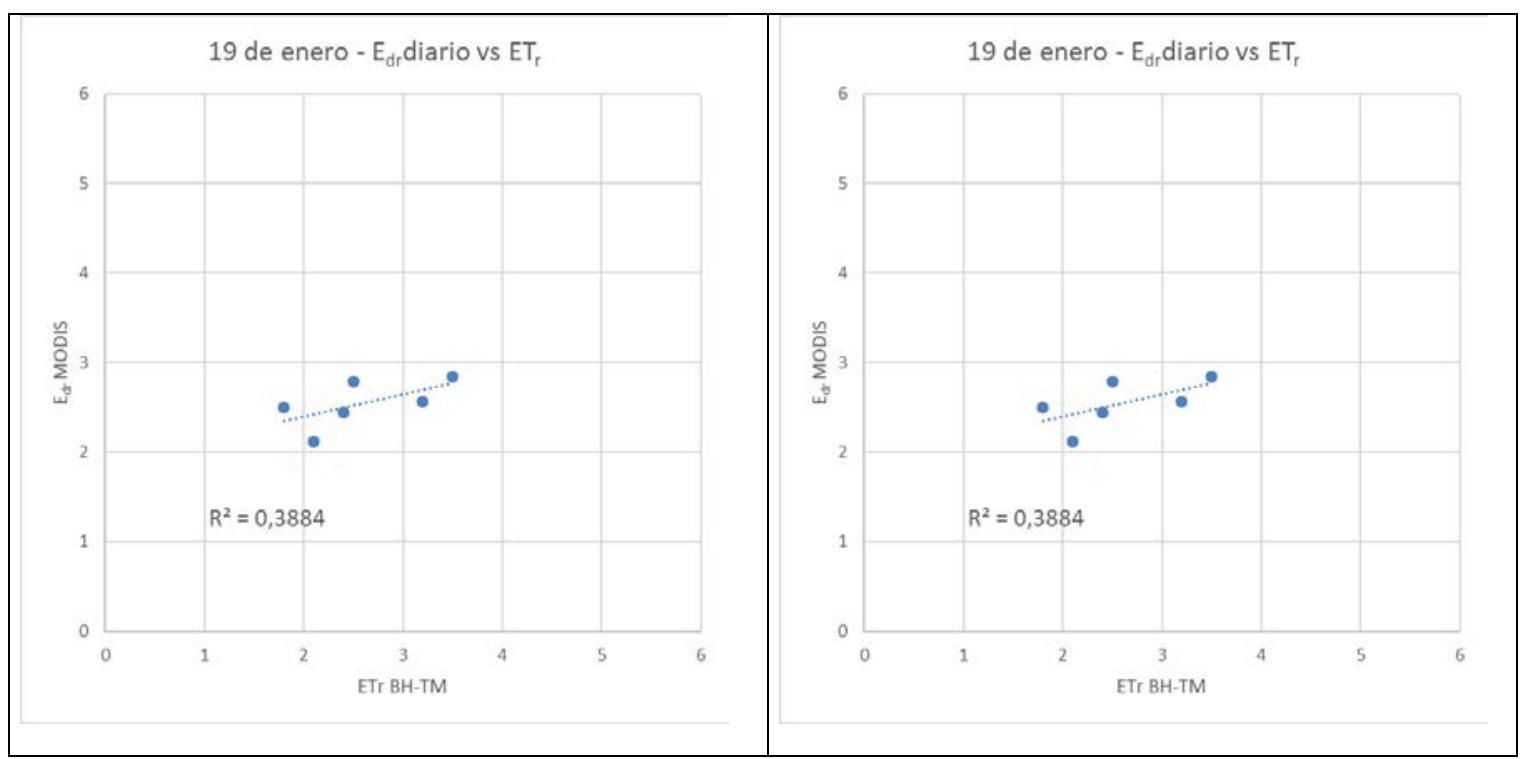

GRÁFICO 6. 9: REGRESIÓN LINEAL - 19 DE ENERO - $E_{\mathrm{DR}} \mathrm{VS} \mathrm{ET}_{\mathrm{R}}-$ DIARIO Y 16 DÍAS

En el gráfico 6.10, se realizó una regresión lineal, teniendo en cuenta todas las estaciones y todos los días.

Como puede observarse en el gráfico 6.10 el $\mathrm{R}^{2}$ para productos MODIS diarios $\mathrm{y}$ productos MODIS de dieciséis días fue similar, a diferencia de lo mostrado en los gráficos anteriores donde aparecen discrepancias entre los productos utilizados y los días de estudio. En ambos casos se obtuvo una baja correlación (R). 


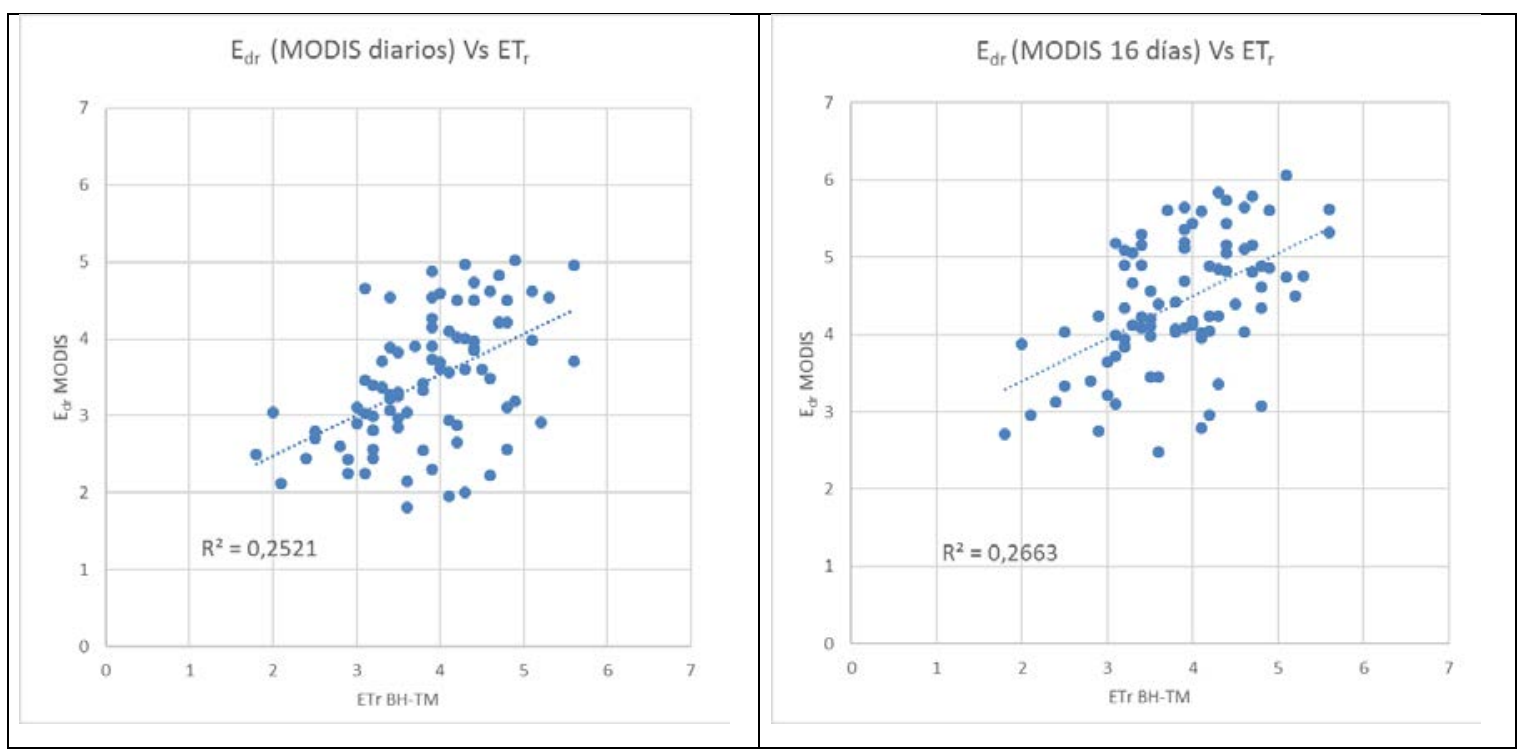

GRÁFICO 6. 10: REGRESIÓN LINEAL - TODAS LAS ESTACIONES METEOROLÓGICAS Y TODOS LOS DÍAS $E_{D R}$ (DIARIOY 16 DÍAS) VS ET $T_{R}$

En el gráfico 6.11 se observa la relación para los mismos días y localidades, pero para la condición de cielo despejado, correlación previa a la corrección por nubosidad. La correlación aquí es apreciablemente mejor que para los días con la corrección por nubosidad.

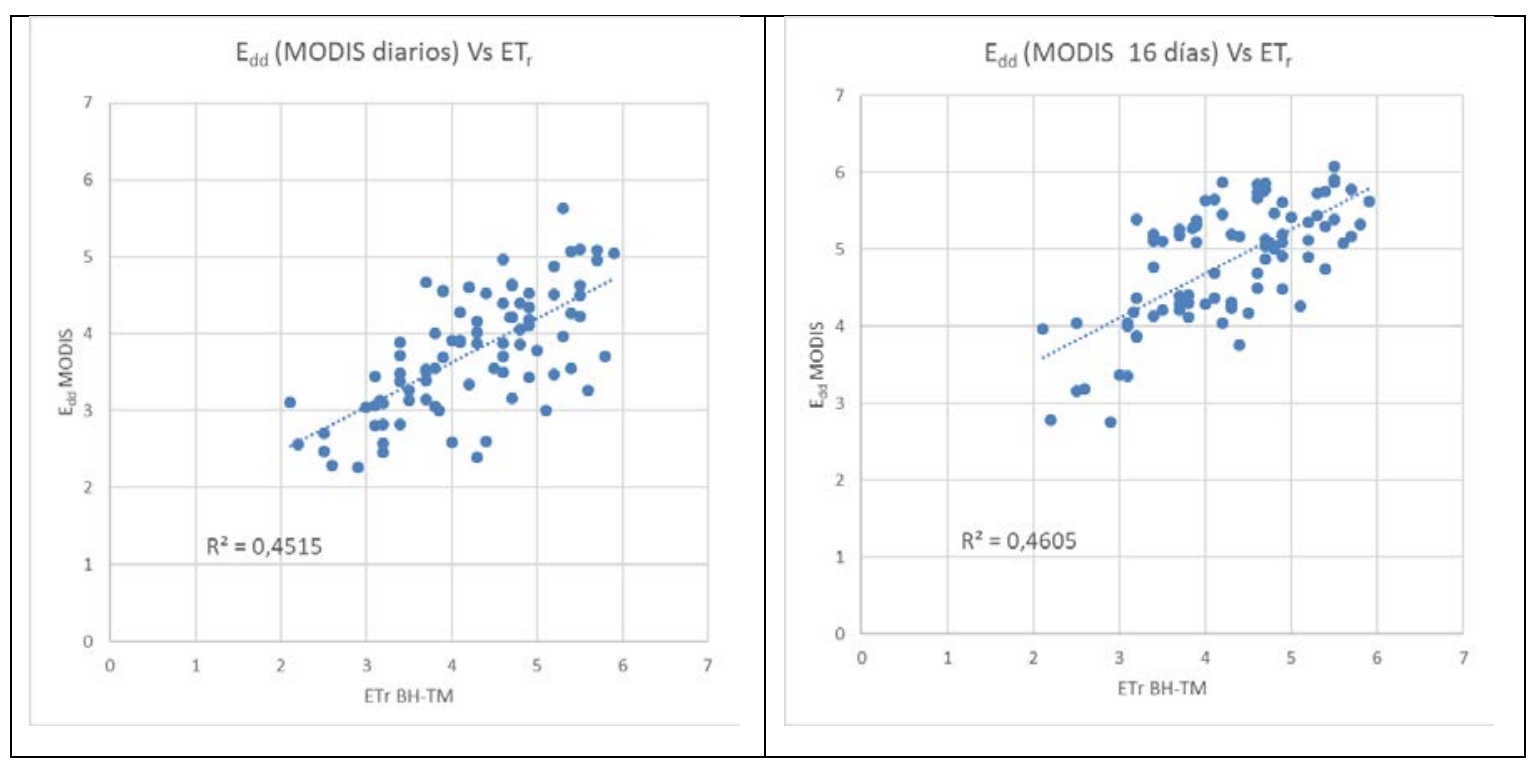

GRÁFICO 6. 11: REGRESIÓN LINEAL - TODAS LAS ESTACIONES METEOROLÓGICAS Y TODOS LOS DÍAS $E_{\mathrm{DD}}$ (DIARIO Y 16 DÍAS) VS ET

Los datos que pertenecen al gráfico 6.11 se encuentran en el Anexo I.

A fin de poder aceptar estos valores de $\mathrm{R}^{2}$ para la condición de día despejado y la condición real, se realizó una prueba de significancia del coeficiente de correlación (R) 
de Pearson usando la función cor.test() del software R, (Team, 2017) y los resultados aparecen en la tabla 6.10 .

\begin{tabular}{|c|c|c|c|}
\hline Testigo $\left(\mathrm{ET}_{\mathrm{r}}\right) \mathbf{V s}$ & $\boldsymbol{R}$ & Valor $-\boldsymbol{p}$ & $\begin{array}{c}\text { 95\% intervalo } \\
\text { de confianza }\end{array}$ \\
\hline $\mathrm{ET}_{\mathrm{dr}}$ diario & 0,502 & $2,942 \times 10^{-7}$ & $0,344-0,656$ \\
\hline $\mathrm{ET}_{\mathrm{dr}} \mathbf{1 6}$ dias & 0,517 & $2,916 \times 10^{-7}$ & $0,348-0,659$ \\
\hline $\mathrm{ET}_{\mathrm{dd}}$ diario & 0,672 & $1,045 \times 10^{-12}$ & $0,537-0,773$ \\
\hline $\mathrm{ET}_{\mathrm{dd}} \mathbf{1 6}$ dias & 0,679 & $5,09 \times 10^{-13}$ & $0,546-0,778$ \\
\hline
\end{tabular}

TABLA 6. 10: TEST DE SIGNIFICANCIA PARA R. ET $T_{R} V S E_{D R}$ Y $E_{R} V S E_{D D}$ DIARIO Y 16 DÍAS

Este tipo de test consiste en probar la hipótesis nula ( $\sin$ asociación. $\mathrm{R}=0$ ). Los valores de "p" obtenidos permiten descartar dicha hipótesis y aceptar la hipótesis alternativa (sí hay asociación. $R \neq 0$ ). No obstante, los valores de "p" son muy bajos, por lo que se observa también el intervalo de confianza, quien permite ver que existe asociación, aunque el mismo es bastante amplio en todos los casos.

Por otra parte, se realizó un análisis de sensibilidad con el paquete pse versión 0.4.7. (Chalom y Lopez de Prado, 2017) del software R, versión 3.5.2 (Team, 2018) para observar la influencia que tienen las variables del modelo, considerando sus distribuciones empíricas, sobre las predicciones. Debido a que las variables son muchas, solo se trabajó con los 5 parámetros que componen la ecuación 4.8 ( $F, \gamma, \Delta, R n$ y G). Para realizar la búsqueda y ajuste de funciones de distribución empírica se utilizó el paquete fitdistrplus del software R, versión 1.0.11 (Delignette-Muller y Dutang, 2015). El análisis de sensibilidad se realizó simulando 300 muestras distribuidas sobre el espacio de los parámetros. La concordancia entre dos corridas con diferente número de muestras fue de 0.88 , indicando que 300 es un número adecuado para las mismas.

Los resultados de dicho análisis muestran que las predicciones del modelo $\left(\mathrm{ET}_{\mathrm{i}}\right)$ son altamente sensibles a cambios en los valores de $\mathrm{F}$ y que dicho efecto es de signo positivo, posiblemente causado por la alta dispersión de los valores típicos de $\mathrm{F}$, hecho que puede ser explicado dado que es el factor más difícil de estimar.

Por otra parte, los parámetros $\Delta \mathrm{y}$ Rn presentan efectos positivos leves. Mientras que $\mathrm{G}$ tiene un impacto negativo y pequeño sobre las predicciones, lo cual es propio de una energía que es restada de la Rn. Por último, $\gamma$ no modifica a ET. 
Lo explicado en el párrafo anterior puede apreciarse en el gráfico 6.12 de correlaciones parciales (PRCC), que muestra la correlación entre cada parámetro del modelo y los valores predichos de $\mathrm{ET}_{\mathrm{i}}$ descontando el efecto de las otras variables.

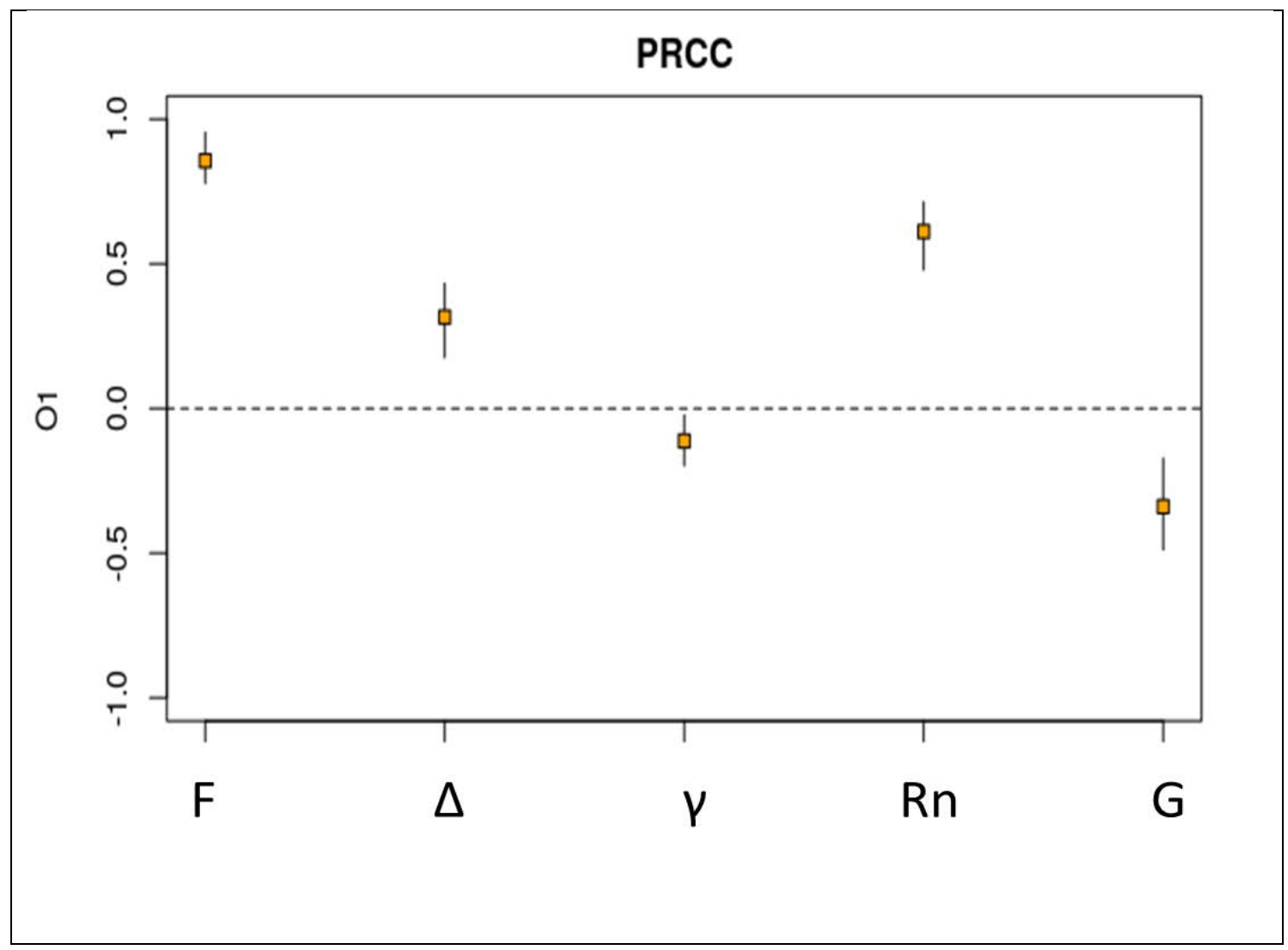

GRÁFICO 6. 12: PRCC PARA LOS 5 PARÁMETROS QUE COMPONEN LA ECUACIÓN 4.8

Estos valores estadísticos, se consideran aceptables teniendo en cuenta que la $\mathrm{ET}_{\mathrm{r}}$ se calculó para una situación puntual, con cobertura vegetal completa, libre de enfermedades, mientras que, para la estimación de la $E_{\mathrm{rd}}$, las condiciones sanitarias y de cobertura son propias del lugar y del momento de estudio. Además, el pasaje a la condición de nubosidad existente se asocia a un conjunto de imágenes satelitales que son factibles de conseguir desde $15^{\prime}$ a $30^{\prime}$ como mínimo, mientras que la nubosidad puede variar con intervalos de tiempo muchísimo menor.

Asimismo, cabe señalar que los datos satelitales MODIS de presión atmosférica, $\mathrm{T}_{\mathrm{a}} \mathrm{y}$ de $\mathrm{T}_{\mathrm{d}}$, son promedios areales de píxeles de $5 \mathrm{~km}$ de lado. Puesto que los restantes datos satelitales tienen mejor resolución ( $1 \mathrm{Km}$ o menos de lado del píxel) y a fin de no perder resolución, hemos supuesto que la presión atmosférica y las temperaturas $T_{a}$ y $T_{d}$ son homogéneas en todo el píxel de $25 \mathrm{Km}^{2}$. Con esta suposición hemos obtenido estimaciones satelitales de evapotranspiración en píxeles de $1 \mathrm{~km}^{2}$. 
A su vez, los valores de temperatura que se obtuvieron a $950 \mathrm{hPa}$ debieron ser corregidos con un gradiente térmico teórico.

Por otra parte, los valores de $E_{\mathrm{dr}}$ para ambos grupos de productos MODIS utilizados estuvieron dentro del rango de los $0 \mathrm{~mm} /$ día y $7 \mathrm{~mm} /$ día. Estos rangos son similares a los hallados por otros autores, aunque con técnicas y en regiones diferentes, como es el cado de Murillas Rayo y Lordoño Cruz (2015) en Chile, con valores que oscilan entre 0,5 y $6 \mathrm{~mm} /$ día; Bastiaanssen (2000) en Turquía, con valores que entre 0 a los 5,2 mm/día; Tsouni (2008) en Grecia, cuyos rango de valores obtenidos fue entre 0 y 8 mm/día y Castañeda (2013) en México, con valores que ondearon entre 1 a 6 mm/día. Aquellos autores que trabajaron dentro de la misma región de estudio, generalmente, lo hicieron en sitios determinados y para coberturas de suelo homogéneas, obteniendo valores también similares. Siendo el caso Serio (2015) que trabajó sobre el ciclo del maíz en Balcarce, Provincia de Buenos Aires y los valores de $E_{\mathrm{dr}}$ rondan entre 1,5 y 8 mm/día; el trabajo de Marini et al. (2017) en el sudeste de la provincia de Buenos Aires, con valores que rondaron los 1 y 4 mm/día para enero de 2011 .

También se puede nombrar el caso de Carmona y Rivas (2011) que trabajaron en Tandil, Provincia de Buenos Aires, sobre cultivo de soja y pastura para marzo de 2007, pero, expresando la evapotranspiración real como flujo de calor latente en $\mathrm{W} / \mathrm{m}^{2}$. Como también, Righetti y Gassmann (2013), que trabajaron sobre el cultivo de trigo en el Sudoeste de la región pampeana y expresando la evapotranspiración como flujo de calor latente en $\mathrm{W} / \mathrm{m}^{2}$, obteniendo como valor promedio para enero de $334.8 \mathrm{~W} / \mathrm{m}^{2}$.

Recordando las hipótesis:

2. La evapotranspiración diaria en condiciones de cielo despejado puede estimarse a partir de la radiación neta diaria sobre la misma superficie evaporante.

3. La disminución de la evapotranspiración diaria (para condiciones de cielo despejado), debido a la nubosidad puede determinarse con la ayuda de imágenes sucesivas del satélite geoestacionario GOES-Este a lo largo del período diurno.

Los resultados hasta aquí discutidos (que incluyen los datos de los anexos I y II), permiten admitir las mismas, teniendo en cuenta las salvedades antedichas. 


\section{Capítulo 7. Conclusiones}

Luego del exhaustivo análisis expuesto en los capítulos previos, arribamos a las siguientes conclusiones:

1. La tasa de evapotranspiración instantánea pudo estimarse bajo la forma de flujo de calor latente según la metodología ofrecida en esta tesis, que consiste en la combinación de lo propuesto por Venturini y Girolimeto, y la modificación del cálculo del parámetro $\Omega$ como indicador de la disponibilidad de agua en la franja radicular del suelo.

2. La evapotranspiración diaria como flujo de calor latente pudo estimarse a partir de la radiación neta acumulada diurna, bajo condiciones de cielo despejado.

3. La evapotranspiración real diaria (en condiciones reales de nubosidad) como flujo de calor latente acumulado durante el período diurno, pudo estimarse a partir de la respectiva radiación neta, observando la disminución de la $\mathrm{ET}_{\mathrm{dd}}$ al ser transformada en $\mathrm{ET}_{\mathrm{dr}}$. $\mathrm{Al}$ expresarla como tasa en $\mathrm{mm} /$ día $\left(E_{\mathrm{dr}}\right)$ fue posible compararla con la $\mathrm{ET}_{\mathrm{r}}$ obtenida del BH-TM

4. Al contrastar los valores estimados de $E$ con los calculados para la $\mathrm{ET}_{\mathrm{r}} \mathrm{BH}-\mathrm{TM}$, ya sea para la condición de cielo despejado o bien con la corrección por nubosidad, se considera buena dadas las diferencias, de resolución espacial y de las condiciones de cobertura, sanidad y cobertura de la vegetación que existen entre las dos metodologías.

5. En función de lo concluido hasta aquí, podemos decir que, es factible de estimar la evapotranspiración acumulada diurna a partir de imágenes MODIS-GOES.

\subsection{Comentarios}

Una limitación importante de la técnica empleada es que usa productos MODIS de temperatura que están disponibles en niveles de presión atmosférica muy distanciados entre sí: $1000 \mathrm{hPa}$ y $950 \mathrm{hPa}$. Cuando la superficie tiene una presión menor que 1000 $\mathrm{hPa}$ solo se dispone de los valores a $950 \mathrm{hPa}$, nivel que está situado a alturas entre 550 $\mathrm{m}$ a $600 \mathrm{msnm}$, lejos de los niveles del terreno en la llanura bonaerense. Esto introduce una fuente importante de error en la estimación satelital. Sin embargo, es altamente 
probable que en el futuro próximo se pueda disponer de sondeos satelitales de la atmósfera con mayor resolución vertical.

La alternativa a esta situación es corregir los valores de temperatura de los sondeos según la diferencia métrica a la superficie con modelos digitales de elevación (DEMs). Teniendo presente que aproximadamente la variación vertical de temperatura troposférica es de $6,5^{\circ} \mathrm{C}$ por $\mathrm{Km}$.

Por otro lado, el pasaje de $\mathrm{ET}_{\mathrm{i}}$ a $\mathrm{ET}_{\mathrm{dd}}$ trae aparejado un error intrínseco y al pasar a $\mathrm{ET}_{\mathrm{dr}}$ con las imágenes GOES, se generan mayores diferencias al tomar un cielo nublado/despejado por intervalos y no continuo como lo es en la realidad.

\subsection{Consideraciones finales}

A partir de lo expuesto hasta aquí, y considerando que este trabajo es una tesis en Geomática que pretende mostrar la posibilidad de usar herramientas de teledetección para la estimación de la evapotranspiración, se considera entonces que es posible estimar la tasa de evapotranspiración real en $\mathrm{mm} /$ día $\left(E_{\mathrm{rd}}\right)$ a nivel regional utilizando únicamente información remota. Esto permite tener una aproximación de la demanda hídrica de la vegetación a nivel regional de manera rápida y sencilla.

En cuanto al proceso físico compuesto de la ET, queremos mostrar que es posible estimarlo, pero no pretendemos obtener una excelente validación cuantitativa pues no contamos con datos suficientes.

Este esquema de estimación totalmente remota que se propone en esta tesis, con algunas mejoras, podría ser utilizado por los servicios meteorológicos y agropecuarios para brindar, en forma operativa y en tiempo cuasi-real, información regional de la evapotranspiración a múltiples usuarios. 


\section{Capítulo 8. Tabla de abreviaturas}

BH-TM: Balance hidrológico de Thornthwaite - Mather

C-C: Ecuación de Clausius-Clapeyron

CC: Capacidad de campo de los suelos

$\mathrm{C}_{\mathrm{p}}$ : calor específico del aire a presión constante.

día $a_{\text {corr }}$ Cantidad de días corridos desde el 21 de diciembre anterior

$\mathrm{e}_{\mathrm{a}}^{*}$ : Presión de vapor de saturación del aire

$\mathrm{e}_{\mathrm{a}}$ : Presión de vapor del aire.

$E_{\mathrm{dd}}$ : Evapotranspiración diaria para cielo despejado en $\mathrm{mm} /$ día

$E_{\mathrm{dr}}$ : Evapotranspiración diaria real en $\mathrm{mm} /$ día

EF: Fracción evaporable

$\mathrm{e}_{\mathrm{s}}^{*}$ : Presión de vapor de saturación de la superficie

$\mathrm{e}_{\mathrm{s}}$ : Presión de vapor de la superficie

$\mathrm{e}_{\mathrm{sf}}$ : Presión de vapor de saturación del agua a la temperatura de congelación del agua

ET: Evapotranspiración

$\mathrm{ET}_{0}$ : Evapotranspiración de Referencia

ET $_{\mathrm{c}}$ : Evapotranspiración del Cultivo

$\mathrm{ET}_{\mathrm{d}}$ : Evapotranspiración diaria

$\mathrm{ET}_{\mathrm{dd}}:$ Evapotranspiración diaria para días despejados

$\mathrm{ET}_{\mathrm{dr}}:$ Evapotranspiración diaria real

$\mathrm{ET}_{\mathrm{f}}$ : Evapotranspiración expresada como flujo de calor latente de vaporización

$\mathrm{ET}_{\mathrm{i}}$ : Evapotranspiración instantánea

$\mathrm{ET}_{\mathrm{p}}$ : Evapotranspiración potencial

$\mathrm{ET}_{\mathrm{r}}$ : Evapotranspiración real

$\mathrm{ET}_{\mathrm{w}}$ : Tasa de evapotranspiración cuando $\mathrm{ET}_{\mathrm{r}}=\mathrm{ET}_{\mathrm{P}}$

F: Evapotranspiración relativa

G: Flujo de calor del suelo

$\mathrm{G}_{\mathrm{dd}}$ : Flujo de calor del suelo diario para cielo despejado

$\mathrm{G}_{\mathrm{dr}}$ : Flujo de calor del suelo diario para cielo con nubosidad

$\mathrm{H}$ : Flujo de calor sensible

$\mathrm{K}_{\mathrm{c}}$ : coeficiente del cultivo

P: Presión atmosférica 
PMP: Punto de marchitez permanente de los suelos

$\mathrm{r}_{\mathrm{a}}$ : Resistencia del aire al transporte vertical del vapor de agua, relacionada con la difusividad turbulenta.

$r_{c}$ : Resistencia de la superficie al transporte vertical de vapor que opone el suelo.

Rn: Radiación neta

$\mathrm{Rn}_{\text {_diaria: }}$ Radiación neta diaria

$\mathrm{Rn}_{\mathrm{dd}}$ : Radiación neta diaria para cielo despejado

$\mathrm{Rn}_{\mathrm{d}-\mathrm{Real}}$ : Radiación neta diaria real

$\mathrm{Rn}_{\mathrm{i}}$ : Radiación neta instantánea

$\mathrm{Rn}_{\max }$ : Radiación neta máxima durante un día

Roce: Radiación de onda corta entrante

Role: Radiación de onda larga entrante

Rols: Radiación de onda sarga saliente

Rr: Radiación Relativa

Rv: Constante de los gases para el vapor del agua

$\mathrm{s} / \mathrm{d}$ : $\sin$ dato

$\mathrm{S}_{0}$ : Constante solar en el tope de la atmósfera

S-B: Ley de Stefan-Boltzman

Ss: Superficie saturada. En suelo, la saturación implica saturado de agua líquida, mientras que en atmósfera la saturación implica saturado de vapor de agua.

$\mathrm{t}(-)$ :Hora local donde la $\mathrm{Rn}$ se vuelve negativa

$\mathrm{t}(+)$ : Hora local donde la Rn se vuelve positiva

$\mathrm{T}_{0}$ : Temperatura aerodinámica

$\mathrm{T}_{\mathrm{a}}$ : Temperatura del aire

$\mathrm{T}_{\mathrm{d}}$ : Temperatura de rocío

$\mathrm{T}_{\mathrm{f}}$ : Temperatura de fusión en CNPT

$\mathrm{T}_{\mathrm{s}}$ : Temperatura de superficie

tv: Hora de visita del satélite

$f_{\mathrm{u}}$ : es una función del viento

PSV-T: Curva de presión de saturación de vapor-temperatura

$\alpha$ : Albedo

$\alpha \mathrm{PT}$ : Constante de Priestley-Taylor

$\beta$ : Relación de Bowen 
$\gamma$ : Constante psicrométrica.

$\Delta:$ Pendiente de la ecuación de presión de vapor saturante de Clausius-Clapeyron.

$\lambda$ : Flujo de calor latente de vaporización

$\xi_{\mathrm{a}}$ : Emisividad del aire

$\xi_{\mathrm{s}}$ : Emisividad de la superficie

$\rho$ : Densidad del aire.

$\rho_{\mathrm{w}}$ : Densidad del agua

$\sigma:$ Constante de Stefan-Boltzman

$\sigma_{\mathrm{cs}}:$ Ángulo cenital solar

$\tau_{\mathrm{sw}}$ : Factor de transmisividad de la atmósfera

$\Omega$ : Relación entre presión parcial de vapor y la presión parcial de vapor de saturación. 


\section{Capítulo 9. Bibliografía citada}

1. Allen, R.G., Pereira, L.S., Raes, D. and Smith, M. (1998). Crop Evapotranspiration - Guidelines for Computing Crop Water Requirements. FAO Irrigation \& Drainage Paper 56. FAO.

2. Barton, I. J. (1979). A parameterization of the evaporation from nonsaturated surfaces. Journal of Applied Meteorology, 18, 43-47.

3. Bastiaanssen, W. G. (2000). SEBAL - based Sensible and Latent Heat Fluxes in the Irrigated Gediz Basen, Turkey. Journal of Hydrology, 229 (1), 87-100p.

4. Bastiaanssen, W. G., Ahmad, M. U. D. and Chemin, Y. (2002). Satellite surveillance of evaporative depletion across the Indus Basin. Water Resources Research, 38(12).

5. Bisht, G., Venturini, V., Jiang, L. and Islam, S., (2005). Estimation of net radiation using MODIS (Moderate Resolution Imaging Spectroradiometer) Terra Data for clear sky days, Remote Sensing of Environment, vol. 97, pp. 5267.

6. Boegh, E., Soegaard, H. and Thomsen, A. (2002). Evaluating evapotranspiration rates and surface conditions using Landsat TM to estimate atmospheric resistance and surface resistance. Remote Sensing of Enronment, 79, 329-343

7. Boegh, E., and Søgaard, H. (2004). Remote sensing based estimation of evapotranspiration rates. International Journal of Remote Sensing, 25(13), $2535-2551$. 
8. Bouchet, R.J. (1963). E' vapotranspiration re'elle et potentielle, signification climatique. In Symposium on Surface Waters . IAHS Publication No.62. IAHS Press: Wallingford; $134-142$.

9. Brunt, D. (1932). Notes on radiation in the atmosphere. I. Quarterly Journal of the Royal Meteorological Society, 58, 389-420.

10. Brutsaert, W. (1984). Evaporation into the atmosphere. Theory history an applications. Reidel Publishing Company (eds), Dordrecht.

11. Brutsaert, W. and El-Kadi, A. I. (1984). The relative importance of compressibility and partial saturation in unconfined groundwater flow. Water Resources Research, 20(3), 400-408.

12. Brutsaert, W. and Sugita, M. (1992). Application of self-preservation in the diurnal evolution of the surface energy budget to determine daily evaporation. Journal of Geophysical Research: Atmospheres, 97(D17), 1837718382.

13. Brutsaert, W. and Chen, D. (1996). Diurnal variation of surface fluxes during thorough drying (or severe drought) of natural prairie. Water Resources Research, 32, 2013-2019.

14. Carmona, F., y Rivas, R. (2011). Estimación de la evapotranspiración real mediante datos meteorológicos e imágenes de satélite. Teledetección: Recientes aplicaciones en la región Pampeana, capítulo 5, pp 83-101. ISBN 978-987-543443-1. Buenos Aires-Argentina.

15. Castañeda, C. R. (2013). Estimación de la evapotranspiración mediante un balance de energía utilizando sensores remotos. Tesis para optar el título de Maestro en Ciencias. Montexillo, México: Institución de enseñanza e investigación de Ciencias Agrícolas. 
16. Ceccato, P., Flasse, S., Tarantola, S., Jacquemoud, S. and Gregoire, J.M. (2001). Detecting vegetation leaf water content using reflectance in the optical domain, Remote Sensing of Environment, vol. 77, pp. 22-33.

17. Chalom A. and Lopez de Prado P.I. (2017). pse: Parameter Space Exploration with Latin Hypercubes. $\mathrm{R}$ package version 0.4.7. https://CRAN.Rproject.org/package $=$ pse

18. Chen, D., Huang, J. and Jackson, T. (2005). Vegetation water content estimation for corn and soybeans using spectral indices derived from MODIS near-and short-wave infrared bands, Remote Sensing of Environment, vol. 98, pp. 225236

19. Chuvieco, E. (2002). Teledetección ambiental: la observación de la tierra desde el espacio. Editorial Ariel. 586p. ISBN: 978-84-344-8032-8

20. Coll, C., and Caselles, V. (1997). A split-window algorithm for land surface temperature from advanced very high resolution radiometer data: validation and algorithm comparison. Journal of Geophysical Research: tmospheres,102(D14), 16697-16713.

21. Crago, R. D. and Brutsaert, W. (1996). Conservation and variability of the evaporative fraction during the daytime. Journal of Hydrology, 180, 173-194.

22. Crago, R. and Crowley, R. (2005). Complementary relationships for nearinstantaneous evaporation. Journal of Hydrology, 300, 199-211.

23. Crago, R., Hervol, N. and Crowley R. (2005). A complementary evaporation approach to the scalar roughness length. Water Resources Research, 41, W06017, ISSN 0043-1397.\} 
24. Delignette-Muller, M. L. and Dutang, C. (2015). fitdistrplus: An R Package for Fitting Distributions. Journal of Statistical Software, 64(4), 1-34. URL http://www.jstatsoft.org/v64/i04/.

25. Díaz, R.A. y Rébori, M.G. (2003). Intercepción de la lluvia en un monte de Eucalyptus dunnii. XII Congreso Forestal Mundial, Quebec City, Canadá. 6 p.

26. Doorenbos, J., and W. O. Pruitt. Crop water requirement. Rome: FAO, 1977. 144p." Irrigation and Drainage Paper 24 (1977).

27. Flatau, P. J., Walko, R. L. and Cotton, W. R. (1992). Polynomial fits to saturation vapor pressure. Journal of Applied Meteorology, 31(12), 1507-1513.

28. Foken, T. (2008). The energy balance closure problem: an overview. Ecological Applications, 18(6), 1351-1367.

29. FAO, 1992. Evapotranspiración del cultivo. Guías para la determinación de los requerimientos de agua de los cultivos. Serie FAO RIEGO Y DRENAJE, Publicación Nro. 56. ISSN 0254-5293 ISBN 92-5-304219-2.

30. Friedl, M. (2002). Forward and inverse modeling of land surface energy balance using surface temperature measurements. Remote Sensing of Envirenment, 79, 344-354.

31. García-Mora, T. J. y Mas, J. F. (2010). Evaluación de Imágenes del Sensor MODIS para la Cartografía de la Cobertura del Suelo en una Región Altamente Diversa de México. Boletín de la Sociedad Geológica Mexicana, 63 (1): 83-94.

32. Girolimetto, D. and Venturini, D. (2014). Evapotranspiration and water stress estimation from TIR and SWIR bands. Agriculture, Forestry and Fisheries, 3(16), $36-45$. 
33. Granger, R. J. (1989a). A complementary relationship approach for evaporation from nonsaturated surfaces. Journal of Hydrology, 111, 31-38.

34. Granger, R. J. (1989b). An examination of the concept of potential evaporation. Journal of Hydrology 111: 9 - 19.

35. Granger, R. J. and Gray, D. M. (1989). Evaporation from natural non saturated surfaces. Journal of Hydrology, 111, 21-29.

36. Han, S., Hu, H., Yang, D. and Tian, F. (2011). A complementary relationship evaporation model referring to the Granger model and the advection-aridity model. Hydrological Processes, 25(13), 2094-2101.

37. Hunt, E.R., Rock, B.N. and Nobe,1 P.S. (1987). Measurement of leaf relative water content by infrared reflectance, Remote Sensing of Environment, Vol. 22, pp. 429-435.

38. Huntington, J. L., Szilagyi, J., Tyler S. W. and Pohll G. M. (2011). Evaluating the complementary relationship for estimating evapotranspiration from arid shrublands. Water Resources Research, 47(5).

39. Hurtado, E. and Sobrino, J. A. (2001). Daily net radiation estimated from air temperature and NOAA-AVHRR data: A casestudy for the Iberian Peninsula. International Journal of Remote Sensing, 22 (8). 1521-1533p.

40. Idso, S., Jackson, R. and Reginato, R. (1975). Estimating evaporation: a technique adaptable to remote sensing. Science. 189: 991-992.

41. Ibáñez, M. y Caselles, V. (1999). Evapotranspiración estimada a partir de la temperatura radiativa: 1. Métodos aerodinámico y de la razón de Bowen radiativa. Revista de teledetección, 11, 1-5. 
42. Islam, K., Singh, B. and McBratney, A. (2003). Simultaneous estimation of several soil properties by ultra-violet, visible, and near-infrared reflectance spectroscopy. Soil Research, 41(6), 1101-1114.

43. Islam, S., Jiang, L. and Eltahir, E. (2003). Satellite based evapotranspiration estimates. Final Project report: South Florida Water Management District September 2003.

44. Jackson, R. D., Hatfield, J. L., Reginato, R. J., Idso, S. B. and Pinter, P. J. (1983). Estimation of daily evapotranstpiration from one-time-of-day measurements. Agricultural Eater Management, 7, 351-362.

45. Jacobs, J. M., Myers, D. A., Anderson, M. C. and Diak, G. R. (2000). GOES surface insolation to estimate wetlands evapotranspiration, Journal of Hydrology, 266, 53-65p.

46. Jarvis, P. G., \& McNaughton, K. G. (1986). Stomatal control of transpiration: scaling up from leaf to region. In Advances in ecological research (Vol. 15, pp. 1-49). Academic Press.

47. Jia, L., Xi G., Liu, S., Huang, C., Yan, Y. and Liu, G. (2009). Regional estimation of daily to annual regional evapotranspiration with MODIS data in the Yellow River Delta wetland. Hydrology and Earth System Sciences, 13, 1 $775-1787$.

48. Jiang, L., Islam, S., Guo, W., Jutla, A. S., Senarath, S. U., Ramsay, B. H. and Eltahir, E. (2009). A satellite-based daily actual evapotranspiration estimation algorithm over South Florida. Global and Planetary Change, 67(1), 62-77.

49. Kalluri, V., Townshend, J. \& Doraiswamy, P., 1998. A simple single layer model to estimate transpiration from vegetation using multi-spectral and meteorological data. International Journal of Remote Sensing, 19, pp.1037-53. 
50. Knaeps, E., Dogliotti, A. I., Raymaekers, D., Ruddick, K., and Sterckx, S. (2012). In situ evidence of non-zero reflectance in the OLCI 1020nm band for a turbid estuary. Remote Sensing of Environment, 120, 133-144.

51. Lagouarde, J. P. and Brunet, Y. (1993). A simple model for estimating the daily upward longwave surface radiation flux from NOAA-AVHRR data. International Journal of Remote Sensing, 14(5), 907-925.

52. Liang, S., Fang H., Chen, M., Shuey, C. J., Walthall, C. L., Daughtry, C.S.T., Morisette, J.T., Schaaf, C. B. and Strahler, A. H. (2002). Validating MODIS land surface reflectance and albedo products: methods and preliminary results. Remote Sensing of Environment, 83 (1-2): 149-162p.

53. Lobell, D. B. and Asner, G. P. (2002). Moisture effects on soil reflectance. Soil Science Society of America Journal, 66(3), 722-727.

54. Lucht, W., Schaaf, C. B. and Strahler, A. H. (2000). An Algorithm for the retrieval of albedo from space using semiempirical BRDF models, IEEE Trans. Geosci. Remot Sens., 38:977-998p.

55. Marini, F., Santamaría, M., Oricchio, P., di Bella, C. M. y Basualdo, A. (2017). Estimación de la evapotranspiración real (ETR) y de evapotranspiración potencial (ETP) en el sudoeste bonaerense (Argentina) a partir de imágenes MODIS. Revista de Teledetección. AET. ISSN 1133-0953. EISSN1988-8740. 48: 29-41p.

56. Moran, M.S., Jackson, R. D., Raymond, L. H.; Gay, L. W. and Slater, P.N. (1989). Mapping surface energy balance components by combining LandSat thematic mapper and groundbased meteorological data, Remote Sensing of Environment, 30: 77-87. 
57. Moran, M., Clarke, T.R.; Inoue, Y. and Vidal, A. (1994). Estimating crop water deficit using the relation between surface-air temperature and spectral vegetation index. Remote Sensing of Environment. $N^{\circ} 49$, p. 246-263.

58. Monteith, J. L. (1965). Evaporation and Environment. 19th Symposia of the Society for Experimental Biology, University Press, Cambridge, 19:205-234.

59. Monteith, J. L., 1973. Principles of Environmental Physics. American Elsevier, New York, 243 pp.

60. Monteith, J. L. (1981). Evaporation and surface temperature. Quart. J. Roy. Meteorol.Soc. 107:1-27.

61. Monteith, J. L. (1985). Evaporation from land surfaces: progress in analysis and prediction since 1948. pp. 4-12 in Advances in Evapotranspiration, Proceedings of the ASAE Conference on Evapotranspiration, Chicago, Ill. ASAE, St. Joseph, Estados Unidos de America.

62. Mulleady, C. (2011). Estimación de la evapotranspiración en escala regional, basada en percepción remota. Tesis de Licenciatura en Ciencias de la Atmósfera, UBA.

63. Mulleady, C. y Barrera, D., 2013: Estimación de la tasa de evapotranspiración a partir de datos satelitales MODIS. Meteorologica, 38(1), 21-40. ISSN 0325187X y 1850-460X. http://www.cenamet.org.ar/archivos/Vol38-Nro1-2013.pdf (en línea)

64. Murillas Rayo, A. and Londoño Cruz, E. A. (2015). Estimación de la evapotranspiración en cultivos de arroz con sensores remotos. Tesis doctoral, Universidad de PIPICUCU. 
65. Nemani, R.R. and Running, S.W., 1989. Estimation of regional surface resistance to evapotranspiration from NDVI and Thermal-IR AVHRR data. Journal of Applied Meteorology, 28, pp.276-84.

66. Nemani, R., Pierce, L., Running, S. \& Band, L., 1993. Forest ecosystem processes at the watershed scale: sensitivity to remotely-sensed leaf area index estimates. International Journal of Remote Sensing, 14, pp.2519-34.

67. a - Niemelä, S., Räisänen, P. and Savijärvi, H. 2001. Comparison of surface radiative flux parameterizations: Part I. Longwave radiation. Atmospheric Research, 58, 1-18p.

68. b - Niemelä, S., Räisänen, P. and Savijärvi, H. 2001. Comparison of surface radiative flux parameterizations: Part II. Shortwave radiati. Atmospheric Research, 58, 141-154p.

69. Nishida, K., Nemani, R. R., Running, S. W., and Glassy, J. M. (2003). An operacional remote sensing algorithm of land evaporation. Journal of Geophysical Research, 108(D9), 4270.

70. Norman, J. M., Anderson, M. C. Kustas, W. P., French, A. N., Mecikalski, J. and Torn, R. (2003). Remote sensing of surface energy fluxes at 101-m pixel resolutions, Water Resources Research, vol. 39, Issue 8, pp. 1221-1232.

71. Prata, A. J. (1996). A new long-wave formula for estimating downward clearsky radiation at the Surface. Quartely Journal of the Royal Meteorological Society, $122,1127-1151$.

72. Penman H. L. (1948). Natural evaporation from open water, bare and grass. Proceedings of the Royal Society of London, Series A: Mathematical, Physical and Engineering Sciences 193: $12 \mathrm{O}-145$. 
73. Priestley C. H. B. and Taylor R. J. (1972). On the assessment of surface heat fluxes and evaporation using large-scale parameters. Monthly Weather Review 100: $81-92$.

74. Righetti, S., y Gassmann, M. I. (2013). Balance de energía sobre una superficie cultivada en el sudeste de la provincia de Buenos Aires. Meteorologica, 38(2), 91-104.

75. Rivas, R. and Caselles, V. (2004). A simplified equation to estimate spatial reference evaporation from remote sensing-based surface temperature and local meteorological data. Remote Sensing of Environment, 93(1), 68-76.

76. Rivas, R. E. (2005). Propuesta de un modelo operativo para la estimación de la evapotranspiración. Tesis Doctoral. Universitad de Valencia. 142 Pp.

77. Román, M. O., Schaaf, C. B., Woodcock, C. E., Strahler, A. H., Yang, X., Braswell, R. H., Curtis, K. J., Dragoni, D., Goulden, M. L., Gu, L., Hollinger, D. Y., Kolb, T. E., Meyers, T. P., Munger, J. W., Privett, J. L., Richardson, A. D., Wilson, T. B. and Wofsy, S. C. (2009). The MODIS (Collection V005) BRDF/ albedo product: Assessment of spatial representativeness over forested landscapes, Remote Sensing of Environmento, 113: 2476-2498.

78. Rubio, E., Caselles, V. and Badenas, C. (1997). Emissivity measurements of several soils and vegetation types in the 8-14, $\mu m$ Wave band: Analysis of two field methods. Remote Sensing of Environment, 59(3), 490-521.

79. Sadeh, E., (2002). A failure of international space cooperation: the International Earth Observing System, Space Policy, 18 (2): 135-150p.

80. Sánchez, M. y Chuvieco, E. (2000). Estimación de la evapotranspiración del cultivo de referencia, ETO, a partir de imágenes NOAA-AVHRR. Revista de Teledetección, 14, 11-21. 
81. Serio, L. A. (2015). Desarrollo y validación de un modelo del sistema sueloplanta-atmósfera para la estimación de la evapotranspiración real del cultivo de maiz (Doctoral disertación, Facultad de Ciencias Exactas y Naturales. Universidad de Buenos Aires).

82. Shuttleworth, W. J. and Wallace, J. S. (1985). Evaporation from sparse crops an energy combination theory. Quart. J. Roy Meteorol. Soc. 111: 839-853. Quarterly Journal of the Royal Meteorological Society, 111(469), 839-855.

83. Shuttleworth, W., Gumer, R., Hsu, A. and Omsby, J. (1989). FIFE: the variation in energy portioning at surface flux sities, remote sensing and large scale global processes. International Association of Hydrological Sciences, 186(4), pp.67-74.

84. Sobrino, J. A. ande Caselles, V. (1992). A field method for measuring the termal infrared emissivity. ISPRS J. Photogramm. Remote Sensing (forth coming).

85. Stull R. B. (1988) An Introduction to Boundary Layer Meteorology. Kluwer Academic Pub. 666 pp.

86. Tanré, D., C. Deroo, P. Duhaut, M. Herman, J.J. Morcrette, J. Perbos y P.Y. Deschamps,1986. Simulation of the Satellite Signal in the Solar Spectrum (5S). Laboratoire d'Optique Atmosphérique, Université des Sciences et Techniques de Lille.

87. Team, R. C. (2017). R: A language and environment for statistical computing. Vienna, Austria. R Foundation for Statistical Computing; 2016.

88. Team, R. C. (2018). R: A language and environment for statistical computing. Vienna, Austria. R Foundation for Statistical Computing URL https://www.Rproject.org/.

89. Thornthwaite, C.W. and J.R. Mather. 1955. The water balance. Publications in Climatology VIII, (1):104 p. Drexel Inst. of Tech., New Jersey. USA. 
90. Tonti N. E., Gassmann M. I., Covi M., Pérez C. F. y Righetti S. A. (2013). Balance de energía sobre un cultivo de soja. Soybean crop energy balance Ciencia y Natura, volumen Especial diciembre 2013, pág. 305-307 ISSN:0100-8307. http://cascavel.ufsm.br/revista_ccne/ojs/index.php/cienciaenatura.

91. Tsouni A., Kontoes C., Koutsoyiannis D., Elias P. and Mamassis N. (2008), Estimation of Actual Evapotranspiration by Remote Sensing: Application in Thessaly Plain, Greece, Sensors, 8(6):3586- 3600.

92. Tucker, C. J. (1980). Remote sensing of leaf water content in the near infrared. Remote sensing of Environment, 10(1), 23-32.

93. Valor, E. and Caselles, V. (1996). Mapping Land Surface Emissivity from NDVI: Appplication to European, African and South American Areas. Remote Sensing of Environment, 57, 167-184p.

94. Van Leeuwen, W. J. D., Huete, A. R. and Liang, T. W. (1999). MODIS Vegetation Index Compositing approach: a prototype with AVHRR data. Remote Sensing of Environment, 69: 264-280.

95. Venturini V.; Islam, S.; Bisht, F. and Rodriguez, L. (2006). Estimation of Evaporative Fraction and Evapotranspiration From Remotely Sensed Data Using Complementary Relationship. Amerucab Meteorological society 86th Annual Meeting and 20th Conference on Hydrology, Atlanta, Georgia, USA. January 29 - February2, 2006.

96. Venturini, V.; Rodríguez, L. e Islam, S. (2007). Metodología para la estimación de la fracción evaporable y la evapotranspiración con productos MODIS. Revista de teledetección. 27, 44-52. 
97. Venturini, V., Islam, S. and Rodríguez, L. (2008). Estimation of evaporative fraction and evapotranspiration from MODIS products using a complemetary based model. Remote Sensing of Environment, 112, 132-141.

98. Venturini, V., Rodriguez, L. and Bisht G. (2011). A comparison among diferente modified Priestley and Taylor equations to calculate actual evapotranspiration with MODIS data. Tnternational Journal of Remote Sensing, 3285), 1319-1338. ISSN 0143-1161. DOI: 10.1080/01431160903547965.

99. Venturini, V.; Krepper, C. and Rodriguez, L. (2012). Evapotranspiration Estimation Base don the Complementary Relationship. Evapotranspiration Remote Sensing and Modeling. A. Irmak Ed, InTech, 19-40.

100. Wan, Z. and Li, Z. L. (2008). Radiance-based validation of the MODIS land-surface temperature product, International Journal of Remote Sensing, 29: 5373-5395.

101. Winter, K. and Smith, J. A. C. (1996). An introduction to crassulacean acid metabolism: biochemical principles and biological diversity. En: Winter K. y Smith J.A.C. Eds. Crassulacean Acid Metabolism. Biochemistry, Ecophysiology and Evolution: 1-13, Springer, Berlín.

102. Xiong, J. (2008). MCST Calibration Information, URL:www.jmcst.ssai.biz/mcst-web/calib/calibration.html

103. Xu, C. Y. and Singh, V. P. (2005). Evaluation of three complementary relationship evapotranspiration models by water balance approach to estimate actual regional evapotranspiration in different climatic regions. Journal of Hydrology, 308(1), 105-121.

104. Yang, X., Zhou, Q. \& Melville, M., 1997. Estimating local sugarcane evapotranspiration using Lansdsat TM image and a VITT concept. International Journal of Remote Sensing, 18, pp.453-59. 
105. Yilmaz M. T, Hunt Jr. E. R., Goins L. D., Ustin S. L., Vanderbilt V. C. and Jackson T. J. (2008). Vegetation water content during SMEX04 from ground data and Landsat 5 Thematic Mapper imagery, Remote Sensing of Environment, vol. 112, pp. 350-362.

106. Zillman, J. W. (1972). A study of some aspects of the radiation and heat budgets of the southem hemisphere oceans. Meteorol. Studyl 26, p 562, Bur. Of Meteorol. Canberra, Australia: Dept. of the Inter.

\section{Páginas web consultadas}
a) http://aa.usno,navy.mil
b) http://modis-atmos.gsfc.nasa.gov/MOD07 L2/format.html
c) http://www.conae.gov.ar/satelites/sac-c/terra/modis.html
d) http://www.goes-r.gov
e) http://www.goes-r.gov/users/comet/goes_r/envmon_es
f) https://lpdaac.usgs.gov/dataset discovery/modis/modis products table
g) http://reverb.echo.nasa.gov
h) http://step.esa.int/main/download/ 


\section{Anexo 1. RESULTADOS - TABLAS}

El presente capítulo muestra los resultados parciales obtenidos:

1. La $\mathrm{Rn}_{\mathrm{i}}$ a partir de imágenes MODIS

2. La ET $i$ a partir de imágenes MODIS

3. La $E_{\mathrm{dd}}$, a partir de la $\mathrm{ET}_{\mathrm{i}}$ al momento de la visita del satélite Terra o Acqua.

Nota: La expresión "s/d" en las siguientes tablas hace referencia a la falta de dato (sin dato). Ello pudo deberse a la presencia de nubes al momento de paso del satélite MODIS, o a la falta de dato del sensor MODIS, o a falta de observaciones en la estación meteorológica correspondiente.

Así mismo, tanto la radiación neta como la evapotranspiración fueron estimadas con productos MODIS diarios y por otra parte con algunos productos de 16 días como el caso del albedo (MOD43) y el NDVI (MOD13).

En las Tablas AI-1 y AI-2 se muestra la evapotranspiración instantánea para productos MODIS diarios y de 16 días respectivamente. 


\begin{tabular}{|c|c|c|c|c|c|c|c|}
\hline \multirow[t]{2}{*}{$\begin{array}{c}\text { Estaciones } \\
\text { Meteorológicas }\end{array}$} & \multicolumn{7}{|c|}{$R n_{i}-$ diario $\mathrm{W} / \mathrm{m}^{2}$} \\
\hline & $\begin{array}{c}4 \text { de } \\
\text { enero }\end{array}$ & $\begin{array}{c}6 \text { de } \\
\text { enero }\end{array}$ & $\begin{array}{c}7 \mathrm{de} \\
\text { enero }\end{array}$ & $\begin{array}{c}8 \mathrm{de} \\
\text { enero }\end{array}$ & $\begin{array}{c}9 \text { de } \\
\text { enero }\end{array}$ & $\begin{array}{l}13 \text { de } \\
\text { enero }\end{array}$ & $\begin{array}{l}19 \text { de } \\
\text { enero }\end{array}$ \\
\hline San Fernando & $s / d$ & 634,83 & $s / d$ & $s / d$ & 694,62 & $s / d$ & $s / d$ \\
\hline Las Flores Aero & $s / d$ & 603,67 & $s / d$ & $s / d$ & 674,17 & 617,37 & $s / d$ \\
\hline San Miguel & $\mathrm{s} / \mathrm{d}$ & 605,35 & $s / d$ & $s / d$ & $s / d$ & $s / d$ & $s / d$ \\
\hline Ezeiza Aero & 629,63 & 571,51 & $s / d$ & $s / d$ & 676,97 & 645,23 & $s / d$ \\
\hline La Plata Aero & $s / d$ & 626,93 & $s / d$ & $s / d$ & 693,22 & $s / d$ & $s / d$ \\
\hline Punta Indio (BA) & 646,48 & 651,28 & $\mathrm{~s} / \mathrm{d}$ & $s / d$ & 686,34 & $s / d$ & $\mathrm{~s} / \mathrm{d}$ \\
\hline Cnel Suárez Aero & $s / d$ & 561,89 & 635,84 & 490,62 & 638,38 & 582,36 & $s / d$ \\
\hline Bolívar Aero & 599,47 & 594,69 & 712,93 & $s / d$ & 658,07 & 612,61 & $s / d$ \\
\hline Azul Aero & 591,33 & 593,98 & 705,07 & $s / d$ & 656,84 & 624,71 & 474,7 \\
\hline Olavarría Aero & 617,84 & 618,88 & 687,31 & $s / d$ & 651,65 & 628,75 & $s / d$ \\
\hline Tandil Aero & 584,75 & 584,50 & $s / d$ & $s / d$ & 632,66 & 629,52 & $s / d$ \\
\hline Dolores Aero & $\mathrm{s} / \mathrm{d}$ & 626,49 & 657,60 & $\mathrm{~s} / \mathrm{d}$ & 650,70 & 624,20 & 605,78 \\
\hline B. Juárez Aero & 624,03 & 626,17 & 714,42 & 552,93 & 658,10 & $\mathrm{~s} / \mathrm{d}$ & $s / d$ \\
\hline Villa Gesell Aero & 640,53 & 644,82 & 644,81 & 598,71 & 678,58 & 653,16 & 560,58 \\
\hline Pigüé Aero & $\mathrm{s} / \mathrm{d}$ & 563,00 & 644,88 & 522,66 & 632,10 & 586,31 & $\mathrm{~s} / \mathrm{d}$ \\
\hline C. Pringles Aero & 585,84 & 582,51 & 656,49 & 527,86 & 636,91 & 565,37 & 598,23 \\
\hline Barrow INTA & 569,64 & 556,79 & 640,62 & 511,21 & 620,74 & $s / d$ & 522,26 \\
\hline Balcarce INTA & 647,14 & 613,35 & $s / d$ & 550,40 & 699,59 & 495,23 & $s / d$ \\
\hline M. del Plata Aero & 602,00 & 602,41 & $s / d$ & 560,92 & 654,10 & $\mathrm{~s} / \mathrm{d}$ & $\mathrm{s} / \mathrm{d}$ \\
\hline H. Ascasubi INTA & $s / d$ & 551,48 & 631,64 & 491,00 & 608,57 & $s / d$ & 524,1 \\
\hline Bahía Blanca & 560,31 & 556,54 & 641,20 & 517,19 & 620,20 & $s / d$ & $s / d$ \\
\hline
\end{tabular}

Tabla AI-1: $\mathrm{Rn}_{\mathrm{i}}$ en $\mathrm{W} / \mathrm{m}^{2}$ - Productos MODIS diarios. 


\begin{tabular}{|l|c|c|c|c|c|c|c|}
\hline \multirow{2}{*}{$\begin{array}{c}\text { Estaciones } \\
\text { Meteorológicas }\end{array}$} & \multicolumn{7}{|c|}{ Rni - 16 días W/m } \\
\cline { 2 - 9 } & $\begin{array}{c}\text { 4 de } \\
\text { enero }\end{array}$ & $\begin{array}{c}\mathbf{6} \text { de } \\
\text { enero }\end{array}$ & $\begin{array}{c}\mathbf{7} \text { de } \\
\text { enero }\end{array}$ & $\begin{array}{c}\mathbf{8} \text { de } \\
\text { enero }\end{array}$ & $\begin{array}{c}\text { 9 de } \\
\text { enero }\end{array}$ & $\begin{array}{c}\text { 13 de } \\
\text { enero }\end{array}$ & $\begin{array}{c}\text { 19 de } \\
\text { enero }\end{array}$ \\
\hline San Fernando & s/d & 649,93 & $\mathrm{~s} / \mathrm{d}$ & $\mathrm{s} / \mathrm{d}$ & 682,06 & $\mathrm{~s} / \mathrm{d}$ & $\mathrm{s} / \mathrm{d}$ \\
\hline Las Flores Aero & $\mathrm{s} / \mathrm{d}$ & 729,02 & $\mathrm{~s} / \mathrm{d}$ & $\mathrm{s} / \mathrm{d}$ & 784,28 & 734,68 & $\mathrm{~s} / \mathrm{d}$ \\
\hline San Miguel & $\mathrm{s} / \mathrm{d}$ & 640,47 & $\mathrm{~s} / \mathrm{d}$ & $\mathrm{s} / \mathrm{d}$ & $\mathrm{s} / \mathrm{d}$ & $\mathrm{s} / \mathrm{d}$ & $\mathrm{s} / \mathrm{d}$ \\
\hline Ezeiza Aero & 744,10 & 731,01 & $\mathrm{~s} / \mathrm{d}$ & $\mathrm{s} / \mathrm{d}$ & 881,50 & 807,55 & $\mathrm{~s} / \mathrm{d}$ \\
\hline La Plata Aero & $\mathrm{s} / \mathrm{d}$ & 782,59 & $\mathrm{~s} / \mathrm{d}$ & $\mathrm{s} / \mathrm{d}$ & 811,59 & $\mathrm{~s} / \mathrm{d}$ & $\mathrm{s} / \mathrm{d}$ \\
\hline Punta Indio (BA) & 769,67 & 765,57 & $\mathrm{~s} / \mathrm{d}$ & $\mathrm{s} / \mathrm{d}$ & 776,98 & $\mathrm{~s} / \mathrm{d}$ & $\mathrm{s} / \mathrm{d}$ \\
\hline Cnel Suárez Aero & $\mathrm{s} / \mathrm{d}$ & 726,84 & 764,92 & 630,03 & 758,98 & 735,54 & $\mathrm{~s} / \mathrm{d}$ \\
\hline Bolívar Aero & 705,38 & 708,92 & 817,51 & $\mathrm{~s} / \mathrm{d}$ & 760,75 & 729,16 & $\mathrm{~s} / \mathrm{d}$ \\
\hline Azul Aero & 693,03 & 729,15 & 833,70 & $\mathrm{~s} / \mathrm{d}$ & 774,38 & 751,14 & 586,25 \\
\hline Olavarría Aero & 724,11 & 738,49 & 798,22 & $\mathrm{~s} / \mathrm{d}$ & 758,59 & 740,61 & $\mathrm{~s} / \mathrm{d}$ \\
\hline Tandil Aero & 685,32 & 737,79 & $\mathrm{~s} / \mathrm{d}$ & $\mathrm{s} / \mathrm{d}$ & 763,28 & 754,41 & $\mathrm{~s} / \mathrm{d}$ \\
\hline Dolores Aero & $\mathrm{s} / \mathrm{d}$ & 748,57 & 855,99 & $\mathrm{~s} / \mathrm{d}$ & 777,11 & 748,85 & 717,31 \\
\hline B. Juárez Aero & 733,24 & 723,47 & 825,04 & 661,81 & 758,24 & $\mathrm{~s} / \mathrm{d}$ & $\mathrm{s} / \mathrm{d}$ \\
\hline Villa Gesell Aero & 750,16 & 761,41 & 809,44 & 714,17 & 775,56 & 765,06 & 713,31 \\
\hline Pigüé Aero & $\mathrm{s} / \mathrm{d}$ & 663,01 & 762,51 & 674,37 & 747,24 & 737,74 & $\mathrm{~s} / \mathrm{d}$ \\
\hline C. Pringles Aero & 688,95 & 753,50 & 760,02 & 664,39 & 737,10 & 706,50 & 784,17 \\
\hline Barrow INTA & 669,89 & 663,73 & 752,88 & 684,73 & 745,16 & $\mathrm{~s} / \mathrm{d}$ & 679,53 \\
\hline Balcarce INTA & 654,67 & 617,95 & $\mathrm{~s} / \mathrm{d}$ & 588,48 & 649,09 & 567,56 & $\mathrm{~s} / \mathrm{d}$ \\
\hline M del Plata Aero & 720,81 & 718,84 & $\mathrm{~s} / \mathrm{d}$ & 698,55 & 771,23 & $\mathrm{~s} / \mathrm{d}$ & $\mathrm{s} / \mathrm{d}$ \\
\hline H Ascasubi INTA & $\mathrm{s} / \mathrm{d}$ & 696,11 & 745,19 & 618,82 & 722,25 & $\mathrm{~s} / \mathrm{d}$ & 672,26 \\
\hline Bahía Blanca & 655,45 & 665,94 & 741,85 & 631,50 & 715,18 & $\mathrm{~s} / \mathrm{d}$ & $\mathrm{s} / \mathrm{d}$ \\
\hline
\end{tabular}

Tabla AI-2: $\mathrm{Rn}_{\mathrm{i}}$ en $\mathrm{W} / \mathrm{m}^{2}$ - Productos MODIS de 16 días. 


\begin{tabular}{|c|c|c|c|c|c|c|c|}
\hline \multirow[t]{2}{*}{$\begin{array}{c}\text { Estaciones } \\
\text { Meteorológicas }\end{array}$} & \multicolumn{7}{|c|}{$E T_{i}-$ diario $\mathrm{W} / \mathrm{m}^{2}$} \\
\hline & $\begin{array}{c}4 \text { de } \\
\text { enero }\end{array}$ & $\begin{array}{c}6 \text { de } \\
\text { enero }\end{array}$ & $\begin{array}{c}7 \mathrm{de} \\
\text { enero }\end{array}$ & $\begin{array}{c}8 \mathrm{de} \\
\text { enero }\end{array}$ & $\begin{array}{c}9 \text { de } \\
\text { enero }\end{array}$ & $\begin{array}{l}13 \text { de } \\
\text { enero }\end{array}$ & $\begin{array}{l}19 \text { de } \\
\text { enero }\end{array}$ \\
\hline San Fernando & $s / d$ & 467,25 & $s / d$ & $s / d$ & 194,38 & $s / d$ & $s / d$ \\
\hline Las Flores Aero & $s / d$ & 399,96 & $s / d$ & $s / d$ & 512,27 & 508,09 & $s / d$ \\
\hline San Miguel & $\mathrm{s} / \mathrm{d}$ & 254,97 & $s / d$ & $s / d$ & $s / d$ & $s / d$ & $s / d$ \\
\hline Ezeiza Aero & 497,57 & 217,09 & $s / d$ & $s / d$ & 573,20 & 502,58 & $s / d$ \\
\hline La Plata Aero & $s / d$ & 405,14 & $s / d$ & $s / d$ & 486,90 & $s / d$ & $s / d$ \\
\hline Punta Indio (BA) & 611,38 & 541,16 & $s / d$ & $s / d$ & 537,48 & $s / d$ & $s / d$ \\
\hline Cnel Suárez Aero & $s / d$ & 412,66 & 537,50 & 436,57 & 558,06 & 501,36 & $s / d$ \\
\hline Bolívar Aero & 483,54 & 423,57 & 546,50 & $s / d$ & 550,72 & 499,98 & $s / d$ \\
\hline Azul Aero & 454,30 & 347,67 & 486,83 & $s / d$ & 499,55 & 547,73 & 284,98 \\
\hline Olavarría Aero & 456,54 & 445,07 & 328,59 & $s / d$ & 421,66 & 432,87 & $\mathrm{~s} / \mathrm{d}$ \\
\hline Tandil Aero & 512,50 & 446,63 & $s / d$ & $s / d$ & 445,24 & 537,97 & $s / d$ \\
\hline Dolores Aero & $\mathrm{s} / \mathrm{d}$ & 538,39 & 517,48 & $\mathrm{~s} / \mathrm{d}$ & 513,72 & 590,18 & 348,51 \\
\hline B Juárez Aero & 492,50 & 422,29 & 322,30 & 383,15 & 344,91 & $s / d$ & $s / d$ \\
\hline Villa Gesell Aero & 577,86 & 506,83 & 216,94 & 383,45 & 564,99 & 564,56 & 427,63 \\
\hline Pigüé Aero & $\mathrm{s} / \mathrm{d}$ & 163,00 & 336,27 & 191,26 & 314,88 & 311,80 & $s / d$ \\
\hline C. Pringles Aero & 403,12 & 348,09 & 409,19 & 329,39 & 447,99 & 358,45 & 276,74 \\
\hline Barrow INTA & 252,07 & 183,12 & 308,75 & 255,22 & 294,53 & $s / d$ & 121,77 \\
\hline Balcarce INTA & 133,83 & 291,88 & $s / d$ & 180,45 & 328,07 & 210,53 & $s / d$ \\
\hline M del Plata Aero & 417,58 & 286,06 & $s / d$ & 361,70 & 461,27 & $s / d$ & $s / d$ \\
\hline H. Ascasubi INTA & $s / d$ & 415,73 & 490,36 & 352,61 & 506,43 & $s / d$ & 417,05 \\
\hline Bahía Blanca & 414,75 & 329,80 & 394,64 & 329,54 & 415,10 & $s / d$ & $s / d$ \\
\hline
\end{tabular}

Tabla AI-3: $\mathrm{ET}_{\mathrm{i}} \mathrm{W} / \mathrm{m}^{2}$ - Productos MODIS diarios. 


\begin{tabular}{|c|c|c|c|c|c|c|c|}
\hline \multirow[t]{2}{*}{$\begin{array}{c}\text { Estaciones } \\
\text { Meteorológicas }\end{array}$} & \multicolumn{7}{|c|}{$\mathrm{ET}_{\mathrm{i}}-16$ días $\mathrm{W} / \mathrm{m}^{2}$} \\
\hline & $\begin{array}{c}4 \text { de } \\
\text { enero }\end{array}$ & $\begin{array}{c}6 \text { de } \\
\text { enero }\end{array}$ & $\begin{array}{c}7 \mathrm{de} \\
\text { enero }\end{array}$ & $\begin{array}{c}8 \mathrm{de} \\
\text { enero }\end{array}$ & $\begin{array}{c}9 \text { de } \\
\text { enero }\end{array}$ & $\begin{array}{l}13 \text { de } \\
\text { enero }\end{array}$ & $\begin{array}{l}19 \text { de } \\
\text { enero }\end{array}$ \\
\hline San Fernando & $s / d$ & 478,37 & $s / d$ & $s / d$ & 190,87 & $s / d$ & $s / d$ \\
\hline Las Flores Aero & $s / d$ & 483,02 & $s / d$ & $s / d$ & 595,93 & 604,64 & $s / d$ \\
\hline San Miguel & $\mathrm{s} / \mathrm{d}$ & 269,76 & $s / d$ & $s / d$ & $s / d$ & $s / d$ & $s / d$ \\
\hline Ezeiza Aero & 588,03 & 277,69 & $s / d$ & $s / d$ & 746,38 & 629,01 & $s / d$ \\
\hline La Plata Aero & $s / d$ & 505,74 & $s / d$ & $s / d$ & 570,04 & $s / d$ & $s / d$ \\
\hline Punta Indio (BA) & 727,89 & 636,13 & $\mathrm{~s} / \mathrm{d}$ & $s / d$ & 608,46 & $s / d$ & $\mathrm{~s} / \mathrm{d}$ \\
\hline Cnel Suárez Aero & $s / d$ & 533,80 & 646,62 & 560,62 & 663,48 & 633,24 & $s / d$ \\
\hline Bolívar Aero & 568,97 & 504,93 & 626,67 & $s / d$ & 636,65 & 595,11 & $s / d$ \\
\hline Azul Aero & 532,44 & 426,80 & 575,64 & $s / d$ & 588,94 & 658,58 & 351,95 \\
\hline Olavarría Aero & 535,06 & 531,09 & 381,61 & $s / d$ & 490,85 & 509,87 & $\mathrm{~s} / \mathrm{d}$ \\
\hline Tandil Aero & 600,65 & 563,76 & $s / d$ & $s / d$ & 537,17 & 644,70 & $s / d$ \\
\hline Dolores Aero & $\mathrm{s} / \mathrm{d}$ & 643,30 & 673,60 & $\mathrm{~s} / \mathrm{d}$ & 613,52 & 708,05 & 412,68 \\
\hline B. Juárez Aero & 578,68 & 487,91 & 372,20 & 458,60 & 397,39 & $\mathrm{~s} / \mathrm{d}$ & $\mathrm{s} / \mathrm{d}$ \\
\hline Villa Gesell Aero & 676,76 & 598,48 & 272,33 & 457,40 & 645,74 & 661,28 & 544,13 \\
\hline Pigüé Aero & $\mathrm{s} / \mathrm{d}$ & 191,96 & 397,61 & 246,77 & 372,24 & 392,33 & $s / d$ \\
\hline C. Pringles Aero & 474,07 & 450,28 & 473,72 & 414,58 & 518,46 & 447,92 & 362,75 \\
\hline Barrow INTA & 296,44 & 218,30 & 362,85 & 341,85 & 353,57 & $s / d$ & 158,44 \\
\hline Balcarce INTA & 102,63 & 319,98 & $\mathrm{~s} / \mathrm{d}$ & 334,91 & 328,61 & 213,90 & $s / d$ \\
\hline M del Plata Aero & 500,00 & 341,35 & $s / d$ & 450,45 & 543,87 & $\mathrm{~s} / \mathrm{d}$ & $s / d$ \\
\hline H. Ascasubi INTA & $s / d$ & 524,76 & 578,52 & 444,41 & 601,03 & $s / d$ & 534,95 \\
\hline Bahía Blanca & 485,18 & 394,63 & 456,58 & 402,38 & 478,67 & $s / d$ & $s / d$ \\
\hline
\end{tabular}

Tabla AI-4: $\mathrm{ET}_{\mathrm{i}} \mathrm{W} / \mathrm{m}^{2}$ - Productos MODIS de 16 días.

En las próximas 7 tablas (Tabla AI-5 hasta Tabla AI-11) se muestran los resultados de la $\mathrm{E}_{\mathrm{dd}}$ en $\mathrm{mm} / \mathrm{dí}$.

\begin{tabular}{||l|c|c|c||}
\hline \multicolumn{4}{|c|}{ 4 de enero } \\
\hline \multicolumn{1}{|c|}{$\begin{array}{c}\text { Estaciones } \\
\text { Meteorológicas }\end{array}$} & $\mathbf{E T}_{\mathrm{r}}$ & $\mathbf{E}_{\mathrm{dd}}$ diario & $\mathbf{E}_{\mathrm{dd}}$ 16 días \\
\hline Ezeiza Aero & 5,40 & 4,26 & 5,76 \\
Punta Indio (BA) & 5,50 & 4,23 & 5,91 \\
Bolívar Aero & 5,10 & 3,01 & 4,26 \\
Mar del Plata Aero & 4,60 & 3,71 & 4,50 \\
Azul Aero & 4,80 & 4,06 & 5,47 \\
Olavarría Aero & 5,60 & 3,27 & 5,08 \\
Tandil Aero & 4,70 & 3,16 & 5,05 \\
Benito Juárez Aero & 5,40 & 3,55 & 4,75 \\
Coronel Pringles Aero & 5,00 & 3,78 & 5,42 \\
Villa Gesell Aero & 5,70 & 5,08 & 5,78 \\
Barrow INTA & 5,50 & 4,50 & 5,40 \\
Balcarce INTA & 5,20 & 3,47 & 5,35 \\
\hline
\end{tabular}

Tabla AI-5: $\mathrm{E}_{\mathrm{dd}} \mathrm{mm} /$ día para el 4 de enero - Productos MODIS diarios y productos MODIS de 16 días. 


\begin{tabular}{||l|c|c|c||}
\hline \multicolumn{4}{|c|}{ 6 de enero } \\
\hline $\begin{array}{c}\text { Estaciones } \\
\text { Meteorológicas }\end{array}$ & $\mathbf{E T}_{\mathbf{r}}$ & $\mathbf{E}_{\text {dd }}$ diario & $\mathbf{E}_{\text {dd }} \mathbf{1 6}$ días \\
\hline Ezeiza & 4,40 & 2,60 & 3,76 \\
Punta Indio (BA) & 4,60 & 4,40 & 4,69 \\
Dolores Aero & 5,70 & 4,95 & 5,18 \\
Las Flores Aero & 5,30 & 3,97 & 5,45 \\
Coronel Suárez Aero & 4,60 & 3,50 & 5,67 \\
Bolívar Aero & 3,40 & 2,82 & 5,11 \\
Azul Aero & 4,60 & 3,88 & 5,75 \\
Olavarría Aero & 5,50 & 4,63 & 6,08 \\
Tandil Aero & 4,80 & 3,86 & 5,06 \\
Benito Juárez Aero & 5,80 & 3,71 & 5,33 \\
Pigüé Aero & 5,90 & 5,04 & 5,63 \\
Coronel Pringles Aero & 4,90 & 4,11 & 5,61 \\
Bahía Blanca & 3,80 & 3,06 & 4,41 \\
Barrow INTA & 5,20 & 4,51 & 4,91 \\
Balcarce INTA & 3,20 & 2,45 & 3,86 \\
Hilario Ascasubi INTA & 2,11 & 3,11 & 3,96 \\
\hline
\end{tabular}

Tabla AI-6: $\mathrm{E}_{\mathrm{dd}} \mathrm{mm} /$ día para el 6 de enero - Productos MODIS diarios y productos MODIS de 16 días.

\begin{tabular}{|l|c|c|c|}
\hline \multicolumn{4}{|c|}{7 de enero } \\
\hline $\begin{array}{c}\text { Estaciones } \\
\text { Meteorológicas }\end{array}$ & $\mathbf{E T}_{\mathbf{r}}$ & $\mathbf{E}_{\mathrm{dd}}$ diario & $\mathbf{E}_{\mathrm{dd}}$ 16 días \\
\hline Dolores Aero & 5,50 & 5,10 & 5,88 \\
Bolívar Aero & 4,90 & 4,19 & 5,20 \\
Azul Aero & 4,70 & 4,22 & 5,86 \\
Olavarría Aero & 4,68 & 4,22 & 5,76 \\
Benito Juárez Aero & 3,85 & 3,01 & 5,28 \\
Pigüé Aero & 3,16 & 3,13 & 4,19 \\
Coronel Pringles Aero & 4,20 & 4,60 & 5,87 \\
Bahía Blanca & 3,40 & 3,72 & 4,77 \\
Villa Gesell Aero & 4,00 & 2,59 & 4,29 \\
Barrow INTA & 4,90 & 3,43 & 5,09 \\
Hilario Ascasubi INTA & 4,70 & 4,22 & 5,79 \\
\hline
\end{tabular}

Tabla AI-7: $E_{\mathrm{dd}} \mathrm{mm} /$ día para el 7 de enero - Productos MODIS diarios y productos MODIS de 16 días. 


\begin{tabular}{||l|c|c|c||}
\hline \multicolumn{4}{|c|}{$\mathbf{8}$ de enero } \\
\hline $\begin{array}{c}\text { Estaciones } \\
\text { Meteorológicas }\end{array}$ & $\mathbf{E T}_{\mathbf{r}}$ & $\mathbf{E}_{\mathrm{dd}}$ diario & $\mathbf{E}_{\mathrm{dd}} \mathbf{1 6}$ días \\
\hline Mar del Plata Aero & 4,50 & 3,55 & 4,18 \\
Coronel Suárez Aero & 4,30 & 2,39 & 4,24 \\
Benito Juárez Aero & 4,80 & 4,39 & 5,01 \\
Pigüé Aero & 4,30 & 3,87 & 4,32 \\
Cnel Pringles Aero & 3,80 & 3,55 & 4,12 \\
Bahía Blanca & 3,00 & 3,04 & 3,37 \\
Villa Gesell Aero & 3,80 & 4,00 & 4,31 \\
Barrow INTA & 5,40 & 5,07 & 5,31 \\
Balcarce INTA & 5,30 & 5,63 & 5,73 \\
Hilario Ascasubi INTA & 3,50 & 3,13 & 5,11 \\
\hline
\end{tabular}

Tabla AI-8: $\mathrm{E}_{\mathrm{dd}} \mathrm{mm} /$ día para el 8 de enero - Productos MODIS diarios y productos MODIS de 16 días.

\begin{tabular}{||l|c|c|c||}
\hline \multicolumn{3}{|c|}{$\mathbf{9}$ de enero } \\
\hline \multicolumn{1}{|c|}{$\begin{array}{c}\text { Estaciones } \\
\text { Meteorológicas }\end{array}$} & $\mathbf{E T}_{\mathbf{r}}$ & $\mathbf{E}_{\mathrm{dd}}$ diario & $\mathbf{E}_{\mathrm{ddd}} \mathbf{1 6}$ días \\
\hline San Fernando & 3,90 & 4,55 & 5,38 \\
Las Flores Aero & 4,10 & 3,92 & 5,66 \\
Ezeiza Aero & 2,90 & 2,26 & 2,76 \\
La Plata Aero & 4,10 & 3,89 & 4,37 \\
Punta Indio (BA) & 4,10 & 4,28 & 4,70 \\
Bolívar Aero & 4,30 & 4,02 & 4,26 \\
Dolores Aero & 5,20 & 4,88 & 5,12 \\
Mar del Plata Aero & 3,40 & 3,49 & 5,20 \\
Bahía Blanca & 3,20 & 2,83 & 3,87 \\
Coronel Suárez Aero & 4,00 & 3,92 & 5,64 \\
Azul Aero & 4,20 & 4,60 & 5,46 \\
Olavarría Aero & 4,40 & 4,52 & 5,17 \\
Tandil Aero & 4,30 & 4,16 & 5,20 \\
Benito Juárez Aero & 4,90 & 4,35 & 4,49 \\
Pigüé Aero & 4,90 & 4,52 & 4,92 \\
Coronel Pringles Aero & 3,90 & 4,56 & 5,32 \\
Villa Gesell Aero & 3,70 & 4,67 & 5,19 \\
Barrow INTA & 2,50 & 2,71 & 4,04 \\
Balcarce INTA & 3,70 & 3,39 & 4,29 \\
Hilario Ascasubi INTA & 4,70 & 4,64 & 5,13 \\
\hline
\end{tabular}

Tabla AI-9: $\mathrm{E}_{\mathrm{dd}} \mathrm{mm} /$ día para el 9 de enero - Productos MODIS diarios y productos MODIS de 16 días. 


\begin{tabular}{||l|c|c|c|}
\hline \multicolumn{3}{|c|}{ 13 de enero } \\
\hline \multicolumn{1}{|c|}{ Estaciones } & $\mathbf{E T}_{\mathbf{r}}$ & $\mathbf{E}_{\mathrm{dd}}$ diario & $\mathbf{E}_{\mathrm{dd}} \mathbf{1 6}$ días \\
\hline Las Flores Aero & 3,50 & 3,26 & 4,21 \\
Ezeiza Aero & 3,40 & 3,39 & 4,14 \\
Bolívar Aero & 3,70 & 3,14 & 4,21 \\
Dolores Aero & 4,60 & 4,97 & 5,85 \\
Coronel Suárez Aero & 3,10 & 3,07 & 4,01 \\
Azul Aero & 3,70 & 3,54 & 4,39 \\
Olavarría Aero & 4,70 & 4,63 & 4,88 \\
Tandil Aero & 3,70 & 3,52 & 5,27 \\
Pigüé Aero & 3,20 & 3,10 & 5,39 \\
Coronel Pringles Aero & 3,90 & 3,69 & 5,09 \\
Villa Gesell Aero & 3,40 & 3,89 & 5,16 \\
Balcarce INTA & 3,10 & 3,45 & 4,04 \\
\hline
\end{tabular}

Tabla AI-10: $\mathrm{E}_{\mathrm{dd}} \mathrm{mm} /$ día para el 13 de enero - Productos MODIS diarios y productos MODIS de 16 días.

\begin{tabular}{|l|c|c|c|}
\hline \multicolumn{3}{|c|}{ 19 de enero } \\
\hline $\begin{array}{c}\text { Estaciones } \\
\text { Meteorológicas }\end{array}$ & $\mathbf{E T}_{\mathrm{r}}$ & $\mathbf{E}_{\mathrm{dd}}$ diario & $\mathbf{E}_{\mathrm{dd}} \mathbf{1 6}$ días \\
\hline Azul Aero & 2,60 & 2,29 & 3,19 \\
Dolores Aero & 4,20 & 3,34 & 4,05 \\
Coronel Pringles Aero & 2,20 & 2,56 & 2,79 \\
Villa Gesell Aero & 3,10 & 2,81 & 3,36 \\
Barrow INTA & 2,50 & 2,47 & 3,16 \\
Hilario Ascasubi INTA & 3,20 & 2,58 & 4,37 \\
\hline
\end{tabular}

Tabla AI-11: $\mathrm{E}_{\mathrm{dd}} \mathrm{mm} /$ día para el 19 de enero - Productos MODIS diarios y productos MODIS de 16 días.

Se recuerda en este Anexo que la $\mathrm{ET}_{\mathrm{r}}$ determinada a partir del BH-TM que se utilizó como dato testigo para comparar con la $\mathrm{E}_{\mathrm{dd}}$. Se calculó para condición de cielo despejado, por lo tanto, la heliofanía fue igual a 1 y no el dato brindado por el SMN. 


\section{Anexo II. RESULTADOS - IMÁGENES}

En este anexo se muestra el resultado del trabajo, mostrado en imágenes para los 7 días de estudio.

Aquí se comparan los resultados de Evapotranspiración diaria en mm/día en condiciones de cielo despejado y en condiciones reales de nubosidad. Teniendo en cuenta los productos MODIS diarios y los productos MODIS de 16 días.

Todos estos datos se corresponden con las figuras AII-1 hasta AII-14. Donde la numeración impar corresponde a la estimación con productos MODIS diarios y la numeración par a la estimación con productos MODIS de 16 días, a su vez, la imagen de la izquierda corresponde a la condición de cielo despejado y la de la derecha a la condición de cielo con nubosidad.

Lo que observamos en dichos gráficos es el resultado principal del presente trabajo, la Evapotranspiración diaria real en $\mathrm{mm}$ /día $\left(E_{\mathrm{dr}}\right)$ y la Evapotranspiración diaria para día con cielo despejado en $\mathrm{mm} /$ día $\left(E_{\mathrm{dd}}\right)$. También se muestran las estaciones meteorológicas y los partidos de la provincia de Buenos Aires en los mismos.

Se puede apreciar en ellas, áreas de la provincia de Buenos Aires en color blanco; ello se corresponde con zonas donde no se ha podido determinar la Evapotranspiración ya sea por encontrarse el área nublada al momento de la visita del satélite AQUA/TERRA, por no contar con valores de temperatura provistos por el producto MOD07 o bien por algún error en alguno de los productos MODIS impidiendo el cálculo de la $E_{\mathrm{rd}}$ a posteriori. 


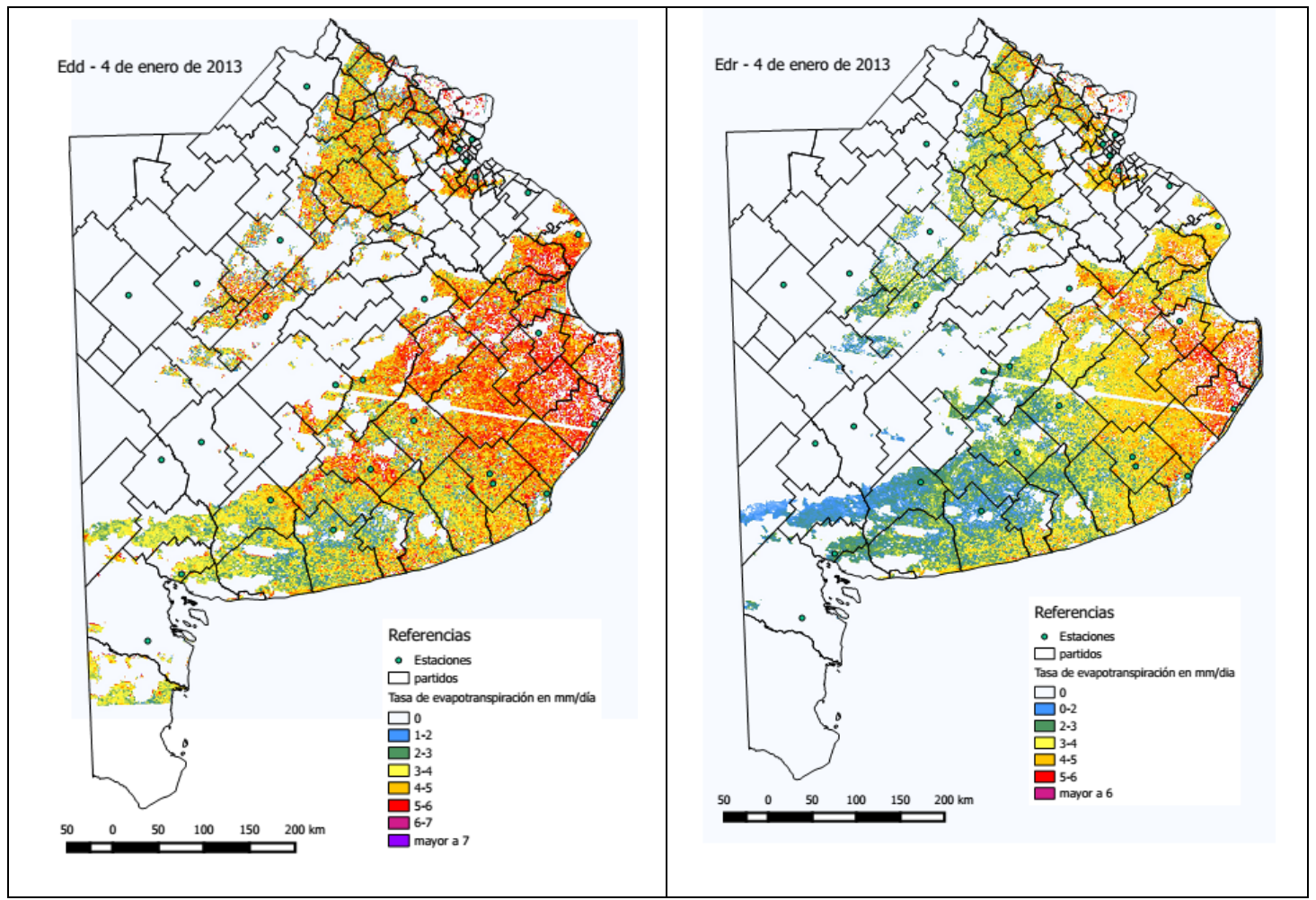

Figura A II -1: Imágenes del 4 de enero $-E_{\mathrm{dd}} \mathrm{y} E_{\mathrm{dr}}$ en mm/día -productos MODIS diarios.

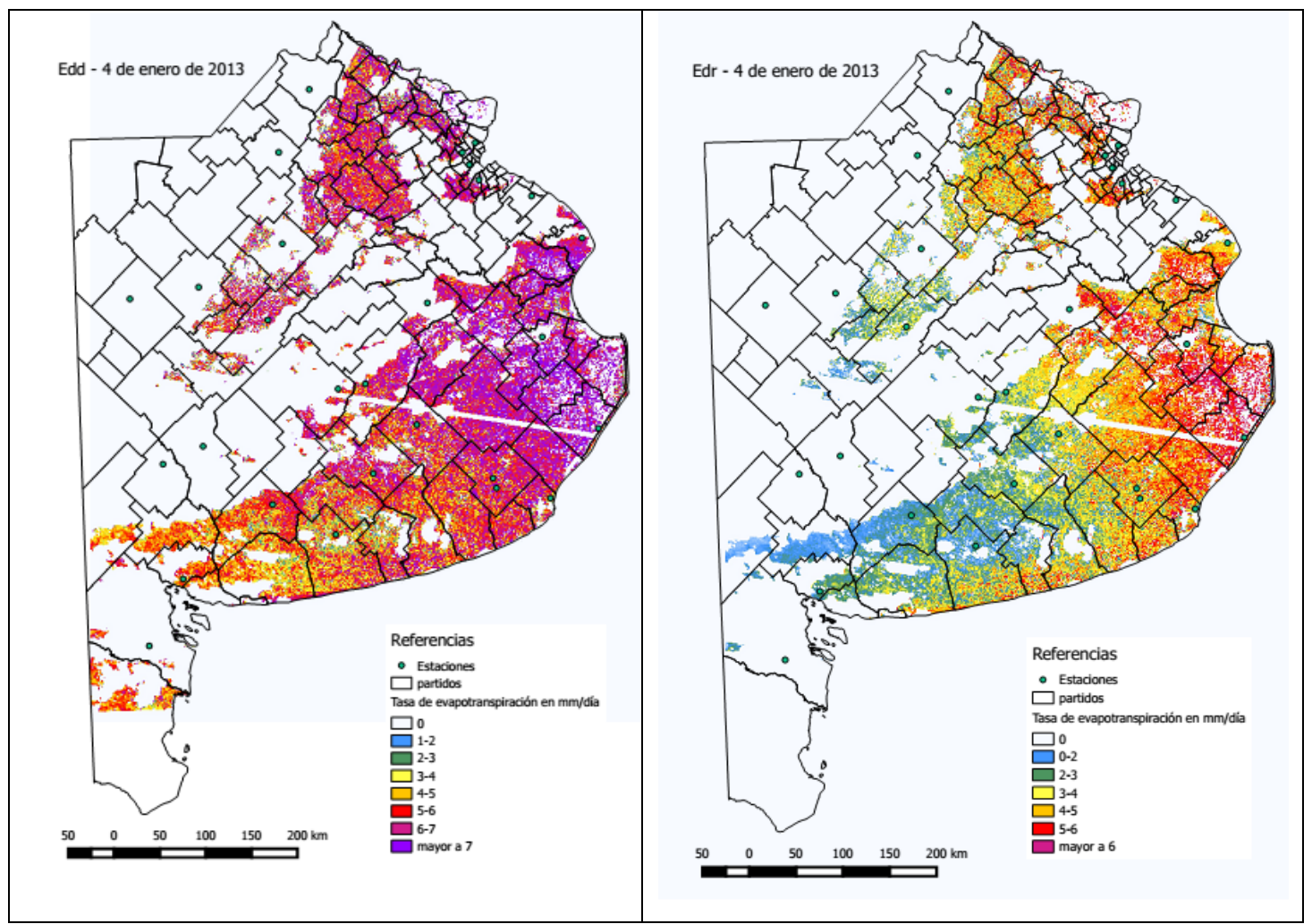

Figura A II -2: Imágenes del 4 de enero $-E_{\mathrm{dd}}$ y $E_{\mathrm{dr}}$ en $\mathrm{mm} /$ día - productos MODIS de 16 días. 


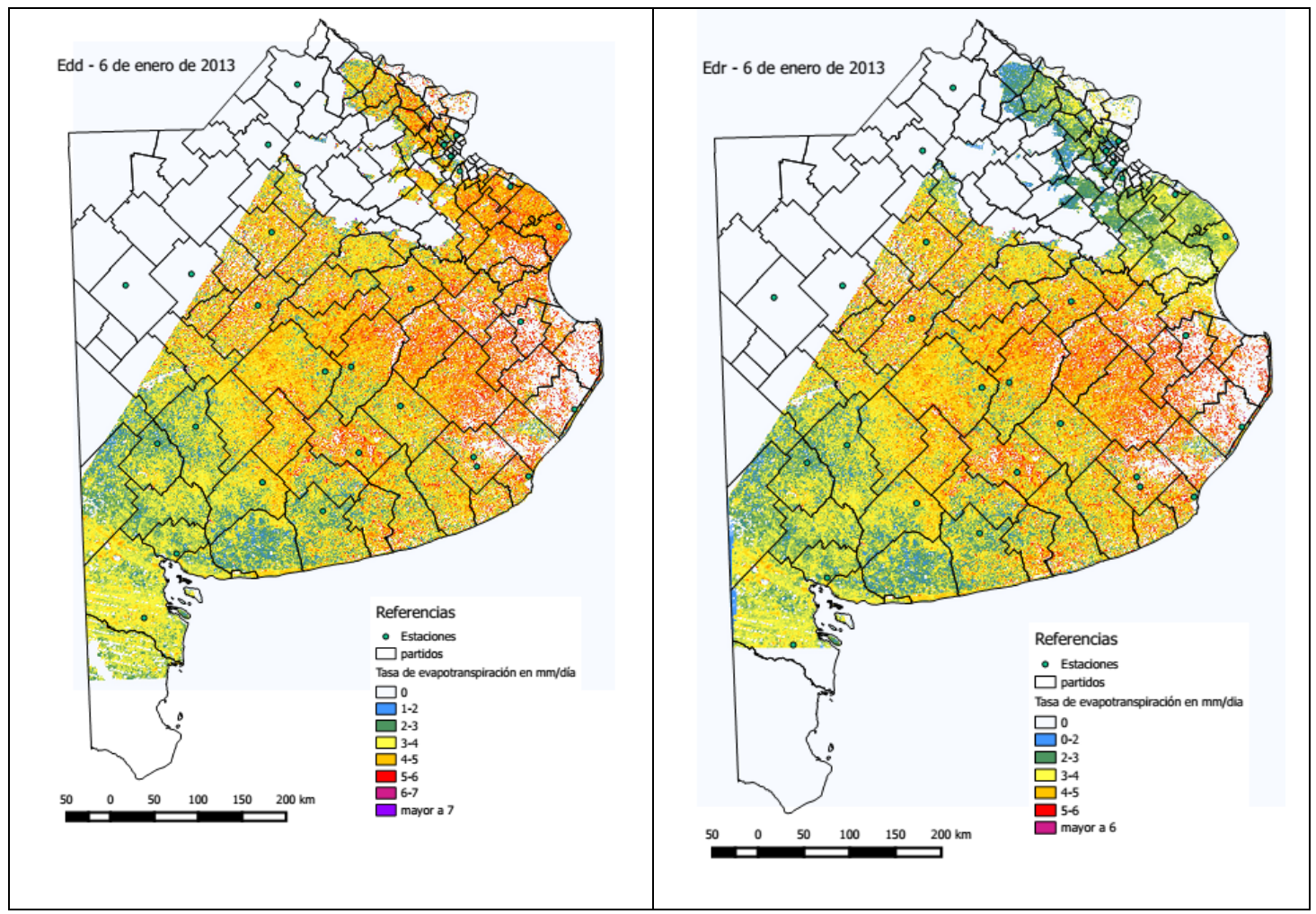

Figura A II -3: Imágenes del 6 de enero $-E_{\mathrm{dd}} \mathrm{y} E_{\mathrm{dr}}$ en mm/día - productos MODIS diarios.

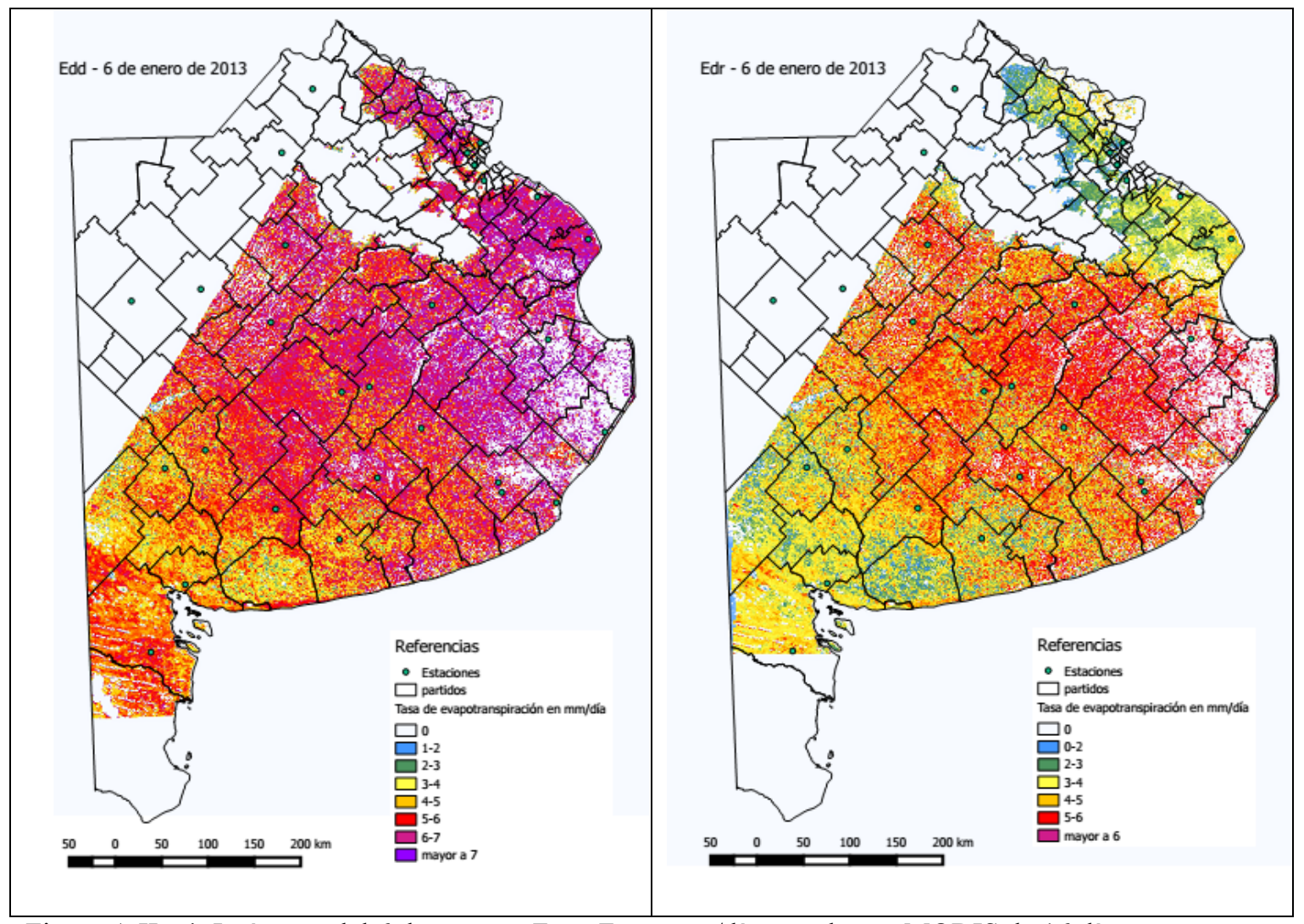

Figura A II - 4: Imágenes del 6 de enero $-E_{\mathrm{dd}}$ y $E_{\mathrm{dr}}$ en $\mathrm{mm} /$ día -productos MODIS de 16 días. 


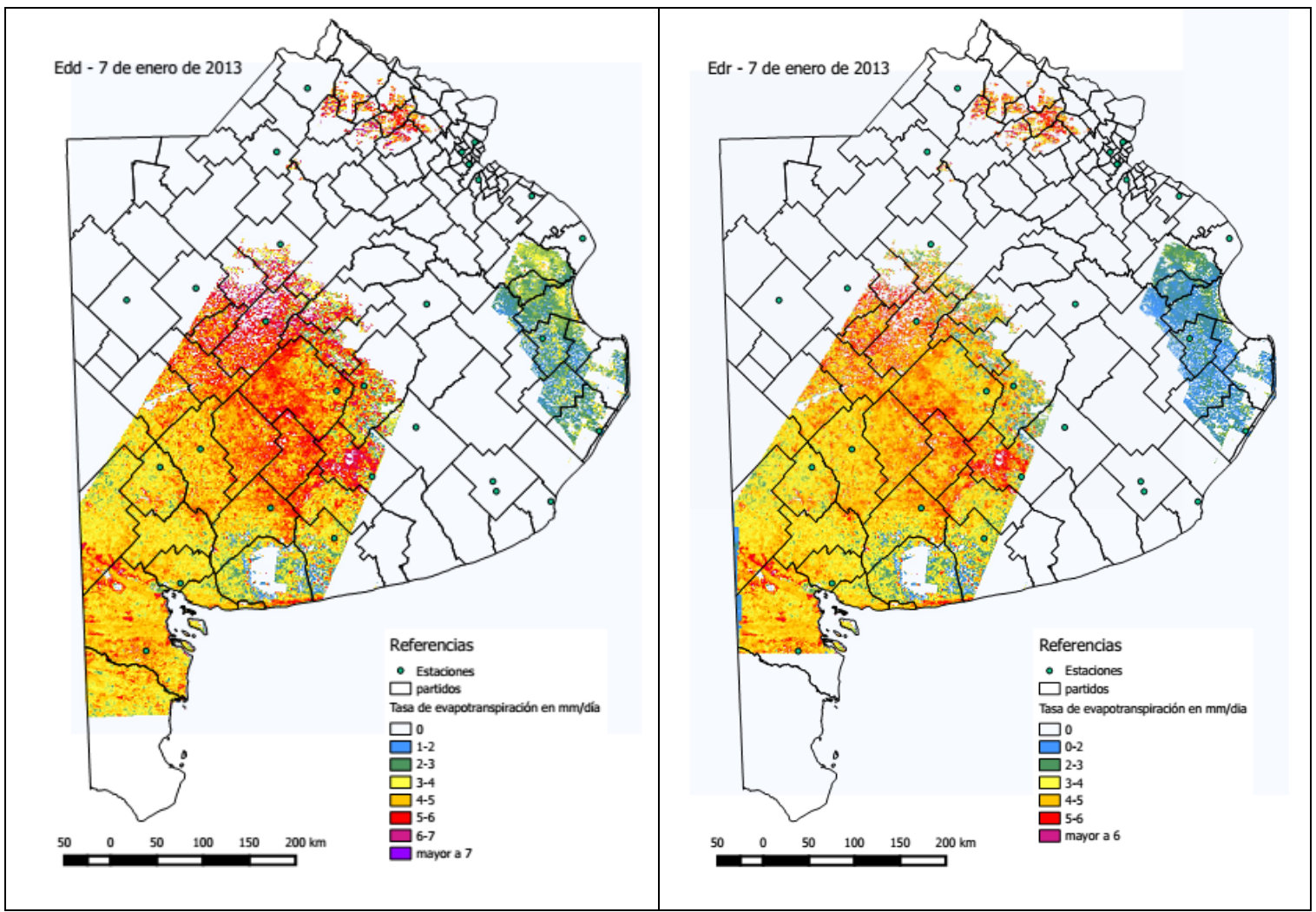

Figura A II -5: Imágenes del 7 de enero $-E_{\mathrm{dd}}$ y $E_{\mathrm{dr}}$ en mm/día - productos MODIS diarios.

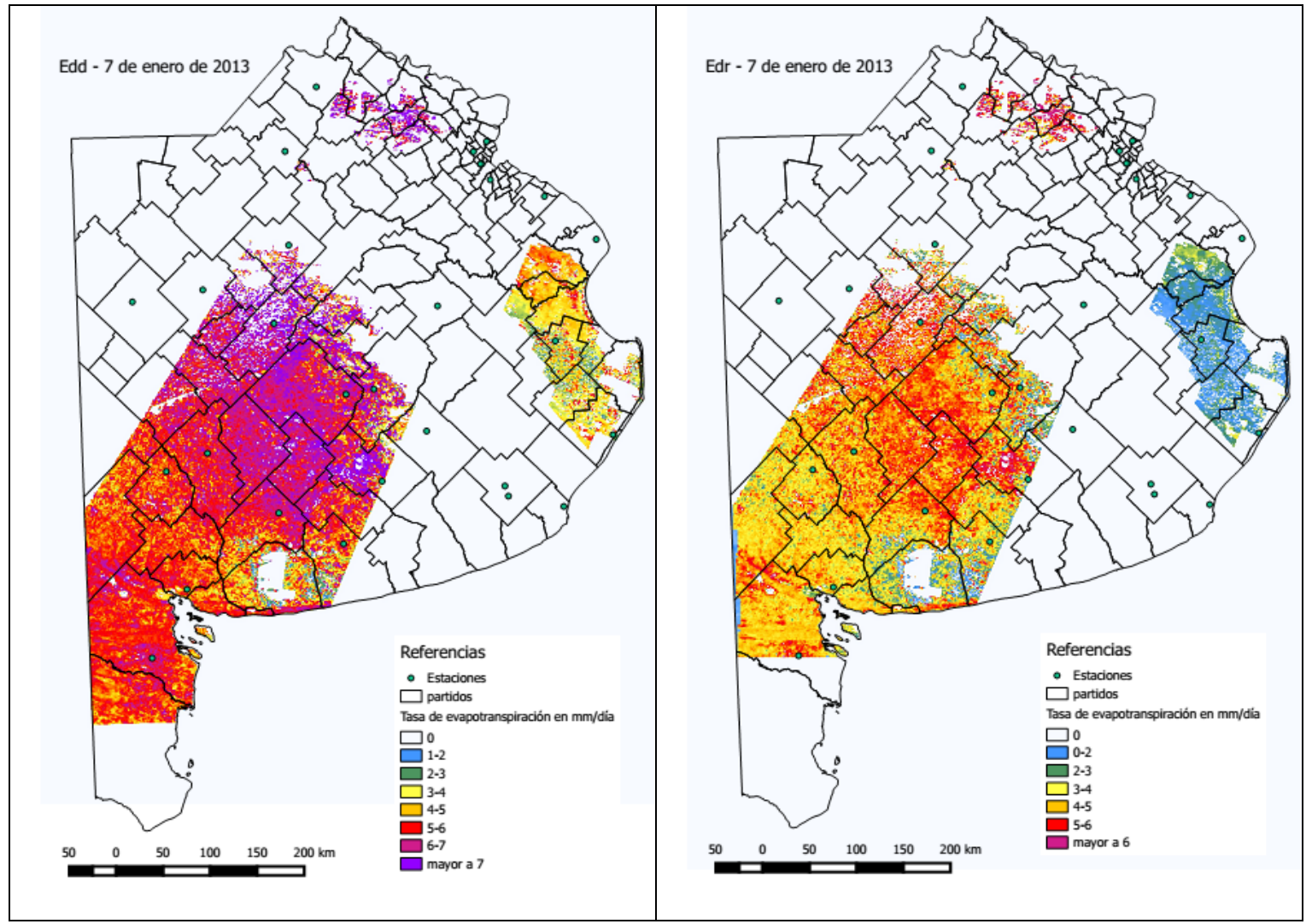

Figura A II -6: Imágenes del 7 de enero $-E_{\mathrm{dd}}$ y $E_{\mathrm{dr}}$ en $\mathrm{mm} /$ día -productos MODIS de 16 días. 


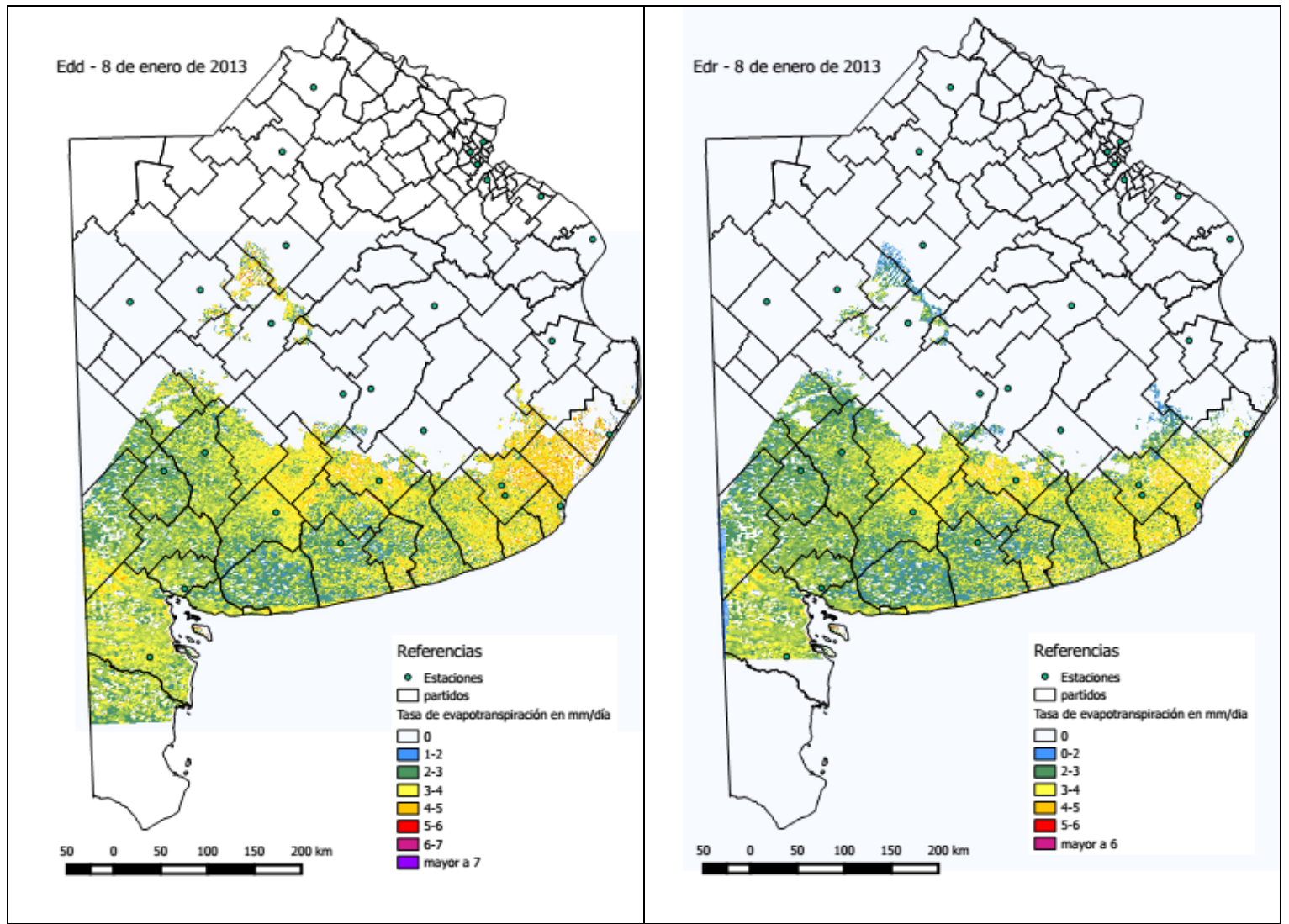

Figura A II -7: Imágenes del 8 de enero $-E_{\mathrm{dd}} \mathrm{y} E_{\mathrm{dr}}$ en mm/día - productos MODIS diarios.

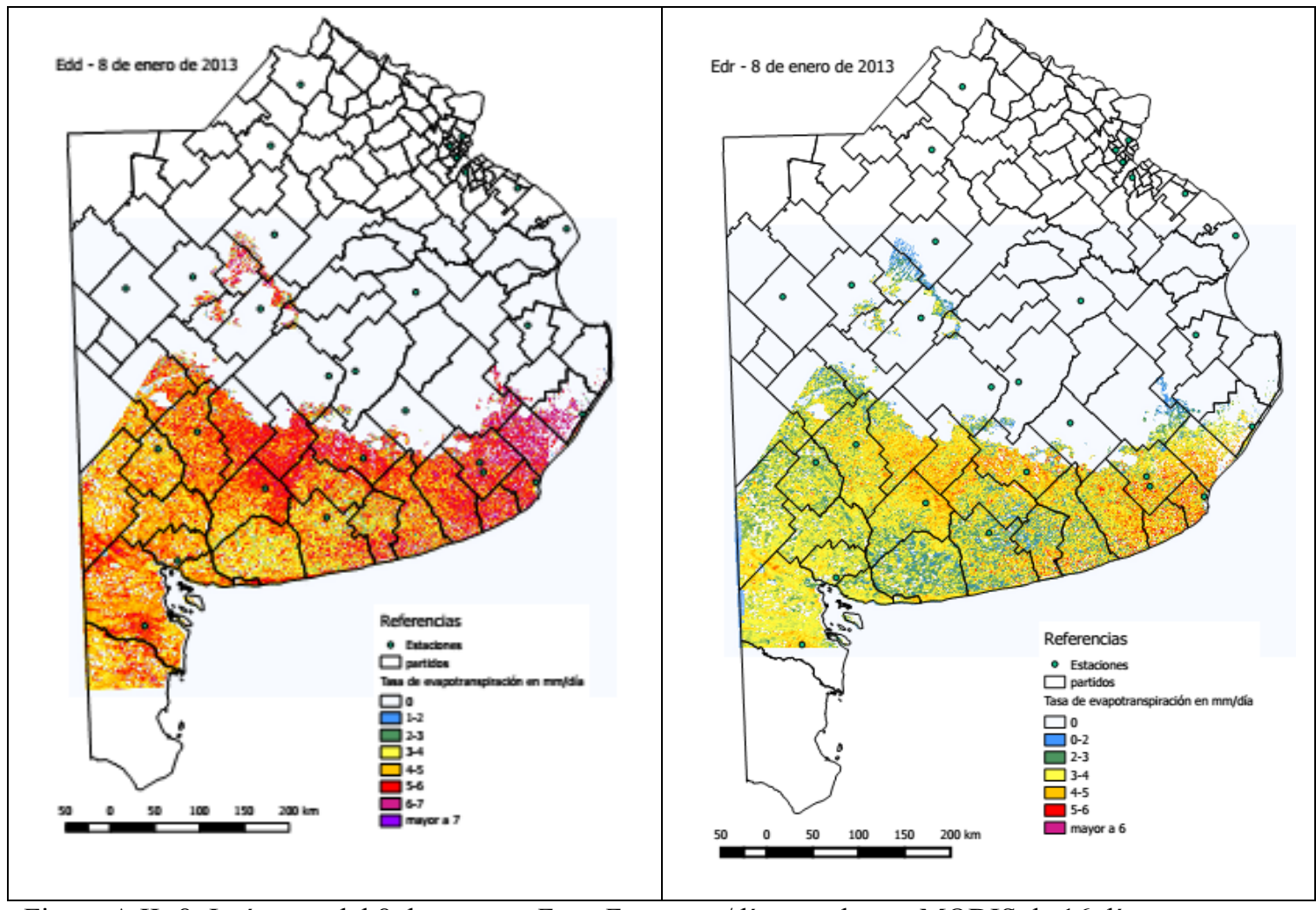

Figura A II -8: Imágenes del 8 de enero $-E_{\mathrm{dd}}$ y $E_{\mathrm{dr}}$ en $\mathrm{mm} /$ día -productos MODIS de 16 días. 


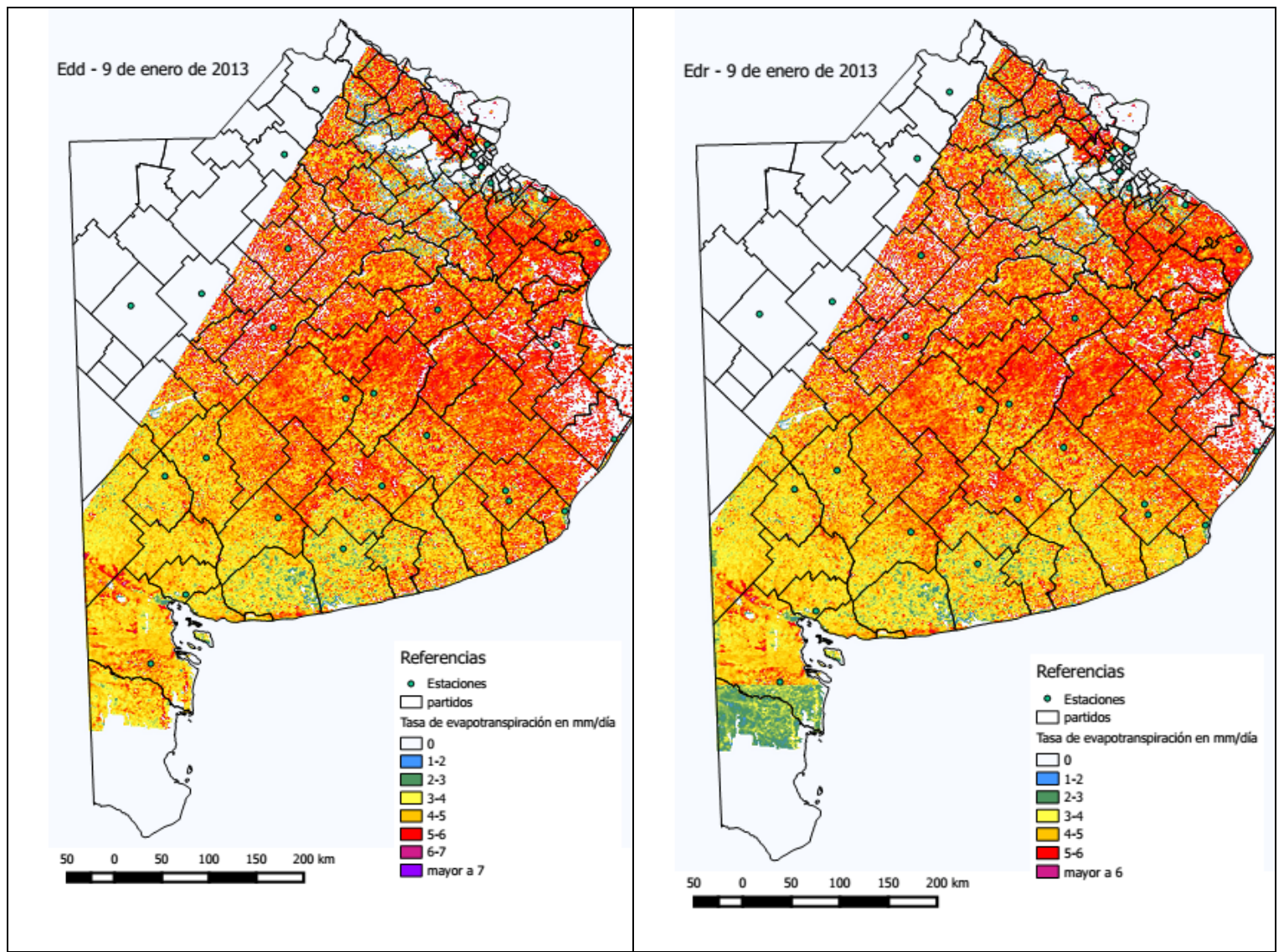

Figura A II -9: Imágenes del 9 de enero $-E_{\mathrm{dd}} \mathrm{y} E_{\mathrm{dr}}$ en mm/día - productos MODIS diarios.

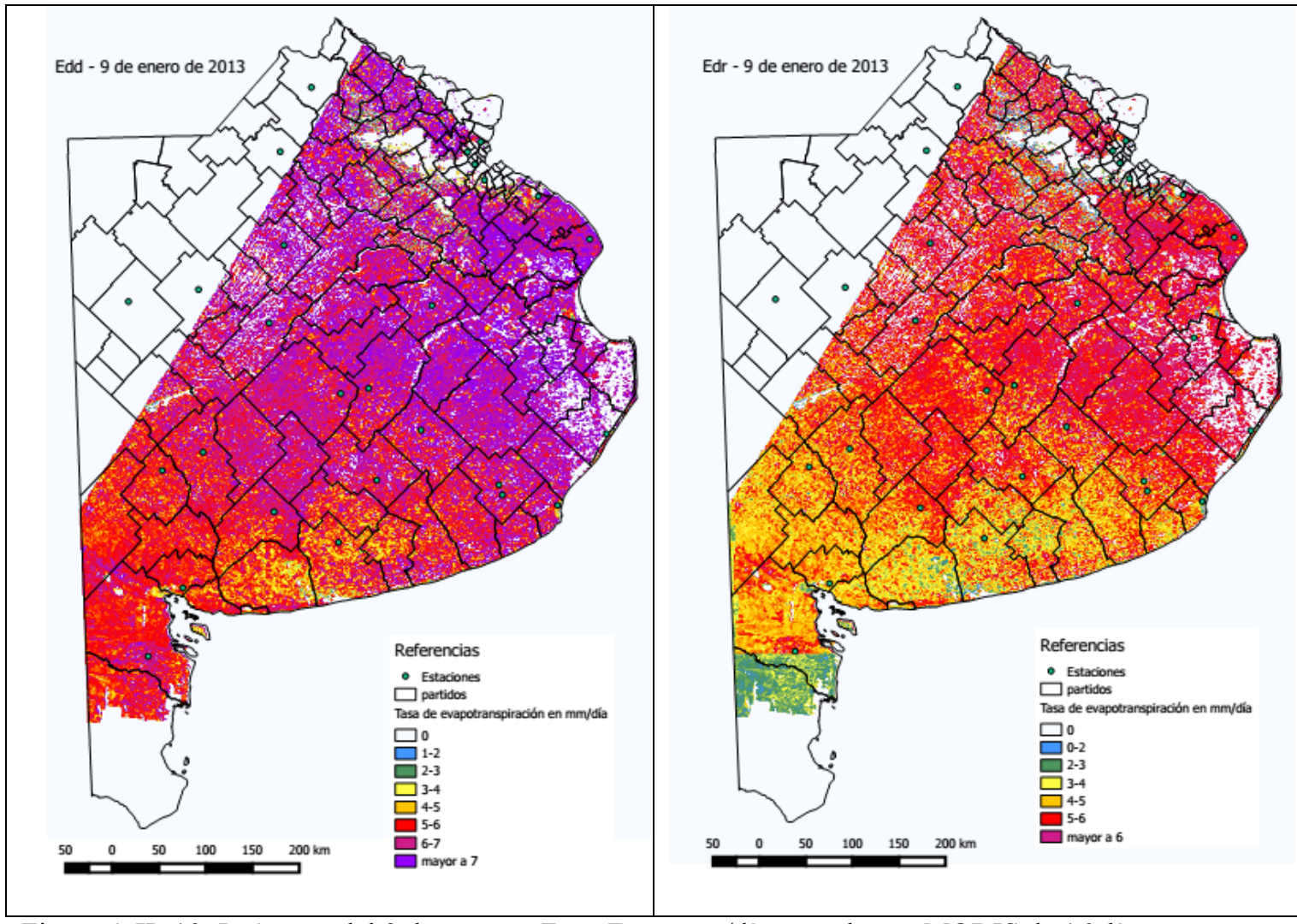

Figura A II -10: Imágenes del 9 de enero $-E_{\mathrm{dd}}$ y $E_{\mathrm{dr}}$ en $\mathrm{mm} /$ día - productos MODIS de 16 días. 


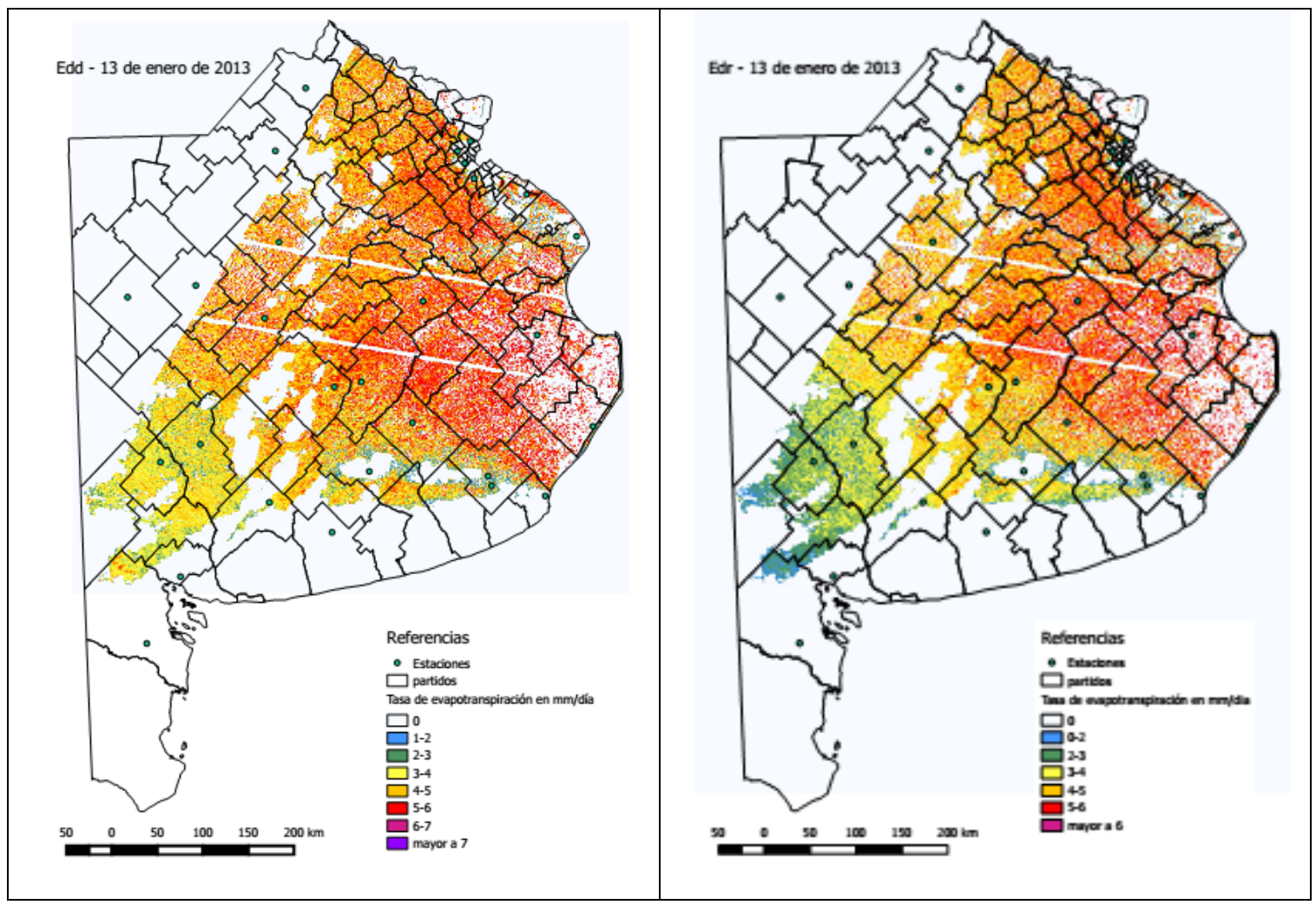

Figura A II -11: Imágenes del 13 de enero $-E_{\mathrm{dd}}$ y $E_{\mathrm{dr}}$ en $\mathrm{mm}$ /día - y productos MODIS diarios.

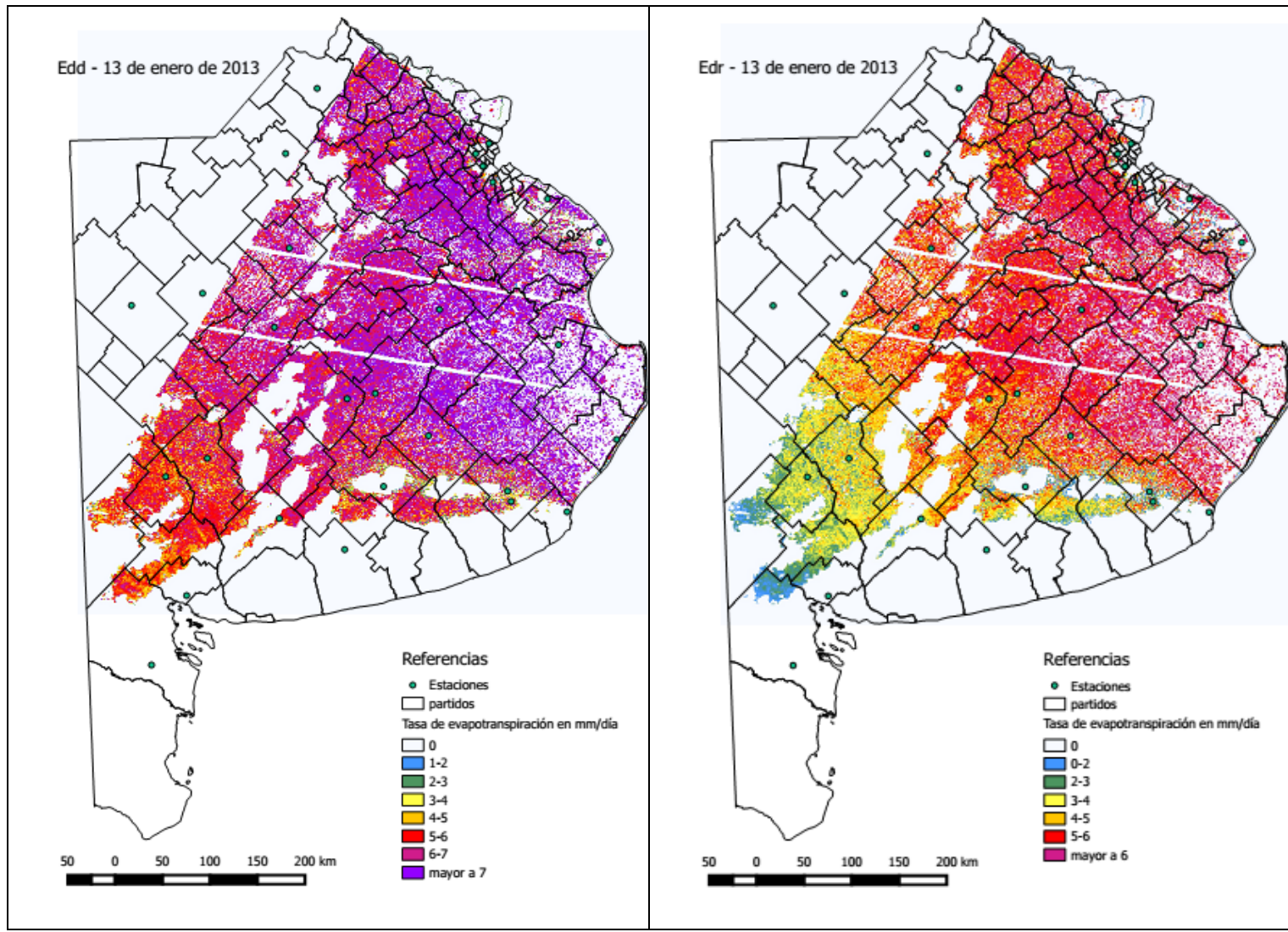

Figura A II -12: Imágenes del 13 de enero $-E_{\mathrm{dd}}$ y $E_{\mathrm{dr}}$ en $\mathrm{mm} /$ día $-\mathrm{y}$ productos MODIS de 16 días. 


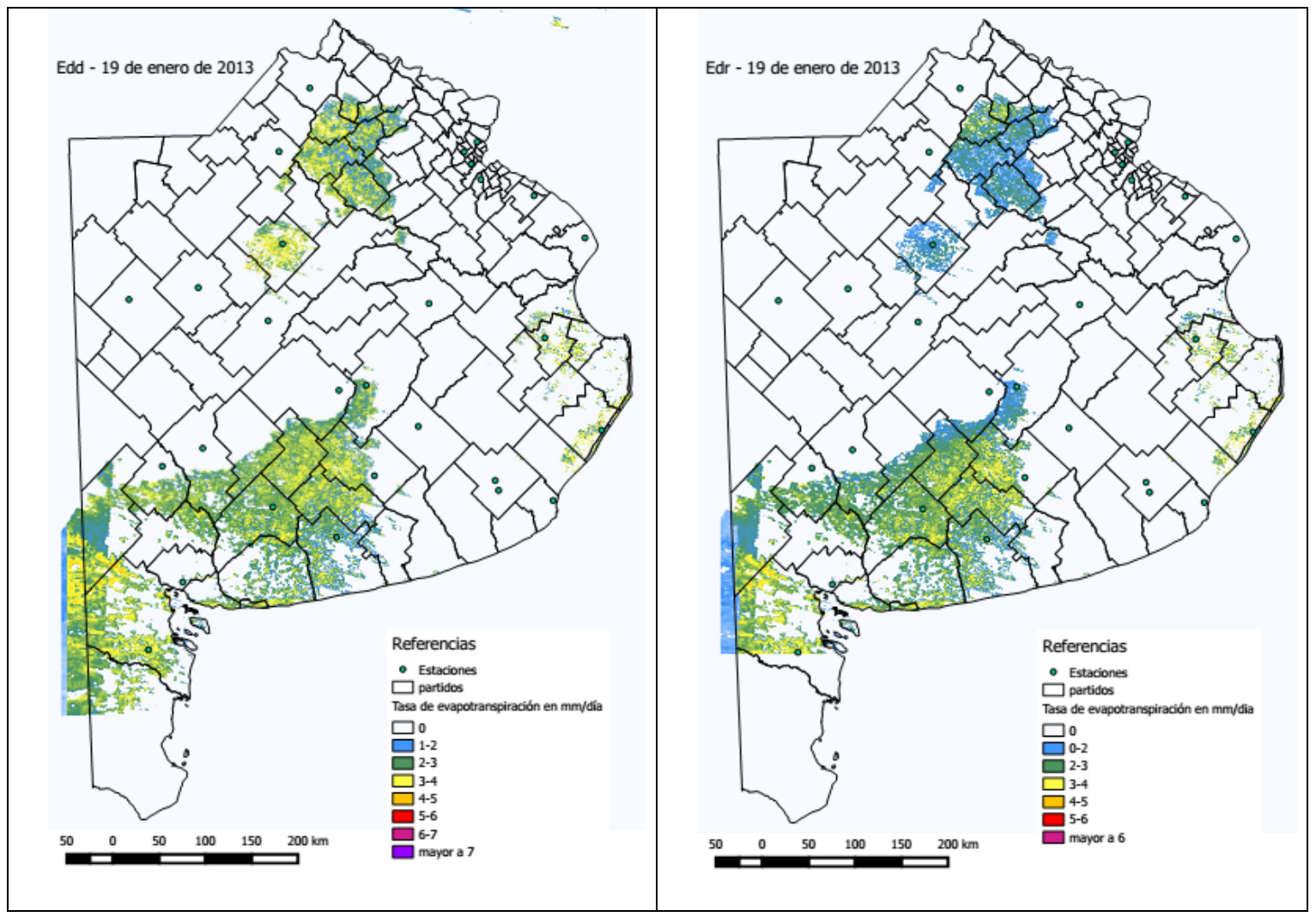

Figura A II -13: Imágenes del 19 de enero $-E_{\mathrm{dd}}$ y $E_{\mathrm{dr}}$ en $\mathrm{mm} /$ día - y productos MODIS diarios.

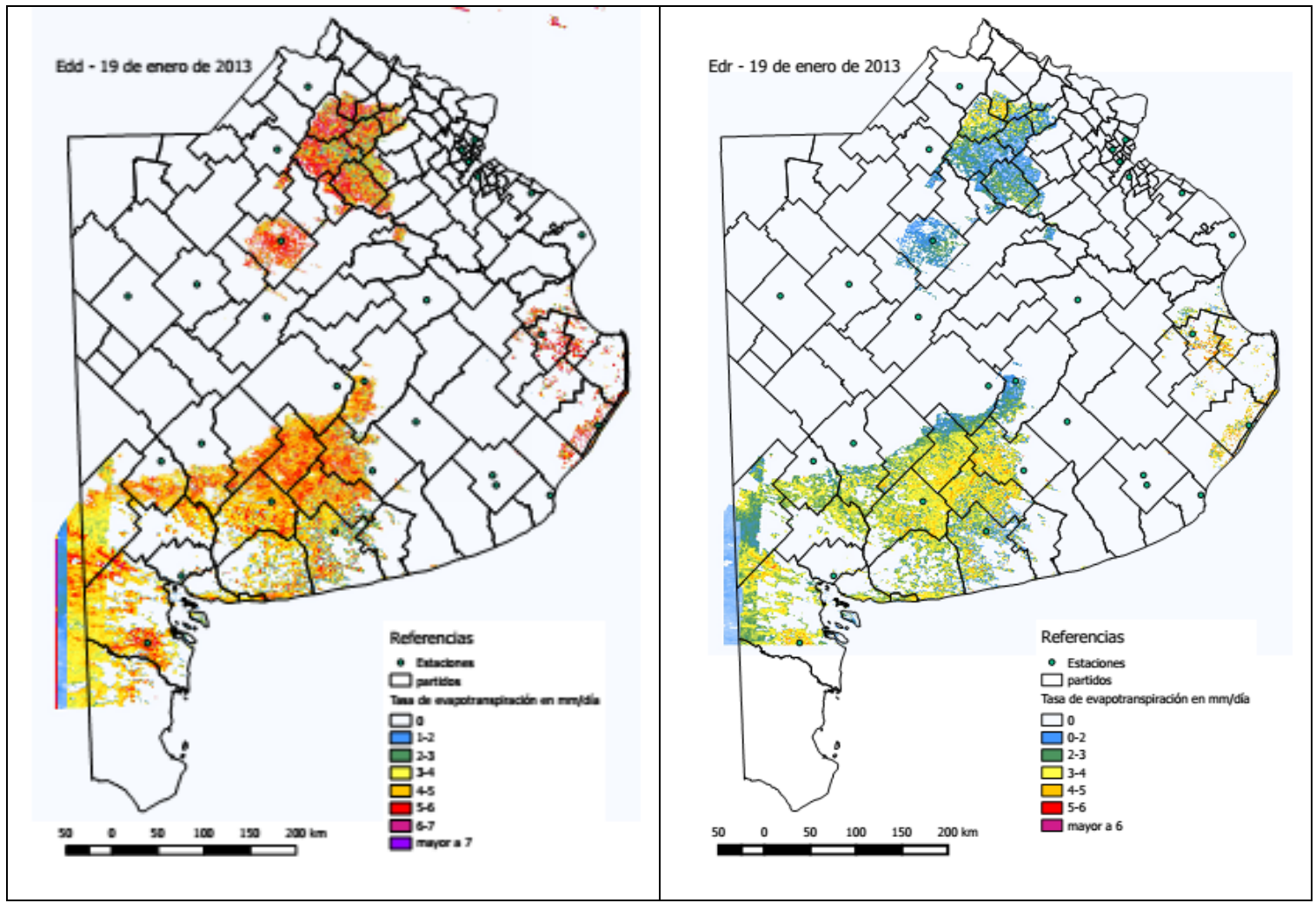

Figura A II -14: Imágenes del 19 de enero $-E_{\mathrm{dd}} \mathrm{y} E_{\mathrm{dr}}$ en mm/día - productos MODIS de 16 días. 
Anexo II

Como puede observarse en las figuras previas, la Evapotranspiración diaria en condiciones de cielo despejado siempre es mayor o igual que para días con cielo nublado. Lo cual es lógico debido a que la nubosidad disminuye la radiación y la temperatura, estando la evapotranspiración en dependencia de ellas, entre otros factores. 


\section{Anexo III - El sensor MODIS y GOES}

\section{1- Sensor MODIS}

El sensor Moderate Resolution Imaging Spectroradiometer (MODIS), creado por un grupo interdisciplinario de científicos de la National Aeronautics and Space Administration (NASA), se encuentra a bordo de los satélites Aqua y Terra. Es un sensor híperespectral que genera mediciones de radiancias en 36 canales, cubriendo el rango del espectro electromagnético del visible, infrarrojo cercano, infrarrojo medio e infrarrojo térmico. El tamaño del píxel es de $250 \mathrm{~m}$ para los canales del visible, $500 \mathrm{~m}$ para el infrarrojo cercano y 1000m para el infrarrojo térmico. Los satélites Aqua y Terra son heliosincrónicos y de órbita polar retrógrada. Repiten la visita sobre la misma franja terrestre (el camino) cada 16 días, y se encuentran a aproximadamente $705 \mathrm{~km}$ de altitud sobre la superficie terrestre. Todas sus características orbitales son similares a las de los satélites LANDSAT de recursos naturales. Los datos originales y los productos hechos por la NASA tienen acceso libre a través de internet.

Desde fines de los años 80 , surgieron varios proyectos para el monitoreo de la cobertura terrestre, lo que permitió el mapeo del planeta usando los datos del sensor Advanced Very High Resolution Raiometer (AVHRR), creado originariamente para el monitoreo climatológico, pero con buenos resultados en el mapeo de coberturas terrestre, motivando las bases a proyectos más aptos para el monitoreo de las coberturas terrestre como lo es el sensor MODIS.

En 1988 la NASA consultó a diferentes agencias espaciales y comunidad científica para la selección de cada uno de los sensores a bordo de diferentes plataformas, siendo seleccionados 30 instrumentos y sus equipos de ciencia y 20 proyectos de investigación (García-mora, Mas 2010).

La política para el manejo de datos del EOSDIS (Earth Observing System Data and Information System) se basa en dos principios: la no discriminación y la no exclusividad. La no discriminación está basada en la igualdad de trato para todos los usuarios en términos de acceso y uso de los datos al más bajo costo posible para la investigación científica. La no exclusividad se basa en que nadie haga uso indebido de los datos, y que las investigaciones realizadas deben ser publicadas en la literatura científica y de acceso público (Sadeh, 2002). 
Dentro del proyecto EOS sobresale el sensor MODIS. Fue diseñado por un equipo interdisciplinario de científicos con una vasta experiencia en sensores remotos. Este equipo trabajó por cerca de 10 años para finalmente definir los requisitos para la toma, calibración y procesamiento de los datos (Xiong, 2008). El equipo científico de MODIS Land (MODLAND) desarrolla métodos y algoritmos para generar productos sobre cubiertas terrestres.

Como ya se comentó, el sensor MODIS se encuentra a bordo de los satélites TERRA y AQUA, ambos con órbitas helio-sincrónica y cuasi-polar, con una inclinación de $98.2^{\circ}$ y $98^{\circ}$ y una altitud de 708 y $705 \mathrm{~km}$ respectivamente (NASA MODIS WEB, 2008). Terra está programada para pasar de norte a sur cruzando el ecuador a las 10:30 de la mañana en su órbita descendente, mientras que Aqua pasa de sur a norte sobre el ecuador a las 1:30 de la tarde.

El instrumento MODIS cuenta con una alta sensibilidad radiométrica (12 bit) en 36 bandas espectrales, en un rango de longitud de onda que va de los $0.4 \mu \mathrm{m}$ a los $14.4 \mu \mathrm{m}$ (Ver tabla AIII-1). Las primeras 19 bandas están posicionadas en la región del espectro electromagnético situado entre $0.405 \mu \mathrm{m}$ y $2.155 \mu \mathrm{m}$. Las bandas de la 1 a la 7 son útiles para las aplicaciones terrestres; las bandas 8 a la 16 para las observaciones oceánicas y las bandas 17 a 19 para las mediciones atmosféricas. Las bandas 20 a la 36, cubren la porción del infrarrojo térmico del espectro de $(3,660-14,385 \mu \mathrm{m})$ (NASA, 2008). Dos bandas ( 1 y 2) son tomadas a una resolución nominal de $250 \mathrm{~m}$ al nadir, cinco bandas ( 3 a 7) a $500 \mathrm{~m}$ y las 29 bandas restantes a $1 \mathrm{~km}$. MODIS posee una alta calidad geométrica que permite el monitoreo preciso de las alteraciones de la superficie terrestre (error RMS inferior a $50 \mathrm{~m}$ ).

a. Tiene un ancho de barrido de $2330 \mathrm{Km}$ y provee imágenes de alta resolución radiométrica de la radiación reflejada diurna y de la emisión térmica diurna y nocturna. Opera continuamente durante el día y la noche. Durante el día toma datos de todas las bandas (ver Tabla AIII-1) mientras que por la noche sólo las correspondientes al térmico. El instrumento es calibrado periódicamente. (http://www.conae.gov.ar/satelites/sac-c/terra/modis.html). 


\begin{tabular}{|c|c|c|}
\hline Banda No & Longitud de onda (m) & Resolución Espacial (m) \\
\hline 1 & $620-670$ & 250 \\
\hline 2 & $841-876$ & 250 \\
\hline 3 & $459-479$ & 500 \\
\hline 4 & $545-565$ & 500 \\
\hline 5 & $1230-1250$ & 500 \\
\hline 6 & $1628-1652$ & 500 \\
\hline 7 & $2105-2155$ & 500 \\
\hline 8 & $405-420$ & 1000 \\
\hline 9 & $438-448$ & 1000 \\
\hline 10 & $483-493$ & 1000 \\
\hline 11 & $526-536$ & 1000 \\
\hline 12 & $546-556$ & 1000 \\
\hline 13 & $662-672$ & 1000 \\
\hline 14 & $673-683$ & 1000 \\
\hline 15 & $743-753$ & 1000 \\
\hline 16 & $862-877$ & 1000 \\
\hline 17 & $890-920$ & 1000 \\
\hline 18 & $931-941$ & 1000 \\
\hline 19 & $915-965$ & 1000 \\
\hline 26 & $1360-1390$ & 1000 \\
\hline 20 & $3660-3840$ & 1000 \\
\hline 21 & 3929-3989 & 1000 \\
\hline 22 & 3929-3989 & 1000 \\
\hline 23 & $4020-4080$ & 1000 \\
\hline 24 & $4433-4498$ & 1000 \\
\hline 25 & $4482-4549$ & 1000 \\
\hline 27 & $6535-6895$ & 1000 \\
\hline 28 & $7175-7475$ & 1000 \\
\hline 29 & $8400-8700$ & 1000 \\
\hline 30 & $9580-9880$ & 1000 \\
\hline 31 & $10780-11280$ & 1000 \\
\hline 32 & $11770-12270$ & 1000 \\
\hline 33 & $13185-13485$ & 1000 \\
\hline 34 & $13485-13785$ & 1000 \\
\hline 35 & $13785-14085$ & 1000 \\
\hline 36 & $14085-14385$ & 1000 \\
\hline
\end{tabular}

Tabla AIII-1: Bandas y longitud de onda del sensor MODIS. - http://www.conae.gov.ar/satelites/sacc/terra/modis.html

En la Tabla AIII-2 se muestran los usos principales de las bandas MODIS

\begin{tabular}{|c|c|c|c|c|c|c|c|c|c|}
\hline Uso principal & Banda & $\begin{array}{l}\text { Ancho de } \\
\text { banda }^{1}\end{array}$ & $\begin{array}{l}\text { Radianza } \\
\text { espectral }\end{array}$ & $\begin{array}{l}\mathrm{SNR}^{3} \circ \mathrm{NE} \\
\text { (delta) } \mathrm{T} \text { re- } \\
\text { querido } \mathrm{T}(\mathrm{K})^{4}\end{array}$ & Uso principal & Banda & $\begin{array}{l}\text { Ancho de } \\
\text { banda }^{1}\end{array}$ & $\begin{array}{l}\text { Radianza } \\
\text { espectral }\end{array}$ & $\begin{array}{l}\mathrm{SNR}^{3} \circ \mathrm{NE} \\
\text { (delta) } \mathrm{Tre} \text { re } \\
\text { querido } \mathrm{T}(\mathrm{K})^{4}\end{array}$ \\
\hline \multirow{2}{*}{$\begin{array}{l}\text { Limites de Tierra/Nubes/ } \\
\text { aerosoles }\end{array}$} & 1 & $620-670$ & 21.8 & 128 & \multirow[t]{4}{*}{ Temperatura atmosférica } & 21 & $3.929-3.989$ & $2.38(335 K)$ & $2.00^{*}$ \\
\hline & 2 & $841-876$ & 24.7 & 201 & & 22 & $3.929-3.989$ & $0.67(300 K)$ & $0.07^{*}$ \\
\hline \multirow{5}{*}{$\begin{array}{l}\text { Propiedades de Tierra/ } \\
\text { Nubes/aerosoles }\end{array}$} & 3 & $459-479$ & 35.3 & 243 & & 23 & $4.020-4.080$ & $0.79(300 \mathrm{~K})$ & $0.07^{*}$ \\
\hline & 4 & $545-565$ & 29.0 & 228 & & 24 & $4.433-4.498$ & $0.17(250 K)$ & $0.25^{*}$ \\
\hline & 5 & $1230-1250$ & 5.4 & 74 & \multirow[t]{2}{*}{$\begin{array}{l}\text { Vapor de agua de nubes } \\
\text { Cirrus }\end{array}$} & 25 & $4.482-4.549$ & $0.59(275 K)$ & $0.25^{*}$ \\
\hline & 6 & $1628-1652$ & 7.3 & 275 & & 26 & $1.360-1.390$ & 6.00 & 150 \\
\hline & 7 & $2105-2155$ & 1.0 & 110 & \multirow{3}{*}{ Propiedades de las nubes } & 27 & $6.535-6.895$ & $1.16(240 \mathrm{~K})$ & $0.25^{*}$ \\
\hline \multirow{9}{*}{$\begin{array}{l}\text { Color del océano / } \\
\text { fitoplancton/biogeoquimica }\end{array}$} & 8 & $405-420$ & 44.9 & 880 & & 28 & $7.175-7.475$ & $2.18(250 \mathrm{~K})$ & $0.25^{*}$ \\
\hline & 9 & $438-448$ & 41.9 & 838 & & 29 & $8.400-8.700$ & $9.58(300 \mathrm{~K})$ & $0.05^{*}$ \\
\hline & 10 & $483-493$ & 32.1 & 802 & \multirow{5}{*}{$\begin{array}{l}\text { Ozono } \\
\text { Temperatura de la } \\
\text { superficie/nubes }\end{array}$} & 30 & $9.580-9.880$ & $3.69(250 K)$ & $0.25^{*}$ \\
\hline & 11 & $526-536$ & 27.9 & 754 & & 31 & 10.780 & $9.55(300 K)$ & $0.05^{*}$ \\
\hline & 12 & $546-556$ & 21.0 & 750 & & & -11.280 & & \\
\hline & 13 & $662-672$ & 9.5 & 910 & & 32 & 11.770 & $8.94(300 K)$ & $0.05^{*}$ \\
\hline & 14 & $673-683$ & 8.7 & 1087 & & & -12.270 & & \\
\hline & 15 & $743-753$ & 10.2 & 586 & \multirow[t]{6}{*}{ Altitud de las nubes } & 33 & $\begin{array}{l}13.185 \\
-13.485\end{array}$ & $4.52(260 \mathrm{~K})$ & $0.25^{*}$ \\
\hline & 16 & $862-877$ & 6.2 & 516 & & 34 & 13.485 & $3.76(250 \mathrm{~K})$ & $0.25^{*}$ \\
\hline \multirow[t]{3}{*}{ Vapor de agua atmosférico } & 17 & $890-920$ & 10.0 & 167 & & & -13.785 & & \\
\hline & 18 & $931-941$ & 3.6 & 57 & & \multirow[t]{2}{*}{35} & \multirow{2}{*}{$\begin{array}{l}13.785 \\
-14.085\end{array}$} & \multirow[t]{2}{*}{$3.11(240 \mathrm{~K})$} & \multirow[t]{2}{*}{$0.25^{*}$} \\
\hline & 19 & $915-965$ & 15.0 & 250 & & & & & \\
\hline $\begin{array}{l}\text { Temperatura de la superficie/ } \\
\text { nubes }\end{array}$ & 20 & $\begin{array}{l}3.660 \\
-3.840 \\
\end{array}$ & $0.45(300 \mathrm{~K})$ & $0.05^{*}$ & & 36 & $\begin{array}{l}14.085 \\
-14.385 \\
\end{array}$ & $2.08(220 K)$ & $0.35^{*}$ \\
\hline
\end{tabular}

Tabla AIII-2: Usos de las bandas MODIS 
La distribución de los productos MODIS son libres y gratuitas, en especial para la comunidad científica. Para este trabajo las imágenes fueron obtenidas desde la página web: http://reverb.echo.nasa.gov

\subsection{1 - Niveles de procesamiento:}

Los productos MODIS son divididos en cinco niveles (0 a 4) en función del grado de procesamiento realizado:

- Nivel 0: Son los datos brutos sin ningún tratamiento, como por ejemplo los paquetes de sincronización y los encabezados de comunicación entre el satélite y la estación de recepción.

- Nivel L1: Son los datos de geolocación (identificados como MOD03) que contiene coordenadas geodésicas, información sobre la elevación del terreno, máscara de tierra/agua, ángulo de elevación, cenit y azimut del satélite y del sol.

- Nivel 1A: Son los productos utilizados para la geolocalización, la calibración y el procesamiento. Contienen los niveles de radiancia (MOD01) de las 36 bandas, junto con datos auxiliares del sensor y del satélite como coeficientes de calibración radiométrica y corrección geométrica, parámetros de georreferenciación (efemérides de la plataforma).

- Nivel 1B: Son los productos que contienen las radiancias calibradas y con geolocación (MOD02) para las 36 bandas generadas por el nivel 1A. Es por lo tanto una imagen radiométricamente corregida y calibrada a unidades físicas Datos adicionales incluyen estimaciones de calidad, del error y datos de calibración.

- Nivel L2G: Son los productos que contienen variables geofísicas proyectadas en una malla uniforme. Los datos adquiridos durante un periodo fijo de tiempo (12 o 24 horas) son agrupados en una cuadrícula de 1,200 x 1,200 km, llamado tile, en la proyección sinusoidal de igual área.

- Nivel L2: Son los productos que contienen variables geofísicas. Estos productos se generan a partir del producto nivel L1B aplicando correcciones atmosféricas y algoritmos bio-ópticos. Estos productos generados pueden ser almacenados en gránulos, que corresponden a 5 minutos de datos colectados por MODIS, de tal forma que cada gránulo es de aproximadamente 2,340 x 2,330 km.

- Nivel 3: Son productos de valor agregado derivados de variables geofísicas mapeadas. En algunos casos, se realiza un remuestreo a una menor resolución espacial que las 
bandas originales y se elaboran compuestos de intervalos de tiempo establecidos $(1,8$, 16 y 30 días). Algunos productos de nivel 3 son; reflectancia (MOD09), índices de vegetación (MOD13), temperatura y emisividad de la superficie terrestre (MOD11) y puntos de calor e incendios (MOD14).

- Nivel 4: Son los productos generados por la incorporación de los datos MODIS en modelos para así estimar variables geofísicas (NASA, 2008). Estos productos se generan usando productos nivel L2 y datos auxiliares. Algunos ejemplos son el índice de área foliar / fracción de radiación activa fotosintética (MOD15), las coberturas del suelo (MOD12) y la producción primaria (MOD17).

Los productos de nivel 0, 1 y 2 son presentados en "gránulos", que corresponden a los datos sin proyectar tomados durante el paso del sensor durante cinco minutos, lo cual representa un área de aproximadamente 2,340 x 2,330 km. Los datos de niveles $2 \mathrm{G}, 3$, y 4 son distribuidos en mosaicos en proyección sinusoidal llamados tiles de aproximadamente $10 \times 10$ grados.

\subsection{2 - Breve descripción de los productos utilizados en el presente trabajo:}

MOD09: Reflectancia de la superficie. Corresponde a una evaluación de la reflectancia de las cubiertas terrestres (relación entre el flujo luminoso reflejado y el flujo luminoso incidente). La estimación de la reflectancia se realiza para todos los píxeles sin nubes para cada una de las 7 primeras bandas del sensor MODIS. Se corrigen los efectos atmosféricos producidos por gases, aerosoles y nubes cirrus. El cálculo es realizado con base en al radiancia al nivel del sensor (MOD02, nivel 1B), el procedimiento de corrección se basa en un modelo de transferencia radiativa desarrollado por Tanré et al (1986). En la Tabla AIII-3 se observan las características del MOD09. 


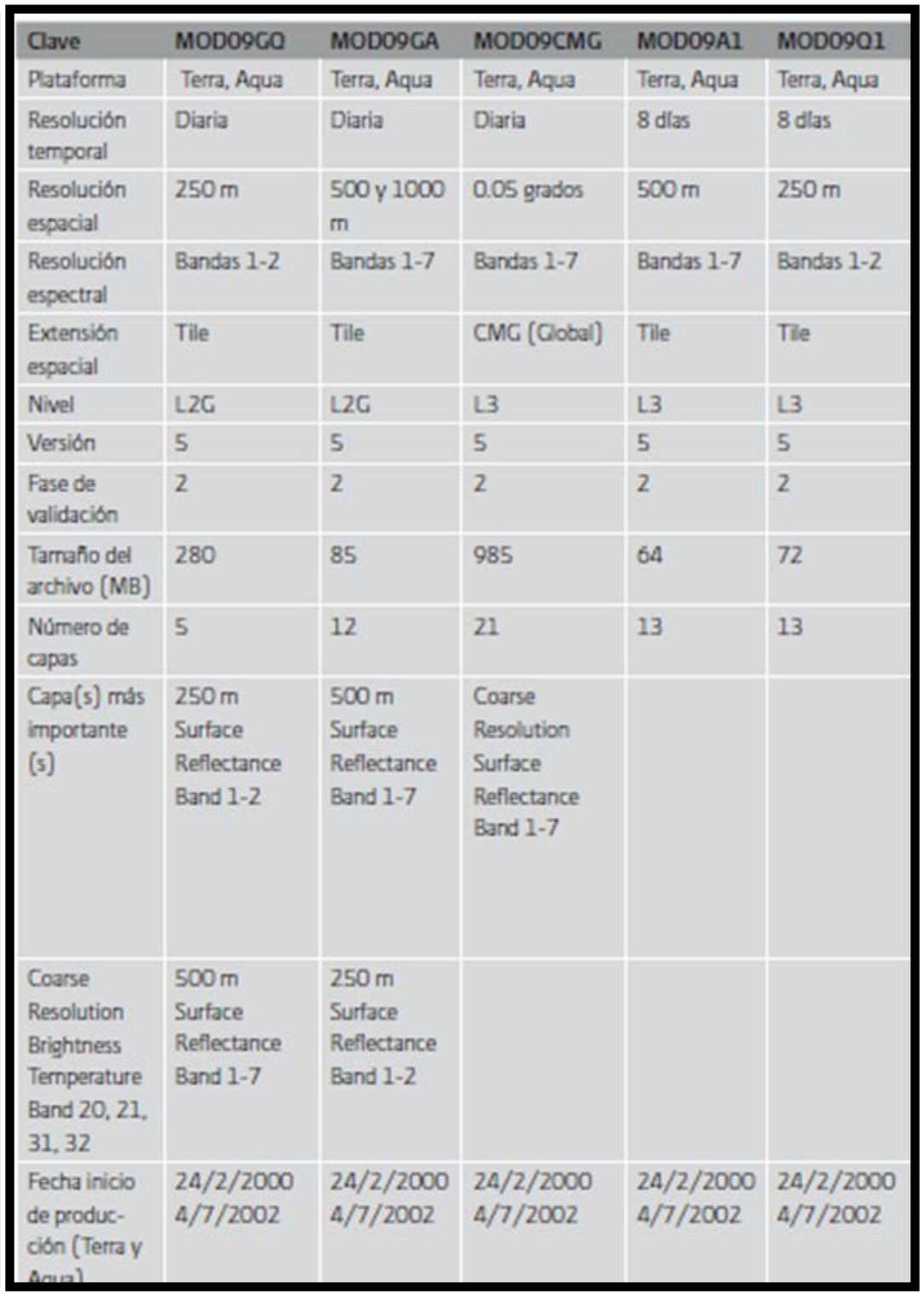

Tabla AIII-3: Características MOD09. Fuente: Aplicaciones del sensor MODIS para el monitoreo del territorio

MOD11: Temperatura y emisividad de la superficie terrestre. Brinda estimaciones de la temperatura y la emisividad diurna y nocturna de las coberturas terrestres. La temperatura se mide en grados Kelvin (K), la emisividad es adimensional y surge del cociente entre la radiación emitida por un objeto y un cuerpo negro a la misma temperatura. Para el cálculo de ambos productos se trabaja con dos imágenes diurnas y dos nocturnas en condiciones de cielo despejado y utilizando 7 bandas del infrarrojo medio y térmico (bandas 20, 22, 23, 29, 31 y 33) (Wan y Li, 2008)

Se llevaron a cabo campañas de validación en la estimación de temperaturas en áreas homogéneas en diferentes tipos de coberturas y mostraron un buen ajuste, con diferencia de menos de un grado para temperaturas entre -10 y $50^{\circ} \mathrm{C}$ (Wan y Li, 2008). 
Los productos MOD11 son producidos con una resolución espacial de $1000 \mathrm{~m}$ con base diaria y cada 8 días (MOD11A1 y MOD11A2). En la Tabla AIII-4 se observan las características del MOD11.

\begin{tabular}{|c|c|c|c|c|c|c|c|}
\hline Clave & MOD11_L2 & MOD11A1 & MOD11B1 & MOD11A2 & MOD11C1 & MODHC2 & MODHC3 \\
\hline Plataforma & Terra, Aqua & Terra, Aqua & Terra, Aqua & Terra, Aqua & Terra, Aqua & Terra, Aqua & Terra, Aqua \\
\hline $\begin{array}{l}\text { Resdución } \\
\text { temparal }\end{array}$ & escena & diario & diario & 8 das & diario & 8 das & mersual \\
\hline $\begin{array}{l}\text { Resdución } \\
\text { espacid }\end{array}$ & $1000 \mathrm{~m}$ & $1000 \mathrm{~m}$ & $6000 \mathrm{~m}$ & $1000 \mathrm{~m}$ & $0.05^{\circ}$ & $0.05^{\circ}$ & $0.05^{\circ}$ \\
\hline $\begin{array}{l}\text { Extensión } \\
\text { espocid }\end{array}$ & exens & Tile & Tile & Tile & CMC & CMC & CNC \\
\hline Nivel & L2 & L3 & L3 & L3 & $L 3$ & L3 & L3 \\
\hline Versión & 5 & 5 & 5 & 5 & 5 & 5 & 5 \\
\hline $\begin{array}{l}\text { Fase de } \\
\text { validución }\end{array}$ & 2 & 2 & 2 & 2 & 2 & 2 & 2 \\
\hline $\begin{array}{l}\text { Tamaño del } \\
\text { archivo (MB) }\end{array}$ & 6 & 4 & $a_{4}$ & 5 & 50 & 70 & 80 \\
\hline $\begin{array}{l}\text { Número de } \\
\text { capas }\end{array}$ & 9 & 12 & 18 & 12 & 16 & 17 & 17 \\
\hline $\begin{array}{l}\text { Capa(s) más } \\
\text { importante(s) }\end{array}$ & $\begin{array}{l}\text { LST } \\
\text { (temperatura) }\end{array}$ & & & & & & \\
\hline $\begin{array}{l}\text { Lapa(s) mass } \\
\text { mportante(s) }\end{array}$ & $\begin{array}{l}\text { LST (tempera- } \\
\text { tura) Emis_31. } \\
\text { Emis_32 }\end{array}$ & $\begin{array}{l}\text { LST_Day_llkm } \\
\text { LST_- } \\
\text { Night__km } \\
\text { (tempertura } \\
\text { diay noches) } \\
\text { Emis_31 } \\
\text { yEmis_32 } \\
\text { (emisividad) }\end{array}$ & $\begin{array}{l}\text { LST_Day_Glom } \\
\text { LST_- } \\
\text { Nighto6m } \\
\text { Emis_20,22, } \\
23,29,31,32\end{array}$ & $\begin{array}{l}\text { LST_Day_1km } \\
\text { LST_- } \\
\text { Night_Lkm } \\
\text { (tempertug } \\
\text { diaynoches) } \\
\text { Emis_31 } \\
\text { yEmis_32 } \\
\text { (emisididad) }\end{array}$ & $\begin{array}{l}\text { LST_Day_- } \\
\text { CMḠLST_- } \\
\text { Night_CMG } \\
\text { Emis } 20,22 \text {, } \\
23,29,31,32\end{array}$ & $\begin{array}{l}\text { LST_Day__ } \\
\text { CMÉLITT_ } \\
\text { Night_CMC } \\
\text { Emis_20,22, } \\
23,29,31,32\end{array}$ & $\begin{array}{l}\text { LST_Day_ } \\
\text { OMG LST_- } \\
\text { Night_CMC } \\
\text { Emis_20, 22, } \\
23, \overline{29}, 31,32\end{array}$ \\
\hline $\begin{array}{l}\text { echa de hicio } \\
\text { e producción } \\
\text { Tera y Aqua) }\end{array}$ & $\begin{array}{l}5 / 3 / 2000 \\
4 / 7 / 2002\end{array}$ & $\begin{array}{l}5 / 3 / 2000 \\
8 / 7 / 2002\end{array}$ & $\begin{array}{l}5 / 3 / 2000 \\
8 / 7 / 2002\end{array}$ & $\begin{array}{l}5 / 3 / 2000 \\
4 / 7 / 2002\end{array}$ & $\begin{array}{l}5 / 3 / 2000 \\
8 / 7 / 2002\end{array}$ & $\begin{array}{l}5 / 3 / 2000 \\
4 / 7 / 2002\end{array}$ & $\begin{array}{l}5 / 3 / 2000 \\
1 / 7 / 2002\end{array}$ \\
\hline
\end{tabular}

Tabla AIII-4: Características MOD11. Fuente: Aplicaciones del sensor MODIS para el monitoreo del territorio

MOD43: Albedo. Este producto describe el albedo, los parámetros de distribución de la función de reflectancia bidireccional (BRDF por sus siglas en inglés) que caracteriza la anisotropía de las coberturas del suelo y la reflectancia corregida por esta función. Debido a que la superficie terrestre es anisotrópica, es decir que, dependiendo del ángulo de iluminación solar, la energía reflejada no será la misma en todas las direcciones como ocurre en una superficie isotrópica.

El albedo, relación (expresada en porcentaje) de la radiación que refleja cualquier superficie sobre la radiación que incide sobre la misma, es un parámetro muy importante para evaluar el balance energético de nuestro planeta.

El algoritmo permite evaluar los parámetros de un modelo semi empírico, que permite describir la anisotropía de cada píxel tomando en cuenta la dispersión y las sombras (Lucht et al., 2000). Los parámetros utilizados en BRDF se aplican a las reflectancias del MOD09 tomando en cuenta el ángulo solar al mediodía local. Según liang et al 
(2002) y Román et al (2009) la comparación entre las reflectancias ajustadas y los datos Landsat mostraron una buena correspondencia.

Se presentan, además, estimaciones de la reflectancia bihemisférica ("White Sky") que se puede definir como el albedo en ausencia de la componente directa cuando la componente difusa es isotrópica y la reflectancia direccional esférica ("Black Sky") que se define como el albedo en ausencia de la componente difusa en función del ángulo cenital solar. El producto es un compuesto de 16 días que se produce cada 8 días. En la Tabla AIII-5 se observan las características del MOD43.

\begin{tabular}{|c|c|c|c|c|c|c|c|c|c|c|c|c|}
\hline Clave & $\begin{array}{l}\text { MOD } \\
4341\end{array}$ & $\begin{array}{l}100 \\
1342\end{array}$ & $\begin{array}{l}190 D \\
43 A 3\end{array}$ & $\begin{array}{l}M O D \\
4394\end{array}$ & $\begin{array}{l}\text { MCO } \\
4381\end{array}$ & $\begin{array}{l}\text { MOD } \\
4382\end{array}$ & $\begin{array}{l}\text { MOD } \\
4383\end{array}$ & $\begin{array}{l}1900 \\
4384\end{array}$ & $\begin{array}{l}1900 \\
43 C 1\end{array}$ & $\begin{array}{l}\text { MOD } \\
4 \times 2\end{array}$ & $\begin{array}{l}\text { MOD } \\
43 C 3\end{array}$ & $\begin{array}{l}\text { MOD } \\
43 C 4\end{array}$ \\
\hline Pacalorma & Combinada & & & & & & & & & & & \\
\hline $\begin{array}{l}\text { Resolucihn } \\
\text { tamparal }\end{array}$ & $26 \mathrm{~d}$ 's & $6 \mathrm{~d} d x$ & 16 dhs & 16 dias & $26 d x$ & $26 \mathrm{des}$ & 16 d'as & 16 dis & 10 d'as & $20 d x$ & 16 dbs & 16 d'as \\
\hline $\begin{array}{l}\text { Resolucion } \\
\text { espocial }\end{array}$ & $500 \mathrm{~m}$ & $\infty \mathrm{m}$ & $500 \mathrm{~m}$ & $500 \mathrm{~m}$ & $1000 \mathrm{~m}$ & $1000 \mathrm{~m}$ & $1000 \mathrm{~m}$ & $1000 \mathrm{~m}$ & $0.05^{\circ}$ & oos. & a.cos" & $0.05^{\circ}$ \\
\hline $\begin{array}{l}\text { Extensidn } \\
\text { espocial }\end{array}$ & nile & tile & Tive & The & nile & Tik & nile & Tik & CMC & CMC & CMC & CMC \\
\hline Nhel & 13 & 3 & 13 & 13 & 13 & 13 & 13 & 23 & 13 & 13 & $L 3$ & 13 \\
\hline Versiba & 5 & & 5 & 5 & 5 & 5 & 5 & 5 & 5 & 5 & 5 & 5 \\
\hline $\begin{array}{l}\text { Fasede } \\
\text { validacion }\end{array}$ & 2 & & 2 & 2 & 2 & 2 & 2 & 2 & 2 & 2 & 2 & 2 \\
\hline $\begin{array}{l}\text { Tanalo } \\
\text { delarhivo } \\
\text { (MB) }\end{array}$ & 41 & & 31 & 16 & $\mathbf{u}$ & 0.4 & 9 & 4 & 231 & 237 & 185 & 83 \\
\hline $\begin{array}{l}\text { Nómen de } \\
\text { apas }\end{array}$ & 11 & & 20 & 7 & 11 & 4 & 20 & 7 & 34 & 33 & 24 & 11 \\
\hline Clave & $M C O 43 A 1$ & $\begin{array}{l}\text { MOD } \\
43 A 2\end{array}$ & $\begin{array}{l}\text { MCO } \\
43 a 3\end{array}$ & $\begin{array}{l}\text { MOD } \\
43 A 4\end{array}$ & $\begin{array}{l}\text { MOD } \\
43 B 1 \\
\end{array}$ & $\begin{array}{l}\text { MCO } \\
43 B 2\end{array}$ & $\begin{array}{l}\text { MOD } \\
4383\end{array}$ & $\begin{array}{l}\text { MOD } \\
43 B 4\end{array}$ & $\begin{array}{l}\text { MOD } \\
43 C 1\end{array}$ & $\begin{array}{l}M O D \\
43 C 2\end{array}$ & $\begin{array}{l}\text { MOD } \\
43 \mathrm{C} 3\end{array}$ & $\begin{array}{l}\text { MOD } \\
43 C 4\end{array}$ \\
\hline $\begin{array}{l}\text { Capas(s) mbs } \\
\text { imponante(s) }\end{array}$ & 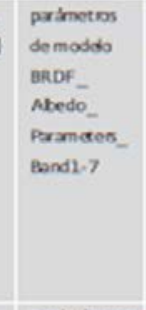 & $\begin{array}{l}\text { BRDF_ } \\
\text { Mbado_ } \\
\text { Oualty }\end{array}$ & $\begin{array}{l}\text { Abodo_ } \\
\text { BSa_ } \\
\text { lland_1-7 } \\
\text { abedo_ } \\
\text { usa_ } \\
\text { and_1-7 }\end{array}$ & $\begin{array}{l}\text { Nodil_- } \\
\text { Reflex- } \\
\text { unce- } \\
\text { Eondi-7 }\end{array}$ & $\begin{array}{l}\text { Brof_- } \\
\text { Albedo_ } \\
\text { Pame } \\
\text { ten_. } \\
\text { Bandi }\end{array}$ & $\begin{array}{l}\text { expof_- } \\
\text { abedo_ } \\
\text { aualty }\end{array}$ & $\begin{array}{l}\text { Albedo_ } \\
\text { BSa_ } \\
\text { Bnd_1-7 } \\
\text { Albedo_ } \\
\text { wisa_ } \\
\text { Band_1-7 }\end{array}$ & $\begin{array}{l}\text { Nadit- } \\
\text { Roflac- } \\
\text { tance- } \\
\text { Bandi-7 }\end{array}$ & $\begin{array}{l}\text { BRDF__ } \\
\text { Albedo_- } \\
\text { Paramete } \\
1.2 .3 \text { _- } \\
\text { Bendl-7. } \\
\text { nit, vis. } \\
\text { shortwave }\end{array}$ & $\begin{array}{l}\text { BRDF_, } \\
\text { qualty }\end{array}$ & 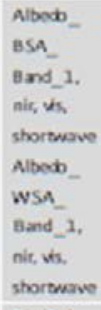 & $\begin{array}{l}\text { Nalit_- } \\
\text { Refle- } \\
\text { tance- } \\
\text { Bands-? }\end{array}$ \\
\hline $\begin{array}{l}\text { Fechade ini- } \\
\text { cia de produo } \\
\text { cion (Tema y } \\
\text { combinado) }\end{array}$ & $\begin{array}{l}24 / 2 / 2000 \\
18 / 2 / 2000\end{array}$ & $\begin{array}{r}24 / 2 / \\
2000 \\
18 / 2 / \\
2000 \\
\end{array}$ & $\begin{array}{r}24 / 21 \\
2000\end{array}$ & $\begin{array}{r}24 / 21 \\
2000\end{array}$ & $\begin{array}{r}24 / 21 \\
2000 \\
18 / 2 / \\
2000\end{array}$ & $\begin{array}{r}24 / 2 / \\
2000 \\
18 / 2 / \\
2000\end{array}$ & $\begin{array}{r}24 / 2 / \\
2000\end{array}$ & $\begin{array}{l}24 / 21 \\
2000\end{array}$ & $\begin{array}{c}24 / 21 \\
2000 \\
18 / 21 \\
2000\end{array}$ & $\begin{array}{r}24 / 2 / \\
2000 \\
18 / 2 / \\
2000\end{array}$ & $\begin{array}{r}24 / 21 \\
2000\end{array}$ & $\begin{array}{r}24 / 2 / \\
2000\end{array}$ \\
\hline
\end{tabular}

Tabla AIII-5: Características MOD43. Fuente: Aplicaciones del sensor MODIS para el monitoreo del territorio

MOD13: Índices de vegetación. Presenta dos índices de vegetación. El índice de vegetación de diferencia normalizada (NDVI) y el índice de vegetación mejorado (EVI). El empleo de los índices de vegetación, son ampliamente utilizados para discriminar masas vegetales, lo cual deriva de un peculiar comportamiento de la vegetación. Como puede apreciarse en la figura 1 en el capítulo 4; la firma espectral de la vegetación sana muestra un claro contraste entre las bandas del visible (especialmente la roja - $\mathrm{R}-0.6 \mathrm{a}$ $0.7 \mu \mathrm{m}$ ) y el infrarrojo cercano (IRC -0.7 a $1.1 \mu \mathrm{m}$ ) (Chuvieco et al, 2002). Este 
contraste muestra como la radiación solar es absorbida en las bandas del visible, mientras es altamente reflejada en el IRC.

A partir de esta particularidad de la vegetación que surgen los diferentes índices de vegetación.

El producto MOD13 procesa y brinda dos de ellos.

$$
\begin{gathered}
N D V I=\frac{(I R C-R)}{(R+I R C)} \\
E V I=2.5 \times\left[\frac{(I R C-R)}{(I R C+6 \times R-7.5 A+1)}\right]
\end{gathered}
$$

Donde, A es la banda de azul

El algoritmo para elaborar los compuestos de 16 días opera para cada píxel y consiste en seleccionar las "mejores" observaciones durante dichos días. Una vez colectados los datos, el algoritmo aplica un filtro basado en la calidad, presencia de nubes y geometría de observación y solo los píxeles de mayor calidad se toman en cuenta para la elaboración del compuesto (Van Leeuwen et al., 1999). En la Tabla AIII-6 se observan

\begin{tabular}{|c|c|c|c|c|c|c|}
\hline Clave & $\begin{array}{l}\text { MOD } \\
1301\end{array}$ & $\begin{array}{l}\text { MOD } \\
13 A 1\end{array}$ & $\begin{array}{l}\text { MOD } \\
13 A 2\end{array}$ & $\begin{array}{l}\text { MOD } \\
13 A 3\end{array}$ & $\begin{array}{l}\text { MOD } \\
13 \mathrm{Cl}\end{array}$ & $\begin{array}{l}\text { MOD } \\
13 C 2\end{array}$ \\
\hline Plataforma & Terra Aqua & Terra Aqua & Terra Aqua & Terra Aqua & Terra Aqua & Terra Aqua \\
\hline $\begin{array}{l}\text { Resolución } \\
\text { temporal }\end{array}$ & 16-dlas & 16 dlas & 16 dlas & Mensual & 16 dlas & Mensual \\
\hline $\begin{array}{l}\text { Resolución } \\
\text { espacial }\end{array}$ & $250 \mathrm{~m}$ & $500 \mathrm{~m}$ & $1 \mathrm{~km}$ & $1 \mathrm{~km}$ & $\begin{array}{l}0.05 \\
\text { grados }\end{array}$ & $\begin{array}{l}0.05 \\
\text { grados }\end{array}$ \\
\hline $\begin{array}{l}\text { Extensión } \\
\text { espacial }\end{array}$ & Tile & Tile & Tile & Tile & CMG & CMG \\
\hline Nivel & 13 & L3 & L3 & 13 & L3 & 13 \\
\hline $\begin{array}{l}\text { Fase de } \\
\text { validación }\end{array}$ & 2 & 2 & 2 & 2 & 2 & 2 \\
\hline Version & 5 & 5 & 5 & 5 & 5 & 5 \\
\hline $\begin{array}{l}\text { Tamaño } \\
\text { del archivo } \\
\text { (MB) }\end{array}$ & $5-270$ & $2-77$ & $1-22$ & $0.15-20$ & 35.5 & 19 \\
\hline $\begin{array}{l}\text { Núrnero de } \\
\text { capas }\end{array}$ & 12 & 12 & 12 & 11 & 13 & 13 \\
\hline $\begin{array}{l}\text { Capa(s) } \\
\text { más impor- } \\
\text { tante (s) }\end{array}$ & NDVI, EVI & NDVI, EVI & NDVI, EVI & NDVL, EVI & NDVI, EVI & NDVI, EVI \\
\hline $\begin{array}{l}\text { Fecha de } \\
\text { inicio de } \\
\text { producción } \\
\text { (Terray } \\
\text { Aqua) }\end{array}$ & $\begin{array}{r}24 / 21 \\
2000 \\
14 / 7 / \\
2002\end{array}$ & $\begin{array}{r}24 / 2 / \\
2000 \\
14 / 7 / \\
2002\end{array}$ & $\begin{array}{r}24 / 2 / \\
2000 \\
14 / 7 / \\
2002\end{array}$ & $\begin{array}{c}18 / 2 / \\
2000 \\
1 / 7 / \\
2002\end{array}$ & $\begin{array}{r}18 / 2 / \\
2000 \\
14 / 7 / \\
2002\end{array}$ & $\begin{array}{c}18 / 2 / \\
2000 \\
1 / 7 / \\
2002\end{array}$ \\
\hline
\end{tabular}
las características del MOD13.

Tabla AIII-6: Características MOD13. Fuente: Aplicaciones del sensor MODIS para el monitoreo del territorio. 
La descripción previa corresponde a los "productos de superficie terrestre" (MODLAND).

A continuación, se describe el MOD07, correspondiente a los "productos de atmósfera". MOD 07: Perfiles atmosféricos. Los productos atmosféricos de MODIS consisten en varios parámetros. Ellos son: carga total de ozono, estabilidad atmosférica, perfiles de temperatura y de humedad, vapor de agua de la atmósfera. Todos estos parámetros son producidos para el día y la noche para el nivel 2 con $1 \mathrm{~km}$ de resolución espacial. Los productos MOD07 contienen datos colectados por la plataforma TERRA, mientras que MYD07 de la plataforma AQUA.

La carga total de ozono se estima a través del contenido total en la columna troposférica y estratosférica. La estabilidad atmosférica consiste en tres índices del nivel 2, como son el TT (Total Totals) el LI (índice de elevación) y el índice K. Se calcula a partir de los datos de temperatura y humedad de los perfiles en el infrarrojo derivados del MOD07. Los perfiles de temperatura y humedad se producen a 20 niveles verticales. Se utiliza un algoritmo para cielo claro donde se derivan los coeficientes de regresión mediante el uso de un modelo de transferencia radiativa atmosférica y datos de radiosondeo vertical. El producto del vapor de agua es una estimación de la columna total del vapor de agua a partir de datos infrarrojos integrados en los perfiles de humedad atmosférica en escenas claras.

Para estos productos son usados los canales 24, 25, 27, 28, 29, 30, 31, 32, 33, 34, 35 y 36.

La validación de los productos resulta de la comparación con mediciones in situ con radiosonda, radiómetro de microondas y mediciones GPS. El control de calidad consiste en inspecciones manuales y automáticas, con temperaturas medias regionales $\mathrm{y}$ mundiales a 300-500-700 hPa (diferentes alturas), monitoreado semanalmente. A su vez, temperaturas de rocío a $700 \mathrm{hPa}$ y vapor de agua atmosférico.

MOD07_L2 Sets de datos científicos (SDS):

Fuente: http://modis-atmos.gsfc.nasa.gov/MOD07_L2/format.html

$\underline{\text { Geolocation and Time Parameters }}$

- Latitude

Description: Geodetic Latitude

Dimensions: (Cell_Along_Swath, Cell_Across_Swath)

Valid Range: -90 to +90 degrees north 
- Longitude

Description: Geodetic Longitude

Dimensions: (Cell_Along_Swath, Cell_Across_Swath)

Valid Range: -180 to +180 degrees east

- Scan_Start_Time

Description: International Atomic Time at Start of Scan replicated across the Swath

Dimensions: (Cell_Along_Swath, Cell_Across_Swath)

Valid Range: 0.0 to $3.1558 \mathrm{E}+9$ seconds since 1 January 1993

00:00:00

\section{$\underline{\text { Solar and Viewing Geometry Parameters }}$}

- Solar_Zenith

Description: Solar Zenith Angle, Cell to Sun

Dimensions: (Cell_Along_Swath, Cell_Across_Swath)

Valid Range: 0 to +180 degrees

- Solar_Azimuth

Description: Solar Azimuth Angle, Cell to Sun

Dimensions: (Cell_Along_Swath, Cell_Across_Swath)

Valid Range: -180 to +180 degrees

- Sensor_Zenith

Description: Sensor Zenith Angle, Cell to Sensor

Dimensions: (Cell_Along_Swath, Cell_Across_Swath)

Valid Range: 0 to 180 degrees

- Sensor_Azimuth

Description: Sensor Azimuth Angle, Cell to Sensor

Dimensions: (Cell_Along_Swath, Cell_Across_Swath)

Valid Range: -180 to 180 degrees

$\underline{\text { Science Parameters }}$

- Brightness_Temperature

Description: Brightness Temperature

Dimensions: (Band_Number, Cell_Along_Swath, Cell_Across_Swath)

Valid Range: 150 to $350 \mathrm{~K}$

- Skin_Temperature 
Description: Surface Temperature

Dimensions: (Cell_Along_Swath, Cell_Across_Swath)

Valid Range: 150 to $350 \mathrm{~K}$

- Surface_Pressure

Description: Surface_Pressure

Dimensions: (Cell_Along_Swath, Cell_Across_Swath)

Valid Range: 800 to $1100 \mathrm{hPa}$

- Surface_Elevation

Description: Surface_Elevation

Dimensions: (Cell_Along_Swath, Cell_Across_Swath)

Valid Range: -400 to 8840 meters

- Processing_Flag

Description: Processing_Flag

Dimensions: (Cell_Along_Swath, Cell_Across_Swath)

Valid Range: byte array

- Tropopause_Height

Description: Tropopause_Height

Dimensions: (Cell_Along_Swath, Cell_Across_Swath)

Valid Range: 1 to $1100 \mathrm{hPa}$

- Guess_Temperature_Profile

Description: Guess_Temperature_Profile

Dimensions: (Pressure_Level, Cell_Along_Swath,

Cell_Across_Swath)

Valid Range: 150 to $350 \mathrm{~K}$

- Guess_Moisture_Profile

Description: Guess Dew Point Temperature Profile

Dimensions: (Pressure_Level, Cell_Along_Swath,

Cell_Across_Swath)

Valid Range: 150 to $350 \mathrm{~K}$

- Retrieved_Temperature_Profile

Description: Retrieved Temperature Profile

Dimensions: (Pressure_Level, Cell_Along_Swath,

Cell_Across_Swath)

Valid Range: 150 to $350 \mathrm{~K}$

- Retrieved_Moisture_Profile

Description: Retrieved Dew Point Temperature Profile

Dimensions: (Pressure_Level, Cell_Along_Swath, 
Cell_Across_Swath)

Valid Range: 150 to $350 \mathrm{~K}$

- Retrieved_Height_Profile

Description: Retrieved Geopotential Height Profile

Dimensions: (Pressure_Level, Cell_Along_Swath, Cell_Across_Swath)

Valid Range: 0 to 65000 meters

- Total_Ozone

Description: Total Ozone Burden

Dimensions: (Cell_Along_Swath, Cell_Across_Swath)

Valid Range: 0 to 500 Dobson units

- Total_Totals

Description: Total Totals

Dimensions: (Cell_Along_Swath, Cell_Across_Swath)

Valid Range: 0 to $80 \mathrm{~K}$

- Lifted_Index

Description: Lifted Index

Dimensions: (Cell_Along_Swath, Cell_Across_Swath)

Valid Range: -20 to $40 \mathrm{~K}$

- K_Index

Description: K Index

Dimensions: (Cell_Along_Swath, Cell_Across_Swath)

Valid Range: 268 to $340 \mathrm{~K}$

- Water_Vapor

Description: Total Column Precipitable Water Vapor - IR Retrieval Dimensions: (Cell_Along_Swath, Cell_Across_Swath)

Valid Range: 0 to $20 \mathrm{~cm}$

- Water_Vapor_Direct

Description: Total Column Precipitable Water Vapor - Direct IR

Retrieval

Dimensions: (Cell_Along_Swath, Cell_Across_Swath)

Valid Range: 0 to $20 \mathrm{~cm}$

- Water_Vapor_Low

Description: Precipitable Water Vapor Low - IR Retrieval

Dimensions: (Cell_Along_Swath, Cell_Across_Swath)

Valid Range: 0 to $20 \mathrm{~cm}$ 
- Water_Vapor_High

Description: Precipitable Water Vapor High - IR Retrieval Dimensions: (Cell_Along_Swath, Cell_Across_Swath) Valid Range: 0 to $20 \mathrm{~cm}$

Quality Assurance

- Quality_Assurance

Description: Quality Assurance Parameters

Dimensions: (Cell_Along_Swath, Cell_Across_Swath, Output_Parameter)

Valid Range: bit field

- Quality_Assurance_Infrared

Description: Runtime Quality Assurance Flags for

Water_Vapor_Infrared

Dimensions: (Cell_Along_Swath, Cell_Across_Swath,

Water_Vapor_QA_Bytes)

Valid Range: bit field

$\underline{\text { Cloud Mask }}$

- Cloud_Mask

Description: MODIS Cloud Mask, First Byte

Dimensions: (Cell_Along_Swath, Cell_Across_Swath)

Valid Range: bit field

MOD07_L2 VData (Tables) List

- Band_Number

Description: MODIS Band Number

Dimensions: (Band_Number)

Data Values: 20, 22, 23, 24, 25, 27, 28, 29, 30, 31, 32, 33, 34, 35,

36

- Pressure_Level

Description: Pressure Levels of Profiles

Dimensions: (Band_Number)

Data Values: 05., 10., 20., 30., 50., 70., 100., 150., 200., 250., 300., 400., 500., 620., 700., 780., 850., 920., 950., 1000.

Units: hPa

\subsection{Sensor y satélite GOES}


Los satélites son geosincrónicos cuando orbitan alrededor de la Tierra con una velocidad angular media igual a la de rotación de ésta, acompañando el movimiento y con un período orbital igual al día sidéreo ( 23 hs 56 min 4,091 s ó 23,93447hs).

Los satélites geoestacionarios (fijos en la esfera celeste para un observador terrestre) son geosincrónicos, y sus órbitas cumplen además con otras dos condiciones: una, son circulares (excentricidad nula); y otra, pertenecen al plano ecuatorial.

El valor de equilibrio entre las aceleraciones de la gravedad y centrífuga corresponde a una altura "h" sobre la superficie de la Tierra igual a $35790 \mathrm{~km}$, o unas 5,5 veces el radio terrestre (unas 50 a 100 veces mayor que en el caso de un satélite de órbita baja). Desde esa distancia, el satélite "observa" a la Tierra con el tamaño aproximado de una pelota de fútbol distante unos $80 \mathrm{~cm}$ del ojo humano. Ve el disco terrestre hasta $82^{\circ}$ de latitud norte y sur.

El Geostationary Operational Environmental Satellite (GOES) es operado por la National Oceanic and Atmospheric Administration (NOAA) en dos ubicaciones diferentes: Este $\left(75^{\circ}\right.$ Este) y Oeste $\left(135^{\circ}\right.$ Oeste). La serie actualmente en uso tiene un sensor multiespectral (5 canales). Un canal en el visible, otro en el infrarrojo medio y otros tres en el infrarrojo térmico.

Se muestra a continuación en la Figura AIII-1 una imagen GOES-Este del canal visible (centrado en $0.65 \mu \mathrm{m}$ ) realzada en falso color compuesto con la técnica RGB.

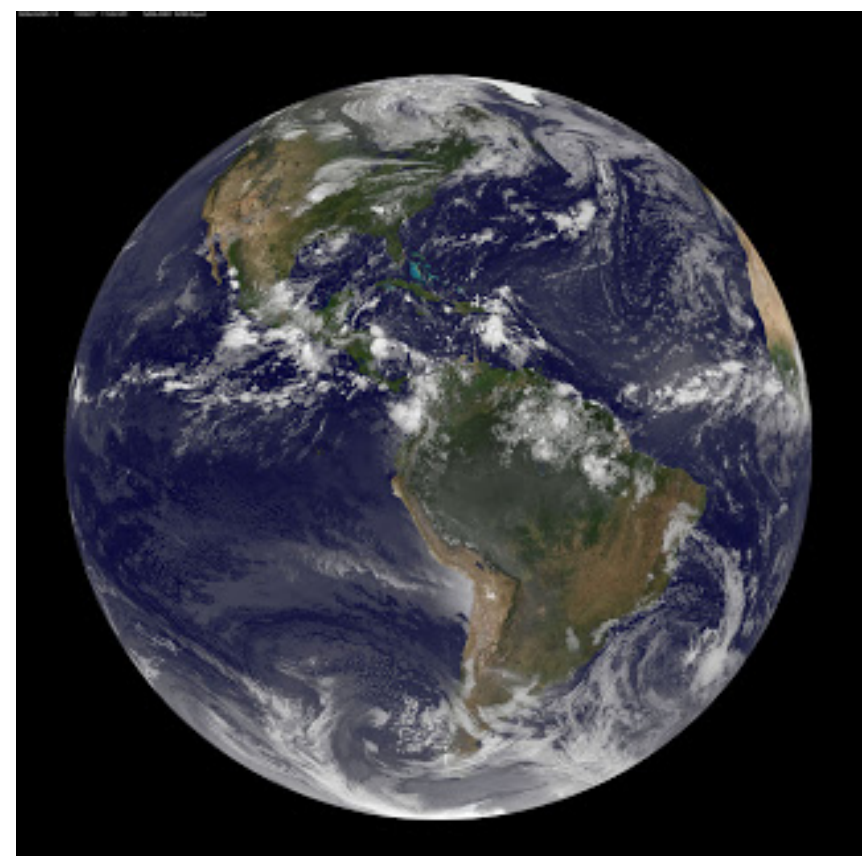

Figura AIII-1: Imagen GOES - Este. Canal Visible. Fuente: NOAA. 
Recientemente se ha lanzado el GOES-R, de nueva generación y con un sensor híperespectral de 12 canales. Está previsto que entre en operaciones en la posición Este (la que usamos en Argentina) en noviembre de 2017. La información sobre este sensor puede hallarse en:

http://www.goes-r.gov/users/comet/goes_r/envmon_es/print.htm\#page_2.0.0

Los satélites meteorológicos geoestacionarios son importantes debido a que proporcionan una mayor resolución temporal, con observaciones cada 30 minutos aproximadamente sobre el territorio argentino. Hecho que les permite seguir fenómenos atmosféricos de características muy cambiantes, tal como la nubosidad. En la Figura AIII-2 se representa un esquema de un satélite geoestacionario (GOES) en comparación con un satélite de órbita polar.

El primer satélite geoestacionario se lanzó en 1966 por la NASA. En forma operacional, este satélite forma parte de la serie GOES (Geostationary Operational Environmental Satellite) a partir de 1975 .

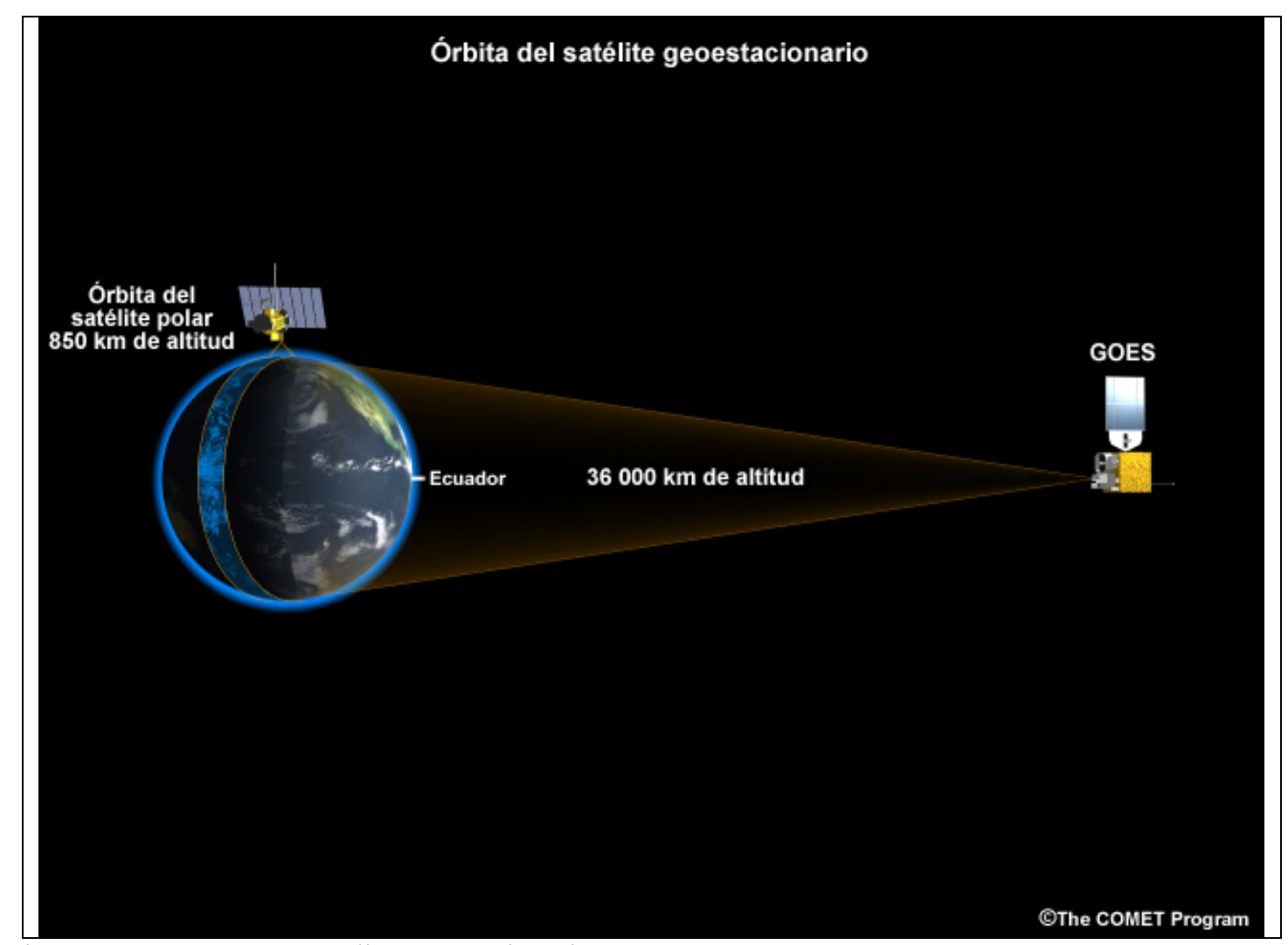

Figura AIII-2: Esquema-satélite geoestacionario. www.goes-r.gov

Esta propiedad de los satélites geoestacionarios permite observar frecuente $\mathrm{y}$ coherentemente las estructuras y los fenómenos de interés, lo que lo hace sumamente 
importante y de gran utilidad al sistema GOES para observar fenómenos meteorológicos y otros, tales como tormentas, huracanes, incendios, erupciones volcánicas, etc

NOAA opera dos satélites GOES activos, cuyas observaciones abarcan la mayor parte del hemisferio occidental. En la Figura AIII-3 se puede observar el área de cobertura de los satélites GOES.

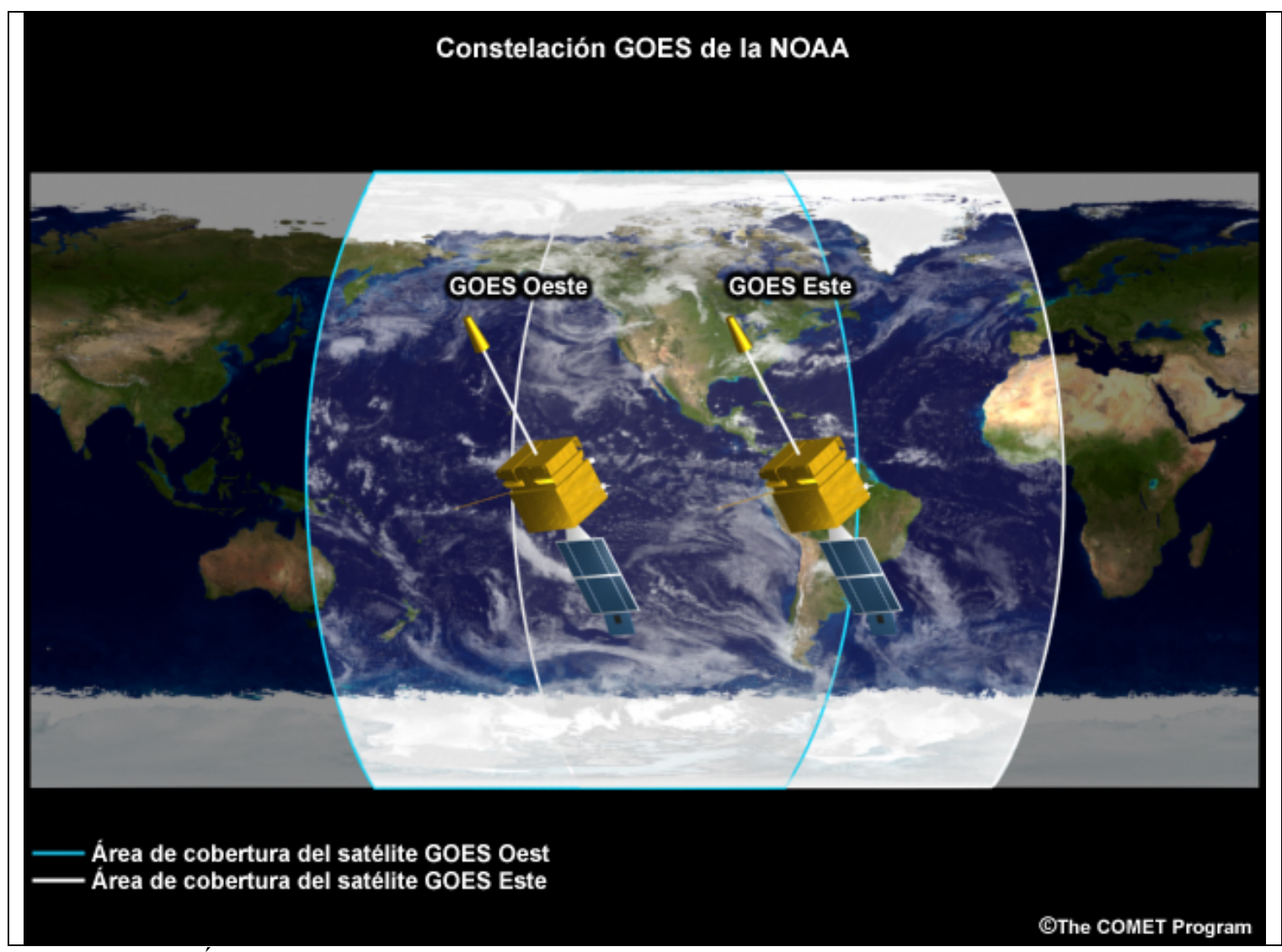

Figura AIII-3: Área de cobertura de los satélites GOES. www.goes-r.gov

Las imágenes GOES cuentan con 5 bandas; una banda en el visible - b1 : 0,53-0,72 $\mu \mathrm{m}$ y 4 en el infrarrojo (IR) - b2: 3,78 - 4,03 $\mu \mathrm{m}$ (MIR); b3: 6,47-7,03 $\mu \mathrm{m} / 5,77-7,33 \mu \mathrm{m}$ (vapor) y b4: 10,21 - 11,20 $\mu \mathrm{m}$ (IR), . En la tabla AIII-7, se puede observar las bandas y características de las imágenes GOES actuales y las futuras de la serie R. 


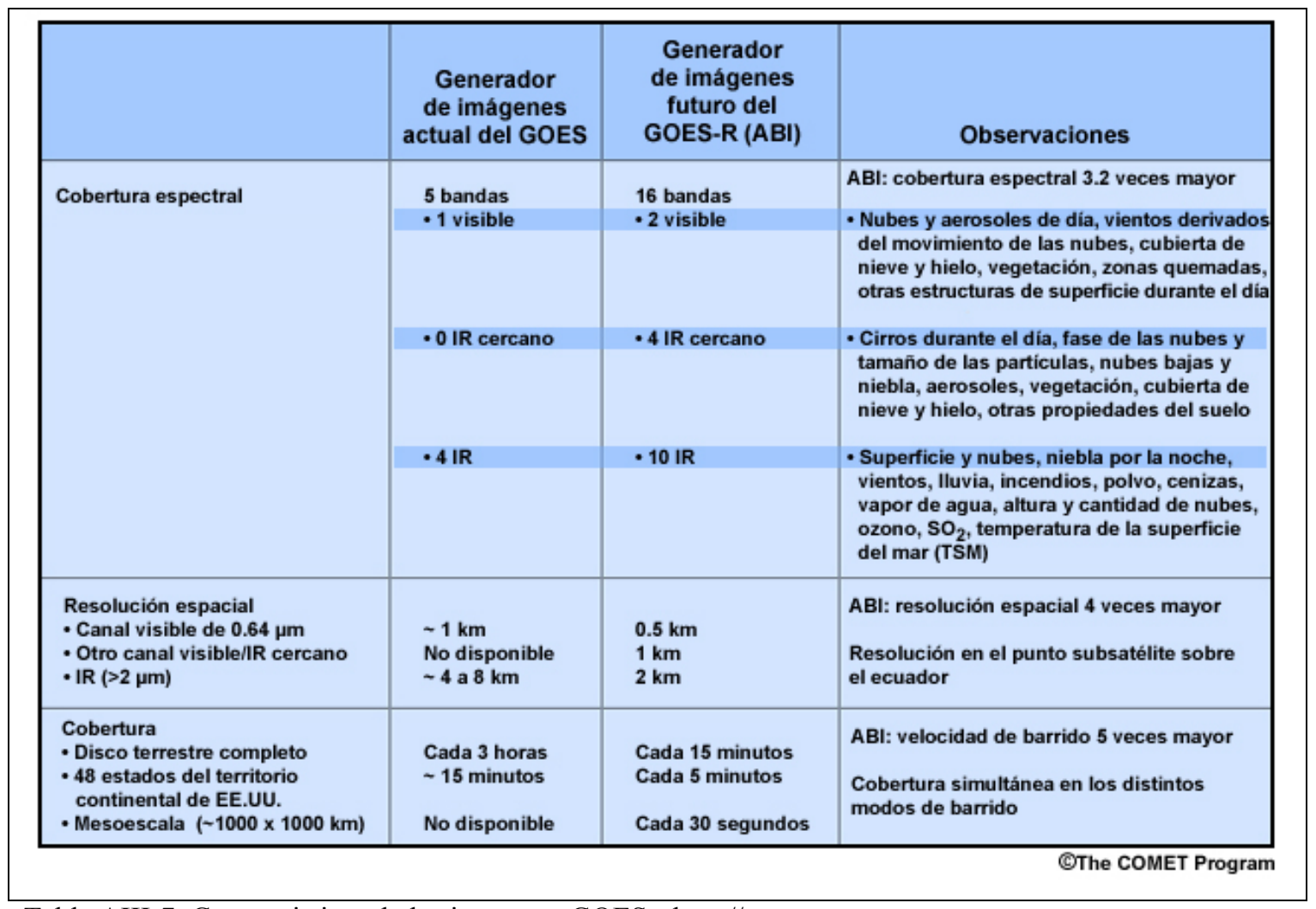

Tabla AIII-7: Caracteristicas de las imagenes GOES - http://www.goes-r.gov

Las imágenes en el infrarrojo miden la radiación emitida desde la superficie terrestre y de los topes de las nubes. A partir de estos datos, es posible calcular su temperatura radiométrica o "de brillo". Por lo tanto, a partir de imágenes en infrarrojo se pueden generar imágenes de temperatura.

Las nubes tienen temperaturas más bajas que la superficie terrestre, las temperaturas de las nubes también indican su altura.

En ausencia de nubes, la temperatura corresponde a la superficie terrestre, con valores mayores.

Esta particularidad en la diferencia de temperaturas entre zonas nubladas y zonas despejadas fue utilizada en el presente trabajo. El canal térmico 4, centrado en $10.7 \mu \mathrm{m}$ es el que se usa en este trabajo. 